\title{
Total Synthesis and Structural Establishment/Revision of the Antibiotics A54145
}

Delin Chen‡a, Hoi Yee Chowła, Kathy Hiu Laam Pob, Wenjie Maa, Emily Lok Yee Leunga, Zhenquan Suna, Ming Liua, Sheng Chen ${ }^{b}$, Xuechen $\mathrm{Li}^{*} \mathrm{a}$

a Department of Chemistry, State Key Laboratory of Synthetic Chemistry, The University of Hong Kong, Hong Kong, P. R. China

b Department of Applied Biology and Chemical Technology, State Key Lab of Chiroscience, The Hong Kong Polytechnic University, Hung Hom, Kowloon, Hong Kong, P. R. China

\section{Table of Contents}

\begin{tabular}{|c|c|}
\hline 1. General methods & S2 \\
\hline 2. Experimental Procedures on Building Blocks Syntheses & S2 \\
\hline 2.1 Synthesis of 3-HO-Asn building blocks & S2 \\
\hline 2.2 Synthesis of 3-MeO-Asp building blocks & S5 \\
\hline 2.3 Synthesis of 3-Me-Glu building block & S9 \\
\hline 3. General Procedures of Fmoc-based solid-phase peptide synthesis (SPPS) of A54145 factors and analogues & S11 \\
\hline 4. Synthesis of $A 54145 A, A_{1}, B, B_{1}, F$ and analogues & S13 \\
\hline Table S1. List of A54145 synthesized & S14 \\
\hline 5. Antimicrobial susceptibility test & S14 \\
\hline 6. LCMS traces of A54145 & S15 \\
\hline 7. NMR Spectra & S24 \\
\hline $7.1{ }^{1} \mathrm{H}$ and ${ }^{13} \mathrm{C}$ NMR spectra of building blocks and intermediates & S24 \\
\hline $7.2^{1} \mathrm{H}$ NMR spectra of synthetic $\mathrm{A} 54145$ factors and analogues & S59 \\
\hline 7.3 Comparison of ${ }^{1} \mathrm{H}$ NMR spectrum of $\mathbf{2 6}$ and literature reported spectrum & S63 \\
\hline 8. References & S64 \\
\hline
\end{tabular}




\section{General methods}

All commercially available materials were used without further purification. Amino acids, coupling reagents and resins were obtained from GL Biochem, C S Bio and Chem-Impex unless otherwise specified. All solvents were reagent grade or $\mathrm{HPLC} \mathrm{grade} \mathrm{(RCl} \mathrm{or}$ DUKSAN). Anhydrous solvents were either prepared from AR grade solvents via standard methods (DCM, THF and MeCN), or purchased in anhydrous form (DMF). All analytical reversed-phase high-performance liquid chromatography (RP-HPLC) separations involving a mobile phase of $0.1 \%$ trifluoroacetic acid (TFA) $(v / v)$ in acetonitrile (Solvent A) and $0.1 \%$ TFA (v/v) in water (Solvent B) were performed on a Waters UPLC H-class system equipped with an ACQUITY UPLC photodiode array detector and a Waters SQ Detector 2 mass spectrometer using a Waters ACQUITY BEH C18 column $(1.7 \mu \mathrm{m}, 130 \AA, 2.1 \times 50 \mathrm{~mm})$ at a flow rate of $0.4 \mathrm{~mL} / \mathrm{min}$. Preparative HPLC separations involving a mobile phase of $0.1 \%$ trifluoroacetic acid (TFA) $(v / v)$ in acetonitrile (Solvent $A)$ and $0.1 \%$ TFA (v/v) in water (Solvent B) were performed on a Waters HPLC system equipped with a quaternary pump (Waters 2545 ) and a UV/Vis detector (Waters 2489) using a Grace Vydac $218 T^{T M}$ C18 column $(10 \mu \mathrm{m}, 300 \AA, 22 \times 250 \mathrm{~mm})$ at a flow rate of $10 \mathrm{~mL} / \mathrm{min}$. Analytical TLC was performed on E. Merck silica gel 60-F254 plates and visualized under UV light (254 nm) or by staining with ninhydrin. The flash column chromatography was performed on E. Merck $230-400$ mesh silica gel 60 . The ${ }^{1} \mathrm{H}$ and ${ }^{13} \mathrm{C}$ NMR spectra were recorded on Advance DRX Bruker 400 and $500 \mathrm{MHz}$ spectrometers. The 2D NMR spectra were recorded on Advance DRX Bruker $500 \mathrm{MHz}$ spectrometer. The high-resolution mass spectrometry (HRMS) was performed on a Waters Micromass Q-TOF Premier Mass Spectrometer. The specific rotations were measured with a Bellingham \& Stanley ADP440+ polarimeter with a path length of $5 \mathrm{~cm}$.

\section{Experimental Procedures on Building Blocks Syntheses}

\subsection{Synthesis of 3-HO-Asn building blocks}

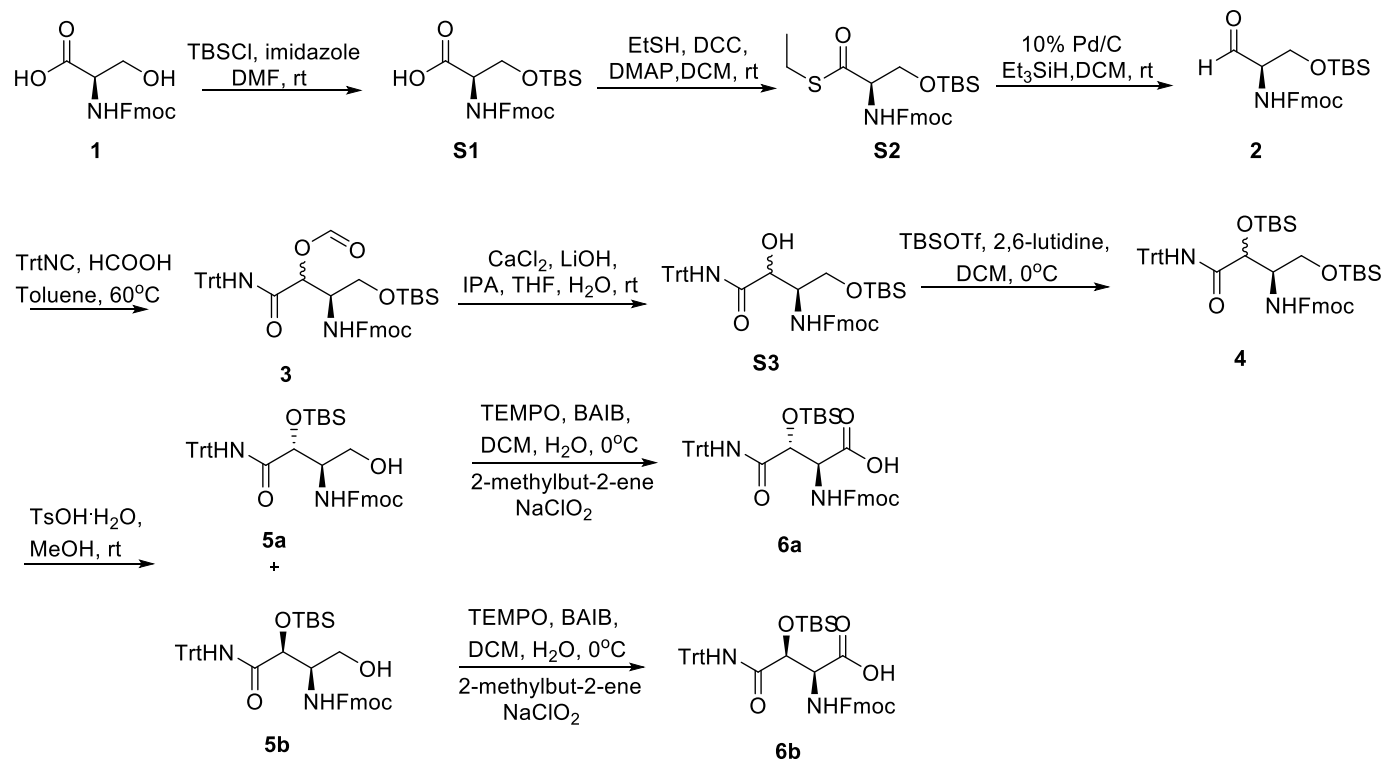

Compound S1:<smiles>CCCCNC(CO[Sb])C(=O)O</smiles>

To a stirred solution of Fmoc-D-Ser-OH (2.01 g, $6.14 \mathrm{mmol}, 1.0$ equiv.) in anhydrous DMF (15 mL), imidazole (1.26 g, $18.5 \mathrm{mmol}, 3.0$ equiv.) and TBSCl (1.84 g, $12.2 \mathrm{mmol}, 2.0$ equiv.) were added sequentially. The mixture was stirred at rt for $16 \mathrm{~h}$. The reaction mixture was diluted by ethyl acetate $(300 \mathrm{~mL})$, washed with $1 \mathrm{~N} \mathrm{HCl}(3 \times 150 \mathrm{~mL})$, brine $(1 \times 150 \mathrm{~mL})$. The organic phase was dried over $\mathrm{Na}_{2} \mathrm{SO}_{4}$, concentrated under vacuo. The residue was purified by flash column chromatography on silica gel $(\mathrm{DCM} / \mathrm{MeOH}, 20: 1)$ to give compound S1 $(1.80 \mathrm{~g}, 67 \%)$ as colorless oil. $[\alpha]_{D}{ }^{20}=-12.5(\mathrm{c}=0.41, \mathrm{DCM})$,

${ }^{1} \mathrm{H}$ NMR $\left(500 \mathrm{MHz}, \mathrm{CDCl}_{3}\right) \delta 7.77(\mathrm{~d}, J=.7 .5 \mathrm{~Hz}, 2 \mathrm{H}), 7.65-7.58(\mathrm{~m}, 2 \mathrm{H}), 7.41(\mathrm{t}, J=7.4 \mathrm{~Hz}, 2 \mathrm{H}), 7.32(\mathrm{t}, J=7.3 \mathrm{~Hz}, 2 \mathrm{H}), 5.66(\mathrm{~d}, J=$ $8.3 \mathrm{~Hz}, 1 \mathrm{H}), 4.52-4.46(\mathrm{~m}, 1 \mathrm{H}), 4.45-4.35(\mathrm{~m}, 2 \mathrm{H}), 4.26(\mathrm{t}, J=7.2 \mathrm{~Hz}, 1 \mathrm{H}), 4.17-4.10(\mathrm{~m}, 1 \mathrm{H}), 3.89(\mathrm{dd}, J=10.1,3.5 \mathrm{~Hz}, 1 \mathrm{H}), 1.26$ $(\mathrm{t}, J=7.1 \mathrm{~Hz}, 1 \mathrm{H}), 0.90(\mathrm{~s}, 9 \mathrm{H}), 0.08(\mathrm{~d}, J=6.4 \mathrm{~Hz}, 6 \mathrm{H}) ;{ }^{13} \mathrm{C}$ NMR $\left(125 \mathrm{MHz}, \mathrm{CDCl}_{3}\right) \delta 175.14,171.54,156.21,144.01,143.82,141.43$, 127.87, 127.20, 125.30, 125.23, 120.12, 67.47, 63.49, 60.63, 55.77, 47.23, 25.88, 21.18, 18.36, 14.31, -5.41; HRMS (ESI ${ }^{+}$) calcd. for $\mathrm{C}_{24} \mathrm{H}_{31} \mathrm{NO}_{5} \mathrm{Si}[\mathrm{M}+\mathrm{H}]^{+} \mathrm{m} / \mathrm{z}$ : 442.2044; found: 442.2029 . 
<smiles></smiles>

To a $100 \mathrm{~mL}$ round bottom flask were added compound $\mathbf{S} 1$ (1.80 g, $4.07 \mathrm{mmol}, 1.0$ equiv.) and DMAP (50.6 mg, $0.414 \mathrm{mmol}, 0.1$ equiv.). After the flask was charged with argon, anhydrous DCM $(14 \mathrm{~mL})$ was added and the mixture was cooled to $0^{\circ} \mathrm{C}$. Ethanethiol $(0.45 \mathrm{~mL}, 6.08 \mathrm{mmol}, 1.5$ equiv.) and DCC $(1.4 \mathrm{~mL}, 8.46 \mathrm{mmol}, 2.0$ equiv.) were added sequentially. The mixture was stirred at $\mathrm{rt}$ for 4 h. The reaction mixture was filtered by celite, concentrated under vacuo. The residue was purified by flash column chromatography on silica gel (hexane/EtOAc, 10:1) to give compound $\mathbf{S 2}(1.80 \mathrm{~g}, 92 \%)$ as white solid. m.p. $=68-70{ }^{\circ} \mathrm{C} ;[\boldsymbol{\alpha}]_{\mathrm{D}}{ }^{20}=-14.0(\mathrm{c}=0.56, \mathrm{DCM}) ;{ }^{1} \mathbf{H}$ NMR $\left(400 \mathrm{MHz}, \mathrm{CDCl}_{3}\right) \delta 7.78(\mathrm{~d}, J=7.5 \mathrm{~Hz}, 2 \mathrm{H}), 7.65(\mathrm{dd}, J=10.2,7.8 \mathrm{~Hz}, 2 \mathrm{H}), 7.41(\mathrm{t}, J=7.4 \mathrm{~Hz}, 2 \mathrm{H}), 7.32(\mathrm{t}, J=7.4 \mathrm{~Hz}, 2 \mathrm{H}), 5.71$ $(\mathrm{d}, J=9.0 \mathrm{~Hz}, 1 \mathrm{H}), 4.51(\mathrm{dd}, J=10.2,6.9 \mathrm{~Hz}, 1 \mathrm{H}), 4.47-4.41(\mathrm{~m}, 1 \mathrm{H}), 4.39-4.27(\mathrm{~m}, 2 \mathrm{H}), 4.17(\mathrm{dd}, J=10.1,2.3 \mathrm{~Hz}, 1 \mathrm{H}), 3.81(\mathrm{dd}, J$ $=10.1,3.5 \mathrm{~Hz}, 1 \mathrm{H}), 2.90(\mathrm{~m}, 2 \mathrm{H}), 1.26(\mathrm{t}, J=7.4 \mathrm{~Hz}, 3 \mathrm{H}), 0.90(\mathrm{~s}, 9 \mathrm{H}), 0.06(\mathrm{~d}, J=8.4 \mathrm{~Hz}, 6 \mathrm{H}) ;{ }^{13} \mathrm{C} \mathrm{NMR}(100 \mathrm{MHz}, \mathrm{CDCl}) \delta 200.34$, 156.05, 144.10, 143.86, 141.48, 127.88, 127.21, 125.36, 125.28, 120.15, 77.48, 67.54, 63.69, 62.32, 47.34, 25.90, 23.60, 18.41, 14.58, 0.14, -5.40, -5.44; HRMS (ESI ${ }^{+}$) calcd. for $\mathrm{C}_{26} \mathrm{H}_{35} \mathrm{NO}_{4} \mathrm{SSi}[\mathrm{M}+\mathrm{H}]^{+} \mathrm{m} / \mathrm{z}$ : 486.2129; found: 486.2105 .

\section{Compound 2:}<smiles>N[C@@H](C=O)C[OH+]</smiles>

To a $100 \mathrm{~mL}$ round bottom flask, compound $\mathbf{S 2}(1.77 \mathrm{~g}, 3.65 \mathrm{mmol}, 1.0$ equiv.) and Pd/C (10\% Pd on activated carbon, $182 \mathrm{mg})$ were added. After argon protection of the flask, anhydrous DCM $(15 \mathrm{~mL})$ was added, and the mixture was stirred until compound $\mathbf{S 2}$ dissolved. $\mathrm{Et}_{3} \mathrm{SiH}(1.75 \mathrm{~mL}, 10.96 \mathrm{mmol}, 3.0$ equiv.) was added dropwise. The reaction mixture was stirred at rt for $2 \mathrm{~h}$. The reaction mixture was filtered through celite, concentrated under vacuo and purified by flash column chromatography on silica gel

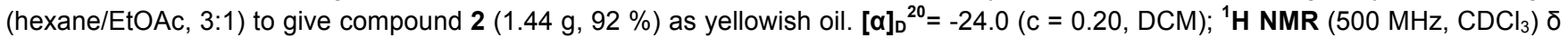
$9.67(\mathrm{~s}, 1 \mathrm{H}), 7.77$ (d, J=7.5 Hz, 2H), $7.61(\mathrm{t}, J=6.7 \mathrm{~Hz}, 2 \mathrm{H}), 7.41$ (t, $J=7.5 \mathrm{~Hz}, 2 \mathrm{H}), 7.32(\mathrm{dt}, J=7.4,0.9 \mathrm{~Hz}, 2 \mathrm{H}), 5.65(\mathrm{~d}, J=7.0 \mathrm{~Hz}$, $1 \mathrm{H}), 4.42(\mathrm{~d}, J=7.1 \mathrm{~Hz}, 2 \mathrm{H}), 4.35(\mathrm{dt}, J=7.2,3.7 \mathrm{~Hz}, 1 \mathrm{H}), 4.24(\mathrm{dt}, J=10.8,5.0 \mathrm{~Hz}, 2 \mathrm{H}), 3.90(\mathrm{dd}, J=10.5,4.3 \mathrm{~Hz}, 1 \mathrm{H}), 0.88(\mathrm{~s}, 9 \mathrm{H})$, 0.06 (s, 6H); ${ }^{13} \mathrm{C}$ NMR $\left(125 \mathrm{MHz}, \mathrm{CDCl}_{3}\right) \delta 198.89,156.20,143.95,143.85,141.46,127.89,127.22,125.24,125.20,120.15,67.37$, 62.02, 61.39, 47.27, 25.86, 18.34, -5.45; HRMS (ESI ${ }^{+}$) calcd. for $\mathrm{C}_{24} \mathrm{H}_{31} \mathrm{NO}_{4} \mathrm{Si}[\mathrm{M}+\mathrm{H}]^{+} \mathrm{m} / \mathrm{z}$ : 426.2095; found: 426.2084

Compound 3:<smiles>CCNC(=O)[C@H](OC=O)[C@H](N)C[OH2+]</smiles>

To a stirred solution of compound $2(1.44 \mathrm{~g}, 3.38 \mathrm{mmol}, 1.0$ equiv.) in toluene ( $20 \mathrm{~mL})$ were added $\operatorname{TrtCN}^{1}(1.18 \mathrm{~g}, 4.38 \mathrm{mmol}, 1.3$ equiv.) and formic acid $\left(0.255 \mathrm{~mL}, 6.76 \mathrm{mmol}, 2.0\right.$ equiv.). The reaction mixture was stirred at $60^{\circ} \mathrm{C}$ for $14 \mathrm{~h}$. The reaction mixture was concentrated under vacuo and purified by flash column chromatography on silica gel (hexane/EtOAc, $5: 1)$ to give compound 3 (2.16 $\mathrm{g}$, $86 \%$, a pair of diastereomer with ratio $\sim 1: 1)$ as white solid. m.p. $=182-188^{\circ} \mathrm{C} ;{ }^{1} \mathrm{H}$ NMR $\left(400 \mathrm{MHz}, \mathrm{CDCl}_{3}\right) \delta 8.16(\mathrm{~s}, 1 \mathrm{H}), 7.81-7.67$ $(\mathrm{m}, 2 \mathrm{H}), 7.55(\mathrm{dd}, J=12.3,6.7 \mathrm{~Hz}, 3 \mathrm{H}), 7.42-7.34(\mathrm{~m}, 3 \mathrm{H}), 7.32-7.23(\mathrm{~m}, 15 \mathrm{H}), 7.23-7.12(\mathrm{~m}, 9 \mathrm{H}), 5.51(\mathrm{~s}, 1 \mathrm{H}), 5.22(\mathrm{~s}, 1 \mathrm{H}), 4.47$ $-4.29(\mathrm{~m}, 3 \mathrm{H}), 4.26(\mathrm{~s}, 1 \mathrm{H}), 4.17(\mathrm{dd}, J=15.1,7.4 \mathrm{~Hz}, 2 \mathrm{H}), 3.66(\mathrm{~d}, J=5.8 \mathrm{~Hz}, 1 \mathrm{H}), 3.62-3.47(\mathrm{~m}, 1 \mathrm{H}), 0.87(\mathrm{t}, J=5.7 \mathrm{~Hz}, 12 \mathrm{H}), 0.02$ $(\mathrm{d}, J=7.2 \mathrm{~Hz}, 6 \mathrm{H}) ;{ }^{13} \mathrm{C}$ NMR $\left(100 \mathrm{MHz}, \mathrm{CDCl}_{3}\right) \delta 166.15,159.73,159.32,156.41,155.86,144.53,144.10,144.01,143.90,143.83$, 141.37, 141.34, 128.64, 128.58, 128.17, 128.13, 128.09, 127.78, 127.36, 127.29, 127.16, 127.13, 125.17, 125.12, 120.03, 72.30, 71.80, 70.84, 70.81, 67.01, 61.99, 54.42, 53.39, 47.25, 47.20, 25.89, 25.85, 18.25, 18.17, -5.32, -5.36, -5.47; HRMS (ESI ) calcd. for $\mathrm{C}_{45} \mathrm{H}_{48} \mathrm{~N}_{2} \mathrm{O}_{6} \mathrm{Si}[\mathrm{M}+\mathrm{H}]^{+} \mathrm{m} / \mathrm{z}: 741.3354$; found: 741.3314 .

\section{Compound S3:}<smiles>CCNC(=O)[C@H](O)[C@@H](C[O+])N=C(F)F</smiles>

To a stirred solution of compound $3(2.06 \mathrm{~g}, 2.78 \mathrm{mmol}, 1.0$ equiv.) in isopropanol (42 mL) and THF (10 mL) were added CaCl $(4.66 \mathrm{~g}$, $41.98 \mathrm{mmol}, 15.0$ equiv.). After $\mathrm{CaCl}_{2}$ was dissolved by sonication, $\mathrm{LiOH} \cdot \mathrm{H}_{2} \mathrm{O}\left(466 \mathrm{mg}, 11.11 \mathrm{mmol}, 4.0\right.$ equiv.) in $\mathrm{H}_{2} \mathrm{O}(12 \mathrm{~mL})$ was added dropwise. The reaction mixture was stirred at rt for $4 \mathrm{~h}$. The reaction mixture was acidified by $1 \mathrm{~N} \mathrm{HCl}$ to $\mathrm{pH} 5$, concentrated under vacuo to remove most of isopropanol and THF. The mixture was diluted by $\mathrm{H}_{2} \mathrm{O}(100 \mathrm{~mL})$ and extracted with $\mathrm{DCM}(3 \times 200 \mathrm{~mL})$. The organic phase was dried over $\mathrm{Na}_{2} \mathrm{SO}_{4}$, concentrated under vacuo and purified by flash column chromatography on silica gel (hexane/EtOAc, 4:1) to give compound $\mathbf{S 3}(1.84 \mathrm{~g}, 93 \%$, a pair of diastereomer with ratio $\sim 1: 1)$ as white solid. m.p. $=91-95{ }^{\circ} \mathrm{C}$; ${ }^{1} \mathbf{H}$ NMR $\left(400 \mathrm{MHz}, \mathrm{CDCl}_{3}\right) \delta 8.25(\mathrm{~s}, 1 \mathrm{H}), 8.19(\mathrm{~s}, 1 \mathrm{H}), 7.78(\mathrm{~d}, J=7.4 \mathrm{~Hz}, 2 \mathrm{H}), 7.59(\mathrm{t}, J=6.9 \mathrm{~Hz}, 2 \mathrm{H}), 7.47-7.36(\mathrm{~m}, 2 \mathrm{H}), 7.35-7.25$ $(\mathrm{m}, 12 \mathrm{H}), 7.25-7.20(\mathrm{~m}, 6 \mathrm{H}), 5.89(\mathrm{~d}, J=8.6 \mathrm{~Hz}, 1 \mathrm{H}), 5.47(\mathrm{~d}, J=6.4 \mathrm{~Hz}, 1 \mathrm{H}), 5.09(\mathrm{~s}, 1 \mathrm{H}), 4.88(\mathrm{~s}, 1 \mathrm{H}), 4.51-4.16(\mathrm{~m}, 5 \mathrm{H}), 4.11(\mathrm{~s}$, 
$1 \mathrm{H}), 3.98(\mathrm{dd}, J=10.4,5.1 \mathrm{~Hz}, 1 \mathrm{H}), 3.88(\mathrm{~d}, J=5.6 \mathrm{~Hz}, 1 \mathrm{H}), 3.79(\mathrm{~d}, J=7.7 \mathrm{~Hz}, 1 \mathrm{H}), 0.91(\mathrm{t}, J=8.2 \mathrm{~Hz}, 10 \mathrm{H}), 0.11(\mathrm{~d}, J=8.1 \mathrm{~Hz}, 3 \mathrm{H})$, 0.07 (s, 3H); ${ }^{13} \mathrm{C}$ NMR $\left(100 \mathrm{MHz}, \mathrm{CDCl}_{3}\right) \delta 171.12,170.33,157.14,156.42,144.58,144.55,144.16,143.89,143.77,141.42,141.38$, 128.72, 128.68, 128.61, 128.27, 128.17, 128.13, 127.87, 127.82, 127.37, 127.28, 127.26, 127.20, 125.23, 125.15, 120.13, 120.11, 120.08, 77.48, 77.16, 76.85, 74.82, 73.92, 70.41, 70.28, 67.36, 64.71, 63.83, 54.89, 53.16, 47.26, 47.21, 25.87, 25.84, 25.77, 18.17, 18.14, -3.46, -5.46, -5.51.; HRMS (ESI ${ }^{+}$) calcd. for $\mathrm{C}_{44} \mathrm{H}_{48} \mathrm{~N}_{2} \mathrm{O}_{5} \mathrm{Si}[\mathrm{M}+\mathrm{H}]^{+} \mathrm{m} / \mathrm{z}$ : 713.3405; found: 713.3373 .

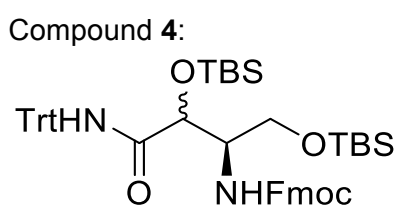

To a stirred solution of compound $\mathbf{S} 3\left(1.93 \mathrm{~g}, 2.71 \mathrm{mmol}, 1.0\right.$ equiv.) in DCM $(15 \mathrm{~mL})$ cooled to $0^{\circ} \mathrm{C}, 2,6$-lutidine $(1.6 \mathrm{~mL}, 13.74 \mathrm{mmol}$, 5.0 equiv.) was added and followed by TBSOTf $\left(1.9 \mathrm{~mL}, 8.27 \mathrm{mmol}, 3.0\right.$ equiv.) dropwise. The reaction mixture was stirred at $0^{\circ} \mathrm{C}$ for 1 h. The reaction mixture was diluted with EtOAc $(100 \mathrm{~mL})$, washed with sat. $\mathrm{NH}_{4} \mathrm{Cl}(50 \mathrm{~mL} \times 2)$, brine $(50 \mathrm{~mL} \times 1)$. The organic phase was dried over $\mathrm{Na}_{2} \mathrm{SO}_{4}$, concentrated under vacuo and purified by flash column chromatography on silica gel (hexane/EtOAc, 6:1) to give compound $4(2.00 \mathrm{~g}, 89 \%$, a pair of diastereomer with ratio $\sim 1: 1)$ as white solid. m.p. $=70-75{ }^{\circ} \mathrm{C} ;{ }^{1} \mathbf{H ~ N M R}\left(400 \mathrm{MHz}^{\mathrm{C}} \mathrm{CDCl} 3\right) \delta$ $7.97(\mathrm{~s}, 1 \mathrm{H}), 7.89(\mathrm{~s}, 1 \mathrm{H}), 7.79-7.71(\mathrm{~m}, 5 \mathrm{H}), 7.64-7.48(\mathrm{~m}, 5 \mathrm{H}), 7.37(\mathrm{t}, \mathrm{J}=7.4 \mathrm{~Hz}, 6 \mathrm{H}), 7.32-7.22(\mathrm{~m}, 27 \mathrm{H}), 7.21-7.15(\mathrm{~m}, 18 \mathrm{H})$, $5.38(\mathrm{~d}, J=9.9 \mathrm{~Hz}, 1 \mathrm{H}), 4.90(\mathrm{~d}, J=6.4 \mathrm{~Hz}, 1 \mathrm{H}), 4.50-4.31(\mathrm{~m}, 7 \mathrm{H}), 4.28(\mathrm{dd}, J=10.3,7.4 \mathrm{~Hz}, 2 \mathrm{H}), 4.22(\mathrm{t}, J=6.9 \mathrm{~Hz}, 2 \mathrm{H}), 4.17-$ $4.07(\mathrm{~m}, 3 \mathrm{H}), 3.97(\mathrm{~s}, 1 \mathrm{H}), 3.79(\mathrm{~s}, 1 \mathrm{H}), 3.66(\mathrm{~d}, \mathrm{~J}=6.2 \mathrm{~Hz}, 1 \mathrm{H}), 3.64-3.59(\mathrm{~m}, 2 \mathrm{H}), 3.56(\mathrm{dd}, J=9.9,7.4 \mathrm{~Hz}, 2 \mathrm{H}), 1.62(\mathrm{~s}, 3 \mathrm{H}), 0.92$ $(\mathrm{s}, 6 \mathrm{H}), 0.90(\mathrm{~s}, 21 \mathrm{H}), 0.87(\mathrm{~d}, J=3.6 \mathrm{~Hz}, 26 \mathrm{H}), 0.21(\mathrm{~s}, 5 \mathrm{H}), 0.10(\mathrm{~d}, J=2.9 \mathrm{~Hz}, 9 \mathrm{H}), 0.06(\mathrm{~s}, 10 \mathrm{H}), 0.01(\mathrm{~d}, J=1.0 \mathrm{~Hz}, 6 \mathrm{H}) ;{ }^{13} \mathrm{C} \mathrm{NMR}$ $\left(125 \mathrm{MHz}, \mathrm{CDCl}_{3}\right) \delta 170.83,155.90,144.49,144.13,144.11,144.08,144.04,144.01,143.96,141.45,141.40,141.38,141.33,128.85$, $128.77,128.72,128.63,128.23,128.18,128.11,128.02,127.78,127.72,127.68,127.45,127.29,127.27,127.17,127.15,127.09$, 125.30, 125.23, 125.09, 125.06, 120.08, 120.03, 120.01, 119.98, 77.41, 77.16, 77.00, 76.91, 75.16, 72.20, 70.68, 70.45, 70.36, 67.00, $66.84,62.62,62.04,62.00,61.50,56.29,56.13,47.36,47.34,47.31,47.23,25.99,25.92,25.86,25.83,25.77,25.75,18.35,18.08$, 18.02, 17.99, -3.46, -4.69, -4.82, $-4.88,-4.90,-4.92,-5.06,-5.24$. HRMS (ESI ${ }^{+}$) calcd. for $\mathrm{C}_{50} \mathrm{H}_{62} \mathrm{~N}_{2} \mathrm{O}_{5} \mathrm{Si}_{2}[\mathrm{M}+\mathrm{H}]^{+} \mathrm{m} / \mathrm{z}: 827.4270 ;$ found: 827.4232 .

\section{Compound $\mathbf{5 a}$ and $\mathbf{5 b}$}

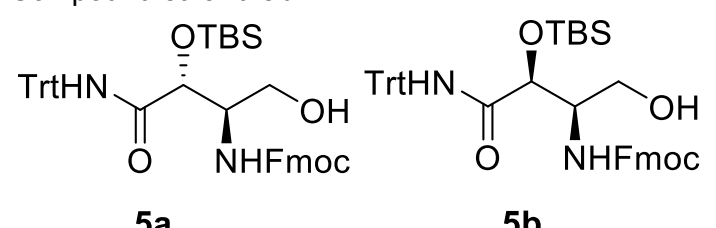

To a stirred solution of compound 4 (214 mg, $0.259 \mathrm{mmol}, 1.0$ equiv.) in $\mathrm{MeOH}(8 \mathrm{~mL}), \mathrm{TsOH}^{\mathrm{H}} \mathrm{H}_{2} \mathrm{O}(47.9 \mathrm{mg}, 0.252 \mathrm{mmol}, 1.0$ equiv.) dissolved in $\mathrm{MeOH}(2 \mathrm{~mL})$ was added dropwise. The reaction mixture was stirred at $\mathrm{rt}$ for $1 \mathrm{~h}$. The reaction mixture was concentrated under vacuo and purified by flash column chromatography on silica gel (DCM/EtOAc, 10:1) to give compound $\mathbf{5 a}(73 \mathbf{m g}, 39 \%)$ and compound 5b (90 mg, 49\%) as white solid. Compound 5a: m.p. $=105-108{ }^{\circ} \mathrm{C} ;[\alpha]_{\mathrm{D}}{ }^{20}=+15.8(\mathrm{c}=0.53, \mathrm{DCM}) ;{ }^{1} \mathrm{H} \mathrm{NMR}(500 \mathrm{MHz}$, $\left.\mathrm{CDCl}_{3}\right) \delta^{1} \mathrm{H}$ NMR $(500 \mathrm{MHz}$, Chloroform-d) $\delta 8.17(\mathrm{~s}, 1 \mathrm{H}), 7.75(\mathrm{~d}, J=7.6 \mathrm{~Hz}, 1 \mathrm{H}), 7.70(\mathrm{~d}, J=7.6 \mathrm{~Hz}, 1 \mathrm{H}), 7.55(\mathrm{t}, J=6.7 \mathrm{~Hz}, 2 \mathrm{H})$, $7.38(\mathrm{t}, J=7.5 \mathrm{~Hz}, 1 \mathrm{H}), 7.32(\mathrm{t}, J=7.4 \mathrm{~Hz}, 2 \mathrm{H}), 7.30-7.27(\mathrm{~m}, 3 \mathrm{H}), 7.26-7.23(\mathrm{~m}, 4 \mathrm{H}), 7.23-7.21(\mathrm{~m}, 4 \mathrm{H}), 7.21-7.18(\mathrm{~m}, 3 \mathrm{H}), 7.16$ (t, $J=7.5 \mathrm{~Hz}, 1 \mathrm{H}), 4.90(\mathrm{~d}, J=9.2 \mathrm{~Hz}, 1 \mathrm{H}), 4.46(\mathrm{dd}, J=10.7,6.9 \mathrm{~Hz}, 1 \mathrm{H}), 4.39(\mathrm{dd}, J=10.8,6.8 \mathrm{~Hz}, 1 \mathrm{H}), 4.34(\mathrm{~d}, J=3.2 \mathrm{~Hz}, 1 \mathrm{H})$, $4.21(\mathrm{t}, J=6.7 \mathrm{~Hz}, 1 \mathrm{H}), 4.02(\mathrm{~s}, 1 \mathrm{H}), 3.77(\mathrm{~d}, J=11.8 \mathrm{~Hz}, 1 \mathrm{H}), 3.49(\mathrm{dd}, J=12.1,5.4 \mathrm{~Hz}, 1 \mathrm{H}), 0.89(\mathrm{~s}, 9 \mathrm{H}), 0.18(\mathrm{~s}, 3 \mathrm{H}), 0.15(\mathrm{~s}, 3 \mathrm{H})$. ${ }^{13} \mathrm{C}$ NMR $\left(125 \mathrm{MHz}, \mathrm{CDCl}_{3}\right) \delta 171.67,156.36,144.11,144.00,141.49,141.43,128.67,128.53,128.38,128.27,127.82,127.77$, $127.49,127.21,125.11,120.13,120.05,77.42,77.16,76.91,75.27,70.73,66.88,62.70,56.29,47.37,25.85,18.05,-4.80,-4.88$; HRMS $\left(E S I^{+}\right)$calcd. for $\mathrm{C}_{44} \mathrm{H}_{48} \mathrm{~N}_{2} \mathrm{O}_{5} \mathrm{Si}[\mathrm{M}+\mathrm{H}]^{+} \mathrm{m} / \mathrm{z}$ : 713.3405; found: 713.3376 . Compound 5b: m.p. $=120-127^{\circ} \mathrm{C} ;[\alpha]_{\mathrm{D}}{ }^{20}=-10.5(\mathrm{c}=$ 0.14, DCM); ${ }^{1} \mathrm{H}$ NMR $\left(500 \mathrm{MHz}, \mathrm{CDCl}_{3}\right) \delta{ }^{1} \mathrm{H}$ NMR $(500 \mathrm{MHz}$, Chloroform-d) $\delta 8.01(\mathrm{~s}, 1 \mathrm{H}), 7.75(\mathrm{~d}, \mathrm{~J}=7.6 \mathrm{~Hz}, 2 \mathrm{H}), 7.56(\mathrm{t}, J=6.5 \mathrm{~Hz}$, 2H), $7.38(\mathrm{t}, J=7.5 \mathrm{~Hz}, 2 \mathrm{H}), 7.32-7.26(\mathrm{~m}, 11 \mathrm{H}), 7.25(\mathrm{~s}, 1 \mathrm{H}), 7.21-7.18(\mathrm{~m}, 6 \mathrm{H}), 5.94(\mathrm{~d}, J=9.0 \mathrm{~Hz}, 1 \mathrm{H}), 4.40(\mathrm{dd}, J=10.6,7.2 \mathrm{~Hz}$, $1 \mathrm{H}), 4.30(\mathrm{dd}, J=10.6,7.1 \mathrm{~Hz}, 1 \mathrm{H}), 4.24(\mathrm{~d}, J=4.7 \mathrm{~Hz}, 1 \mathrm{H}), 4.15(\mathrm{t}, J=7.1 \mathrm{~Hz}, 1 \mathrm{H}), 3.99(\mathrm{~s}, 1 \mathrm{H}), 3.68(\mathrm{dd}, J=11.4,4.2 \mathrm{~Hz}, 1 \mathrm{H}), 3.58$ $(\mathrm{dd}, J=11.4,6.0 \mathrm{~Hz}, 1 \mathrm{H}), 0.88(\mathrm{~s}, 9 \mathrm{H}), 0.18(\mathrm{~s}, 3 \mathrm{H}), 0.10(\mathrm{~s}, 3 \mathrm{H}) ;{ }^{13} \mathrm{C}$ NMR $\left(100 \mathrm{MHz}, \mathrm{CDCl}_{3}\right) \delta 171.22,156.76,144.25,144.01$, 143.99, 141.42, 128.76, 128.24, 127.81, 127.49, 127.22, 127.18, 125.34, 125.25, 120.08, 77.48, 77.16, 76.84, 72.78, 70.67, 67.30, 62.38, 56.73, 47.31, 25.78, 17.95, -4.85. HRMS (ESI ${ }^{+}$) calcd. for $\mathrm{C}_{44} \mathrm{H}_{48} \mathrm{~N}_{2} \mathrm{O}_{5} \mathrm{Si}[\mathrm{M}+\mathrm{H}]^{+} \mathrm{m} / \mathrm{z}$ : 713.3405; found: 713.3375 .

Compound 6a<smiles>CCNC(=O)[C@H]([OH2+])[C@@H](N=CO)C(=O)O</smiles>

To a stirred solution of compound 5 a $(700 \mathrm{mg}, 0.98 \mathrm{mmol}, 1.0$ equiv.) in DCM (10 mL), TEMPO (30.8 mg, $0.20 \mathrm{mmol}, 0.2 \mathrm{equiv}$.) was added and followed by BAIB ( $634 \mathrm{mg}, 1.97 \mathrm{mmol}, 2.0$ equiv.). The reaction mixture was stirred at rt for $3 \mathrm{~h}$. The reaction mixture was then cooled to $0^{\circ} \mathrm{C}$, then 2-methylbut-2-ene $\left(0.2 \mathrm{~mL}, 1.88 \mathrm{mmol}, 2.0\right.$ equiv.) and $\mathrm{NaClO}_{2}(178 \mathrm{mg}, 1.96 \mathrm{mmol}, 2.0$ equiv.) were added sequentially. The reaction mixture was stirred at rt for additional $3 \mathrm{~h}$. The reaction mixture was diluted with $\mathrm{EtOAc}(100 \mathrm{~mL})$, washed with sat. $\mathrm{Na}_{2} \mathrm{~S}_{2} \mathrm{O}_{3}(50 \mathrm{~mL} \times 2)$, brine $(50 \mathrm{~mL} \times 1)$. The organic phase was dried over $\mathrm{Na}_{2} \mathrm{SO}_{4}$, concentrated under vacuo and purified by flash column chromatography on silica gel (hexane/EtOAc, $1: 1$ with $0.5 \% \mathrm{AcOH}$ ) to give compound $6 \mathrm{a}(557 \mathrm{mg}, 78 \%)$ as off-white solid. m.p. $=108-115^{\circ} \mathrm{C} ;[\alpha]_{D}{ }^{20}=\mathbf{+ 2 0 . 2}(\mathrm{c}=0.53, \mathrm{DCM}) ;{ }^{1} \mathrm{H}$ NMR $\left(400 \mathrm{MHz}, \mathrm{CDCl}_{3}\right) \delta 8.00(\mathrm{~s}, 1 \mathrm{H}), 7.73(\mathrm{dd}, \mathrm{J}=15.0,7.6 \mathrm{~Hz}, 2 \mathrm{H}), 7.56$ 
(dd, $J=7.6,3.7 \mathrm{~Hz}, 2 \mathrm{H}), 7.39(\mathrm{t}, J=7.5 \mathrm{~Hz}, 1 \mathrm{H}), 7.33(\mathrm{t}, J=7.5 \mathrm{~Hz}, 1 \mathrm{H}), 7.29-7.27(\mathrm{~m}, 2 \mathrm{H}), 7.25-7.20(\mathrm{~m}, 7 \mathrm{H}), 7.17(\mathrm{dd}, J=7.7$, $2.1 \mathrm{~Hz}, 7 \mathrm{H}), 5.15(\mathrm{~d}, J=8.9 \mathrm{~Hz}, 1 \mathrm{H}), 4.81(\mathrm{~s}, 1 \mathrm{H}), 4.67(\mathrm{dd}, J=9.0,2.6 \mathrm{~Hz}, 1 \mathrm{H}), 4.48-4.34(\mathrm{~m}, 2 \mathrm{H}), 4.24(\mathrm{t}, J=7.0 \mathrm{~Hz}, 1 \mathrm{H}), 0.87(\mathrm{~s}$, $9 \mathrm{H}), 0.20$ (s, 3H), 0.15 (s, 3H); ${ }^{13} \mathrm{C}$ NMR $\left(100 \mathrm{MHz}, \mathrm{CDCl}_{3}\right) \delta 170.81,170.03,156.41,144.15,143.98,143.85,141.45,128.78,128.25$, 127.84, 127.80, 127.46, 127.25, 125.23, 120.12, 120.07, 77.48, 74.62, 70.83, 67.28, 58.16, 47.26, 25.80, 18.06, -4.78, -4.98; HRMS (ESI $^{+}$) calcd. for $\mathrm{C}_{44} \mathrm{H}_{46} \mathrm{~N}_{2} \mathrm{O}_{6} \mathrm{Si}[\mathrm{M}+\mathrm{H}]^{+} \mathrm{m} / \mathrm{z}$ : 727.3198; found: 727.3165 .

Compound 6b:<smiles>CCNC(=O)[C@H]([OH2+])[C@@H](N=CO)C(=O)O</smiles>

To a stirred solution of compound $\mathbf{5 b}(963 \mathrm{mg}, 1.35 \mathrm{mmol}, 1.0$ equiv.) in DCM (10 mL), TEMPO (43.9 mg, $0.28 \mathrm{mmol}, 0.2 \mathrm{equiv}$.) was added and followed by BAIB ( $885 \mathrm{mg}, 2.75 \mathrm{mmol}, 2.0$ equiv.). The reaction mixture was stirred at $\mathrm{rt}$ for $3 \mathrm{~h}$. The reaction mixture was then cooled to $0^{\circ} \mathrm{C}$, then 2-methylbut-2-ene $\left(0.28 \mathrm{~mL}, 2.63 \mathrm{mmol}, 2.0\right.$ equiv.) and $\mathrm{NaClO}_{2}(255 \mathrm{mg}, 2.82 \mathrm{mmol}, 2.0$ equiv.) were added sequentially. The reaction mixture was stirred at rt for additional $1 \mathrm{~h}$. The reaction mixture was diluted with EtOAc (100 mL), washed with sat. $\mathrm{Na}_{2} \mathrm{~S}_{2} \mathrm{O}_{3}(50 \mathrm{~mL} \times 2)$, brine $(50 \mathrm{~mL} \times 1)$. The organic phase was dried over $\mathrm{Na}_{2} \mathrm{SO}_{4}$, concentrated under vacuo and purified by flash column chromatography on silica gel (hexane/EtOAc, $1: 1$ with $0.5 \% \mathrm{AcOH}$ ) to give compound $\mathbf{6 b}$ as off-white solid (821 mg, $84 \%)$. m.p. $=105-110^{\circ} \mathrm{C} ;[\mathbf{\alpha}]_{\mathrm{D}}{ }^{20}=-17.7(\mathrm{c}=0.63, \mathrm{DCM}) ;{ }^{1} \mathrm{H}$ NMR $(500 \mathrm{MHz}, \mathrm{DMSO}) \delta 8.18(\mathrm{~s}, 1 \mathrm{H}), 7.89(\mathrm{~s}, 2 \mathrm{H}), 7.81(\mathrm{dd}, \mathrm{J}=17.3,8.3$ $\mathrm{Hz}, 2 \mathrm{H}), 7.74(\mathrm{~d}, J=7.4 \mathrm{~Hz}, 1 \mathrm{H}), 7.45-7.33(\mathrm{~m}, 3 \mathrm{H}), 7.29(\mathrm{t}, J=7.5 \mathrm{~Hz}, 1 \mathrm{H}), 7.26-7.12(\mathrm{~m}, 20 \mathrm{H}), 4.61(\mathrm{~s}, 1 \mathrm{H}), 4.55-4.49(\mathrm{~m}, 1 \mathrm{H})$, $4.38(\mathrm{~d}, J=9.1 \mathrm{~Hz}, 1 \mathrm{H}), 4.26(\mathrm{t}, J=6.9 \mathrm{~Hz}, 1 \mathrm{H}), 4.23-4.16(\mathrm{~m}, 1 \mathrm{H}), 4.14(\mathrm{~s}, 1 \mathrm{H}), 0.87(\mathrm{~s}, 9 \mathrm{H}), 0.03(\mathrm{~s}, 3 \mathrm{H}), 0.01(\mathrm{~s}, 3 \mathrm{H}) ;{ }^{13} \mathrm{C} \mathrm{NMR}$ (100 MHz, DMSO) $\delta 171.38,168.69,156.46,144.24,143.63,143.59,140.65,140.59,128.43,127.60,127.52,127.11,126.99,126.68$, 125.61, 125.32, 120.02, 73.83, 69.51, 66.22, 57.48, 46.62, 25.60, 17.72, -4.99, -5.39; HRMS (ESI ${ }^{+}$) calcd. for $\mathrm{C}_{44} \mathrm{H}_{46} \mathrm{~N}_{2} \mathrm{O}_{6} \mathrm{Si}[\mathrm{M}+\mathrm{H}]^{+}$ $\mathrm{m} / \mathrm{z}$ : 727.3198; found: 727.3167 .

\subsection{Syntheses of 3-MeOAsp}
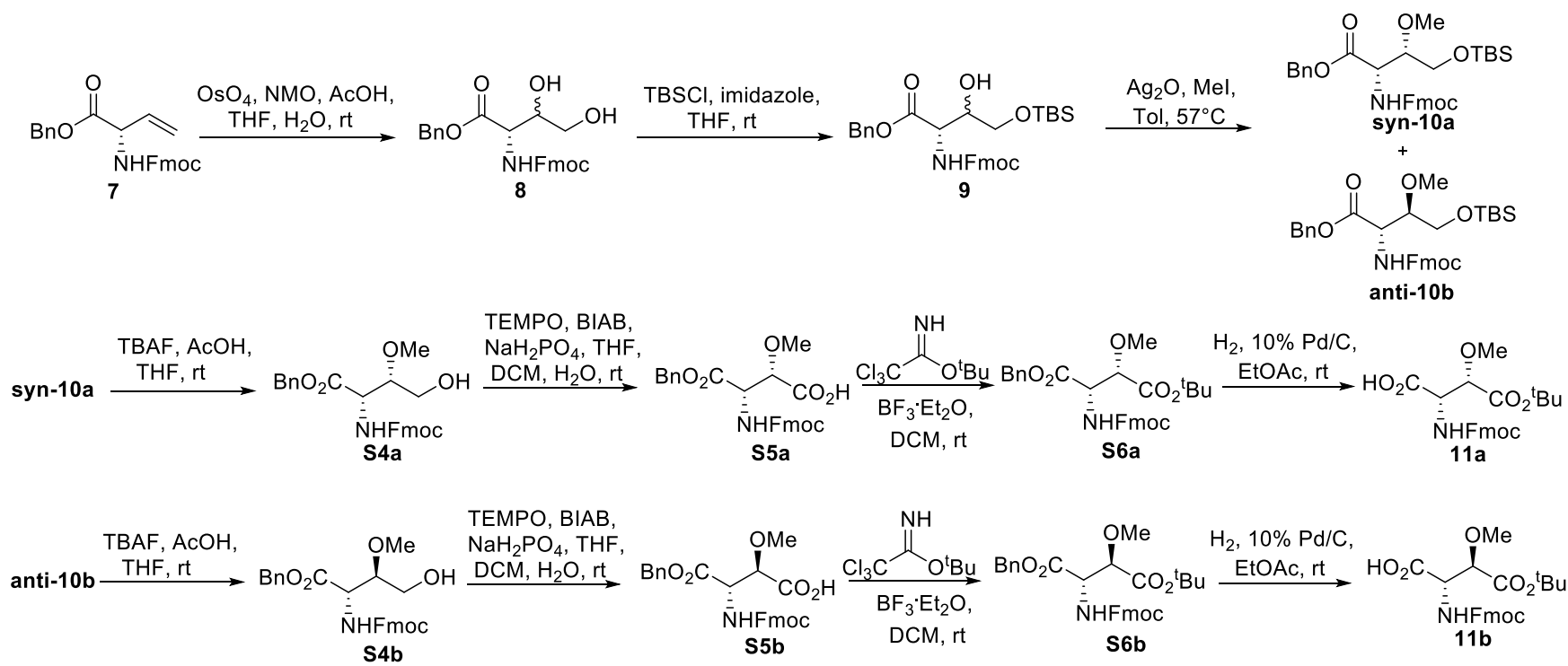

Compound 8:<smiles>[NH-][C@@H](C(=O)O[GaH2])[C@@H](O)CO</smiles>

To a stirred solution of compound 7 (10.0 g, $24.2 \mathrm{mmol}, 1.0$ equiv.) in THF/ $\mathrm{H}_{2} \mathrm{O}$ (2:1, $\left.80 \mathrm{~mL}\right), \mathrm{AcOH}(4.15 \mathrm{~mL}, 72.6 \mathrm{mmol}, 3.0 \mathrm{equiv}$.) and NMO (10.1 mL, $48.4 \mathrm{mmol}, 2.0$ equiv.) were added, followed by a catalytic amount of $\mathrm{OsO}_{4}\left(10 \mathrm{mg} / \mathrm{mL}\right.$ in $\mathrm{H}_{2} \mathrm{O}, 15.3 \mathrm{~mL}, 0.605$ $\mathrm{mmol}, 0.025$ equiv.). The reaction mixture was stirred at rt overnight, the reaction was quenched by the addition of a saturated solution of $\mathrm{NaHSO}_{3}(100 \mathrm{~mL})$. The resulting mixture was extracted with EtOAc $(3 \times 150 \mathrm{~mL})$, and the combined organic layers were washed with water and brine and then dried with $\mathrm{Na}_{2} \mathrm{SO}_{4}$. Concentration under reduced pressure and purified by chromatography on a silica gel column (hexane/EtOAc, 2:1) yielded pure diol $8(9.0 \mathrm{~g}, 83 \%$ yield, a pair of diastereomer with ratio $\sim 3: 2)$ as a colorless solid. $\mathrm{m} . \mathrm{p} .=$ 99-105 ${ }^{\circ} \mathrm{C} ;{ }^{1} \mathrm{H}$ NMR $\left(500 \mathrm{MHz}, \mathrm{CDCl}_{3}\right) \delta 7.75(\mathrm{~d}, J=7.6 \mathrm{~Hz}, 2 \mathrm{H}), 7.56(\mathrm{t}, J=8.3 \mathrm{~Hz}, 2 \mathrm{H}), 7.38(\mathrm{t}, J=7.4 \mathrm{~Hz}, 2 \mathrm{H}), 7.30$ (dd, $J=16.4,8.9$ $\mathrm{Hz}, 6 \mathrm{H}), 5.85(\mathrm{t}, J=8.7 \mathrm{~Hz}, 1 \mathrm{H}), 5.20(\mathrm{~d}, J=2.8 \mathrm{~Hz}, 1 \mathrm{H}), 4.58(\mathrm{~d}, J=7.3 \mathrm{~Hz}, 1 \mathrm{H}), 4.50-4.38(\mathrm{~m}, 3 \mathrm{H}), 4.24(\mathrm{t}, J=6.2 \mathrm{~Hz}, 1 \mathrm{H}), 4.18(\mathrm{dd}$, $J=14.0,6.9 \mathrm{~Hz}, 1 \mathrm{H}), 3.92(\mathrm{~d}, J=3.5 \mathrm{~Hz}, 1 \mathrm{H}), 3.66-3.58(\mathrm{~m}, 1 \mathrm{H}), 3.55(\mathrm{dd}, J=11.5,6.5 \mathrm{~Hz}, 1 \mathrm{H}), 3.44(\mathrm{dd}, J=11.5,7.1 \mathrm{~Hz}, 1 \mathrm{H}), 1.26$ (s, $1 \mathrm{H}), 0.88(\mathrm{t}, J=6.9 \mathrm{~Hz}, 1 \mathrm{H}) ;{ }^{13} \mathrm{C}$ NMR $\left(125 \mathrm{MHz}, \mathrm{CDCl}_{3}\right) \delta 170.68,170.57,157.40,156.86,143.83,143.78,143.59,141.46,141.43$, 
135.13, 134.99, 128.80, 128.74, 128.71, 128.50, 128.38, 127.92, 127.26, 125.18, 125.14, 120.17, 120.14, 77.41, 77.16, 76.91, 72.81, 72.16, 67.84, 67.54, 67.45, 63.01, 56.44, 55.77, 47.24, 32.05, 29.82, 29.78, 29.48, 22.82, 14.24.; HRMS (ESI $\left.{ }^{+}\right)$calcd. for $\mathrm{C}_{26} \mathrm{H}_{25} \mathrm{NO}_{6}$ $[\mathrm{M}+\mathrm{H}]^{+} \mathrm{m} / \mathrm{z}: 448.1755$; found: 448.1738 .

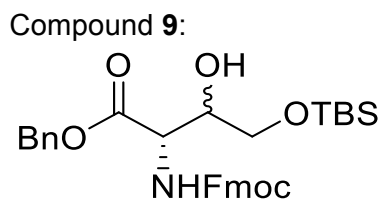

To a stirred solution of compound 8 ( $3.5 \mathrm{~g}, 7.93 \mathrm{mmol}, 1.0$ equiv.) in anhydrous THF (50 mL), imidazole (1.08 g, $15.9 \mathrm{mmol}, 2.0$ equiv.) and TBSCl ( $2.40 \mathrm{~g}, 15.9 \mathrm{mmol}, 2.0$ equiv.) were added sequentially. The mixture was stirred at $\mathrm{rt}$ for $2 \mathrm{~h}$. The reaction mixture was diluted by ethyl acetate $(300 \mathrm{~mL})$, washed with $0.5 \mathrm{~N} \mathrm{HCl}(3 \times 150 \mathrm{~mL})$, brine $(1 \times 150 \mathrm{~mL})$. The organic phase was dried over $\mathrm{Na}_{2} \mathrm{SO}_{4}$, concentrated under vacuo and purified by flash column chromatography on silica gel (hexane/EtOAc, 8:1) to give compound 9 (4.18 $\mathrm{g}$, $94 \%$, a pair of diastereomer with ratio $\sim 3: 2)$ as colorless oil. ${ }^{1} \mathrm{H}$ NMR $\left(500 \mathrm{MHz}, \mathrm{CDCl}_{3}\right) \delta 7.77(\mathrm{~d}, J=7.5 \mathrm{~Hz}, 2 \mathrm{H}), 7.66-7.55(\mathrm{~m}, 2 \mathrm{H})$, $7.40(\mathrm{t}, J=7.4 \mathrm{~Hz}, 2 \mathrm{H}), 7.36-7.28(\mathrm{~m}, 6 \mathrm{H}), 5.95(\mathrm{~d}, J=8.0 \mathrm{~Hz}, 1 \mathrm{H}), 5.70(\mathrm{~d}, J=9.1 \mathrm{~Hz}, 1 \mathrm{H}), 5.24(\mathrm{~s}, 1 \mathrm{H}), 5.20(\mathrm{~s}, 1 \mathrm{H}), 4.61(\mathrm{dd}, J=$ 8.0, 3.6 Hz, 1H), $4.49(\mathrm{~d}, J=9.1 \mathrm{~Hz}, 1 \mathrm{H}), 4.46-4.37(\mathrm{~m}, 2 \mathrm{H}), 4.37-4.29(\mathrm{~m}, 1 \mathrm{H}), 4.23(\mathrm{~d}, J=6.4 \mathrm{~Hz}, 2 \mathrm{H}), 4.10(\mathrm{~s}, 1 \mathrm{H}), 3.69(\mathrm{dd}, J=$ $10.3,4.8 \mathrm{~Hz}, 1 \mathrm{H}), 3.67-3.64(\mathrm{~m}, 1 \mathrm{H}), 3.60(\mathrm{dd}, J=9.8,7.9 \mathrm{~Hz}, 1 \mathrm{H}), 3.13(\mathrm{~d}, J=6.8 \mathrm{~Hz}, 1 \mathrm{H}), 2.77(\mathrm{~s}, 1 \mathrm{H}), 1.63(\mathrm{~d}, J=8.2 \mathrm{~Hz}, 2 \mathrm{H})$, 0.89 (d, $J=1.8 \mathrm{~Hz}, 9 \mathrm{H}), 0.07$ (s, 4H), 0.04 (d, $J=2.9 \mathrm{~Hz}, 2 \mathrm{H}) ;{ }^{13} \mathrm{C}$ NMR $\left(125 \mathrm{MHz}, \mathrm{CDCl}_{3}\right) \delta$ 170.84, 169.96, 156.66, 144.03, 143.81, 143.76, 141.39, 135.37, 135.22, 128.72, 128.60, 128.53, 128.42, 128.26, 127.83, 127.18, 125.30, 125.21, 120.08, 71.74, 71.54, 67.56, $67.45,64.13,64.07,57.53,55.60,47.20,25.94,18.33,-5.33,-5.35,-5.47,-5.50$; HRMS (ESI ${ }^{+}$calcd. for $\mathrm{C}_{32} \mathrm{H}_{39} \mathrm{NO}_{6} \mathrm{Si}[\mathrm{M}+\mathrm{H}]^{+} \mathrm{m} / \mathrm{z}$ : 562.2619; found: 562.2596 .

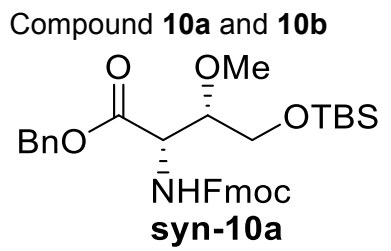<smiles>CO[C@H](C[OH2+])[C@@H](NC(=O)[OH2+])C(=O)OCc1ccccc1</smiles>

To a stirred solution of compound $9\left(1.10 \mathrm{~g}, 1.98 \mathrm{mmol}, 1.0\right.$ equiv.) in anhydrous Toluene $(15 \mathrm{~mL}), \mathrm{Ag}_{2} \mathrm{O}(2.30 \mathrm{~g}, 9.90 \mathrm{mmol}, 5.0$ equiv.) and $\mathrm{Mel}\left(0.247 \mathrm{~mL}, 3.96 \mathrm{mmol}, 2.0\right.$ equiv.) were added sequentially. The mixture was stirred at $55^{\circ} \mathrm{C}$ for $4 \mathrm{~h}$. The reaction mixture was directly purified by flash column chromatography on silica gel (hexane/EtOA, 30:1) to give compound syn-10a (0.52 $\mathrm{g}$, $46 \%$, ) and anti-10b $(0.47 \mathrm{~g}, 42 \%)$ as colorless oil. Compound syn-10a: $[\alpha]_{\mathrm{D}}{ }^{23}=-16.4(\mathrm{c}=0.5, \mathrm{DCM}),{ }^{1} \mathrm{H} \mathrm{NMR}(500 \mathrm{MHz}, \mathrm{CDCl})_{3} \delta$ $7.77(\mathrm{~d}, J=7.5 \mathrm{~Hz}, 2 \mathrm{H}), 7.61(\mathrm{t}, J=8.0 \mathrm{~Hz}, 2 \mathrm{H}), 7.35(\mathrm{~m}, 10 \mathrm{H}), 5.50(\mathrm{~d}, J=9.6 \mathrm{~Hz}, 1 \mathrm{H}), 5.31(\mathrm{~d}, J=12.1 \mathrm{~Hz}, 1 \mathrm{H}), 5.15(\mathrm{~d}, J=12.2 \mathrm{~Hz}$, $1 \mathrm{H}), 4.63(\mathrm{~d}, J=9.7 \mathrm{~Hz}, 1 \mathrm{H}), 4.51-4.37(\mathrm{~m}, 1 \mathrm{H}), 4.38-4.30(\mathrm{~m}, 1 \mathrm{H}), 4.23(\mathrm{t}, J=7.2 \mathrm{~Hz}, 1 \mathrm{H}), 3.87(\mathrm{t}, J=6.3 \mathrm{~Hz}, 1 \mathrm{H}), 3.72(\mathrm{dd}, J=$ $10.0,5.7 \mathrm{~Hz}, 1 \mathrm{H}), 3.66-3.54(\mathrm{~m}, 1 \mathrm{H}), 3.29(\mathrm{~s}, 3 \mathrm{H}), 0.88(\mathrm{~s}, 9 \mathrm{H}), 0.05(\mathrm{~s}, 6 \mathrm{H}) ;{ }^{13} \mathrm{C} \mathrm{NMR}\left(126 \mathrm{MHz}, \mathrm{CDCl}_{3}\right) \delta 171.43,156.71,143.95$, 141.41, 135.62, 128.70, 128.53, 128.48, 127.82, 127.20, 125.40, 125.29, 120.08, 81.27, 77.41, 77.16, 76.91, 67.42, 67.34, 61.92, 59.29, 54.92, 47.28, 25.97, 18.33, -5.40. HRMS (ESI ${ }^{+}$) calcd. for $\mathrm{C}_{33} \mathrm{H}_{41} \mathrm{NO}_{6} \mathrm{Si}[\mathrm{M}+\mathrm{H}]^{+} \mathrm{m} / \mathrm{z}$ : 576.2776; found: 576.2767 . compound anti-10b: $[\alpha]_{\mathrm{D}}{ }^{22}=-2.7(\mathrm{c}=0.9, \mathrm{DCM}),{ }^{1} \mathrm{H}$ NMR $\left(500 \mathrm{MHz}, \mathrm{CDCl}_{3}\right) \delta 7.76(\mathrm{~d}, J=7.4 \mathrm{~Hz}, 2 \mathrm{H}), 7.61(\mathrm{~d}, J=7.2 \mathrm{~Hz}, 2 \mathrm{H}), 7.40(\mathrm{t}, J=7.3 \mathrm{~Hz}$, $2 \mathrm{H}), 7.37-7.26(\mathrm{~m}, 8 \mathrm{H}), 6.05(\mathrm{~d}, J=8.7 \mathrm{~Hz}, 1 \mathrm{H}), 5.20(\mathrm{dd}, J=28.8,12.2 \mathrm{~Hz}, 2 \mathrm{H}), 4.81(\mathrm{~d}, J=6.4 \mathrm{~Hz}, 1 \mathrm{H}), 4.47-4.38(\mathrm{~m}, 1 \mathrm{H}), 4.38-$ $4.30(\mathrm{~m}, 1 \mathrm{H}), 4.24(\mathrm{t}, J=6.9 \mathrm{~Hz}, 1 \mathrm{H}), 3.77(\mathrm{dd}, J=11.5,6.4 \mathrm{~Hz}, 1 \mathrm{H}), 3.71(\mathrm{~s}, 2 \mathrm{H}), 3.44(\mathrm{~s}, 3 \mathrm{H}), 0.90(\mathrm{~s}, 5 \mathrm{H}), 0.05(\mathrm{~d}, J=3.6 \mathrm{~Hz}, 2 \mathrm{H})$; ${ }^{13} \mathrm{C}$ NMR $\left(126 \mathrm{MHz}, \mathrm{CDCl}_{3}\right) \delta 170.31,156.52,144.16,144.00,141.43,135.44,128.73,128.55,128.46,127.79,127.19,125.37$, 125.32, 120.07, 80.62, 67.34, 63.27, 58.25, 55.14, 47.30, 25.97, 18.35, -5.49. HRMS (ESI ${ }^{+}$calcd. for $\mathrm{C}_{33} \mathrm{H}_{41} \mathrm{NO}_{6} \mathrm{Si}[\mathrm{M}+\mathrm{H}]^{+} \mathrm{m} / \mathrm{z}$ : 576.2776; found: 576.2765 .

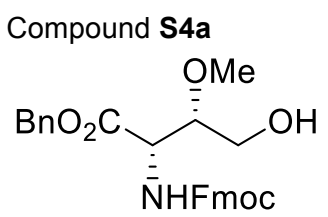

To a stirred solution of compound $10 \mathrm{a}(2.85 \mathrm{~g}, 4.84 \mathrm{mmol}, 1.0$ equiv.) in THF (20 mL), A mixture of Bu $4 \mathrm{NF}(1 \mathrm{M} \mathrm{in} \mathrm{THF,} 1.45 \mathrm{~mL}, 3.0$ equiv.) and acetic acid $(0.91 \mathrm{~mL}, 16.0 \mathrm{mmol}, 3.3$ equiv.) was added dropwise. After stirring the reaction mixture at room temperature for $8 \mathrm{~h}$, it was diluted with ethyl acetate $(200 \mathrm{~mL})$ and then washed with sat. $\mathrm{NaHCO}_{3}(2 \times 30 \mathrm{~mL})$ and brine $(2 \times 30 \mathrm{~mL})$. The organic phase was dried over $\mathrm{Na}_{2} \mathrm{SO}_{4}$, concentrated under vacuo and purified by flash column chromatography on silica gel (hexane/EtOAc, 3:1) to give compound $\mathbf{S} 4 \mathrm{a}(1.81 \mathrm{~g}, 81 \%)$ as colorless solid. m.p. $=74-77^{\circ} \mathrm{C} ;[\boldsymbol{\alpha}]_{\mathrm{D}}{ }^{20}=-1.3(\mathrm{c}=0.92, \mathrm{DCM}) ;{ }^{1} \mathbf{H ~ N M R}\left(500 \mathrm{MHz}, \mathrm{CDCl}_{3}\right) \delta$ $7.76(\mathrm{~d}, J=7.5 \mathrm{~Hz}, 2 \mathrm{H}), 7.59$ (dd, $J=7.4,3.4 \mathrm{~Hz}, 2 \mathrm{H}), 7.44-7.28(\mathrm{~m}, 9 \mathrm{H}), 5.71(\mathrm{~d}, J=8.6 \mathrm{~Hz}, 1 \mathrm{H}), 5.31(\mathrm{~d}, J=12.1 \mathrm{~Hz}, 1 \mathrm{H}), 5.16(\mathrm{~d}$, $J=12.1 \mathrm{~Hz}, 1 \mathrm{H}), 4.68(\mathrm{dd}, J=8.6,1.7 \mathrm{~Hz}, 1 \mathrm{H}), 4.51-4.36(\mathrm{~m}, 2 \mathrm{H}), 4.21(\mathrm{t}, J=7.0 \mathrm{~Hz}, 1 \mathrm{H}), 3.92-3.80(\mathrm{~m}, 1 \mathrm{H}), 3.68(\mathrm{dd}, J=11.8,5.4$ $\mathrm{Hz}, 1 \mathrm{H}), 3.37$ (dd, $J=11.7,9.0 \mathrm{~Hz}, 1 \mathrm{H}), 3.19(\mathrm{~s}, 3 \mathrm{H}) ;{ }^{13} \mathrm{C}$ NMR $(126 \mathrm{MHz}, \mathrm{CDCl} 3) \delta 170.57,157.51,143.84,143.60,141.43,135.18$, $128.78,128.70,127.90,127.24,125.19,120.16,120.13,81.40,67.69,67.66,59.86,58.82,54.89,47.23$; HRMS (ESI ${ }^{+}$) calcd. for $\mathrm{C}_{27} \mathrm{H}_{27} \mathrm{NO}_{6}[\mathrm{M}+\mathrm{H}]^{+} \mathrm{m} / \mathrm{z}: 462.1911$; found: 462.1895.

Compound S4b 
<smiles>COC(CO)C(N=CCOC(=O)OCc1ccccc1)C(=O)O</smiles>

To a stirred solution of compound $10 \mathrm{~b}(2.50 \mathrm{~g}, 4.35 \mathrm{mmol}, 1.0$ equiv.) in THF (20 mL), A mixture of Bu $4 \mathrm{NF}(1 \mathrm{M}$ in THF, $1.3 \mathrm{~mL}, 3.0$ equiv.) and acetic acid $(0.82 \mathrm{~mL}, 14.3 \mathrm{mmol}, 3.3$ equiv.) was added dropwise. After stirring the reaction mixture at room temperature for $8 \mathrm{~h}$, it was diluted with ethyl acetate $(200 \mathrm{~mL})$ and then washed with sat. $\mathrm{NaHCO}_{3}(2 \times 30 \mathrm{~mL})$ and brine $(2 \times 30 \mathrm{~mL})$. The organic phase was dried over $\mathrm{Na}_{2} \mathrm{SO}_{4}$, concentrated under vacuo and purified by flash column chromatography on silica gel (hexane/EtOAc, 3:1) to give compound S4b $(1.6 \mathrm{~g}, 82 \%)$ as colorless solid. m.p. $=83-85^{\circ} \mathrm{C} ;[\boldsymbol{\alpha}]_{\mathrm{D}}{ }^{20}=+3.6(\mathrm{c}=1.7, \mathrm{DCM}) ;{ }^{1} \mathrm{H} \mathrm{NMR}(400 \mathrm{MHz}, \mathrm{CDCl})_{3} \delta$ $7.76(\mathrm{~d}, J=7.5 \mathrm{~Hz}, 2 \mathrm{H}), 7.59(\mathrm{~d}, J=7.4 \mathrm{~Hz}, 2 \mathrm{H}), 7.46-7.28(\mathrm{~m}, 8 \mathrm{H}), 5.75(\mathrm{~d}, J=8.9 \mathrm{~Hz}, 1 \mathrm{H}), 5.21(\mathrm{q}, J=12.2 \mathrm{~Hz}, 2 \mathrm{H}), 4.76(\mathrm{dd}, J=$ $8.3,4.3 \mathrm{~Hz}, 1 \mathrm{H}), 4.42(\mathrm{~d}, J=6.5 \mathrm{~Hz}, 2 \mathrm{H}), 4.22(\mathrm{t}, J=6.8 \mathrm{~Hz}, 1 \mathrm{H}), 3.74(\mathrm{~d}, J=11.1 \mathrm{~Hz}, 1 \mathrm{H}), 3.62(\mathrm{~d}, J=11.8 \mathrm{~Hz}, 2 \mathrm{H}), 3.42(\mathrm{~s}, 3 \mathrm{H}), 3.38$ $(\mathrm{d}, J=7.7 \mathrm{~Hz}, 1 \mathrm{H}) ;{ }^{13} \mathrm{C}$ NMR $\left(125 \mathrm{MHz}, \mathrm{CDCl}_{3}\right) \delta 170.57,156.43,143.94,143.76,141.41,135.16,128.73,128.70,128.64,128.47$, 127.84, 127.20, 125.19, 120.10, 120.08, 80.93, 67.60, 67.33, 61.21, 58.11, 54.62, 47.25; HRMS (ESI ${ }^{+}$calcd. for $\mathrm{C}_{27} \mathrm{H}_{27} \mathrm{NO}_{6}[\mathrm{M}+\mathrm{H}]^{+}$ $\mathrm{m} / \mathrm{z}$ : 462.1911; found: 462.1893 .

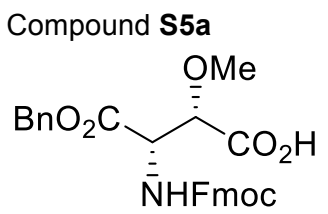

To a stirred solution of compound S4a $\left(1.4 \mathrm{~g}, 3.03 \mathrm{mmol}, 1.0\right.$ equiv.) in DCM/THF/ $\mathrm{H}_{2} \mathrm{O}$ (10 mL, 8:8:1), $\mathrm{NaH}_{2} \mathrm{PO}_{4}(1.7 \mathrm{~g}, 12.1 \mathrm{mmol}, 4$ equiv.), TEMPO (0.236 g, $1.52 \mathrm{mmol}, 0.5$ equiv.) and BAIB ( $634 \mathrm{mg}, 1.97 \mathrm{mmol}, 5.0$ equiv.) were added sequentially. The reaction mixture was stirred at $\mathrm{rt}$ for $1 \mathrm{~h}$. The reaction mixture was diluted with EtOAc (100 mL), washed with sat. $\mathrm{Na}_{2} \mathrm{~S}_{2} \mathrm{O}_{3}(50 \mathrm{~mL} \times 2)$, brine $\left(50 \mathrm{~mL} X\right.$ 1). The organic phase was dried over $\mathrm{Na}_{2} \mathrm{SO}_{4}$, concentrated under vacuo and purified by flash column chromatography on silica gel (hexane/EtOAc, 1:1 with $0.5 \% \mathrm{AcOH}$ ) to give compound $\mathbf{S} 5 \mathrm{a}(1.16 \mathrm{~g}, 81 \%)$ as colorless solid. m.p. $=72-75^{\circ} \mathrm{C} ;[\mathbf{\alpha}]_{\mathrm{D}}{ }^{20}=-20.1$ $(\mathrm{c}=0.91, \mathrm{DCM}) ;{ }^{1} \mathrm{H}$ NMR $\left(500 \mathrm{MHz}, \mathrm{CDCl}_{3}\right) \delta 7.71(\mathrm{~d}, \mathrm{~J}=7.4 \mathrm{~Hz}, 2 \mathrm{H}), 7.54(\mathrm{t}, J=7.4 \mathrm{~Hz}, 2 \mathrm{H}), 7.38-7.29(\mathrm{~m}, 7 \mathrm{H}), 7.28-7.21(\mathrm{~m}$, $2 \mathrm{H}), 5.77(\mathrm{~d}, J=8.8 \mathrm{~Hz}, 1 \mathrm{H}), 5.30(\mathrm{~d}, J=11.2 \mathrm{~Hz}, 1 \mathrm{H}), 5.12(\mathrm{~d}, J=12.2 \mathrm{~Hz}, 1 \mathrm{H}), 4.98(\mathrm{~d}, J=9.8 \mathrm{~Hz}, 1 \mathrm{H}), 4.38-4.23(\mathrm{~m}, 3 \mathrm{H}), 4.16(\mathrm{t}$, $J=7.3 \mathrm{~Hz}, 1 \mathrm{H}), 3.29$ (s, 3H); ${ }^{13} \mathrm{C}$ NMR $(126 \mathrm{MHz}, \mathrm{CDCl} 3) \delta 169.05,156.79,143.87,143.78,141.34,135.21,128.77,128.72,128.47$, 127.81, 127.23, 125.39, 120.04, 79.62, 67.94, 67.86, 59.34, 56.50, 47.03; HRMS (ESI ${ }^{+}$) calcd. for $\mathrm{C}_{27} \mathrm{H}_{25} \mathrm{NO}_{7}[\mathrm{M}+\mathrm{H}]^{+} \mathrm{m} / \mathrm{z}: 476.1704$; found: 476.1682 .<smiles>C[C@H](O)[C@H](N=C[O+])C(=O)O</smiles>

To a stirred solution of compound S4b $\left(1.2 \mathrm{~g}, 2.51 \mathrm{mmol}, 1.0\right.$ equiv.) in DCM/THF/ $\mathrm{H}_{2} \mathrm{O}(10 \mathrm{~mL}, 8: 8: 1), \mathrm{NaH}_{2} \mathrm{PO}_{4}(1.43 \mathrm{~g}, 10.4 \mathrm{mmol}$, 4.0 equiv.), TEMPO (0.203 g, $1.25 \mathrm{mmol}, 0.5$ equiv.) and BAIB ( $4.2 \mathrm{~g}, 1.25 \mathrm{mmol}, 5.0$ equiv.) were added sequentially. The reaction mixture was stirred at $\mathrm{rt}$ for $1 \mathrm{~h}$. The reaction mixture was diluted with EtOAc (100 mL), washed with sat. $\mathrm{Na}_{2} \mathrm{~S}_{2} \mathrm{O}_{3}(50 \mathrm{~mL} \times 2)$, brine $(50 \mathrm{~mL} X 1)$. The organic phase was dried over $\mathrm{Na}_{2} \mathrm{SO}_{4}$, concentrated under vacuo and purified by flash column chromatography on silica gel (hexane/EtOAc, $1: 1$ with $0.5 \% \mathrm{AcOH}$ ) to give compound $\mathbf{S} 5 \mathbf{b}(0.99 \mathrm{~g}, 83 \%)$ as colorless solid. m.p. $=77-82{ }^{\circ} \mathrm{C} ;[\boldsymbol{\alpha}]_{\mathrm{D}}{ }^{20}=+17.8$ (c = 0.28, DCM); ${ }^{1} \mathrm{H}$ NMR $\left(400 \mathrm{MHz}, \mathrm{CDCl}_{3}\right) \delta 7.76(\mathrm{~d}, J=7.5 \mathrm{~Hz}, 2 \mathrm{H}), 7.59(\mathrm{~d}, J=7.4 \mathrm{~Hz}, 2 \mathrm{H}), 7.39(\mathrm{~d}, J=7.6 \mathrm{~Hz}, 2 \mathrm{H}), 7.38-7.27(\mathrm{~m}$, $6 \mathrm{H}), 7.26(\mathrm{~d}, J=1.3 \mathrm{~Hz}, 3 \mathrm{H}), 5.75(\mathrm{~d}, J=8.9 \mathrm{~Hz}, 1 \mathrm{H}), 5.21(\mathrm{q}, J=12.2 \mathrm{~Hz}, 2 \mathrm{H}), 4.76(\mathrm{~s}, 1 \mathrm{H}), 4.42(\mathrm{~d}, J=6.5 \mathrm{~Hz}, 2 \mathrm{H}), 4.22(\mathrm{t}, J=6.8$ $\mathrm{Hz}, 1 \mathrm{H}), 3.88-3.67(\mathrm{~m}, 2 \mathrm{H}), 3.62(\mathrm{~d}, J=11.8 \mathrm{~Hz}, 2 \mathrm{H}), 3.42(\mathrm{~s}, 3 \mathrm{H}) ;{ }^{13} \mathrm{C}$ NMR $\left(125 \mathrm{MHz}, \mathrm{CDCl}_{3}\right) \delta 170.57,156.43,143.94,143.76$, $141.41,135.16,128.73,128.70,128.68,128.64,128.47,128.43,127.84,127.20,125.19,120.10,120.08,80.93,67.60,67.33,61.21$, 58.11, 54.62, 47.25; HRMS (ESI ${ }^{+}$) calcd. for $\mathrm{C}_{27} \mathrm{H}_{25} \mathrm{NO}_{7}[\mathrm{M}+\mathrm{H}]^{+} \mathrm{m} / \mathrm{z}$ : 476.1704; found: 476.1683.

Compound S6a:<smiles>COC(=O)C(OC)[C@@H](N=COC(=O)OCc1ccccc1)C(=O)O</smiles>

To a stirred solution of compound $\mathbf{S 5 a}$ (523 mg, $1.10 \mathrm{mmol}, 1.0$ equiv.) in anhydrous DCM (7 mL), Tert-butyl-2,2,2-trichloroacetimidate $\left(0.797 \mathrm{~mL}, 4.40 \mathrm{mmol}, 4.0\right.$ equiv.) and $\mathrm{BF}_{3} \cdot \mathrm{Et}_{2} \mathrm{O}(14 \mathrm{uL}, 0.11 \mathrm{mmol}, 0.1$ equiv.) were slowly added. The mixture was stirred at $\mathrm{rt}$ overnight under argon protection. The reaction was concentrated in vacuo and directly purified by flash column chromatography on silica gel (hexane/EtOAc, 20:1) to give compound S6a $(480 \mathrm{mg}, 82 \%)$ as colorless oil. [a $]_{\mathrm{D}}{ }^{20}=-26.8\left(\mathrm{C}=1.45\right.$, DCM); ${ }^{1} \mathbf{H} \mathbf{~ N M R}(500$ $\left.\mathrm{MHz}, \mathrm{CDCl}_{3}\right) \delta 7.75(\mathrm{~d}, J=7.5 \mathrm{~Hz}, 2 \mathrm{H}), 7.58(\mathrm{t}, J=8.2 \mathrm{~Hz}, 2 \mathrm{H}), 7.41-7.26(\mathrm{~m}, 9 \mathrm{H}), 5.61(\mathrm{~d}, J=10.2 \mathrm{~Hz}, 1 \mathrm{H}), 5.32(\mathrm{~d}, J=12.2 \mathrm{~Hz}, 1 \mathrm{H})$, $5.15(\mathrm{~d}, J=12.2 \mathrm{~Hz}, 1 \mathrm{H}), 4.95(\mathrm{dd}, J=10.2,2.4 \mathrm{~Hz}, 1 \mathrm{H}), 4.47-4.29(\mathrm{~m}, 2 \mathrm{H}), 4.27(\mathrm{~d}, J=2.5 \mathrm{~Hz}, 1 \mathrm{H}), 4.20(\mathrm{t}, J=7.4 \mathrm{~Hz}, 1 \mathrm{H}), 3.34(\mathrm{~s}$, $3 \mathrm{H}), 1.43$ (s, 9H); ${ }^{13} \mathrm{C}$ NMR $\left(126 \mathrm{MHz}, \mathrm{CDCl}_{3}\right) \delta 169.38,167.96,156.36,143.96,143.82,141.35,135.41,128.73,128.62,128.43$, $127.80,127.78,127.22,125.36,125.30,120.04,83.02,79.90,67.62,59.20,56.75,47.11,28.01 ;$ HRMS (ESI $)$ calcd. for $\mathrm{C}_{31} \mathrm{H}_{33} \mathrm{NO}_{7}$ $[\mathrm{M}+\mathrm{H}]^{+} \mathrm{m} / \mathrm{z}: 532.2330$; found: 532.2306 . 


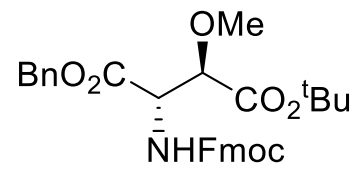

To a stirred solution of compound S5b $(749 \mathrm{mg}, 1.57 \mathrm{mmol}, 1.0$ equiv. $)$ in anhydrous DCM $(9 \mathrm{~mL})$, Tert-butyl-2,2,2-trichloroacetimidate (1.14 mL, $6.30 \mathrm{mmol}, 4.0$ equiv.) and $\mathrm{BF}_{3} \cdot \mathrm{Et}_{2} \mathrm{O}(20 \mathrm{uL}, 0.157 \mathrm{mmol}, 0.1$ equiv.) were slowly added. The mixture was stirred at $\mathrm{rt}$ overnight under argon protection. The reaction was concentrated in vacuo, and directly purified by flash column chromatography on

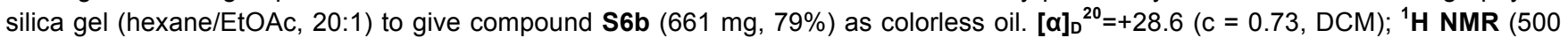
$\left.\mathrm{MHz}, \mathrm{CDCl}_{3}\right) \delta 7.76(\mathrm{~d}, J=7.5 \mathrm{~Hz}, 2 \mathrm{H}), 7.60(\mathrm{~d}, J=7.4 \mathrm{~Hz}, 2 \mathrm{H}), 7.39(\mathrm{~d}, J=7.4 \mathrm{~Hz}, 2 \mathrm{H}), 7.31(\mathrm{dd}, J=14.9,7.5 \mathrm{~Hz}, 8 \mathrm{H}), 5.73(\mathrm{~d}, J=$ $8.7 \mathrm{~Hz}, 1 \mathrm{H}), 5.25(\mathrm{~d}, J=12.2 \mathrm{~Hz}, 1 \mathrm{H}), 5.11(\mathrm{~d}, J=12.1 \mathrm{~Hz}, 1 \mathrm{H}), 4.93(\mathrm{~d}, J=8.7 \mathrm{~Hz}, 1 \mathrm{H}), 4.42(\mathrm{~d}, J=7.3 \mathrm{~Hz}, 1 \mathrm{H}), 4.38(\mathrm{~d}, J=7.4 \mathrm{~Hz}$, $1 \mathrm{H}), 4.24(\mathrm{~d}, J=7.1 \mathrm{~Hz}, 1 \mathrm{H}), 4.02(\mathrm{~s}, 1 \mathrm{H}), 3.50(\mathrm{~s}, 3 \mathrm{H}), 1.40(\mathrm{~s}, 9 \mathrm{H}) ;{ }^{13} \mathrm{C}$ NMR $\left(126 \mathrm{MHz}, \mathrm{CDCl}_{3}\right) \delta 168.78,167.70,156.04,143.99$, $143.83,141.44,135.03,128.74,128.65,128.61,127.87,127.23,125.25,120.13,82.86,81.10,67.90,67.48,59.64,56.16,47.23$, 28.05; HRMS (ESI ${ }^{+}$) calcd. for $\mathrm{C}_{31} \mathrm{H}_{33} \mathrm{NO}_{7}[\mathrm{M}+\mathrm{H}]^{+} \mathrm{m} / \mathrm{z}$ : 532.2330 ; found: 532.2306 .

\section{Compound 11a}<smiles>COC(=O)[C@@H](N)[C@H](N)C(=O)O</smiles>

To a $50 \mathrm{~mL}$ round bottom flask, compound S6a (1.06 g, $2.00 \mathrm{mmol}, 1.0$ equiv.) and Pd/C (10\% Pd on activated carbon, $106 \mathrm{mg})$ were added. After argon protection of the flask, EtOAc $(15 \mathrm{~mL})$ was added, and the mixture was stirred until compound S6a dissolved. The flask was charged with $\mathrm{H}_{2}$ afterwards. The reaction mixture was stirred at $\mathrm{rt}$ for $6 \mathrm{~h}$. The reaction mixture was filtered through celite, concentrated under vacuo, and purified by flash column chromatography on silica gel (hexane/EtOAc, 1:1 with $0.5 \% \mathrm{AcOH}$ ) to give compound 11a $(0.802 \mathrm{~g}, 91 \%)$ as colorless oil. [a] ${ }_{\mathrm{D}}{ }^{20}=-15.0(\mathrm{c}=1.55, \mathrm{DCM}) ;{ }^{1} \mathrm{H}$ NMR $\left(500 \mathrm{MHz}, \mathrm{CDCl}_{3}\right) \delta 7.72(\mathrm{~d}, \mathrm{~J}=7.5 \mathrm{~Hz}, 2 \mathrm{H})$, $7.57(\mathrm{dd}, J=12.7,7.5 \mathrm{~Hz}, 2 \mathrm{H}), 7.36(\mathrm{t}, J=7.4 \mathrm{~Hz}, 2 \mathrm{H}), 7.27(\mathrm{t}, J=7.4 \mathrm{~Hz}, 2 \mathrm{H}), 5.85(\mathrm{~d}, J=9.7 \mathrm{~Hz}, 1 \mathrm{H}), 4.92(\mathrm{~d}, J=9.4 \mathrm{~Hz}, 1 \mathrm{H}), 4.31$ $(\mathrm{m}, 3 \mathrm{H}), 4.18(\mathrm{t}, J=7.3 \mathrm{~Hz}, 1 \mathrm{H}), 3.46(\mathrm{~s}, 3 \mathrm{H}), 1.44(\mathrm{~s}, 3 \mathrm{H}) ;{ }^{13} \mathrm{C}$ NMR $\left(126 \mathrm{MHz}, \mathrm{CDCl}_{3}\right) \delta 173.92,168.46,156.57,143.91,143.77$, 141.32, 127.79, 127.21, 125.35, 125.32, 120.01, 83.28, 79.91, 67.66, 59.37, 56.57, 47.06, 27.99; HRMS (ESI ${ }^{+}$calcd. for $\mathrm{C}_{24} \mathrm{H}_{27} \mathrm{NO}_{7}$ $[\mathrm{M}+\mathrm{H}]^{+} \mathrm{m} / \mathrm{z}: 442.1860$; found: 442.1845

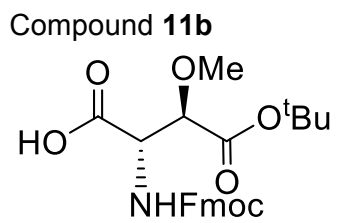

To a $50 \mathrm{~mL}$ round bottom flask, compound $\mathbf{S 6 b}(811 \mathrm{mg}, 1.53 \mathrm{mmol}, 1.0$ equiv.) and $\mathrm{Pd} / \mathrm{C}$ (10\% Pd on activated carbon, $81.1 \mathrm{mg})$ were added. After argon protection of the flask, EtOAc $(6 \mathrm{~mL})$ was added, and the mixture was stirred until compound S6b dissolved. The flask was charged with $\mathrm{H}_{2}$ afterwards. The reaction mixture was stirred at $\mathrm{rt}$ for $6 \mathrm{~h}$. The reaction mixture was filtered through celite, concentrated under vacuo, and purified by flash column chromatography on silica gel (hexane/EtOAc, $1: 1$ with $0.5 \% \mathrm{AcOH}$ ) to give compound 11b $(627 \mathrm{mg}, 93 \%)$ as colorless oil. [a $]_{\mathrm{D}}{ }^{20}=-28.5(\mathrm{c}=0.49, \mathrm{DCM}) ;{ }^{1} \mathrm{H}$ NMR $\left(500 \mathrm{MHz}, \mathrm{CDCl}_{3}\right) \delta 7.75(\mathrm{~d}, \mathrm{~J}=7.5 \mathrm{~Hz}, 2 \mathrm{H})$, $7.62(\mathrm{~s}, 2 \mathrm{H}), 7.60(\mathrm{t}, J=6.8 \mathrm{~Hz}, 2 \mathrm{H}), 7.39(\mathrm{~d}, J=7.4 \mathrm{~Hz}, 1 \mathrm{H}), 7.30(\mathrm{~d}, J=7.4 \mathrm{~Hz}, 1 \mathrm{H}), 5.80(\mathrm{~s}, 1 \mathrm{H}), 4.89(\mathrm{~s}, 1 \mathrm{H}), 4.41(\mathrm{t}, J=6.8 \mathrm{~Hz}, 1 \mathrm{H})$, 4.24 (t, J = 7.0 Hz, 1H), 4.05 (s, 1H), 3.51 (s, 3H), 1.50 (s, 9H); $\left.{ }^{13} \mathrm{C} \mathrm{NMR} \mathrm{(126} \mathrm{MHz,} \mathrm{CDCl}_{3}\right) \delta$ 172.20, 168.40, 156.09, 143.94, 143.80, 141.42, 127.86, 127.22, 125.23, 120.11, 83.34, 81.02, 67.44, 59.85, 47.21, 28.13, 28.08, 28.02; HRMS (ESI ${ }^{+}$calcd. for $\mathrm{C}_{24} \mathrm{H}_{27} \mathrm{NO}_{7}$ $[\mathrm{M}+\mathrm{H}]^{+} \mathrm{m} / \mathrm{z}: 442.1860$; found: 442.1839 .

Compound $12 \mathrm{a}$ and $\mathbf{1 2 b}$

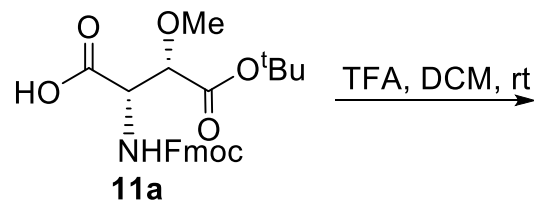<smiles>CO[C@H](C(=O)O)[C@@H](N=[Se])C(=O)O</smiles><smiles>CO[C@H](C(=O)O)[C@@H](N)C(=O)O</smiles>

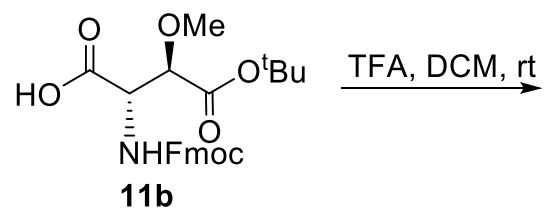<smiles>C=N[C@@H](C(=O)O)[C@H](OC)C(=O)O</smiles><smiles>CO[C@H](C(=O)O)[C@@H](N)C(=O)O</smiles>

To a $10 \mathrm{~mL}$ round bottom flask were added $20 \mathrm{mg}$ compound $11 \mathrm{a} / 11 \mathrm{~b}$ and $95 \%$ TFA ( $2 \mathrm{~mL}$ ). The reaction mixture was stirred for 30 min. Then TFA was removed under a stream of nitrogen. The crude product was dissolved in sat. $\mathrm{NaHCO}_{3}(5 \mathrm{~mL})$ and wash with EtOAc $(3 \times 2 \mathrm{~mL})$. The aqueous phase was acidified by $1 \mathrm{~N} \mathrm{HCl}$ to $\mathrm{pH} 3$ and extracted with EtOAc $(3 \times 10 \mathrm{~mL})$. The combined organic phase was dried with $\mathrm{Na}_{2} \mathrm{SO}_{4}$ and concentrated in vacuo to give crude product $\mathbf{S 7 a / S 7 b}$ for Fmoc-deprotection without purification. The crude product was dissolved in a mixture of diethylamine $(1 \mathrm{~mL})$ and DCM $(0.5 \mathrm{~mL})$ with stirring and monitored by TLC until the reaction was finished. The solvent was removed in vacuo, diluted with $\mathrm{H}_{2} \mathrm{O}(5 \mathrm{~mL})$ and washed with diethyl ether $(3 \mathrm{X} 2 \mathrm{~mL})$. The 
aqueous phase was acidified to $\mathrm{pH} 2$ by $1 \mathrm{~N} \mathrm{HCl}$. This aqueous phase was subjected to purification with a column packed with ion-exchange resin following the protocol reported in literature ${ }^{2}$. The lyophilized product was dissolved in $\mathrm{D}_{2} \mathrm{O}$ and NMR spectra were collected and compared to those reported in literature ${ }^{2}$ for the structural determination of the stereocenters of compound $12 \mathbf{a}$ and $\mathbf{1 2 b}$.

Compound 13a and 13b

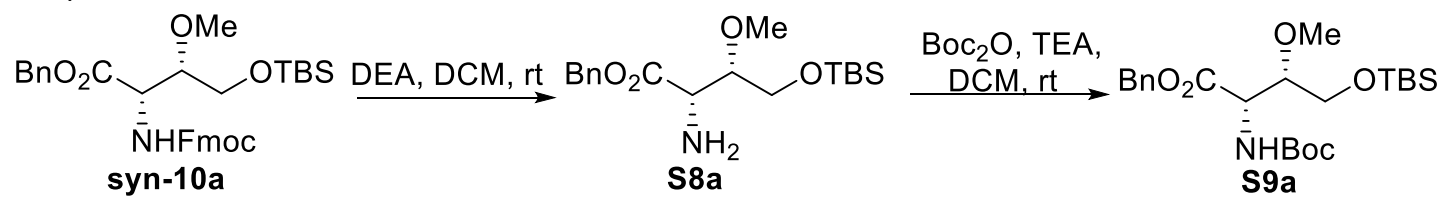

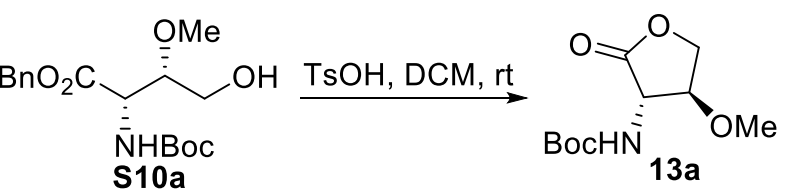

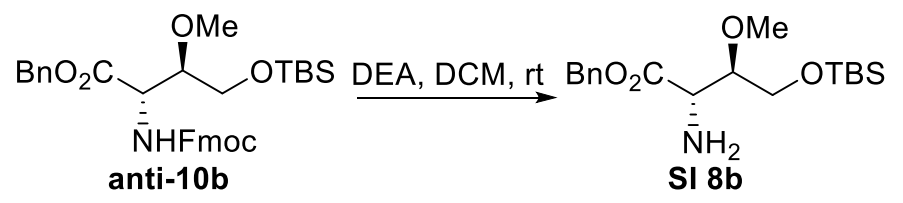

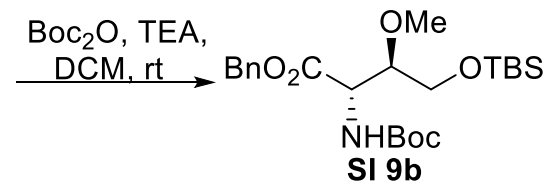

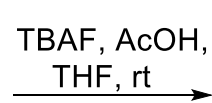<smiles>CO[C@H](CO)[C@H](C(=O)O)C(=O)O[SnH3]</smiles>

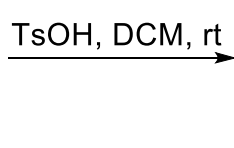<smiles>CO[C@H]1COC(=O)[C@@H]1NC(=O)O</smiles>

To a $10 \mathrm{~mL}$ round bottom flask were added $50 \mathrm{mg}$ compound 10a/10b, DCM $(4 \mathrm{~mL})$ and TFA $(2 \mathrm{~mL})$. The reaction mixture was stirred for $2 \mathrm{~h}$. Then the mixture was concentrated under vacuo, and purified by flash column chromatography on silica gel ( $\mathrm{DCM} / \mathrm{MeOH}$, $20: 1)$ to give free amine product S8a/S8b $(25 \mathrm{mg})$. The $\mathbf{S} 8 \mathbf{a} / \mathbf{S} 8 \mathbf{b}$ was dissolved in DCM (5mL), then DIEA (70 $\mu \mathrm{L})$ and Boc ${ }_{2} \mathrm{O}(49 \mu \mathrm{L})$ were added. After the reaction mixture was stirred for $2 \mathrm{~h}$, the mixture was concentrated under vacuo, and purified by flash column chromatography on silica gel (hexane/EtOAc, 15:1) to give the desired product $\mathbf{S 9 a} / \mathbf{S 9 b}(25 \mathrm{mg})$. The product $\mathbf{S 9 a} / \mathbf{S 9 b}(25 \mathrm{mg})$ was dissolved in THF $(1 \mathrm{~mL})$, a mixture of $\mathrm{Bu}_{4} \mathrm{NF}(1 \mathrm{M}$ in THF, $0.13 \mathrm{~mL})$ and acetic acid $(8 \mu \mathrm{L})$ was added dropwise. After stirring the reaction mixture at room temperature for $8 \mathrm{~h}$, it was diluted with ethyl acetate $(20 \mathrm{~mL})$ and then washed with sat. $\mathrm{NaHCO}_{3}(2 \times 5 \mathrm{~mL})$ and brine $(2 \times 10 \mathrm{~mL})$. The organic phase was dried over $\mathrm{Na}_{2} \mathrm{SO}_{4}$, concentrated under vacuo and purified by flash column chromatography on silica gel (hexane/EtOAc, 3:1) to give compound S10a/S10b (3 mg). The alcohol S10a/S10b (3 mg) was dissolved in DCM (1 mL), a catalytic amount of $p-\mathrm{TsOH}$ was added, the reaction was stirred at rt overnight. The mixture was concentrated under vacuo, and purified by flash column chromatography on silica gel (hexane/EtOAc, 15:1) to give the lactone 13 a (1 mg) as yellow solid and 13b $(1 \mathrm{mg})$ as yellow solid. Compound 13a: ${ }^{1} \mathrm{H}$ NMR $\left(500 \mathrm{MHz}, \mathrm{CDCl}_{3}\right) \delta 5.16(\mathrm{NH}, \mathrm{s}, 1 \mathrm{H}), 4.59(\mathrm{H} 4, \mathrm{t}, \mathrm{J}=7.7 \mathrm{~Hz}, 1 \mathrm{H}), 4.28(\mathrm{H} 3, \mathrm{q}$, $J=6.7 \mathrm{~Hz}, 1 \mathrm{H}), 4.08(\mathrm{H} 4, \mathrm{~d}, J=9.3 \mathrm{~Hz}, 1 \mathrm{H}), 4.06(\mathrm{H} 2, \mathrm{~d}, \mathrm{~J}=6.6 \mathrm{~Hz}, 1 \mathrm{H}) 3.45(\mathrm{OMe}, \mathrm{s}, 3 \mathrm{H}), 1.46\left({ }^{\mathrm{t}} \mathrm{Bu}, \mathrm{s}, 9 \mathrm{H}\right) ;{ }^{13} \mathrm{C} \mathrm{NMR}(126 \mathrm{MHz}$, $\left.\mathrm{CDCl}_{3}\right) \delta$ 173.10, 155.31 80.45, 69.86, 57.89, 56.90, 29.84, 28.37; HRMS $\left(\mathrm{ESI}^{+}\right)$calcd. for $\mathrm{C}_{10} \mathrm{H}_{17} \mathrm{NO}_{5} \mathrm{Si}[\mathrm{M}+\mathrm{H}]^{+} \mathrm{m} / \mathrm{z}: 232.1179$; found: 232.1191. Compound 13b: ${ }^{1} \mathrm{H}$ NMR $\left(500 \mathrm{MHz}, \mathrm{CDCl}_{3}\right) \delta 5.10(\mathrm{NH}, \mathrm{d}, J=7.5 \mathrm{~Hz}, 1 \mathrm{H}), 4.62(\mathrm{H} 2, \mathrm{dd}, J=8.3,4.9 \mathrm{~Hz}, 1 \mathrm{H}), 4.43(\mathrm{H} 4, \mathrm{~d}, J$ $=10.8 \mathrm{~Hz}, 1 \mathrm{H}), 4.26(\mathrm{H} 4, \mathrm{dd}, J=10.8,2.8 \mathrm{~Hz}, 1 \mathrm{H}), 4.12(\mathrm{H} 3, \mathrm{dd}, J=4.8,2.8 \mathrm{~Hz}, 1 \mathrm{H}), 3.43(\mathrm{OMe}, \mathrm{s}, 3 \mathrm{H}), 1.47\left({ }^{\mathrm{t}} \mathrm{Bu}, \mathrm{s}, 9 \mathrm{H}\right) ;{ }^{13} \mathrm{C} \mathrm{NMR}$ $\left(126 \mathrm{MHz}, \mathrm{CDCl}_{3}\right) \delta 173.80,155.65,80.86,76.95,69.19,57.67,53.54,28.42 ; \mathrm{HRMS}\left(\mathrm{ESI}^{+}\right)$calcd. for $\mathrm{C}_{10} \mathrm{H}_{17} \mathrm{NO}_{5} \mathrm{Si}[\mathrm{M}+\mathrm{H}]^{+} \mathrm{m} / \mathrm{z}$ : 232.1179; found: 232.1180 .

\subsection{Syntheses of 3-Me-Glu}
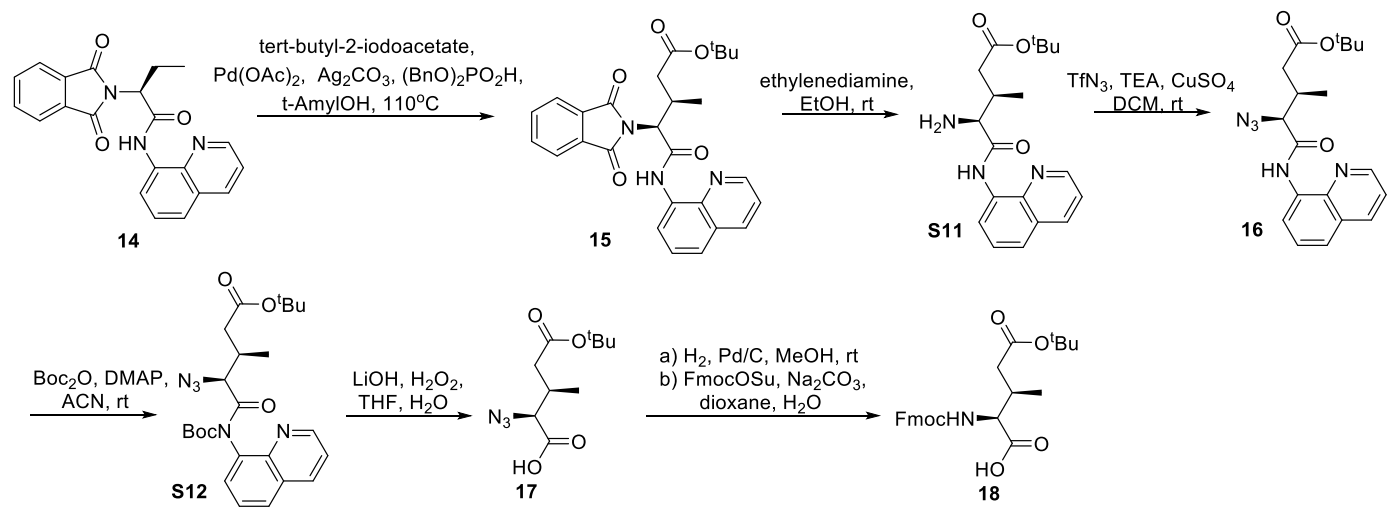

Compound 15: 
<smiles>CC(CC(=O)OC(C)(C)C)C([NH2+])C(=O)NC=O</smiles>

To a $100 \mathrm{~mL}$ sealed tube was added $\mathrm{N}$-Phthaloyl- $\beta$-methylalanine 8-aminoquinoline amide $14^{3}$ (2.13 g, $5.92 \mathrm{mmol}$, $1.0 \mathrm{equiv}$.), tert-butyl 2-iodoacetate (2.88 g, 11.90 mmol, 2.0 equiv.), $\mathrm{Pd}(\mathrm{OAc})_{2}$ (136 mg, $0.605 \mathrm{mmol}, 0.1$ equiv.), $\mathrm{Ag}_{2} \mathrm{CO}_{3}$ (3.29 g, $11.92 \mathrm{mmol}, 2.0$ equiv.) and $(\mathrm{BnO})_{2} \mathrm{PO}_{2} \mathrm{H}(329 \mathrm{mg}, 1.18 \mathrm{mmol}, 0.2$ equiv.). The sealed tube was charged with argon and $t$-Amyl alcohol $(20 \mathrm{~mL})$ was added. The reaction mixture was stirred at $110^{\circ} \mathrm{C}$ for $26 \mathrm{~h}$. The reaction mixture was filtered by celite, concentrated under vacuo and purified by flash column chromatography on silica gel (toluene/acetone, 30:1) to give compound 15 (2.06 g, $73 \%)$ as yellowish oil. $[\alpha]_{D}{ }^{20}=-7.3(\mathrm{c}=0.46, \mathrm{DCM}) ;{ }^{1} \mathrm{H}$ NMR $\left(400 \mathrm{MHz}, \mathrm{CDCl}_{3}\right) \delta 10.48(\mathrm{~s}, 1 \mathrm{H}), 8.74(\mathrm{dd}, J=5.2,3.0 \mathrm{~Hz}, 2 \mathrm{H}), 8.22-8.04(\mathrm{~m}, 1 \mathrm{H}), 7.89(\mathrm{dd}, J$ $=5.4,3.1 \mathrm{~Hz}, 2 \mathrm{H}), 7.80-7.65(\mathrm{~m}, 2 \mathrm{H}), 7.50(\mathrm{~d}, J=4.5 \mathrm{~Hz}, 2 \mathrm{H}), 7.41(\mathrm{dd}, J=8.2,4.2 \mathrm{~Hz}, 1 \mathrm{H}), 5.15(\mathrm{~d}, J=9.9 \mathrm{~Hz}, 1 \mathrm{H}), 3.58-3.42(\mathrm{~m}$, $1 \mathrm{H}), 2.66(\mathrm{dd}, J=15.4,4.6 \mathrm{~Hz}, 1 \mathrm{H}), 2.42(\mathrm{dd}, J=15.4,7.8 \mathrm{~Hz}, 1 \mathrm{H}), 1.48(\mathrm{~s}, 9 \mathrm{H}), 1.08(\mathrm{~d}, J=6.8 \mathrm{~Hz}, 3 \mathrm{H}) ;{ }^{13} \mathrm{C} \mathrm{NMR}(100 \mathrm{MHz}, \mathrm{CDCl} 3)$ $\delta 171.20,168.19,166.51,148.39,138.55,136.53,134.42,134.33,134.11,131.75,128.02,127.40,123.80,123.71,122.21,121.71$, 117.42, 81.06, 59.57, 39.98, 29.83, 28.23, 28.15, 16.58. HRMS (ESI ${ }^{+}$) calcd. for $\mathrm{C}_{27} \mathrm{H}_{27} \mathrm{~N}_{3} \mathrm{O}_{5}[\mathrm{M}+\mathrm{H}]^{+} \mathrm{m} / \mathrm{z}$ : 474.2023; found: 474.2008 .

Compound S11:<smiles>CC(CC(=O)OC(C)(C)C)C(N)C(=O)NC=O</smiles>

To a stirred solution of compound $15(2.06 \mathrm{~g}, 4.34 \mathrm{mmol}, 1.0$ equiv. $)$ in $\mathrm{EtOH}(15 \mathrm{~mL})$ was added ethylenediamine $(3.0 \mathrm{~mL}, 44.8 \mathrm{mmol}$, 10.0 equiv.) The reaction mixture was stirred at $\mathrm{rt}$ for $16 \mathrm{~h}$. The reaction mixture was concentrated under vacuo and purified by flash

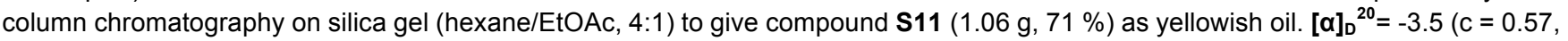
DCM); ${ }^{1} \mathrm{H}$ NMR $\left(400 \mathrm{MHz}, \mathrm{CDCl}_{3}\right) \delta 11.17(\mathrm{~s}, 1 \mathrm{H}), 8.86(\mathrm{dd}, J=4.2,1.6 \mathrm{~Hz}, 1 \mathrm{H}), 8.82(\mathrm{dd}, J=6.0,3.0 \mathrm{~Hz}, 1 \mathrm{H}), 8.16(\mathrm{dd}, J=8.3,1.6$ $\mathrm{Hz}, 1 \mathrm{H}), 7.53(\mathrm{~d}, J=3.1 \mathrm{~Hz}, 1 \mathrm{H}), 7.52(\mathrm{~s}, 1 \mathrm{H}), 7.45(\mathrm{dd}, J=8.3,4.2 \mathrm{~Hz}, 1 \mathrm{H}), 3.85(\mathrm{~d}, J=3.4 \mathrm{~Hz}, 1 \mathrm{H}), 2.82(\mathrm{~m}, 1 \mathrm{H}), 2.52(\mathrm{dd}, J=15.0$, $7.4 \mathrm{~Hz}, 2 \mathrm{H}), 2.31$ (dd, $J=15.0,7.3 \mathrm{~Hz}, 2 \mathrm{H}), 1.47(\mathrm{~s}, 9 \mathrm{H}), 1.04(\mathrm{~d}, J=7.0 \mathrm{~Hz}, 3 \mathrm{H}) ;{ }^{13} \mathrm{C}$ NMR $\left(100 \mathrm{MHz}, \mathrm{CDCl}_{3}\right) \delta 172.52,171.68$, $148.25,138.65,135.93,134.05,127.76,126.94,121.49,121.27,116.12,80.27,59.09,39.81,33.52,27.85,27.70,13.92$. HRMS (ESI ${ }^{+}$) calcd. for $\mathrm{C}_{19} \mathrm{H}_{25} \mathrm{~N}_{3} \mathrm{O}_{3}[\mathrm{M}+\mathrm{H}]^{+} \mathrm{m} / \mathrm{z}$ : 344.1969; found: 344.1966 .

\section{Compound 16:}<smiles>CCCCC(=O)C[C@@H](C)[C@H](N)C(=O)N[O]</smiles>

$\mathrm{NaN}_{3}\left(4.04 \mathrm{~g}, 62.14 \mathrm{mmol}, 20.0\right.$ equiv.) was dissolved in $\mathrm{H}_{2} \mathrm{O}(20 \mathrm{~mL}), \mathrm{DCM}(30 \mathrm{~mL})$ was added and the suspension was cooled to $0^{\circ} \mathrm{C}$. $\mathrm{Tf}_{2} \mathrm{O}\left(2.6 \mathrm{~mL}, 15.36 \mathrm{mmol}, 5.0\right.$ equiv.) was added dropwise. The reaction mixture was stirred at $0^{\circ} \mathrm{C}$ for $2 \mathrm{~h}$. The reaction mixture was diluted with DCM $(10 \mathrm{~mL})$, washed with sat. $\mathrm{NaHCO}_{3}(3 \times 20 \mathrm{~mL})$ and dried over $\mathrm{Na}_{2} \mathrm{SO}_{4}$. The freshly prepared $\mathrm{TfN}_{3}(5.0$ equiv.) in DCM $(40 \mathrm{~mL}$ ) was then added to a $250 \mathrm{~mL}$ flask containing compound $\mathbf{S 1 1}(1.06 \mathrm{~g}, 3.10 \mathrm{mmol}, 1.0$ equiv.). Then, triethylamine (1.3 mL, $9.30 \mathrm{mmol}, 3.0$ equiv.) and $\mathrm{CuSO}_{4} \cdot 5 \mathrm{H}_{2} \mathrm{O}(14.6 \mathrm{mg}, 0.059 \mathrm{mmol}, 0.02$ equiv.) were added sequentially. The reaction mixture was stirred at $\mathrm{rt}$ for $18 \mathrm{~h}$. The reaction mixture was concentrated under vacuo and purified by flash column chromatography on silica gel (hexane/EtOAc, 4:1) to give compound 16 as yellowish oil $(997 \mathrm{mg}, 87 \%)$. [ $]_{\mathrm{D}}{ }^{20}=-122.9(\mathrm{c}=0.69, \mathrm{DCM}) ;{ }^{1} \mathrm{H} \mathrm{NMR}(400 \mathrm{MHz}, \mathrm{CDCl} 3)$ $\delta 10.70(\mathrm{~s}, 1 \mathrm{H}), 8.87(\mathrm{dd}, J=4.2,1.6 \mathrm{~Hz}, 1 \mathrm{H}), 8.78(\mathrm{dd}, J=5.9,3.1 \mathrm{~Hz}, 1 \mathrm{H}), 8.17(\mathrm{dd}, J=8.3,1.6 \mathrm{~Hz}, 1 \mathrm{H}), 7.56-7.53(\mathrm{~m}, 2 \mathrm{H}), 7.48$ $(\mathrm{dd}, J=8.3,4.2 \mathrm{~Hz}, 1 \mathrm{H}), 4.38(\mathrm{~d}, J=4.0 \mathrm{~Hz}, 1 \mathrm{H}), 2.88-2.78(\mathrm{~m}, 1 \mathrm{H}), 2.53(\mathrm{dd}, J=15.3,7.3 \mathrm{~Hz}, 1 \mathrm{H}), 2.34(\mathrm{dd}, J=15.3,7.3 \mathrm{~Hz}, 1 \mathrm{H})$, $1.48(\mathrm{~s}, 9 \mathrm{H}), 1.04(\mathrm{~d}, J=6.8 \mathrm{~Hz}, 3 \mathrm{H}),{ }^{13} \mathrm{C}$ NMR $\left(100 \mathrm{MHz}, \mathrm{CDCl}_{3}\right) \delta 171.18,167.28,148.66,138.70,136.31,133.58,127.97,127.18$, 122.39, 121.78, 116.75, 80.97, 77.48, 77.16, 76.84, 68.92, 39.64, 34.28, 28.11, 28.09, 14.87. HRMS (ESI ) calcd. for $\mathrm{C}_{19} \mathrm{H}_{23} \mathrm{~N}_{5} \mathrm{O}_{3}$ $[\mathrm{M}+\mathrm{H}]^{+} \mathrm{m} / \mathrm{z}: 370.1874$; found: 370.1868 .

\section{Compound S12:}<smiles>CCCCOC(=O)C[C@H](C)[C@H](N)C(=O)N(C=O)OC(=O)c1ccccc1</smiles>

To a $100 \mathrm{~mL}$ round bottom flask was added compound 16 (993 mg, $2.69 \mathrm{mmol}, 1.0$ equiv.) and DMAP (165 mg, $1.35 \mathrm{mmol}, 0.5 \mathrm{equiv}$.). After the flask was charged with argon, anhydrous $\mathrm{MeCN}(15 \mathrm{~mL})$ was added followed by $\mathrm{Boc}_{2} \mathrm{O}(1.3 \mathrm{~mL}, 5.66 \mathrm{mmol}, 2.0$ equiv.). The reaction mixture was stirred at $\mathrm{rt}$ for $12 \mathrm{~h}$. The reaction mixture was concentrated under vacuo and purified by flash column chromatography on silica gel (hexane/EtOAc, 7:1) to give compound $\mathbf{S 1 2}(1.09 \mathrm{~g}, 86 \%)$ as yellowish oil. [ $[\alpha]_{\mathrm{D}}{ }^{20}=+15.0(\mathrm{c}=0.70, \mathrm{DCM})$; ${ }^{1} \mathrm{H}$ NMR $\left(400 \mathrm{MHz} \mathrm{CDCl}_{3}\right) \delta 8.88(\mathrm{dd}, J=4.1,1.4 \mathrm{~Hz}, 1 \mathrm{H}), 8.19(\mathrm{~d}, J=8.0 \mathrm{~Hz}, 1 \mathrm{H}), 7.85(\mathrm{dd}, J=8.1,1.3 \mathrm{~Hz}, 1 \mathrm{H}), 7.55(\mathrm{dt}, J=7.3,6.8$ $\mathrm{Hz}, 2 \mathrm{H}), 7.43(\mathrm{dd}, J=8.3,4.2 \mathrm{~Hz}, 1 \mathrm{H}), 7.26(\mathrm{~s}, 1 \mathrm{H}), 5.37(\mathrm{~d}, J=4.9 \mathrm{~Hz}, 1 \mathrm{H}), 2.87-2.75(\mathrm{~m}, 1 \mathrm{H}), 2.65(\mathrm{dd}, J=14.9,4.6 \mathrm{~Hz}, 1 \mathrm{H}), 2.35$ $(\mathrm{dd}, J=15.0,9.2 \mathrm{~Hz}, 1 \mathrm{H}), 1.48(\mathrm{~s}, 9 \mathrm{H}), 1.22(\mathrm{~s}, 9 \mathrm{H}), 1.14(\mathrm{~d}, J=6.7 \mathrm{~Hz}, 3 \mathrm{H}) ;{ }^{13} \mathrm{C} \mathrm{NMR}\left(125 \mathrm{MHz}, \mathrm{CDCl}_{3}\right) \delta 172.51,170.93,152.23$, $150.04,143.45,135.83,135.75,128.55,128.39,128.15,125.71,121.36,83.12,80.09,66.20,39.82,33.19,27.77,27.12,14.78$. HRMS (ESI ${ }^{+}$) calcd. for $\mathrm{C}_{24} \mathrm{H}_{31} \mathrm{~N}_{5} \mathrm{O}_{5}[\mathrm{M}+\mathrm{H}]^{+} \mathrm{m} / \mathrm{z}$ : 470.2398; found: 470.2378 . 
Compound 17<smiles>CCCCC(=O)OC(=O)C[C@@H](C)C(=O)O</smiles>

To a stirred solution of compound $\mathbf{S 1 2}\left(937 \mathrm{mg}, 2.00 \mathrm{mmol}, 1.0\right.$ equiv.) in THF/ $\mathrm{H}_{2} \mathrm{O}(3: 1,8 \mathrm{~mL})$ were added $\mathrm{LiOH} \cdot \mathrm{H}_{2} \mathrm{O}(172 \mathrm{mg}, 4.10$ mmol, 2.0 equiv.) and $30 \% \mathrm{H}_{2} \mathrm{O}_{2}$ in $\mathrm{H}_{2} \mathrm{O}$ (w/w, $1 \mathrm{~mL}, 9.8 \mathrm{mmol}, 5$ equiv.). The reaction mixture was stirred at rt for $3 \mathrm{~h}$. The reaction mixture was acidified by $1 \mathrm{~N} \mathrm{HCl}$ to $\mathrm{pH}$ 2, then concentrated under vacuo to remove THF. The reaction mixture was diluted with $\mathrm{H}_{2} \mathrm{O}$ $(50 \mathrm{~mL})$ and EtOAc $(100 \mathrm{~mL})$, extracted with EtOAc $(3 \mathrm{X} 100 \mathrm{~mL})$. The combined organic phase was washed with brine $(150 \mathrm{~mL})$, dried over $\mathrm{Na}_{2} \mathrm{SO}_{4}$, concentrated under vacuo and purified by flash column chromatography on silica gel (hexane/EtOAc, $1: 1$ with $0.5 \%$ $\mathrm{AcOH})$ to give compound $17(423 \mathrm{mg}, 87 \%)$ as white solid. m.p. $=55-57^{\circ} \mathrm{C} ;[\mathrm{\alpha}]_{\mathrm{D}}{ }^{20}=-45.4(\mathrm{c}=0.71, \mathrm{DCM}) ;{ }^{1} \mathrm{H} \mathrm{NMR}\left(500 \mathrm{MHz}, \mathrm{CDCl} \mathrm{N}_{3}\right)$ $\delta 4.26(\mathrm{~d}, J=4.1 \mathrm{~Hz}, 1 \mathrm{H}), 2.65-2.56(\mathrm{~m}, 1 \mathrm{H}), 2.43(\mathrm{dd}, J=15.9,7.6 \mathrm{~Hz}, 1 \mathrm{H}), 2.25(\mathrm{dd}, J=15.9,6.7 \mathrm{~Hz}, 1 \mathrm{H}), 1.46(\mathrm{~s}, 9 \mathrm{H}), 0.99(\mathrm{~d}, J=$ $6.8 \mathrm{~Hz}, 3 \mathrm{H}) ;{ }^{13} \mathrm{C}$ NMR $\left.\left(125 \mathrm{MHz}, \mathrm{CDCl}_{3}\right) \delta 174.16,172.00,81.44,65.42,39.23,32.67,28.02,27.98,27.95,14.78 . \mathrm{HRMS}^{(\mathrm{ESI}}{ }^{+}\right) \mathrm{Calcd}$ for $\mathrm{C}_{10} \mathrm{H}_{17} \mathrm{~N}_{3} \mathrm{O}_{4}[\mathrm{M}+\mathrm{H}]^{+} \mathrm{m} / \mathrm{z}$ : 244.1292; found: 244.1290 .

Compound 18:<smiles>CCCCOC(=O)C[C@H](C)[C@H](N=CO)C(=O)O</smiles>

To a $50 \mathrm{~mL}$ round bottom flask, compound 17 (486 mg, $2.00 \mathrm{mmol}, 1.0$ equiv.) and $\mathrm{Pd} / \mathrm{C}$ (10\% Pd on activated carbon, $50.2 \mathrm{mg})$ were added. After argon protection of the flask, $\mathrm{MeOH}(6 \mathrm{~mL})$ was added, and the mixture was stirred until compound 17 dissolved. The flask was charged with $\mathrm{H}_{2}$ afterwards. The reaction mixture was stirred at $\mathrm{rt}$ for $2 \mathrm{~h}$. The reaction mixture was filtered through celite, concentrated under vacuo, dissolved in $\mathrm{H}_{2} \mathrm{O}(15 \mathrm{~mL})$ and cooled to $0^{\circ} \mathrm{C} . \mathrm{Na}_{2} \mathrm{CO}_{3}(1.08 \mathrm{~g}, 10.1 \mathrm{mmol}, 5.0$ equiv.) and $\mathrm{Fmoc}-\mathrm{OSu}(810$ $\mathrm{mg}, 2.40 \mathrm{mmol}, 1.2$ equiv.) dissolved in 1,4-dioxane $(15 \mathrm{~mL})$ were added. The reaction mixture was stirred at $0^{\circ} \mathrm{C}$ to $\mathrm{rt}$ for $14 \mathrm{~h}$. The reaction mixture was acidified by $1 \mathrm{~N} \mathrm{HCl}$ to $\mathrm{pH} 2$ and concentrated under vacuo to remove 1,4-dioxane. The reaction mixture was diluted with EtOAc $(50 \mathrm{~mL})$ and extracted with EtOAc $(3 \times 50 \mathrm{~mL})$. The combined organic phase was washed with brine $(50 \mathrm{~mL})$, dried over $\mathrm{Na}_{2} \mathrm{SO}_{4}$, concentrated under vacuo and purified by flash column chromatography on silica gel (hexane/EtOAc, $1: 1$ with $0.5 \%$ $\mathrm{AcOH})$ to give compound $18(667 \mathrm{mg}, 76 \%)$ as white solid. m.p. $=120-122{ }^{\circ} \mathrm{C} ;[\boldsymbol{\alpha}]_{\mathrm{D}}{ }^{20}=+8.0(\mathrm{c}=0.67, \mathrm{DCM}) ;{ }^{1} \mathrm{H} \mathrm{NMR}(500 \mathrm{MHz}$, $\left.\mathrm{CDCl}_{3}\right) \delta 7.77(\mathrm{~d}, J=7.5 \mathrm{~Hz}, 2 \mathrm{H}), 7.63-7.56(\mathrm{~m}, 2 \mathrm{H}), 7.40(\mathrm{t}, J=7.3 \mathrm{~Hz}, 2 \mathrm{H}), 7.32(\mathrm{t}, J=7.4 \mathrm{~Hz}, 2 \mathrm{H}), 5.44(\mathrm{~d}, J=8.8 \mathrm{~Hz}, 1 \mathrm{H}), 4.56$ $(\mathrm{dd}, J=8.5,3.3 \mathrm{~Hz}, 1 \mathrm{H}), 4.42(\mathrm{~d}, J=7.0 \mathrm{~Hz}, 2 \mathrm{H}), 4.23(\mathrm{t}, J=7.0 \mathrm{~Hz}, 1 \mathrm{H}), 2.64-2.57(\mathrm{~m}, 1 \mathrm{H}), 2.47(\mathrm{dd}, J=16.2,6.8 \mathrm{~Hz}, 1 \mathrm{H}), 2.17(\mathrm{dd}$, $J=16.0,7.3 \mathrm{~Hz}, 1 \mathrm{H}), 1.47(\mathrm{~s}, 9 \mathrm{H}), 0.96(\mathrm{~d}, J=6.9 \mathrm{~Hz}, 3 \mathrm{H}) ;{ }^{13} \mathrm{C}$ NMR $(125 \mathrm{MHz}, \mathrm{MeOD}) \delta$ 173.71, 172.33, 157.02, 144.06, 143.85, $141.43,127.87,127.26,125.22,120.10,81.13,67.14,57.40,47.31,39.55,33.00,29.82,28.08,14.66$. HRMS (ESI $^{+}$) calcd. for $\mathrm{C}_{25} \mathrm{H}_{29} \mathrm{NO}_{6}[\mathrm{M}+\mathrm{H}]^{+} \mathrm{m} / \mathrm{z}: 440.2068$; found: 440.2051 .

\section{General Procedures of Fmoc-based solid-phase peptide synthesis (SPPS) of A54145 factors}

The solid phase peptide synthesis was carried out manually using 2-chlorotrityl chloride resin (GL Biochem, loading: $\sim 0.5 \mathrm{mmol} / \mathrm{g}$ ) under the standard Fmoc SPPS protocols starting from $\operatorname{Gly}^{10}$ to $\operatorname{Trp}^{1}$ (Xaan: amino acid at position $n$ ), followed by coupling of $n$-deacanoic acid/iso-deacanoic acid. After on-resin esterification between $\mathrm{Il}^{13} / \mathrm{Val}^{13}$ and the side chain of $\mathrm{Thr}^{4}$, coupling of $\mathrm{Glu}(\mathrm{OtBu})^{12} / \mathrm{mGlu}(\mathrm{OtBu})^{12}$ and D-Asn(Trt $)^{11}$ to the branched $1 \mathrm{ll}^{13}$ were followed. The crude peptide with side chain protecting groups attached was cleaved from the resin after final Fmoc deprotection and on-resin TBS deprotection. The Fmoc deprotection was carried out using $20 \%$ piperidine in DMF. 


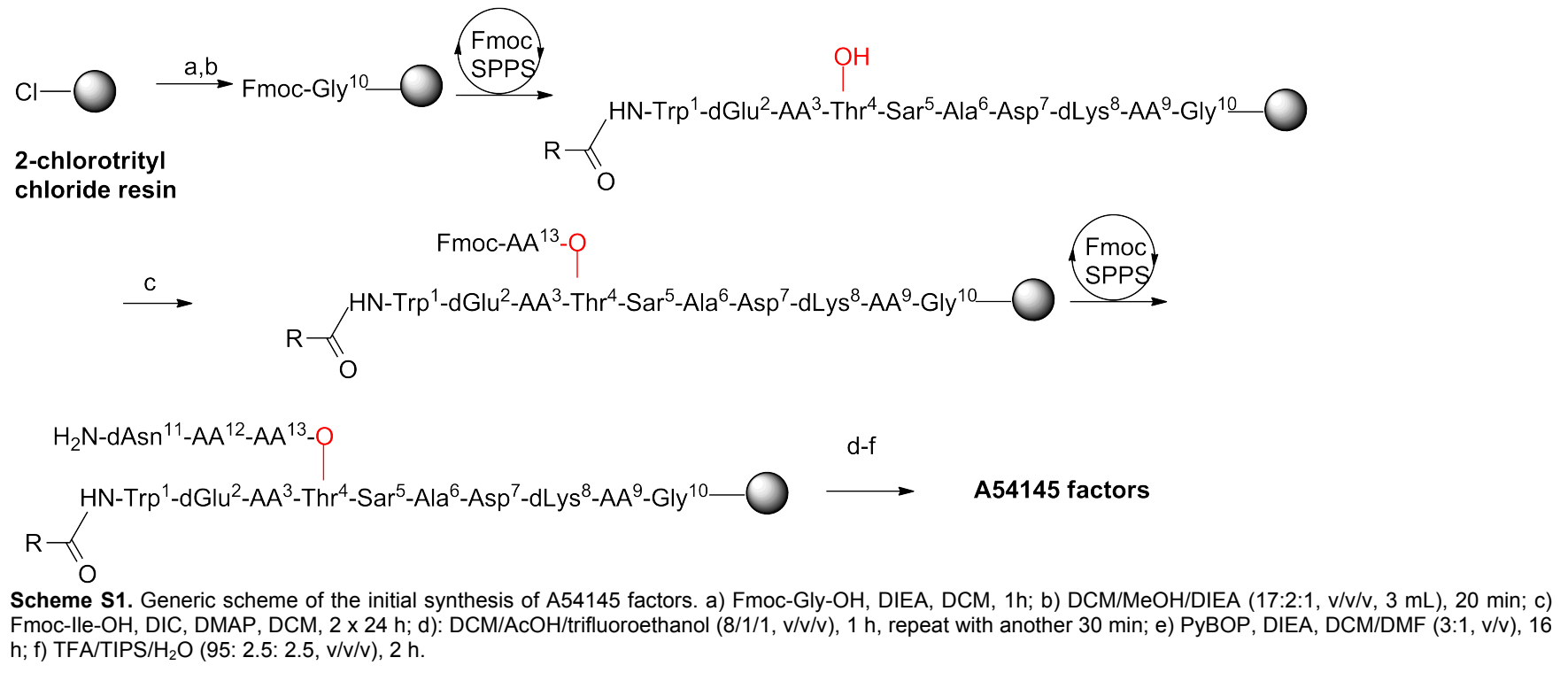

\section{Loading of first amino acid to 2-chlorotrityl chloride resin}

The 2-chlorotrityl chloride resin (100 mg, loading: $0.5 \mathrm{mmol} / \mathrm{g}$ ) was swollen in dry DCM for $20 \mathrm{~min}$ in a $5 \mathrm{~mL}$ disposable vessel (TORIVQ) equipped with a porous polypropylene disc at the bottom. A solution of Fmoc-Gly-OH (2.0 equiv.) and DIEA (4.0 equiv.) in DCM was added and the reaction vessel was shaken on the vortex at room temperature for $1 \mathrm{~h}$. The resin was washed with DMF (5 $\times$ $3 \mathrm{~mL}$ ) followed by a solution of DCM/MeOH/DIEA (17:2:1, v/v/v, $3 \mathrm{~mL}$ ) for 20 min and washed with DMF (5 $3 \mathrm{~mL})$. The resin was subsequently submitted to iterative peptide assembly via the standard Fmoc-SPPS protocol.

\section{Fmoc deprotection}

The Fmoc deprotection was carried out using $3 \mathrm{~mL}$ of $20 \%$ piperidine in DMF at room temperature for 20 min. The resin was then washed with DMF $(5 \times 3 \mathrm{~mL})$.

\section{Procedure of coupling of amino acids and fatty acid}

For the coupling step other than the three unnatural amino acid building blocks and tetrapeptide building block, a solution of Fmoc amino acid or fatty acid (4 equiv.), HATU (4 equiv.), DIEA (8 equiv.) in DMF was gently agitated on vortex with the resin at room temperature for $1 \mathrm{~h}$. The resin was then washed with DMF $(5 \times 3 \mathrm{~mL})$.

\section{Procedure of coupling of Fmoc-MeOAsp(OtBu)-OH, and Fmoc-mGlu(OtBu)-OH}

A solution of Fmoc-amino acid building blocks (2 equiv.), HATU (2 equiv.), DIEA (4 equiv.) in DMF was gently agitated on vortex with the resin at room temperature for $2 \mathrm{~h}$. The resin was then washed with DMF $(5 \times 3 \mathrm{~mL})$ followed by Fmoc-deprotection using $3 \mathrm{~mL}$ of $20 \%$ piperidine in DMF for 10 min.

\section{Procedure of coupling of Fmoc-HOAsn(TBS,Trt)-OH}

A solution of Fmoc-amino acid building blocks (2 equiv.), HATU (2 equiv.), DIEA (4 equiv.) in DMF was gently agitated on vortex with the resin at room temperature for $16 \mathrm{~h}$. The resin was then washed with DMF $(5 \times 3 \mathrm{~mL})$ followed by Fmoc-deprotection using $3 \mathrm{~mL}$ of $20 \%$ piperidine in DMF for $10 \mathrm{~min}$.

\section{On-resin esterification}

A solution of Fmoc-lle-OH or Fmoc-Val-OH (9 equiv.), DIC (20 equiv.), DMAP (0.1 equiv.) in DCM was gently agitated on the vortex with the resin at room temperature for $24 \mathrm{~h}$. The coupling was repeated with another $24 \mathrm{~h}$. The resin was then washed with DMF $(5 \times 3$ $\mathrm{mL}$ ) followed by coupling of the next amino acid. 


\section{On-resin TBS deprotection}

The resin was washed with DMF $(3 \times 3 \mathrm{~mL})$, DCM $(2 \times 3 \mathrm{~mL})$ and THF $(2 \times 3 \mathrm{~mL})$. A solution of TBAF/AcOH $(1: 1, \mathrm{~m} / \mathrm{m}, 6 \mathrm{equiv}$.) in THF was gently agitated on vortex with the resin at room temperature for $1 \mathrm{~h}$. The resin was then washed with THF $(5 \times 3 \mathrm{~mL})$ and DMF $(5 \times 3 \mathrm{~mL})$.

\section{Cleavage of the crude protected peptide from the resin}

The resin was washed with DCM $(5 \times 3 \mathrm{~mL})$ and was subjected to $5 \mathrm{~mL}$ of mild acidic cleavage cocktail of DCM/AcOH/trifluoroethanol $(8 / 1 / 1, \mathrm{v} / \mathrm{v} / \mathrm{v})$ for $1 \mathrm{~h}$ and this step was repeated for another $30 \mathrm{~min}$. Following filtration, the resulting cleavage solutions were combined and concentrated in vacuo to give the crude side-chain protected peptide. The crude peptide was further dried by vacuum overnight prior to the macrocyclization.

\section{Macrocyclization}

To a solution of the crude peptide (1 equiv.) in DCM: DMF=3:1 (5 mM) were added PyBOP (5 equiv.) and DIEA (5 equiv.). The solution was stirred at room temperature for $16 \mathrm{~h}$. The solvent was removed in vacuo afterwards.

\section{Global deprotection}

A solution of $10 \mathrm{~mL}$ cleavage cocktail (TFA: TIPS: $\mathrm{H}_{2} \mathrm{O}=95: 2.5: 2.5, \mathrm{v} / \mathrm{v} / \mathrm{v}$ ) was added and the solution was stirred at room temperature for $2 \mathrm{~h}$. The solution was concentrated under a stream of nitrogen and the crude product was precipitated by cold diethyl ether. Diethyl ether was discarded after centrifugation and the crude product was washed with diethyl ether for 3 times. The washed crude product was dried under vacuum to remove residual diethyl ether and the white solid was ready for HPLC purification. The average yield after HPLC purification is $3 \%$ based on resin loading.

\section{Synthesis of A54145 A, A1, B, B1, F and analogues}

A54145 factor $B$ analogue 24a: $1.3 \mathrm{mg}, 2.6 \%$. LC-MS (ESI ${ }^{+}$): calculated for $\mathrm{C}_{73} \mathrm{H}_{111} \mathrm{~N}_{17} \mathrm{O}_{27}[\mathrm{M}+\mathrm{H}]^{+} \mathrm{m} / \mathrm{z}: 1659.77$; found: 1659.65 , $[\mathrm{M}+2 \mathrm{H}]^{2+} \mathrm{m} / \mathrm{z}$ : 830.39; found: 830.31. (Figure S1). ${ }^{1} \mathrm{H}$ NMR $\left(500 \mathrm{MHz}, \mathrm{D}_{2} \mathrm{O}\right) \delta 7.64(\mathrm{~d}, \mathrm{~J}=7.9 \mathrm{~Hz}, 1 \mathrm{H}), 7.48(\mathrm{~d}, \mathrm{~J}=8.0 \mathrm{~Hz}, 1 \mathrm{H}), 7.27-$ $7.20(\mathrm{~m}, 2 \mathrm{H}), 7.16(\mathrm{dd}, J=13.9,6.7 \mathrm{~Hz}, 1 \mathrm{H}), 5.44(\mathrm{dd}, J=8.3,4.1 \mathrm{~Hz}, 1 \mathrm{H}), 5.19(\mathrm{~d}, J=4.2 \mathrm{~Hz}, 1 \mathrm{H}), 4.99(\mathrm{~d}, J=2.6 \mathrm{~Hz}, 1 \mathrm{H}), 4.84(\mathrm{~s}$, $2 \mathrm{H}), 4.60(\mathrm{~d}, \mathrm{~J}=6.9 \mathrm{~Hz}, 2 \mathrm{H}), 4.52-4.46(\mathrm{~m}, 1 \mathrm{H}), 4.42(\mathrm{~d}, \mathrm{~J}=6.2 \mathrm{~Hz}, 1 \mathrm{H}), 4.37(\mathrm{dd}, \mathrm{J}=14.2,7.4 \mathrm{~Hz}, 2 \mathrm{H}), 4.31-4.23(\mathrm{~m}, 2 \mathrm{H}), 4.21(\mathrm{~d}$, $J=2.8 \mathrm{~Hz}, 1 \mathrm{H}), 4.14(\mathrm{~d}, J=5.0 \mathrm{~Hz}, 1 \mathrm{H}), 4.09(\mathrm{~s}, 1 \mathrm{H}), 4.08-3.87(\mathrm{~m}, 4 \mathrm{H}), 3.45-3.33(\mathrm{~m}, 4 \mathrm{H}), 3.33-3.15(\mathrm{~m}, 5 \mathrm{H}), 3.00(\mathrm{dd}, J=21.1$, $14.0 \mathrm{~Hz}, 4 \mathrm{H}), 2.85-2.68(\mathrm{~m}, 3 \mathrm{H}), 2.62(\mathrm{~d}, J=6.9 \mathrm{~Hz}, 2 \mathrm{H}), 2.42(\mathrm{~s}, 2 \mathrm{H}), 2.32(\mathrm{dd}, J=14.6,5.2 \mathrm{~Hz}, 2 \mathrm{H}), 2.22(\mathrm{~m}, 3 \mathrm{H}), 2.07(\mathrm{~m}, 2 \mathrm{H})$, $2.02-1.60(\mathrm{~m}, 11 \mathrm{H}), 1.55-1.31(\mathrm{~m}, 8 \mathrm{H}), 1.31-1.11(\mathrm{~m}, 10 \mathrm{H}), 1.05(\mathrm{~s}, 3 \mathrm{H}), 0.96-0.78(\mathrm{~m}, 8 \mathrm{H})$.

A54145 factor B 24b: $1.5 \mathrm{mg}, 3 \%$. LC-MS (ESI ${ }^{+}$): calculated for $\mathrm{C}_{73} \mathrm{H}_{111} \mathrm{~N}_{17} \mathrm{O}_{27}[\mathrm{M}+\mathrm{H}]^{+} \mathrm{m} / \mathrm{z}: 1659.77$; found: $1659.99,[\mathrm{M}+2 \mathrm{H}]^{2+} \mathrm{m} / \mathrm{z}$ : 830.39; found: 830.23. (Figure S2). [ $\mathrm{\alpha}_{\mathrm{D}}{ }^{20}=-6.0\left(\mathrm{c}=0.20, \mathrm{H}_{2} \mathrm{O}\right) .{ }^{1} \mathrm{H}$ NMR $\left(500 \mathrm{MHz}, \mathrm{D}_{2} \mathrm{O}\right) \delta 7.66(\mathrm{~d}, \mathrm{~J}=8.0 \mathrm{~Hz}, 1 \mathrm{H}), 7.50(\mathrm{~d}, \mathrm{~J}=8.1 \mathrm{~Hz}$, $1 \mathrm{H}), 7.28-7.21(\mathrm{~m}, 2 \mathrm{H}), 7.17(\mathrm{t}, \mathrm{J}=7.3 \mathrm{~Hz}, 1 \mathrm{H}), 4.63(\mathrm{dd}, \mathrm{J}=17.9,6.2 \mathrm{~Hz}, 2 \mathrm{H}), 4.52-4.46(\mathrm{~m}, 1 \mathrm{H}), 4.46-4.42(\mathrm{~m}, 1 \mathrm{H}), 4.42-4.34$ $(\mathrm{m}, 2 \mathrm{H}), 4.32(\mathrm{~d}, \mathrm{~J}=7.4 \mathrm{~Hz}, 1 \mathrm{H}), 4.26(\mathrm{~d}, \mathrm{~J}=6.0 \mathrm{~Hz}, 1 \mathrm{H}), 4.22(\mathrm{~d}, \mathrm{~J}=2.9 \mathrm{~Hz}, 1 \mathrm{H}), 4.18-4.11(\mathrm{~m}, 2 \mathrm{H}), 4.12-4.05(\mathrm{br}, 1 \mathrm{H}), 4.03-$ $3.98(\mathrm{~m}, 1 \mathrm{H}), 3.98-3.91(\mathrm{~m}, 2 \mathrm{H}), 3.38(\mathrm{t}, \mathrm{J}=2.5 \mathrm{~Hz}, 3 \mathrm{H}), 3.33-3.26(\mathrm{~m}, 2 \mathrm{H}), 3.26-3.15(\mathrm{~m}, 4 \mathrm{H}), 3.09(\mathrm{q}, \mathrm{J}=7.4 \mathrm{~Hz}, 1 \mathrm{H}), 3.05-$ $2.95(\mathrm{~m}, 3 \mathrm{H}), 2.95(\mathrm{~s}, 1 \mathrm{H}), 2.84(\mathrm{dd}, \mathrm{J}=14.4,6.3 \mathrm{~Hz}, 1 \mathrm{H}), 2.80-2.72(\mathrm{~m}, 2 \mathrm{H}), 2.72-2.62(\mathrm{~m}, 3 \mathrm{H}), 2.52-2.40(\mathrm{br}, 2 \mathrm{H}), 2.36-2.28(\mathrm{~m}$, $2 \mathrm{H}), 2.28-2.17(\mathrm{~m}, 3 \mathrm{H}), 2.15-2.04(\mathrm{~m}, 2 \mathrm{H}), 1.94-1.84(\mathrm{~m}, 4 \mathrm{H}), 1.84-1.78(\mathrm{~m}, 3 \mathrm{H}), 1.72-1.62(\mathrm{~m}, 4 \mathrm{H}), 1.50-1.38(\mathrm{~m}, 10 \mathrm{H}), 1.36$ $(\mathrm{d}, \mathrm{J}=6.5 \mathrm{~Hz}, 2 \mathrm{H}), 1.29(\mathrm{t}, \mathrm{J}=6.9 \mathrm{~Hz}, 6 \mathrm{H}), 1.27-1.22(\mathrm{~m}, 6 \mathrm{H}), 1.22-1.13(\mathrm{~m}, 7 \mathrm{H}), 1.13-1.01(\mathrm{~m}, 3 \mathrm{H}), 0.96(\mathrm{~d}, \mathrm{~J}=6.4 \mathrm{~Hz}, 4 \mathrm{H}), 0.93$ $-0.81(\mathrm{~m}, 11 \mathrm{H})$.

A54145 factor B analogue 24c: $1.1 \mathrm{mg}, 2.2 \%$. LC-MS (ESI ${ }^{+}$): calculated for $\mathrm{C}_{73} \mathrm{H}_{111} \mathrm{~N}_{17} \mathrm{O}_{27}[\mathrm{M}+\mathrm{H}]^{+} \mathrm{m} / \mathrm{z}$ : 1659.77; found: 1659.57 , $[\mathrm{M}+2 \mathrm{H}]^{2+} \mathrm{m} / \mathrm{z}$ : 830.39; found: 830.31. (Figure S3). ${ }^{1} \mathrm{H}$ NMR $\left(500 \mathrm{MHz}, \mathrm{D}_{2} \mathrm{O}\right) \delta 7.64(\mathrm{~d}, J=7.8 \mathrm{~Hz}, 1 \mathrm{H}), 7.49(\mathrm{~d}, J=7.9 \mathrm{~Hz}, 1 \mathrm{H}), 7.26(\mathrm{~s}$, $1 \mathrm{H}), 7.22(\mathrm{dd}, J=7.9,3.2 \mathrm{~Hz}, 1 \mathrm{H}), 7.16(\mathrm{dd}, J=13.9,6.9 \mathrm{~Hz}, 1 \mathrm{H}), 5.40(\mathrm{dd}, J=6.5,3.4 \mathrm{~Hz}, 1 \mathrm{H}), 5.37-5.26(\mathrm{~m}, 1 \mathrm{H}), 5.16(\mathrm{~d}, J=3.4$ $\mathrm{Hz}, 1 \mathrm{H}), 5.14-5.06(\mathrm{~m}, 1 \mathrm{H}), 4.97-4.83(\mathrm{~m}, 4 \mathrm{H}), 4.60(\mathrm{dd}, \mathrm{J}=10.7,7.2 \mathrm{~Hz}, 3 \mathrm{H}), 4.52-4.44(\mathrm{~m}, 2 \mathrm{H}), 4.44-4.31(\mathrm{~m}, 4 \mathrm{H}), 4.31-4.19$ $(\mathrm{m}, 3 \mathrm{H}), 4.16-3.88(\mathrm{~m}, 7 \mathrm{H}), 3.53-3.42(\mathrm{~m}, 2 \mathrm{H}), 3.42-3.31(\mathrm{~m}, 4 \mathrm{H}), 3.31-3.12(\mathrm{~m}, 5 \mathrm{H}), 3.12-2.95(\mathrm{~m}, 4 \mathrm{H}), 2.95-2.70(\mathrm{~m}, 5 \mathrm{H})$, $2.70-2.54(\mathrm{~m}, 3 \mathrm{H}), 2.48-2.36(\mathrm{~m}, 2 \mathrm{H}), 2.29(\mathrm{~m}, 4 \mathrm{H}), 2.14-2.00(\mathrm{~m}, 2 \mathrm{H}), 2.00-1.91(\mathrm{~m}, 2 \mathrm{H}), 1.80(\mathrm{~m}, 6 \mathrm{H}), 1.66(\mathrm{~m}, 5 \mathrm{H}), 1.51-$ $1.42(\mathrm{~m}, 2 \mathrm{H}), 1.42-1.31(\mathrm{~m}, 6 \mathrm{H}), 1.31-0.98(\mathrm{~m}, 18 \mathrm{H}), 0.88(\mathrm{~m}, 12 \mathrm{H})$.

A54145 factor B analogue 24d: $1.5 \mathrm{mg}, 3 \%$. LC-MS (ESI ${ }^{+}$): calculated for $\mathrm{C}_{73} \mathrm{H}_{111} \mathrm{~N}_{17} \mathrm{O}_{27}[\mathrm{M}+\mathrm{H}]^{+} \mathrm{m} / \mathrm{z}$ : 1659.77; found: 1659.65, $[\mathrm{M}+2 \mathrm{H}]^{2+} \mathrm{m} / \mathrm{z}$ : 830.39; found: 830.23. (Figure S4). ${ }^{1} \mathrm{H}$ NMR $\left(500 \mathrm{MHz}, \mathrm{D}_{2} \mathrm{O}\right) \delta 7.64(\mathrm{~d}, J=7.8 \mathrm{~Hz}, 1 \mathrm{H}), 7.49(\mathrm{~s}, 1 \mathrm{H}), 7.27-7.20(\mathrm{~m}, 2 \mathrm{H})$, $7.20-7.12(\mathrm{~m}, 1 \mathrm{H}), 5.45(\mathrm{~s}, 1 \mathrm{H}), 5.19(\mathrm{~s}, 1 \mathrm{H}), 4.99(\mathrm{~d}, J=2.7 \mathrm{~Hz}, 1 \mathrm{H}), 4.73-4.54(\mathrm{~m}, 4 \mathrm{H}), 4.44(\mathrm{~m}, 2 \mathrm{H}), 4.41-4.30(\mathrm{~m}, 3 \mathrm{H}), 4.25(\mathrm{~d}$, $J=5.9 \mathrm{~Hz}, 2 \mathrm{H}), 4.23-4.06(\mathrm{~m}, 4 \mathrm{H}), 4.05-3.85(\mathrm{~m}, 4 \mathrm{H}), 3.36(\mathrm{~s}, 3 \mathrm{H}), 3.32-3.25(\mathrm{~m}, 2 \mathrm{H}), 3.21(\mathrm{~m}, 2 \mathrm{H}), 3.08(\mathrm{~d}, J=7.3 \mathrm{~Hz}, 1 \mathrm{H}), 3.04$ 
- $2.91(\mathrm{~m}, 2 \mathrm{H}), 2.86-2.72(\mathrm{~m}, 2 \mathrm{H}), 2.72-2.60(\mathrm{~m}, 2 \mathrm{H}), 2.46(\mathrm{~s}, 2 \mathrm{H}), 2.25(\mathrm{~m}, 3 \mathrm{H}), 2.07(\mathrm{~m}, 1 \mathrm{H}), 1.97-1.75(\mathrm{~m}, 4 \mathrm{H}), 1.66(\mathrm{~s}, 4 \mathrm{H})$, $1.51-1.32(\mathrm{~m}, 8 \mathrm{H}), 1.32-1.11(\mathrm{~m}, 11 \mathrm{H}), 1.08(\mathrm{~m}, 3 \mathrm{H}), 0.94(\mathrm{~m}, 3 \mathrm{H}), 0.92-0.80(\mathrm{~m}, 7 \mathrm{H})$.

A54145 factor A 25a $1.3 \mathrm{mg}, 2.6 \%$. LC-MS (ESI $)$ : calculated for $\mathrm{C}_{72} \mathrm{H}_{109} \mathrm{~N}_{17} \mathrm{O}_{27}[\mathrm{M}+\mathrm{H}]^{+} \mathrm{m} / \mathrm{z}$ : 1645.74 ; found: $1645.26,[\mathrm{M}+2 \mathrm{H}]^{2+} \mathrm{m} / \mathrm{z}$ : 823.37; found: 830.37. (Figure S5). ${ }^{1} \mathrm{H}$ NMR $\left(500 \mathrm{MHz}, \mathrm{D}_{2} \mathrm{O}\right) \delta 7.65(\mathrm{~d}, J=7.8 \mathrm{~Hz}, 1 \mathrm{H}), 7.49(\mathrm{~d}, \mathrm{~J}=8.2 \mathrm{~Hz}, 1 \mathrm{H}), 7.28-7.20(\mathrm{~m}, 3 \mathrm{H})$, $7.16(\mathrm{t}, J=7.8 \mathrm{~Hz}, 0.5 \mathrm{H}), 5.43(\mathrm{~s}, 0.5 \mathrm{H}), 5.18(\mathrm{~s}, 1 \mathrm{H}), 4.45(\mathrm{~m}, 3.5 \mathrm{H}), 4.32(\mathrm{~m}, 5 \mathrm{H}), 4.23(\mathrm{~m}, 2 \mathrm{H}), 4.14(\mathrm{~m}, 2 \mathrm{H}), 4.07(\mathrm{~d}, J=15.7 \mathrm{~Hz}$, $1.5 \mathrm{H}), 3.95(\mathrm{~m}, 4.5 \mathrm{H}), 3.36(\mathrm{~s}, 8 \mathrm{H}), 3.32-3.14(\mathrm{~m}, 8.5 \mathrm{H}), 2.98(\mathrm{~m}, 4.5 \mathrm{H}), 2.75(\mathrm{~m}, 0.5 \mathrm{H}), 2.70-2.60(\mathrm{~m}, 3 \mathrm{H}), 2.25(\mathrm{~m}, 6 \mathrm{H}), 2.07(\mathrm{~s}$, $2 \mathrm{H}), 1.93(\mathrm{~m}, 1.5 \mathrm{H}), 1.85(\mathrm{~m}, 13 \mathrm{H}), 1.66(\mathrm{~m}, 7 \mathrm{H}), 1.53-1.32(\mathrm{~m}, 23 \mathrm{H}), 1.26(\mathrm{~m}, 5 \mathrm{H}), 1.23-0.99(\mathrm{~m}, 24 \mathrm{H}), 0.95-0.77(\mathrm{~m}, 34 \mathrm{H})$.

A54145 factor $\mathrm{A}_{1}$ 25b: $1.4 \mathrm{mg}, 2.8 \%$. LC-MS (ESI ${ }^{+}$: calculated for $\mathrm{C}_{72} \mathrm{H}_{109} \mathrm{~N}_{17} \mathrm{O}_{27}[\mathrm{M}+\mathrm{H}]^{+} \mathrm{m} / \mathrm{z}$ : 1645.74; found: $1645.85,[\mathrm{M}+2 \mathrm{H}]^{2+} \mathrm{m} / \mathrm{z}$ : 823.37; found: 823.45. (Figure S6). ${ }^{1} \mathrm{H}$ NMR $\left(500 \mathrm{MHz}, \mathrm{D}_{2} \mathrm{O}\right) \delta 7.65(\mathrm{~d}, \mathrm{~J}=8.0 \mathrm{~Hz}, 1 \mathrm{H}), 7.49(\mathrm{~d}, \mathrm{~J}=7.9 \mathrm{~Hz}, 1 \mathrm{H}), 7.27(\mathrm{~s}, 1 \mathrm{H}), 7.26-$ $7.13(\mathrm{~m}, 2 \mathrm{H}), 5.43(\mathrm{~s}, 1 \mathrm{H}), 5.23-5.16(\mathrm{~m}, 1 \mathrm{H}), 4.52-4.41(\mathrm{~m}, 3 \mathrm{H}), 4.37-4.28(\mathrm{~m}, 2 \mathrm{H}), 4.23(\mathrm{~m}, 2 \mathrm{H}), 4.16(\mathrm{~m}, 2 \mathrm{H}), 4.06(\mathrm{~d}, J=17.4$ $\mathrm{Hz}, 1 \mathrm{H}), 4.02-3.90(\mathrm{~m}, 3 \mathrm{H}), 3.36(\mathrm{~d}, J=4.4 \mathrm{~Hz}, 2 \mathrm{H}), 3.29(\mathrm{~m}, 2 \mathrm{H}), 3.20(\mathrm{~d}, J=6.9 \mathrm{~Hz}, 3 \mathrm{H}), 2.98(\mathrm{~m}, 3 \mathrm{H}), 2.87-2.71(\mathrm{~m}, 4 \mathrm{H}), 2.66(\mathrm{~m}$, $3 \mathrm{H}), 2.39-2.15(\mathrm{~m}, 5 \mathrm{H}), 2.08(\mathrm{~s}, 3 \mathrm{H}), 2.01-1.72(\mathrm{~m}, 7 \mathrm{H}), 1.66(\mathrm{~s}, 4 \mathrm{H}), 1.39(\mathrm{~m}, 6 \mathrm{H}), 1.31-1.12(\mathrm{~m}, 8 \mathrm{H}), 1.05(\mathrm{~s}, 5 \mathrm{H}), 0.86(\mathrm{dd}, J=$ $15.0,7.8 \mathrm{~Hz}, 6 \mathrm{H})$.

A54145 factor $B_{1}$ 25c: $1.6 \mathrm{mg}, 3.2 \%$. LC-MS $\left(\mathrm{ESI}^{+}\right)$: calculated for $\mathrm{C}_{72} \mathrm{H}_{111} \mathrm{~N}_{17} \mathrm{O}_{27}[\mathrm{M}+\mathrm{H}]^{+} \mathrm{m} / \mathrm{z}$ : 1659.77 ; found: 1659.65 , $[\mathrm{M}+2 \mathrm{H}]^{2+} \mathrm{m} / \mathrm{z}$ : 830.39; found: 830.31. (Figure S7). ${ }^{1} \mathrm{H}$ NMR $\left(500 \mathrm{MHz}, \mathrm{D}_{2} \mathrm{O}\right) \delta 7.64(\mathrm{~d}, J=7.5 \mathrm{~Hz}, 1 \mathrm{H}), 7.49(\mathrm{~d}, J=6.0 \mathrm{~Hz}, 1 \mathrm{H}), 7.24(\mathrm{~d}, J=6.9 \mathrm{~Hz}$, $1 \mathrm{H}), 7.17(\mathrm{~m}, 2 \mathrm{H}), 5.49-5.43(\mathrm{~m}, 1 \mathrm{H}), 5.18(\mathrm{t}, J=3.9 \mathrm{~Hz}, 1 \mathrm{H}), 4.44(\mathrm{~m}, 2 \mathrm{H}), 4.24(\mathrm{~m}, 1 \mathrm{H}), 4.17-4.05(\mathrm{~m}, 1 \mathrm{H}), 3.93(\mathrm{~m}, 1 \mathrm{H}), 3.38(\mathrm{~d}, J$ $=8.8 \mathrm{~Hz}, 8 \mathrm{H}), 3.29-3.16(\mathrm{~m}, 9 \mathrm{H}), 3.03-2.93(\mathrm{~m}, 1 \mathrm{H}), 2.81(\mathrm{~m}, 3 \mathrm{H}), 2.67(\mathrm{~m}, 1 \mathrm{H}), 2.41(\mathrm{~m}, 7 \mathrm{H}), 2.23(\mathrm{~m}, 1 \mathrm{H}), 2.08(\mathrm{~s}, 1 \mathrm{H}), 1.98-$ $1.76(\mathrm{~m}, 10 \mathrm{H}), 1.74-1.59(\mathrm{~m}, 6 \mathrm{H}), 1.38(\mathrm{~m}, 27 \mathrm{H}), 1.28(\mathrm{~m}, 5 \mathrm{H}), 1.21-1.00(\mathrm{~m}, 23 \mathrm{H}), 1.00-0.79(\mathrm{~m}, 51 \mathrm{H})$.

A54145 factor F 25d: $1.1 \mathrm{mg}, 2.2 \%$. LC-MS (ESI $)$ : calculated for $\mathrm{C}_{72} \mathrm{H}_{107} \mathrm{~N}_{17} \mathrm{O}_{27}\left[\mathrm{M}+\mathrm{H}^{+}\right] \mathrm{m} / \mathrm{z}$ : 1631.71; found: 1631.80, $\left[\mathrm{M}+2 \mathrm{H}^{+}\right] \mathrm{m} / \mathrm{z}$ : 816.34; found: 816.43. (Figure S8). ${ }^{1} \mathrm{H}$ NMR $\left(500 \mathrm{MHz}, \mathrm{D}_{2} \mathrm{O}\right) \delta 7.64(\mathrm{~d}, J=8.0 \mathrm{~Hz}, 1 \mathrm{H}), 7.49(\mathrm{~d}, J=8.1 \mathrm{~Hz}, 1 \mathrm{H}), 7.23(\mathrm{~m}, 2 \mathrm{H}), 7.16(\mathrm{~d}$, $J=7.0 \mathrm{~Hz}, 1 \mathrm{H}), 5.42(\mathrm{~d}, J=4.6 \mathrm{~Hz}, 1 \mathrm{H}), 5.18(\mathrm{~d}, J=4.6 \mathrm{~Hz}, 1 \mathrm{H}), 4.51-4.43(\mathrm{~m}, 2 \mathrm{H}), 4.33(\mathrm{~m}, 4 \mathrm{H}), 4.27-4.11(\mathrm{~m}, 4 \mathrm{H}), 3.96(\mathrm{~m}, 5 \mathrm{H})$, $3.37(\mathrm{~m}, 3 \mathrm{H}), 3.25(\mathrm{~m}, 5 \mathrm{H}), 3.06-2.93(\mathrm{~m}, 3 \mathrm{H}), 2.78(\mathrm{~m}, 3 \mathrm{H}), 2.71-2.63(\mathrm{~m}, 2 \mathrm{H}), 2.38-2.17(\mathrm{~m}, 5 \mathrm{H}), 2.17-2.02(\mathrm{~m}, 3 \mathrm{H}), 1.94(\mathrm{~s}$, $2 \mathrm{H}), 1.91-1.73(\mathrm{~m}, 5 \mathrm{H}), 1.66(\mathrm{~s}, 4 \mathrm{H}), 1.54-1.32(\mathrm{~m}, 8 \mathrm{H}), 1.28(\mathrm{t}, J=12.6 \mathrm{~Hz}, 3 \mathrm{H}), 1.22-0.99(\mathrm{~m}, 9 \mathrm{H}), 0.94-0.77(\mathrm{~m}, 10 \mathrm{H})$.

A54145 factor B nucleus 26: $7.5 \mathrm{mg}, 19 \%$. LC-MS (ESI ${ }^{+}$): calculated for $\mathrm{C}_{63} \mathrm{H}_{93} \mathrm{~N}_{17} \mathrm{O}_{26}\left[\mathrm{M}+2 \mathrm{H}^{+}\right] \mathrm{m} / \mathrm{z}$ : 753.26; found: 753.19 . (Figure S9). ${ }^{1} \mathrm{H}$ NMR $\left(400 \mathrm{MHz}, \mathrm{D}_{2} \mathrm{O}\right) \delta 8.20(\mathrm{~d}, J=4.9 \mathrm{~Hz}, 1 \mathrm{H}), 7.91(\mathrm{~d}, \mathrm{~J}=9.4 \mathrm{~Hz}, 1 \mathrm{H}), 7.49(\mathrm{~d}, J=8.2 \mathrm{~Hz}, 3 \mathrm{H}), 7.43(\mathrm{~d}, J=8.0 \mathrm{~Hz}, 2 \mathrm{H}), 7.25$ $(\mathrm{t}, J=7.6 \mathrm{~Hz}, 3 \mathrm{H}), 7.15(\mathrm{t}, J=7.3 \mathrm{~Hz}, 3 \mathrm{H}), 7.00(\mathrm{~s}, 2 \mathrm{H}), 5.46(\mathrm{q}, J=6.2 \mathrm{~Hz}, 2 \mathrm{H}), 5.27(\mathrm{~d}, J=6.8 \mathrm{~Hz}, 2 \mathrm{H}), 4.97-4.91(\mathrm{~m}, 4 \mathrm{H}), 4.84(\mathrm{~d}$, $J=2.3 \mathrm{~Hz}, 2 \mathrm{H}), 4.75-4.71(\mathrm{~m}, 4 \mathrm{H}), 4.67(\mathrm{t}, J=6.8 \mathrm{~Hz}, 3 \mathrm{H}), 4.50-4.43(\mathrm{~m}, 2 \mathrm{H}), 4.37-4.24(\mathrm{~m}, 8 \mathrm{H}), 4.19-4.12(\mathrm{~m}, 4 \mathrm{H}), 4.06(\mathrm{~s}, 1 \mathrm{H})$, $4.01(\mathrm{~s}, 1 \mathrm{H}), 3.85(\mathrm{~s}, 1 \mathrm{H}), 3.82-3.77(\mathrm{~m}, 2 \mathrm{H}), 3.70(\mathrm{~s}, 1 \mathrm{H}), 3.66(\mathrm{~s}, 1 \mathrm{H}), 3.36(\mathrm{~s}, 9 \mathrm{H}), 3.22-3.17(\mathrm{~m}, 2 \mathrm{H}), 3.14(\mathrm{~s}, 7 \mathrm{H}), 2.98(\mathrm{t}, J=7.6$ $\mathrm{Hz}, 6 \mathrm{H}), 2.89(\mathrm{~d}, \mathrm{~J}=7.1 \mathrm{~Hz}, 5 \mathrm{H}), 2.87-2.75(\mathrm{~m}, 7 \mathrm{H}), 2.59-2.45(\mathrm{~m}, 5 \mathrm{H}), 2.34(\mathrm{dd}, J=15.8,7.4 \mathrm{~Hz}, 2 \mathrm{H}), 2.11(\mathrm{q}, J=7.1,6.7 \mathrm{~Hz}, 3 \mathrm{H})$, $2.05(\mathrm{~s}, 1 \mathrm{H}), 1.92(\mathrm{q}, J=7.5 \mathrm{~Hz}, 4 \mathrm{H}), 1.84-1.72(\mathrm{~m}, 5 \mathrm{H}), 1.65(\mathrm{q}, J=7.6 \mathrm{~Hz}, 6 \mathrm{H}), 1.61-1.52(\mathrm{~m}, 3 \mathrm{H}), 1.38(\mathrm{~d}, J=7.3 \mathrm{~Hz}, 10 \mathrm{H}), 1.20$ $(\mathrm{d}, J=6.3 \mathrm{~Hz}, 7 \mathrm{H}), 1.09-0.99(\mathrm{~m}, 3 \mathrm{H}), 0.95(\mathrm{~d}, J=6.6 \mathrm{~Hz}, 8 \mathrm{H}), 0.88-0.80(\mathrm{~m}, 4 \mathrm{H}), 0.75(\mathrm{~d}, J=7.2 \mathrm{~Hz}, 10 \mathrm{H}), 0.72(\mathrm{~s}, 1 \mathrm{H})$.

Supplementary Table 1. List of A54145 synthesized.

\begin{tabular}{|c|c|c|c|c|c|}
\hline Compoud & $A A^{3}$ & $A A^{9}$ & $\mathrm{AA}^{12}$ & $A A^{13}$ & $\mathrm{R}$ \\
\hline $24 a$ & $6 b$ & $12 a$ & mGlu & lle & $n$-decanoyl \\
\hline 24b (Factor B) & $6 b$ & $12 b$ & mGlu & lle & $n$-decanoyl \\
\hline 24c & $6 a$ & $12 a$ & mGlu & lle & $n$-decanoyl \\
\hline 24d & $6 a$ & $12 b$ & mGlu & lle & $n$-decanoyl \\
\hline 25a (Factor A) & $6 b$ & $12 b$ & Glu & lle & iso-decanoyl \\
\hline 25b (Factor $A_{1}$ ) & $6 b$ & $12 b$ & Glu & lle & $n$-decanoyl \\
\hline 25c (Factor $\left.B_{1}\right)$ & $6 b$ & $12 b$ & mGlu & lle & iso-decanoyl \\
\hline 25d (Factor F) & $6 b$ & $12 b$ & Glu & Val & iso-decanoyl \\
\hline 26 (Factor B nucleus) & $6 b$ & $12 b$ & mGlu & lle & $\mathrm{H}$ \\
\hline
\end{tabular}

\section{Antimicrobial susceptibility test}


A54145 and its analogue were subjected to the assessment of their antimicrobial activities by determining their minimal inhibitory concentration on various Gram-positive bacteria strains by the broth microdilution method as recommended by the Clinical and Laboratory Standards Institute $(\mathrm{CLSI})^{5}$ with modification that $50 \mathrm{ng} / \mathrm{\mu l}$ calcium ion was added. 


\section{LCMS traces of A54145}
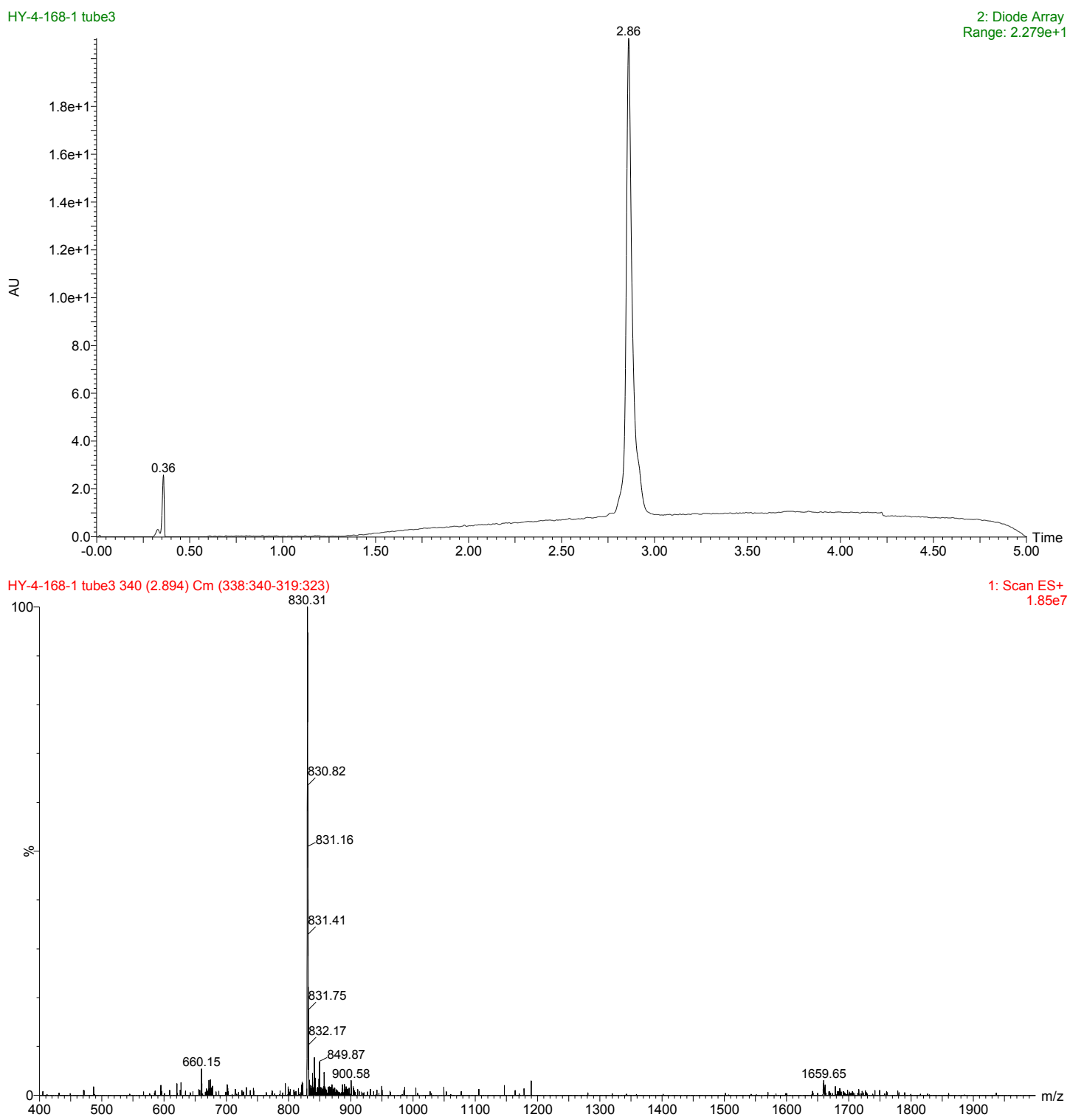

Figure S1. Analytical UPLC analysis UV trace and ESI-MS of purified 24a. Gradient: $30-70 \%$ solvent A/solvent B over $4 \mathrm{~min}$ at a flow rate of $0.4 \mathrm{~mL} / \mathrm{min}^{2} \mathrm{MS}$ (ESI ${ }^{+}$) calcd. for $\mathrm{C}_{73} \mathrm{H}_{111} \mathrm{~N}_{17} \mathrm{O}_{27}[\mathrm{M}+\mathrm{H}]^{+} \mathrm{m} / \mathrm{z}$ : 1659.77 ; found: 1659.65 ; $[\mathrm{M}+2 \mathrm{H}]^{2+} \mathrm{m} / \mathrm{z}$ : 830.39; found: 830.31 . 


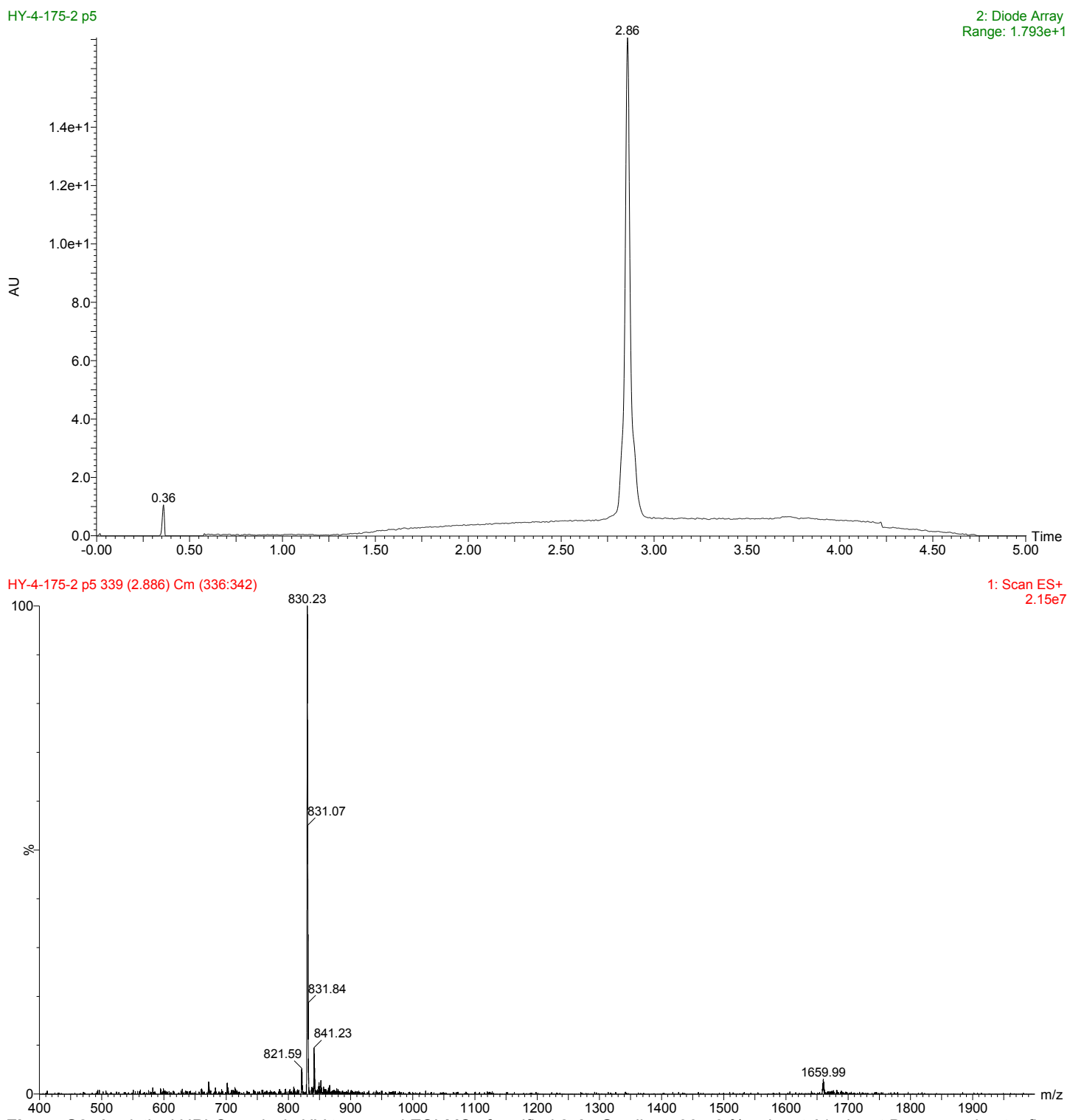

Figure S2. Analytical UPLC analysis UV trace and ESI-MS of purified $\mathbf{2 4 b}$. Gradient: $30-70 \%$ solvent A/solvent B over 4 min at a flow rate of $0.4 \mathrm{~mL} / \mathrm{min}$. MS (ESI ${ }^{+}$) calcd. for $\mathrm{C}_{73} \mathrm{H}_{111} \mathrm{~N}_{17} \mathrm{O}_{27}[\mathrm{M}+\mathrm{H}]^{+} \mathrm{m} / \mathrm{z}$ : 1659.77; found: 1659.99; $[\mathrm{M}+2 \mathrm{H}]^{2+} \mathrm{m} / \mathrm{z}$ : 830.39; found: 830.23. 


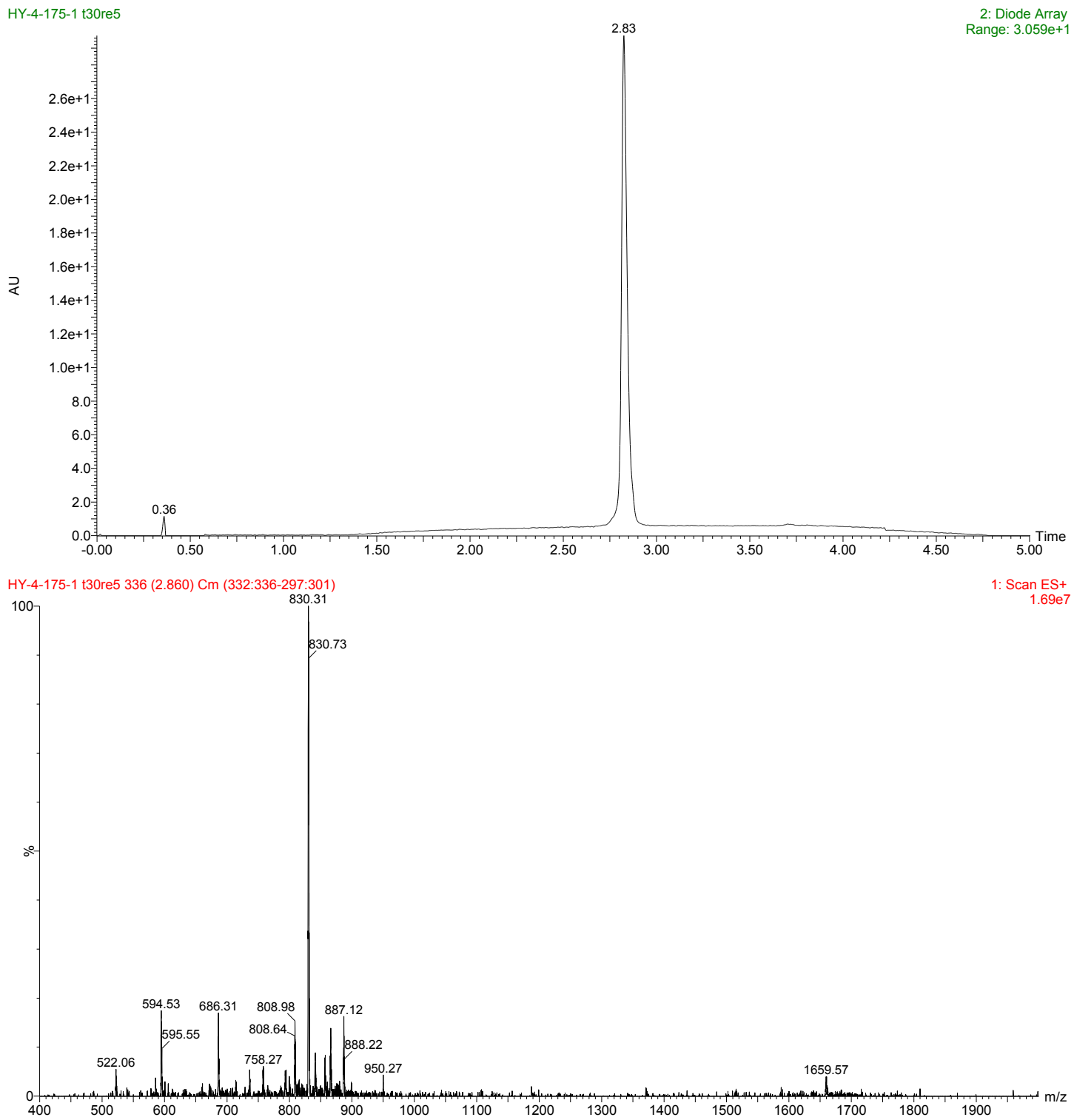

Figure S3. Analytical UPLC analysis UV trace and ESI-MS of purified $24 \mathrm{c}$. Gradient: $30-70 \%$ solvent $\mathrm{A} /$ solvent $\mathrm{B}$ over $4 \mathrm{~min}$ at a flow rate of $0.4 \mathrm{~mL} / \mathrm{min}$. MS (ESI ${ }^{+}$) calcd. for $\mathrm{C}_{73} \mathrm{H}_{111} \mathrm{~N}_{17} \mathrm{O}_{27}[\mathrm{M}+\mathrm{H}]^{+} \mathrm{m} / \mathrm{z}$ : 1659.77; found: 1659.57; $[\mathrm{M}+2 \mathrm{H}]^{2+} \mathrm{m} / \mathrm{z}$ : 830.39; found: 830.31 . 


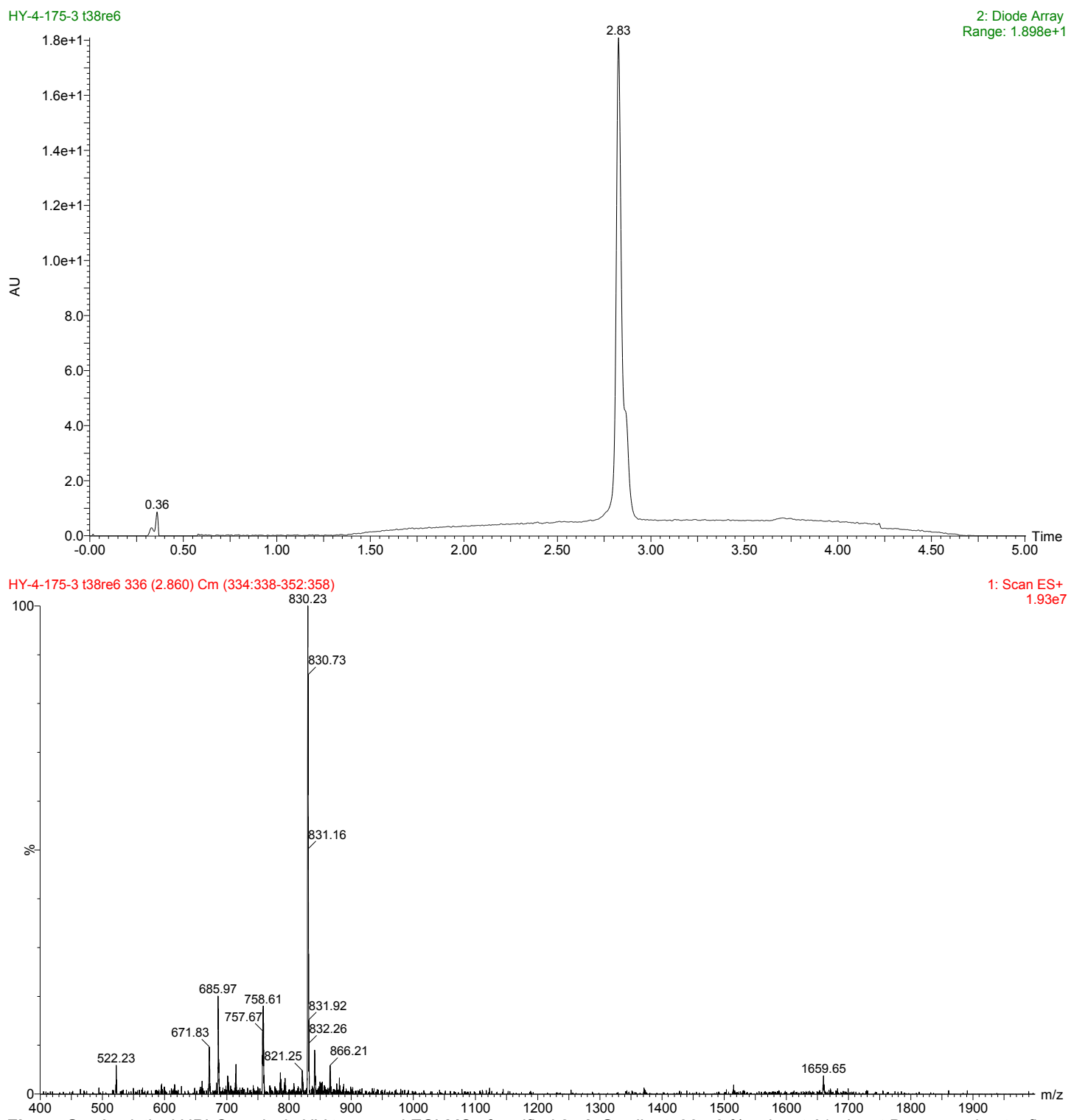

Figure S4. Analytical UPLC analysis UV trace and ESI-MS of purified $24 \mathrm{~d}$. Gradient: $30-70 \%$ solvent A/solvent B over $4 \mathrm{~min}$ at a flow rate of $0.4 \mathrm{~mL} / \mathrm{min}$. MS (ESI $)$ calcd. for $\mathrm{C}_{73} \mathrm{H}_{111} \mathrm{~N}_{17} \mathrm{O}_{27}[\mathrm{M}+\mathrm{H}]^{+} \mathrm{m} / \mathrm{z}$ : 1659.77; found: 1659.65; $[\mathrm{M}+2 \mathrm{H}]^{2+} \mathrm{m} / \mathrm{z}$ : 830.39; found: 830.23 . 


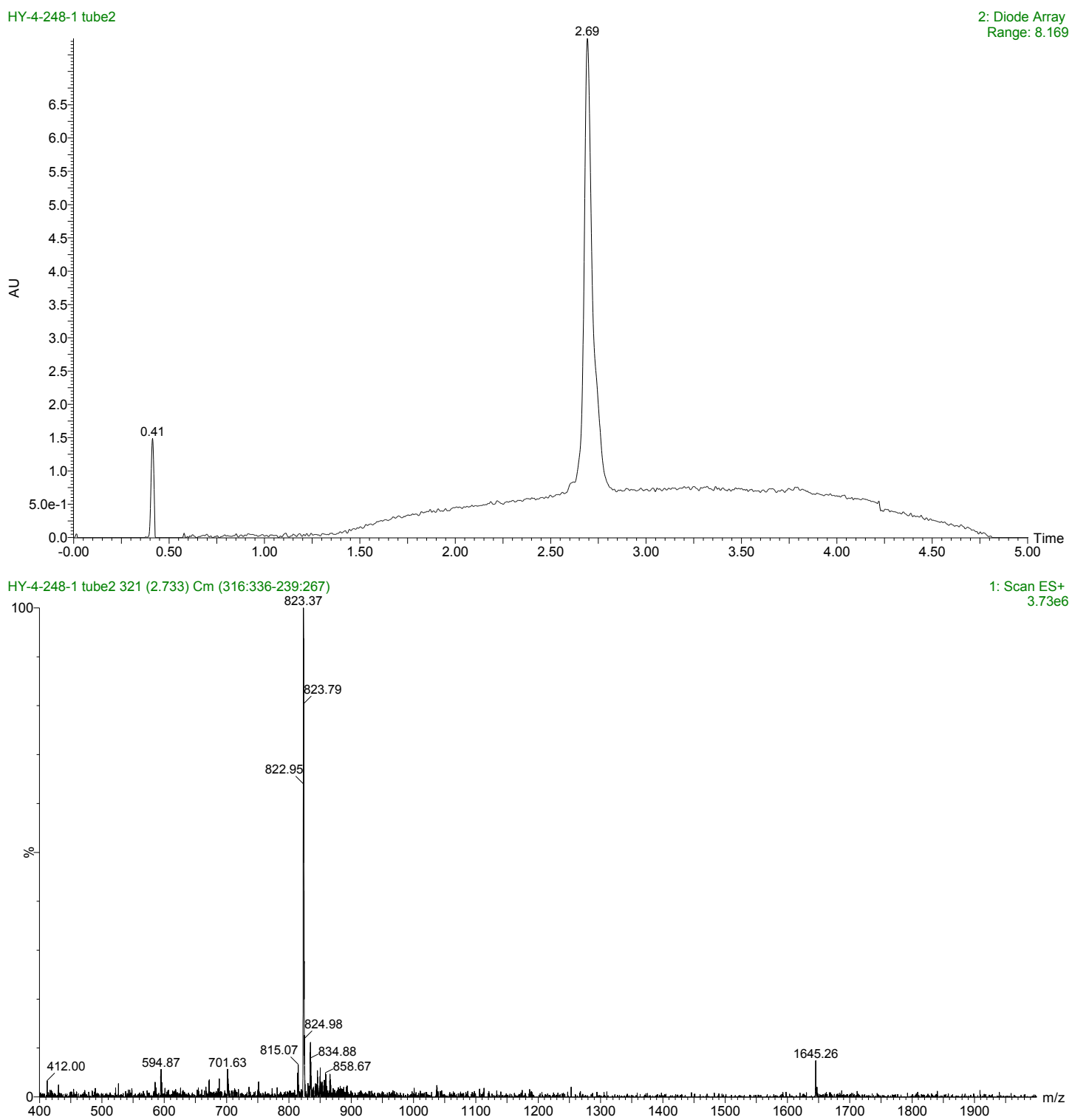

Figure S5. Analytical UPLC analysis UV trace and ESI-MS of purified $25 \mathrm{a}$. Gradient: $30-70 \%$ solvent A/solvent B over $4 \mathrm{~min}$ at a flow rate of $0.4 \mathrm{~mL} / \mathrm{min}$. MS (ESI ${ }^{+}$) calcd. for $\mathrm{C}_{72} \mathrm{H}_{109} \mathrm{~N}_{17} \mathrm{O}_{27}[\mathrm{M}+\mathrm{H}]^{+} \mathrm{m} / \mathrm{z}$ : 1645.74; found: 1645.26; [M+2H] ${ }^{2+} \mathrm{m} / \mathrm{z}$ : 823.37; found: 823.37 . 


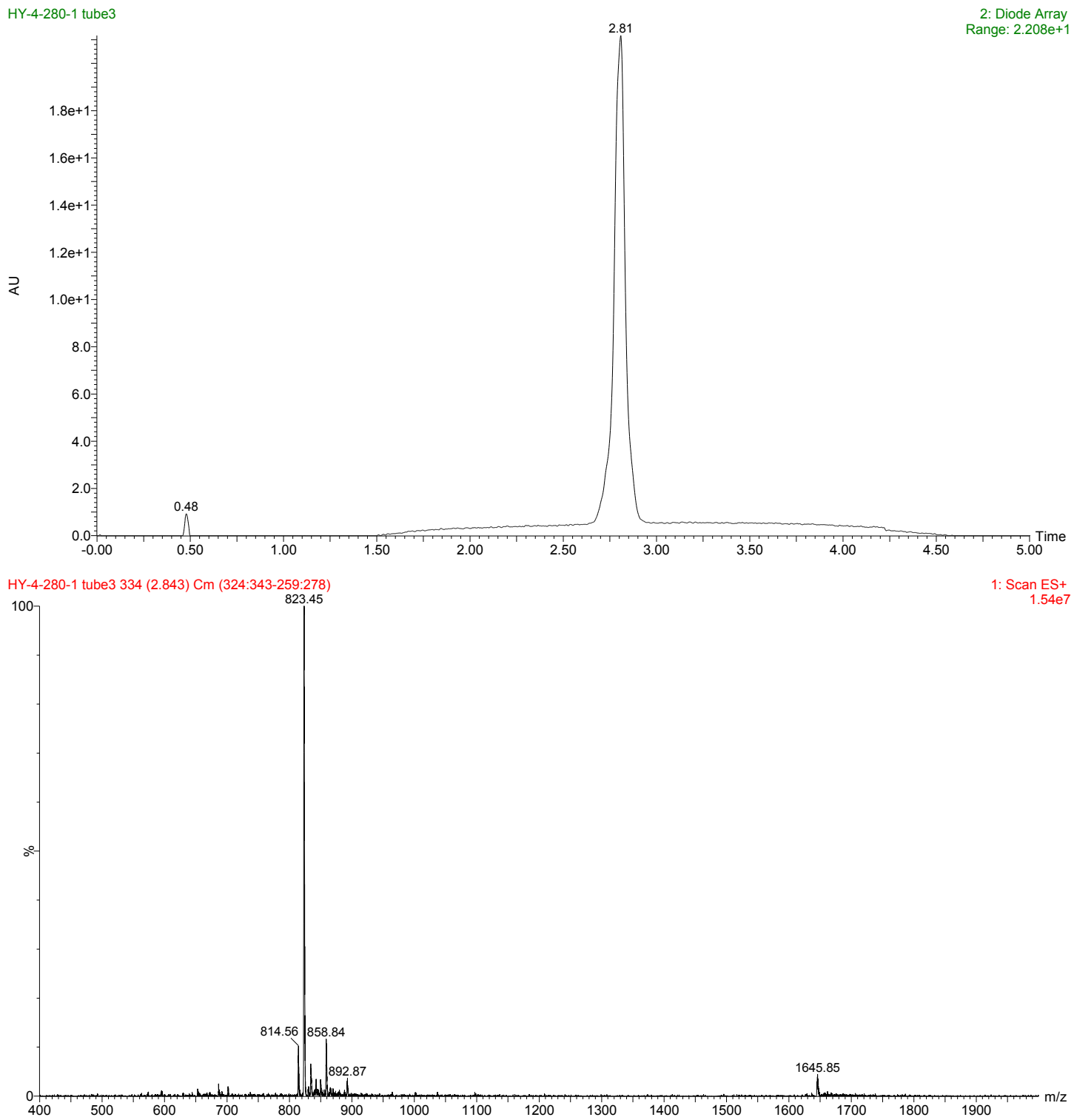

Figure S6. Analytical UPLC analysis UV trace and ESI-MS of purified $25 \mathrm{~b}$. Gradient: $30-70 \%$ solvent A/solvent $\mathrm{B}$ over $4 \mathrm{~min}$ at a flow rate of $0.4 \mathrm{~mL} / \mathrm{min}$. MS (ESI ${ }^{+}$) calcd. for $\mathrm{C}_{72} \mathrm{H}_{109} \mathrm{~N}_{17} \mathrm{O}_{27}[\mathrm{M}+\mathrm{H}]^{+} \mathrm{m} / \mathrm{z}$ : 1645.74; found: 1645.85; $[\mathrm{M}+2 \mathrm{H}]^{2+} \mathrm{m} / \mathrm{z}$ : 823.37; found: 823.45 . 


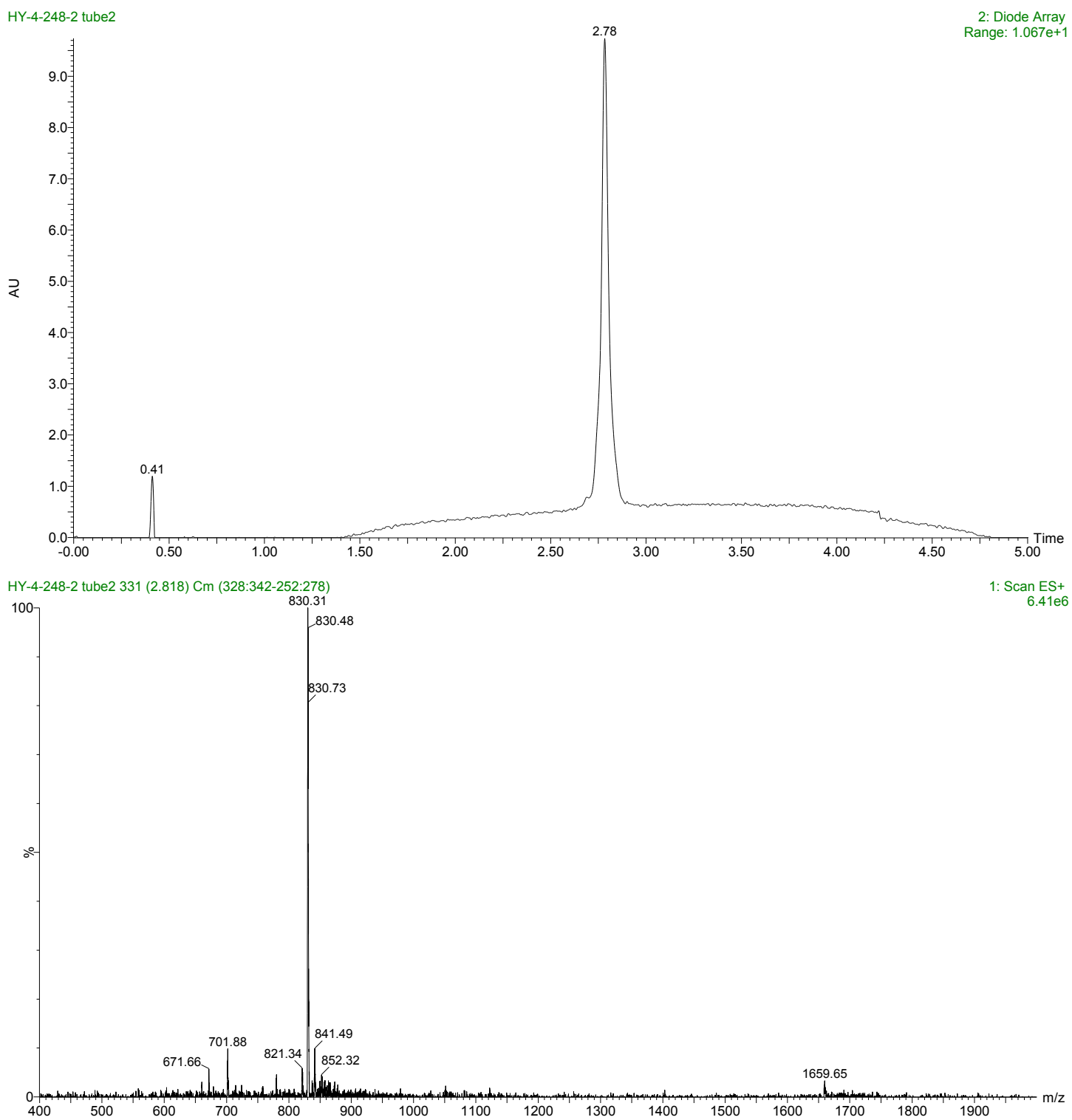

Figure S7. Analytical UPLC analysis UV trace and ESI-MS of purified $25 \mathrm{c}$. Gradient: $30-70 \%$ solvent A/solvent B over $4 \mathrm{~min}$ at a flow rate of $0.4 \mathrm{~mL} / \mathrm{min}$. MS (ESI ${ }^{+}$ calcd. for $\mathrm{C}_{73} \mathrm{H}_{111} \mathrm{~N}_{17} \mathrm{O}_{27}[\mathrm{M}+\mathrm{H}]^{+} \mathrm{m} / \mathrm{z}$ : 1659.77; found: 1659.65; $[\mathrm{M}+2 \mathrm{H}]^{2+} \mathrm{m} / \mathrm{z}$ : 830.39; found: 830.31 


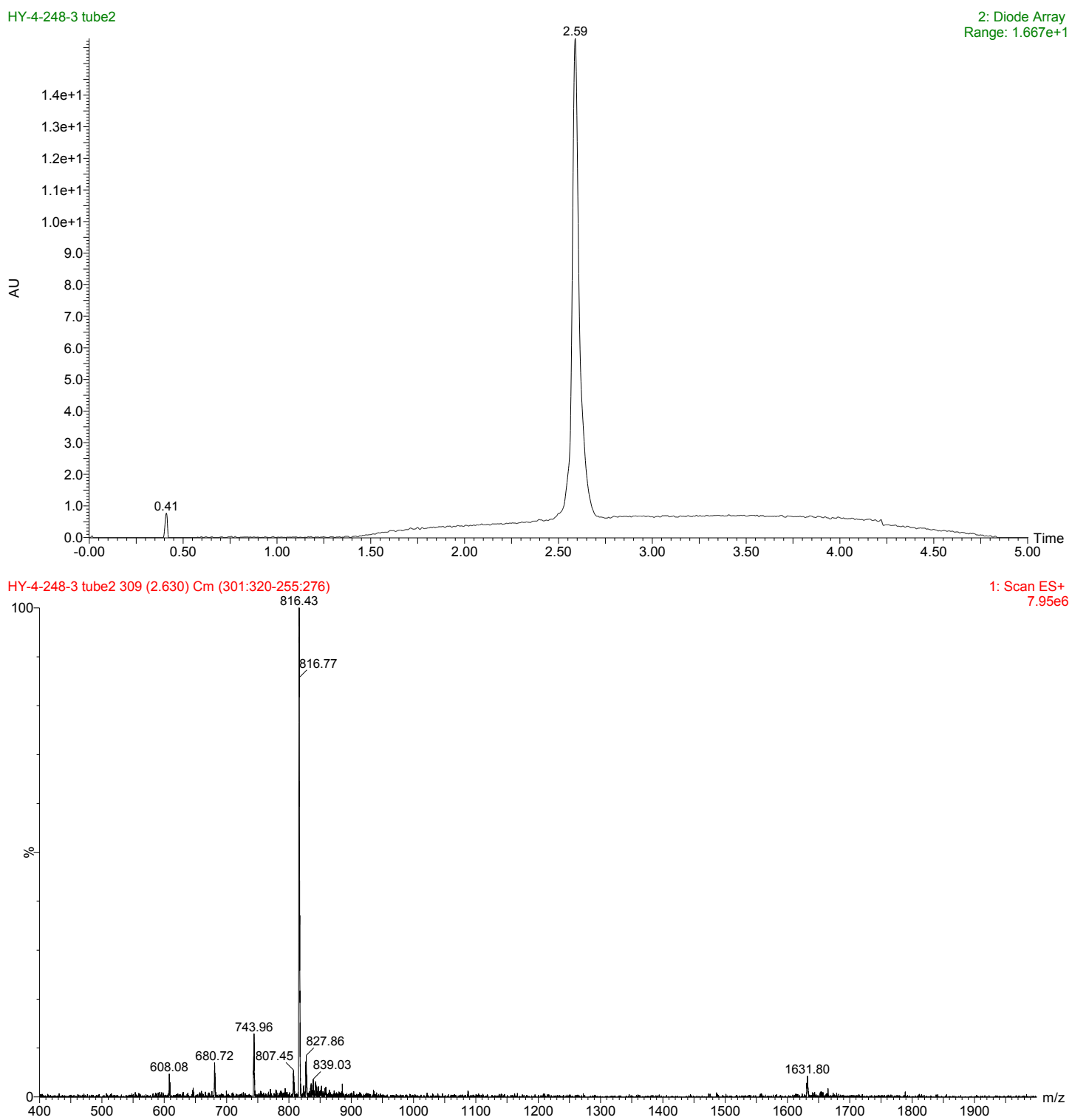

Figure S8. Analytical UPLC analysis UV trace and ESI-MS of purified 25d. Gradient: $30-70 \%$ solvent A/solvent B over 4 min at a flow rate of $0.4 \mathrm{~mL} / \mathrm{min}$. MS (ESI $\left.{ }^{+}\right)$ calcd. for $\mathrm{C}_{71} \mathrm{H}_{107} \mathrm{~N}_{17} \mathrm{O}_{27}[\mathrm{M}+\mathrm{H}]^{+} \mathrm{m} / \mathrm{z}$ : 1631.71; found: 1631.80; $[\mathrm{M}+2 \mathrm{H}]^{2+} \mathrm{m} / \mathrm{z}$ : 816.34; found: 816.43 . 


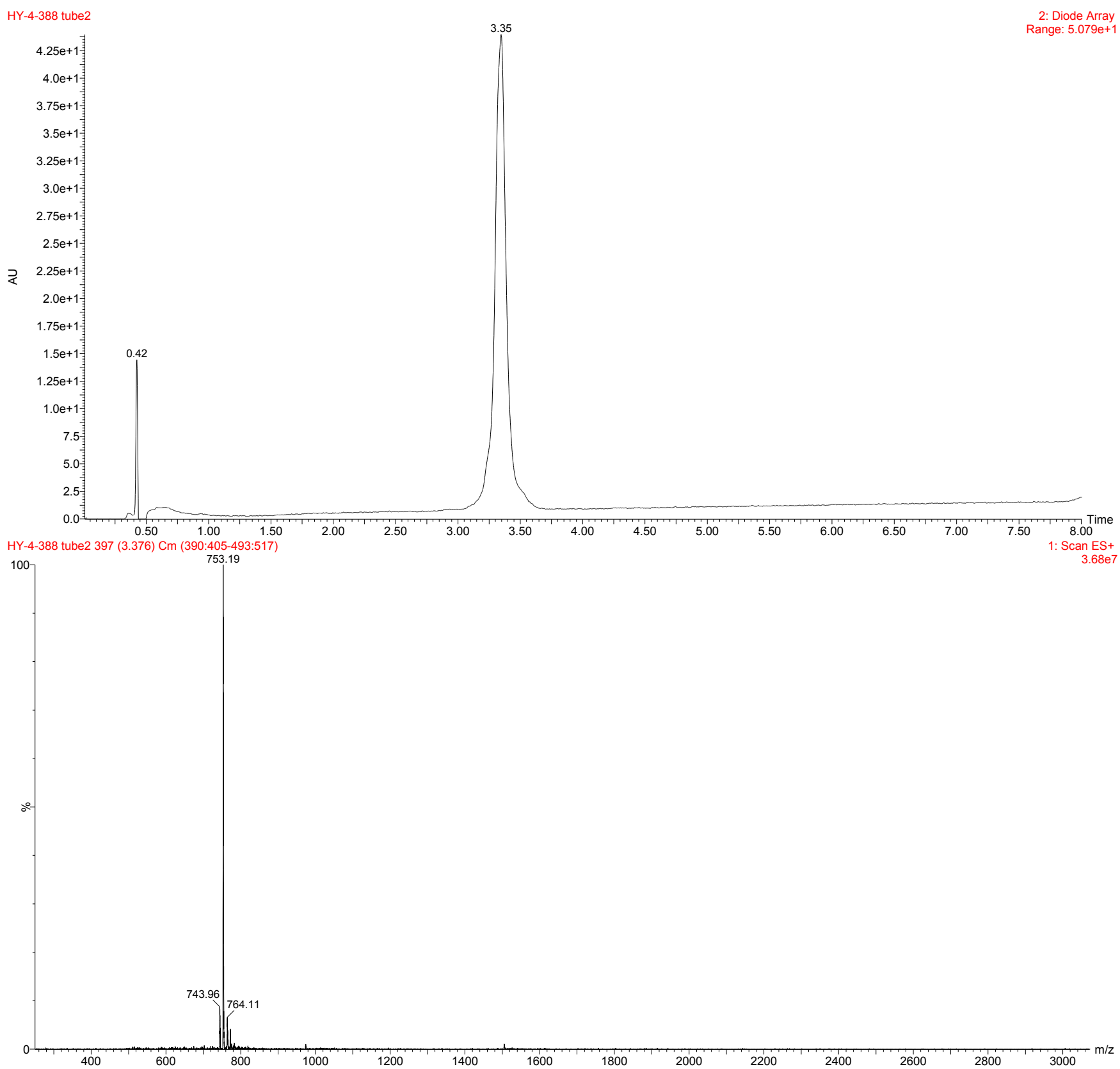

Figure S9. Analytical UPLC analysis UV trace and ESI-MS of purified 26 . Gradient: $10-40 \%$ solvent A/solvent B over $7 \mathrm{~min}$ at a flow rate of $0.4 \mathrm{~mL} / \mathrm{min}$. MS (ESI ${ }^{+}$) calcd. for $\mathrm{C}_{63} \mathrm{H}_{93} \mathrm{~N}_{17} \mathrm{O}_{26}[\mathrm{M}+2 \mathrm{H}]^{2+} \mathrm{m} / \mathrm{z}$ : 753.26; found: 753.19. 


\section{NMR Spectra}

$7.1{ }^{1} \mathrm{H}$ and ${ }^{13} \mathrm{C}$ NMR spectra of building blocks and intermediates

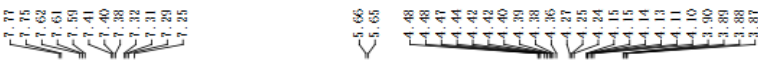

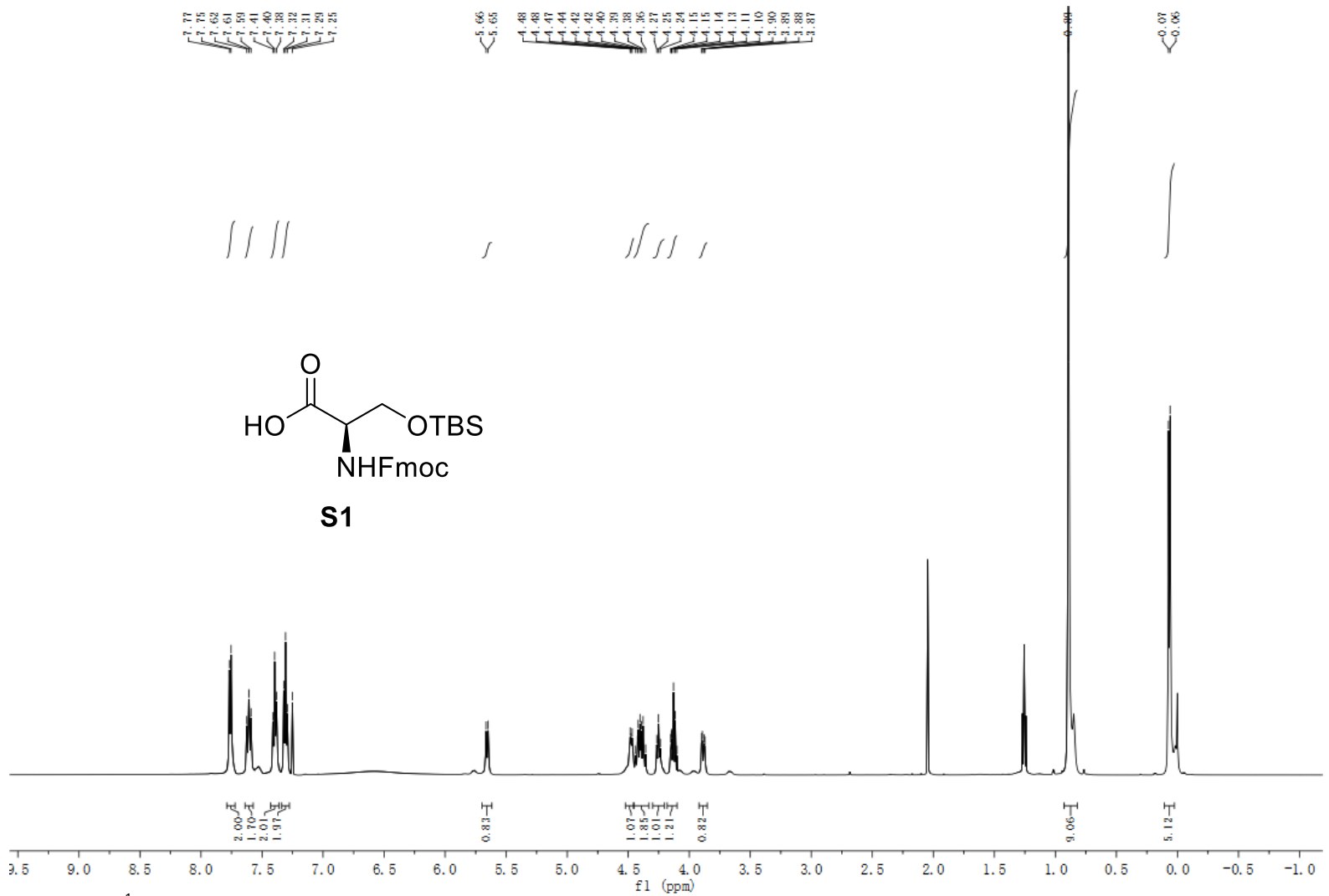

Figure S10. 'H NMR spectrum of compound S1.

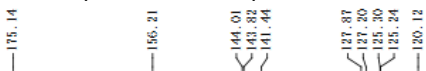

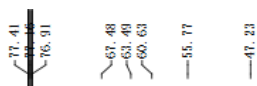

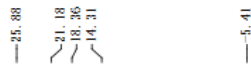<smiles>O=C(O)C(C[OH2+])N=CO</smiles>

S1

$\begin{array}{lllllllllll}190 & 180 & 170 & 160 & 150 & 140 & 130 & 120 & 110 & 100 & 90 \\ \mathrm{fl} 1(\mathrm{ppm})\end{array}$

Figure S11. ${ }^{13} \mathrm{C}$ NMR spectrum of compound $\mathbf{S} 1$. 
<smiles>CCNC(CO[Sb](=O)(=O)c1ccccc1)C(=O)SCC</smiles>

S2

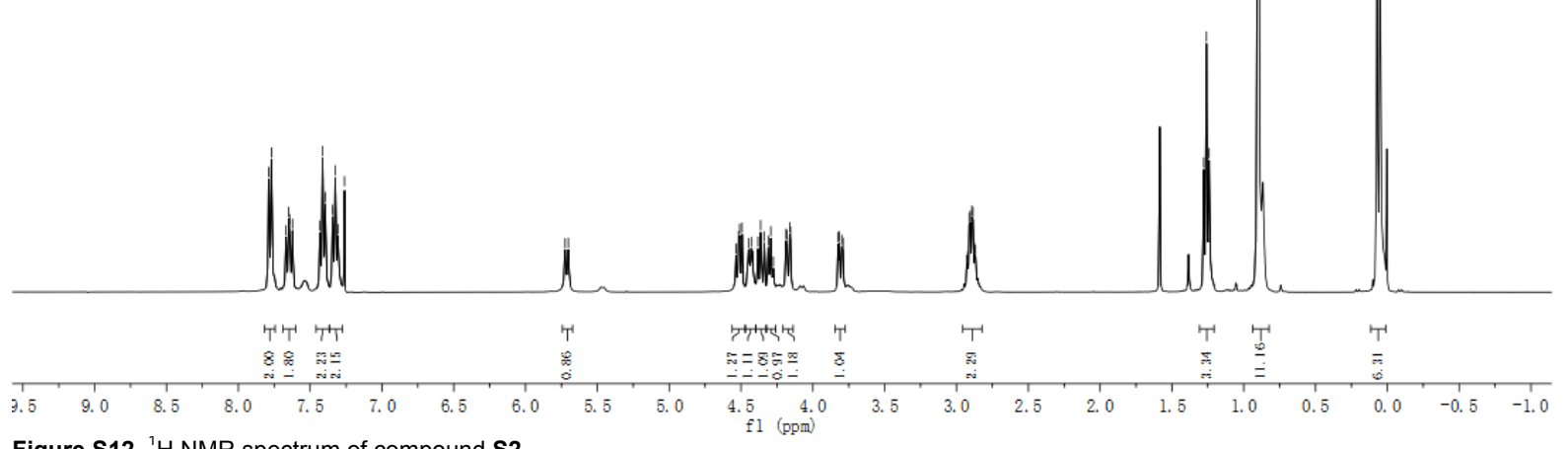

Figure S12. ${ }^{7} \mathrm{H}$ NMR spectrum of compound S2.<smiles>[B-]OCC(C(=O)SCC)C(N)C(=O)OC</smiles>

s2

Figure S13. ${ }^{13} \mathrm{C}$ NMR spectrum of compound $\mathbf{S 2}$. 


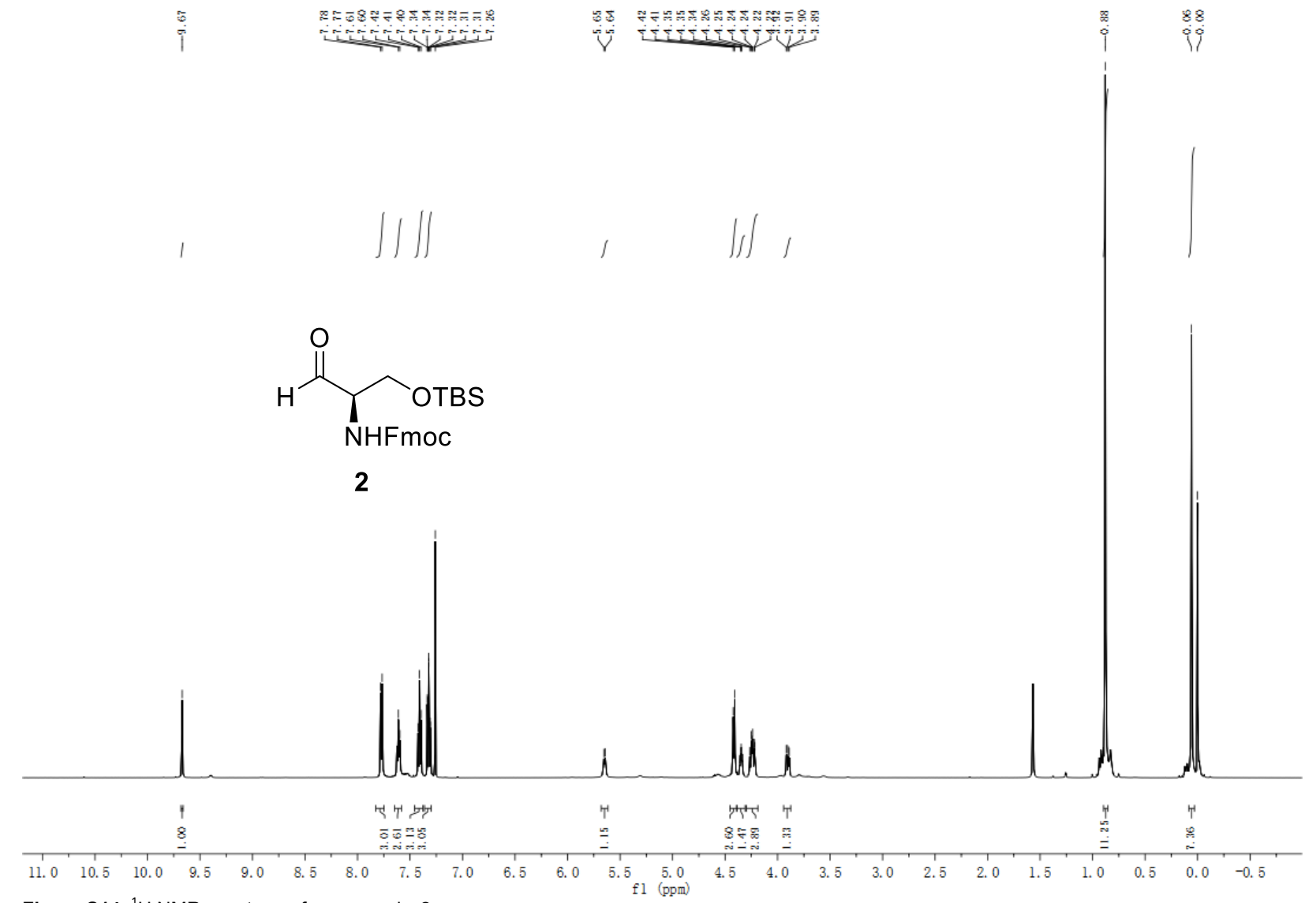

Figure S14. ${ }^{1} \mathrm{H}$ NMR spectrum of compound 2.

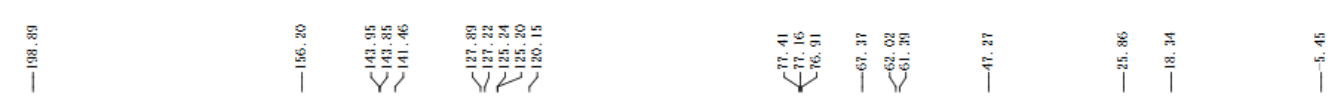

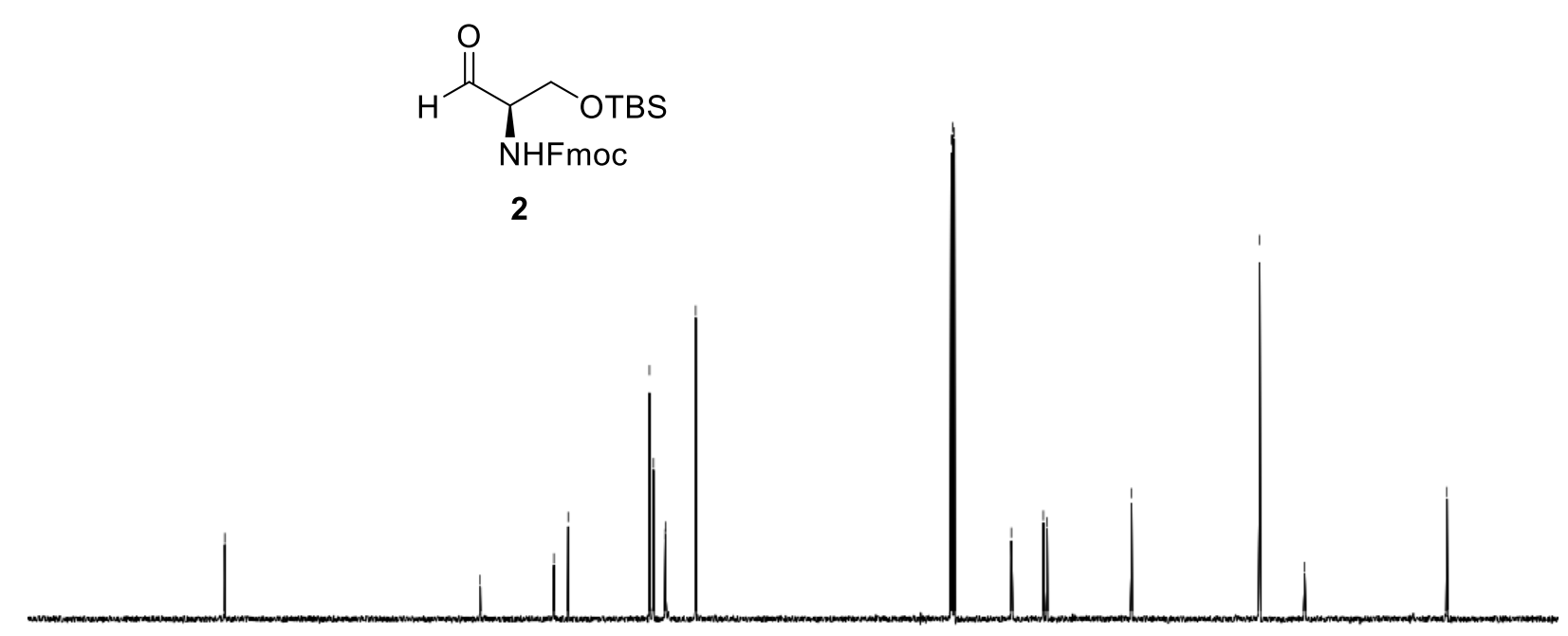

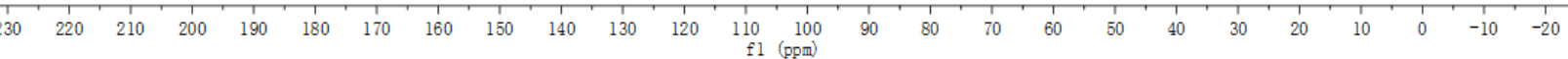

Figure S15. ${ }^{13} \mathrm{C}$ NMR spectrum of compound 2. 


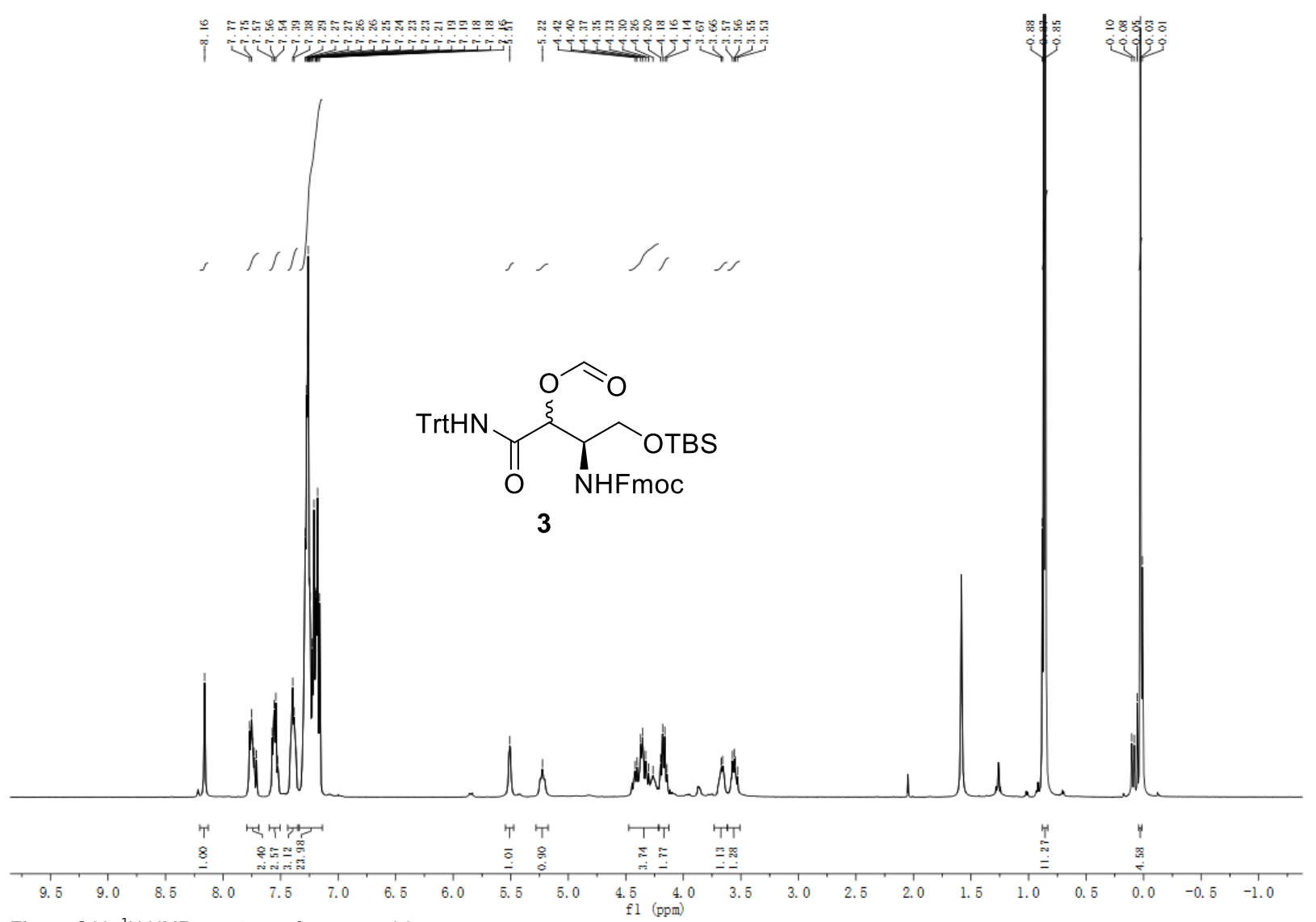

Figure S16. 'H NMR spectrum of compound 3.

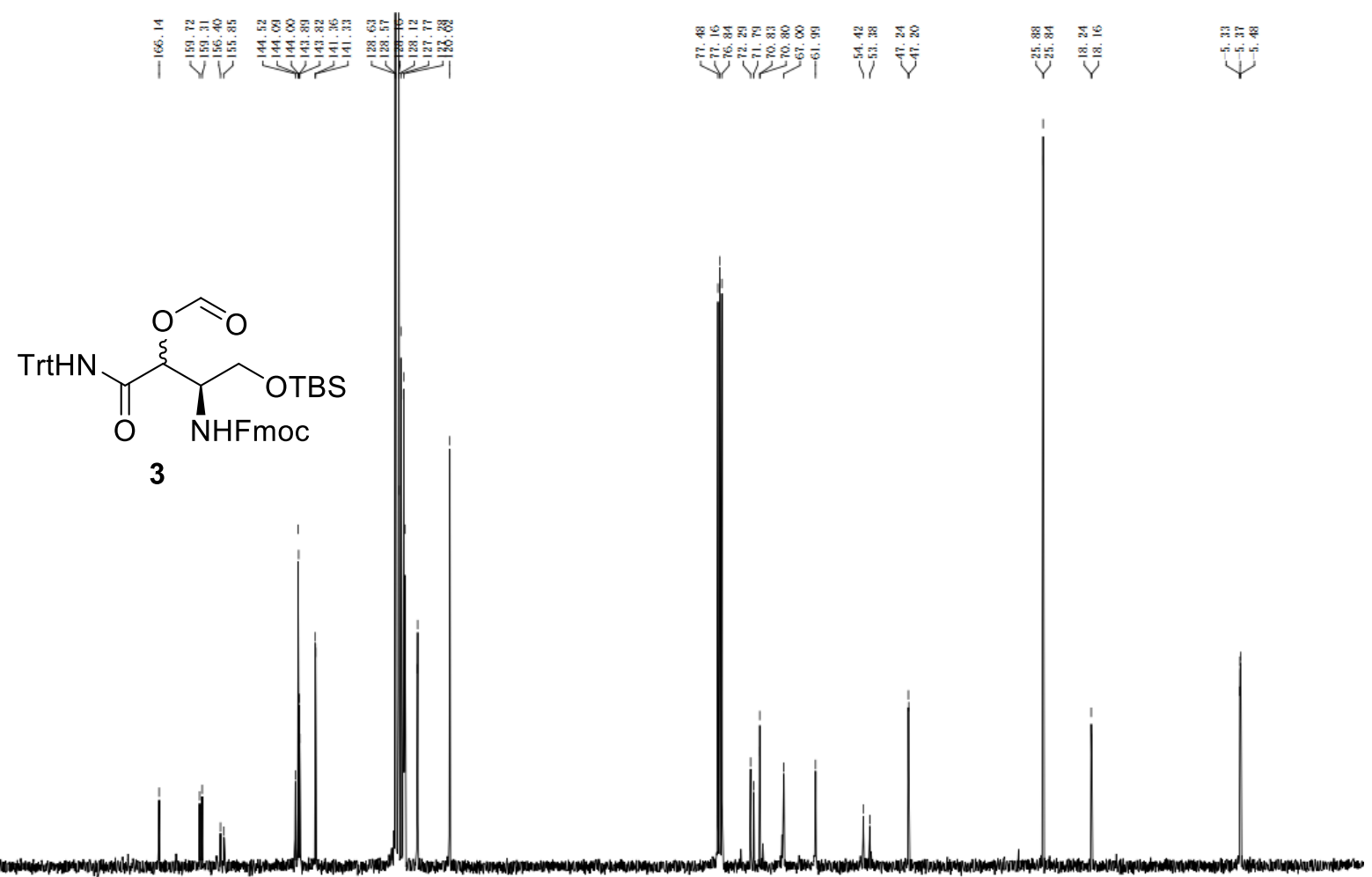

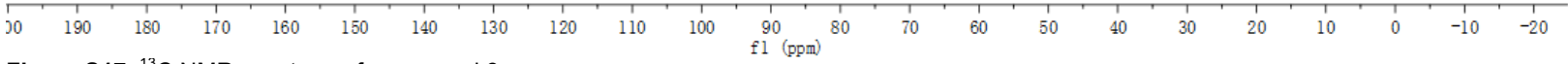

Figure S17. ${ }^{13} \mathrm{C}$ NMR spectrum of compound 3. 


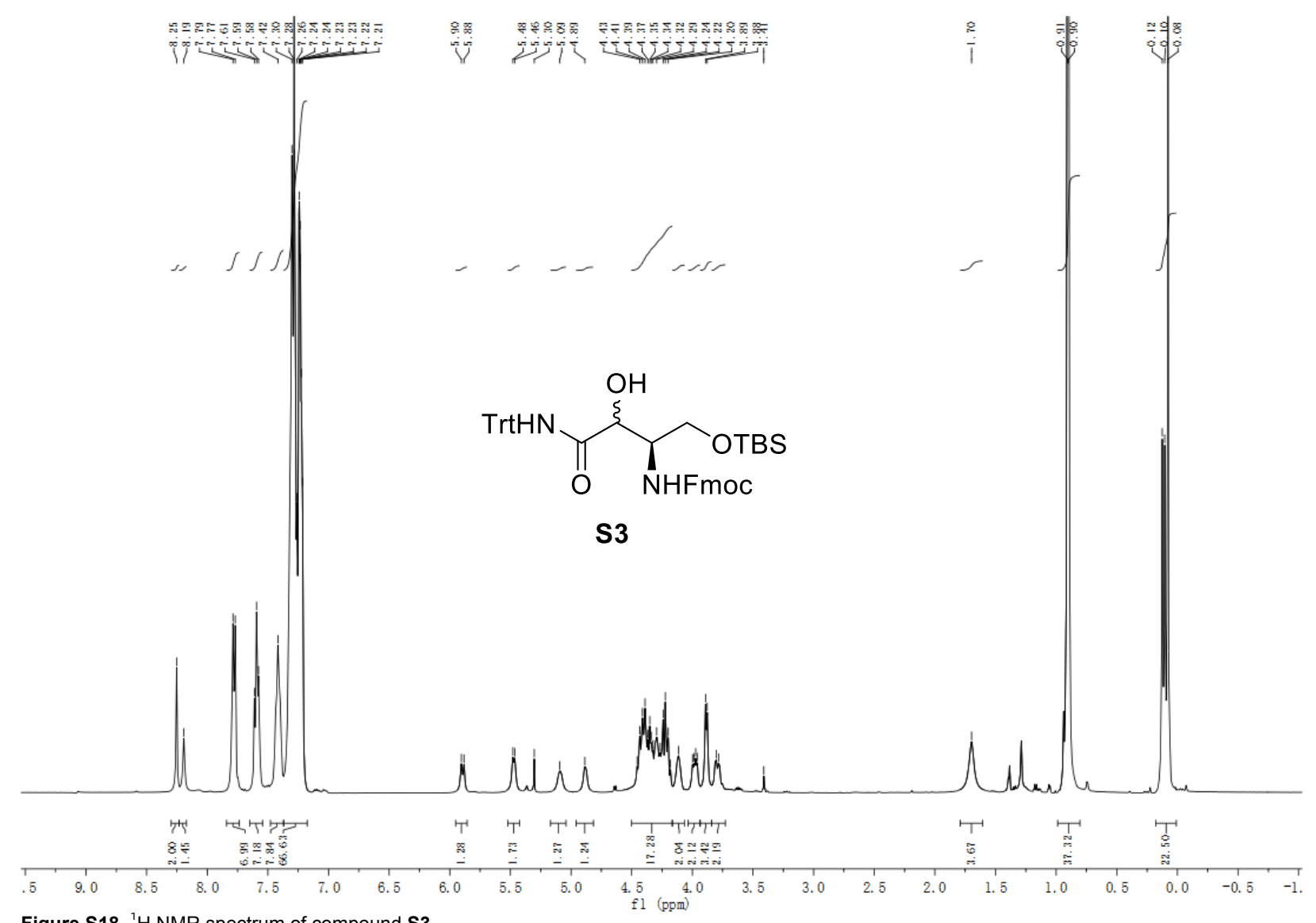

Figure S18. 'H NMR spectrum of compound S3.
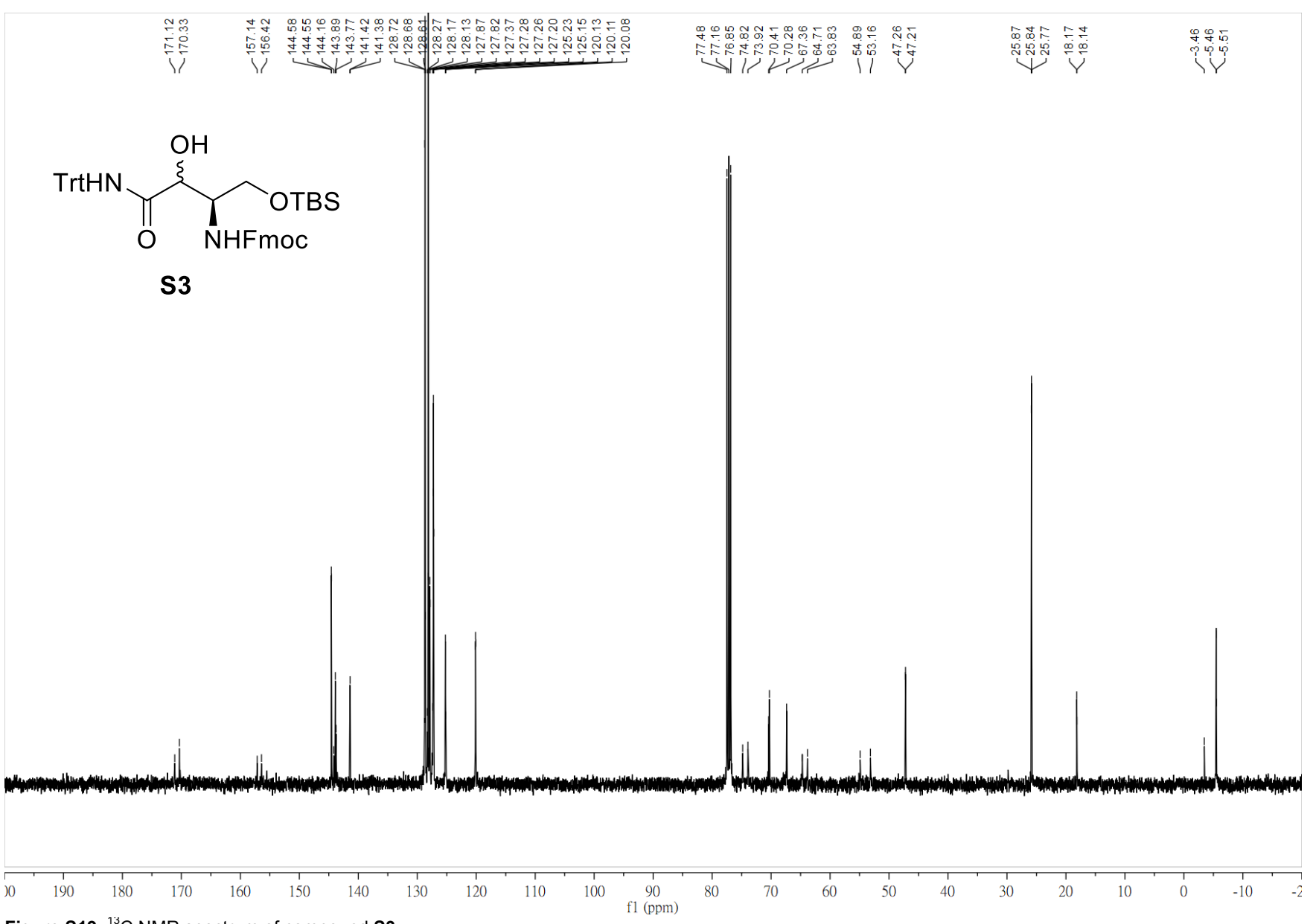

Figure S19. ${ }^{13} \mathrm{C}$ NMR spectrum of compound S3. 


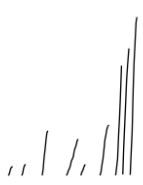

, - Nrsl, II
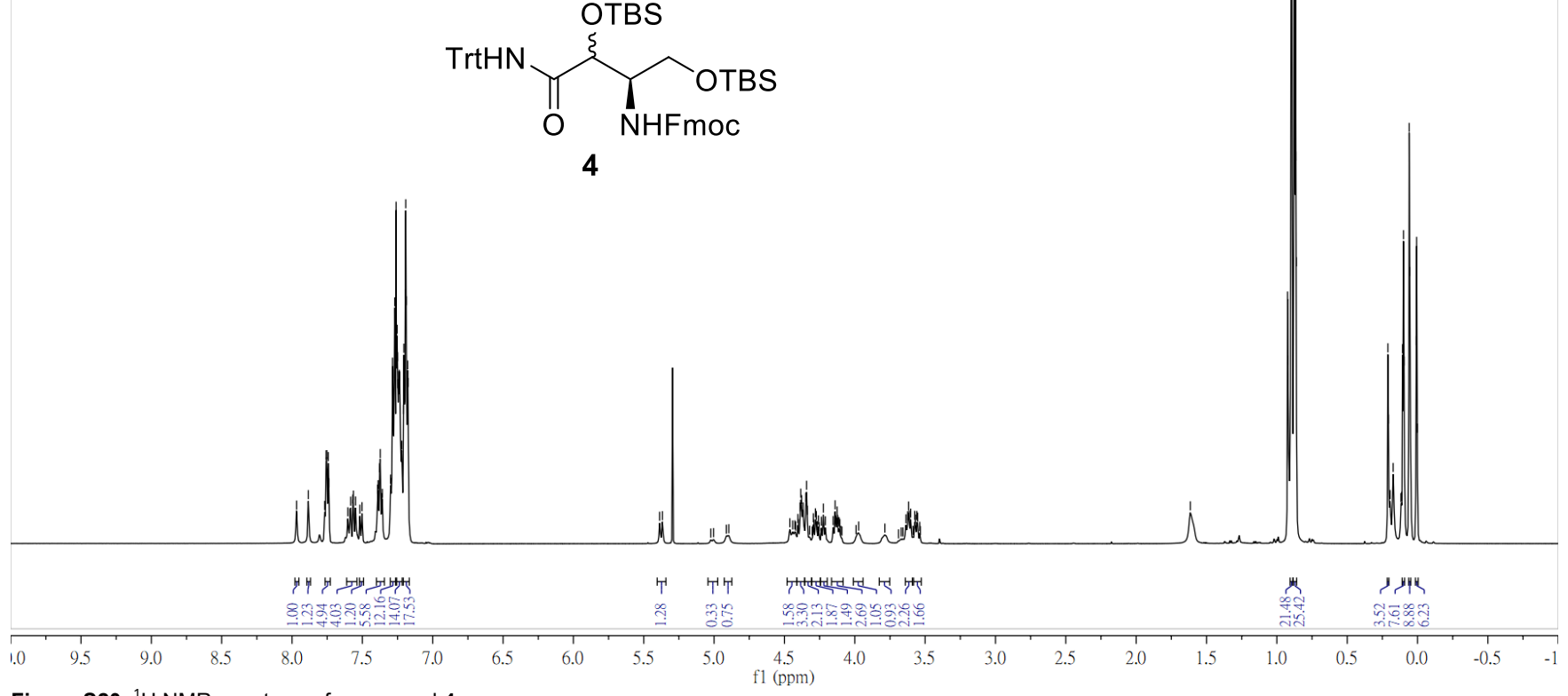

Figure S20. 'H NMR spectrum of compound 4.

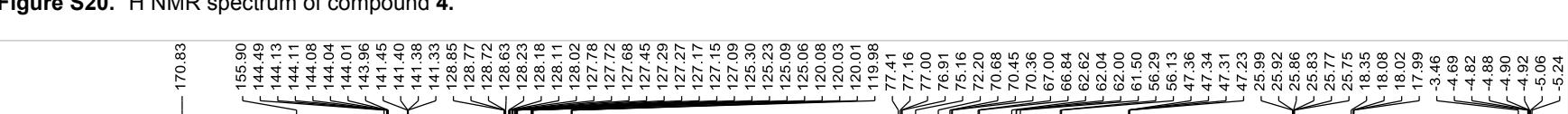

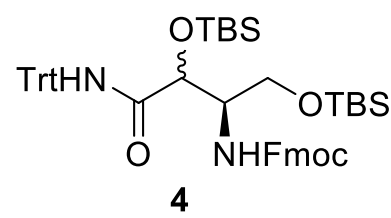

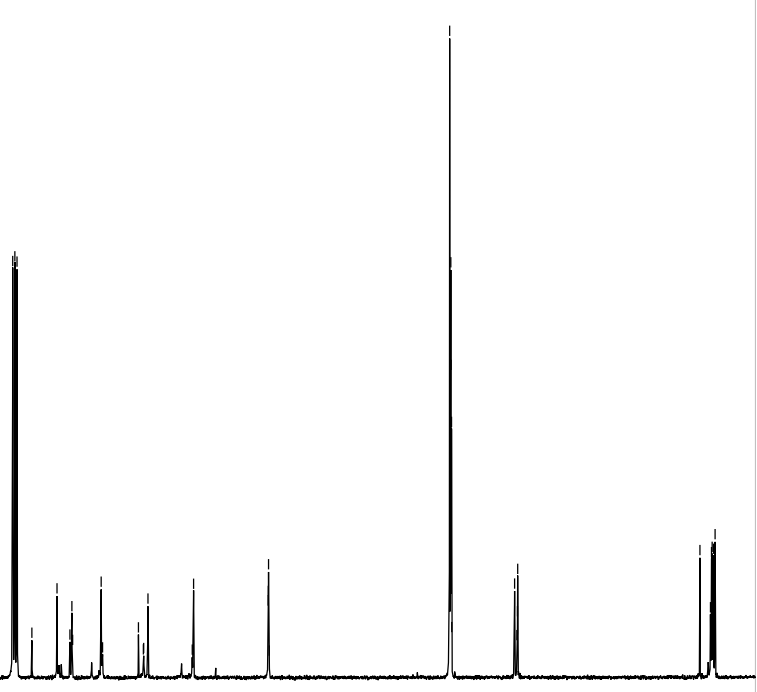




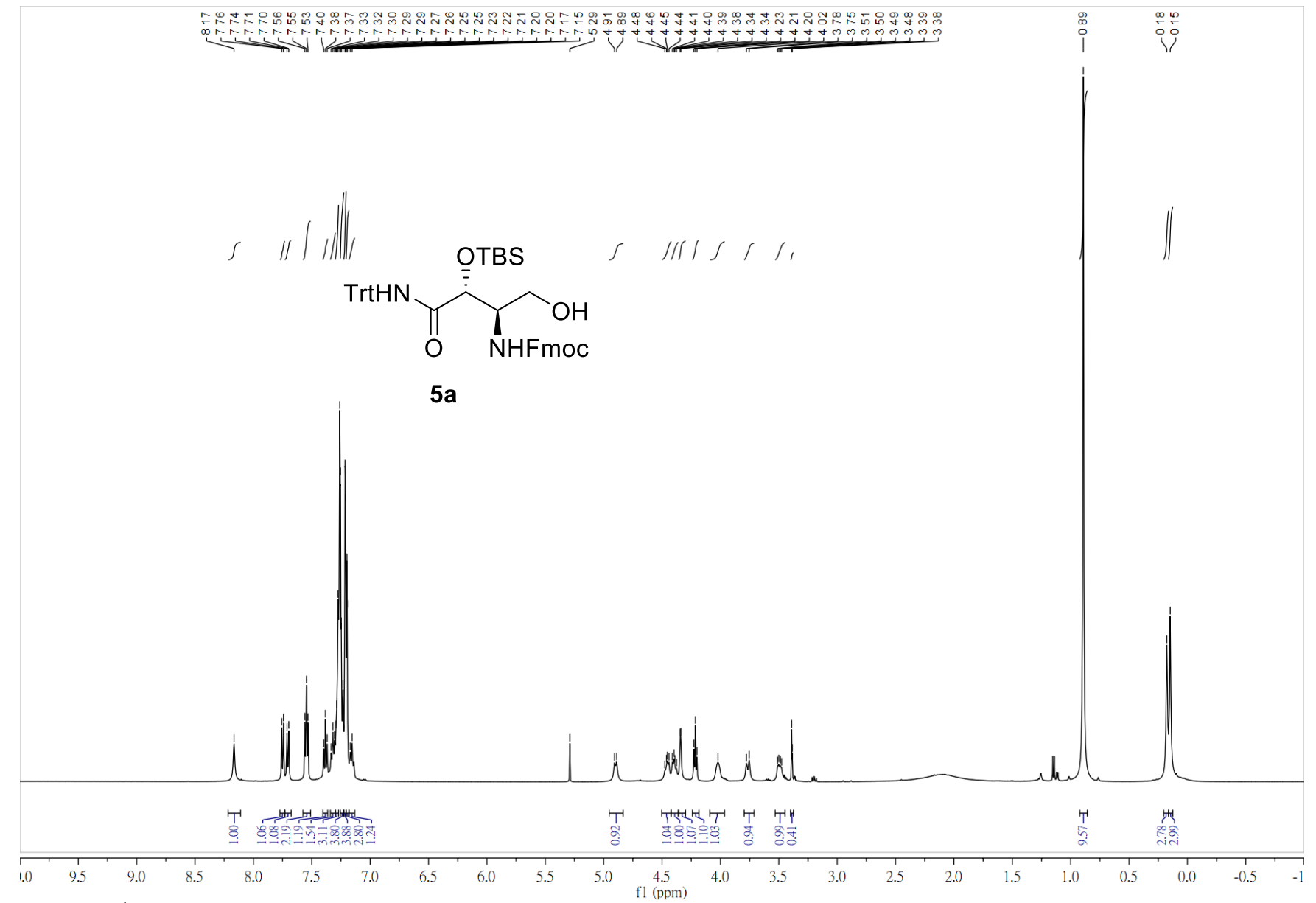

Figure S22. 'H NMR spectrum of compound $\mathbf{5 a}$.

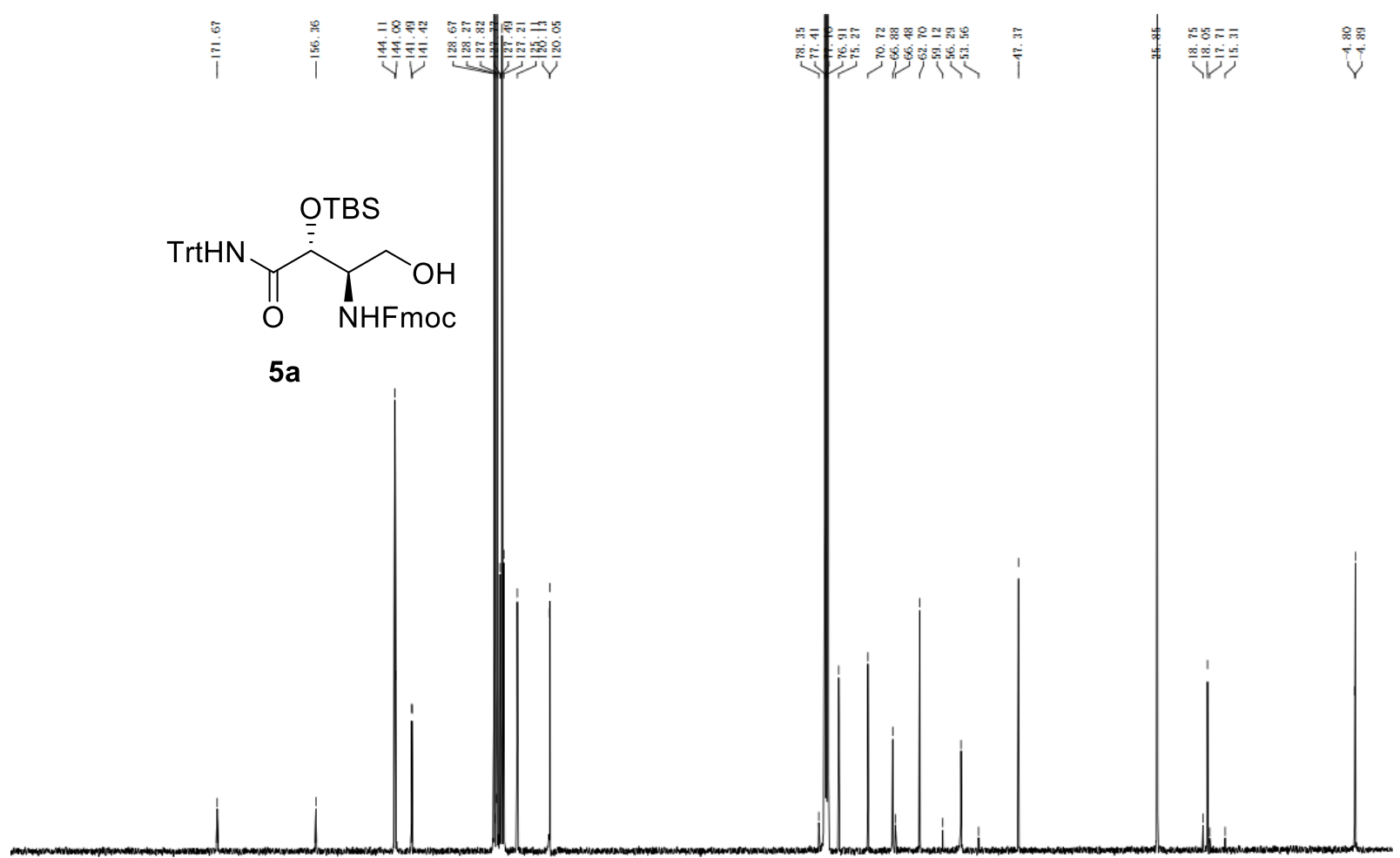

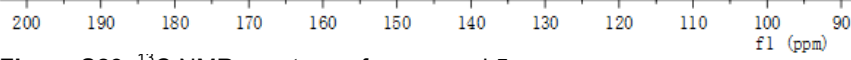

Figure S23. ${ }^{13} \mathrm{C}$ NMR spectrum of compound $\mathbf{5 a}$. 


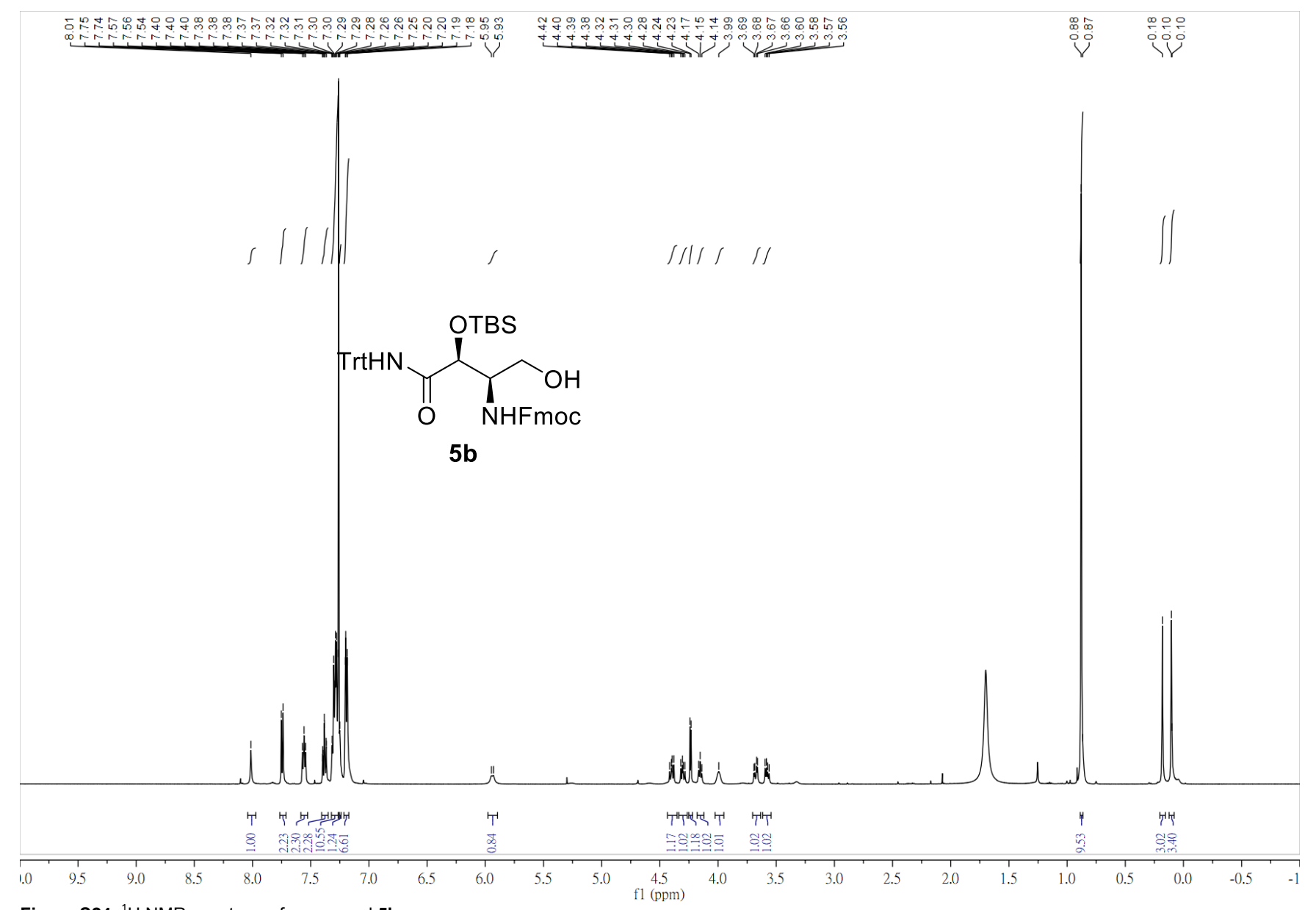

Figure S24. ${ }^{~} \mathrm{H}$ NMR spectrum of compound $\mathbf{5 b}$.

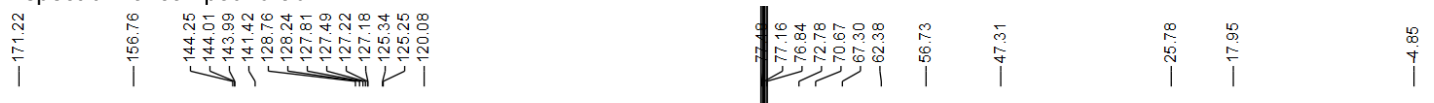

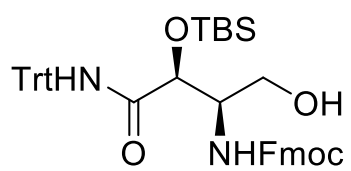

$5 \mathbf{b}$

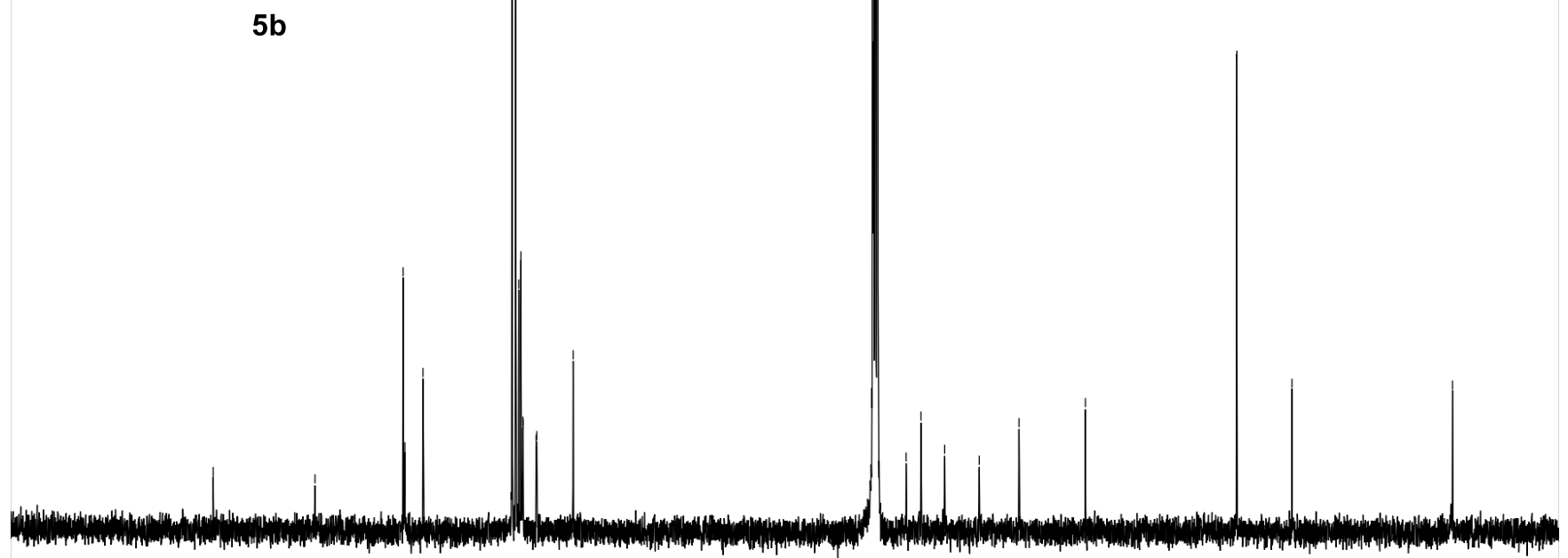

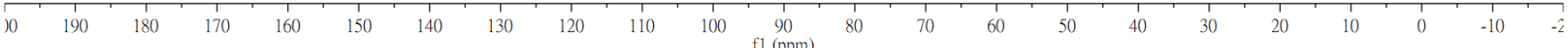

Figure S25. ${ }^{13} \mathrm{C}$ NMR spectrum of compound $\mathbf{5 b}$. 


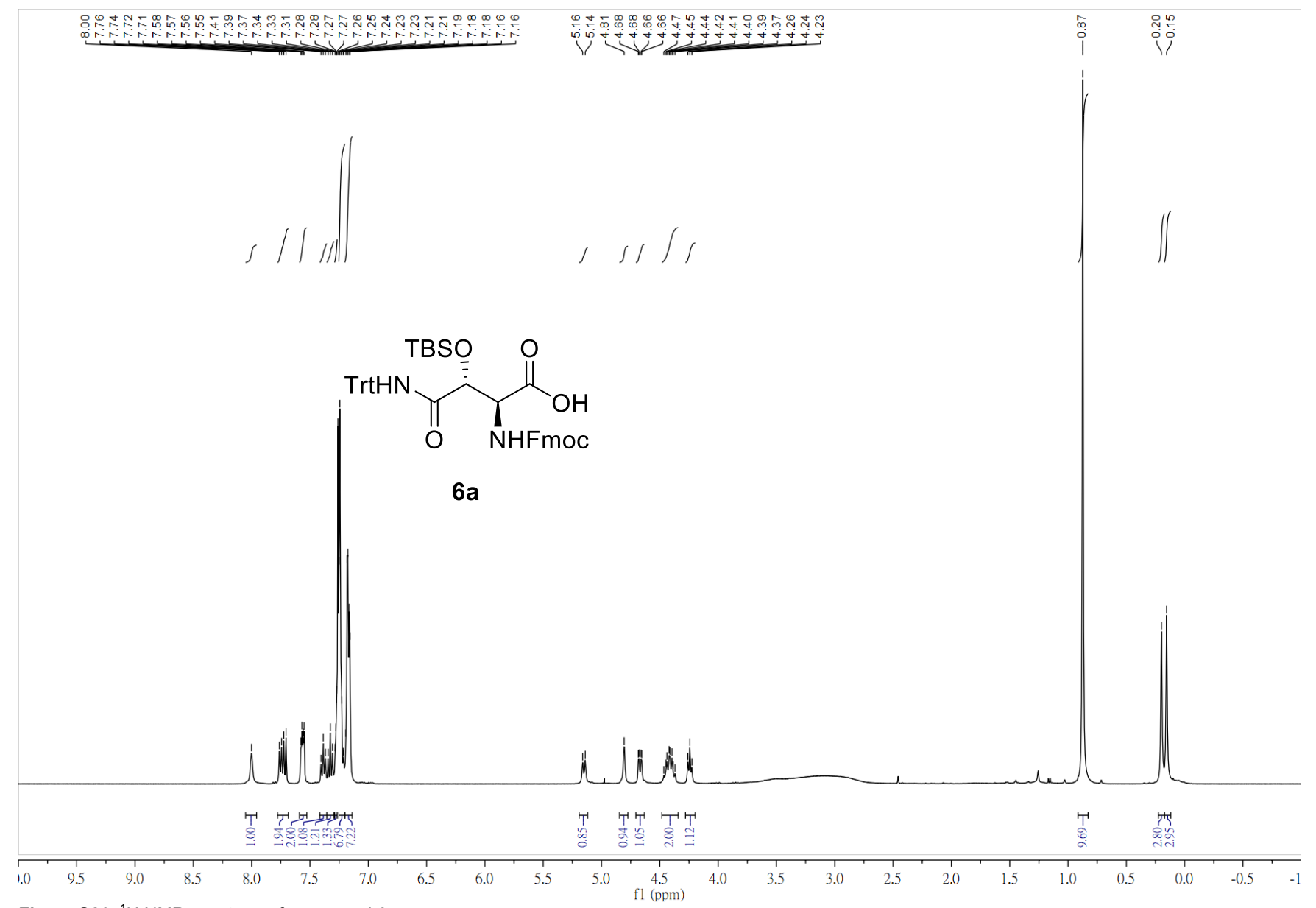

Figure S26. 'H NMR spectrum of compound 6 a.

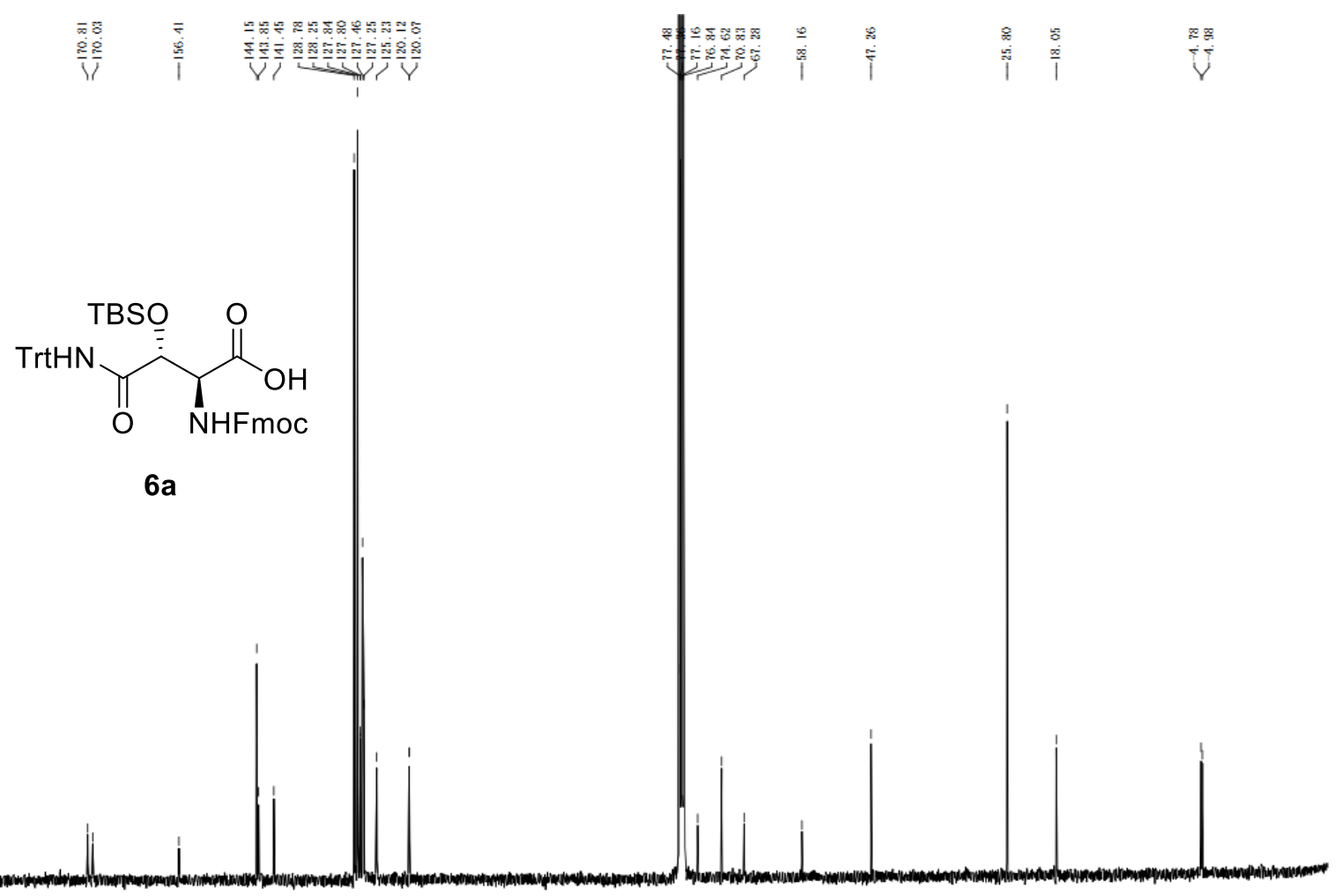

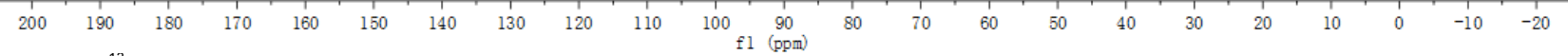

Figure S27. ${ }^{13} \mathrm{C}$ NMR spectrum of compound $\mathbf{6 a}$. 


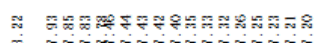

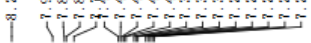

,<smiles>[CH]NC(C(=O)O)C(O[13CH3])C(=O)NCC</smiles>

6b

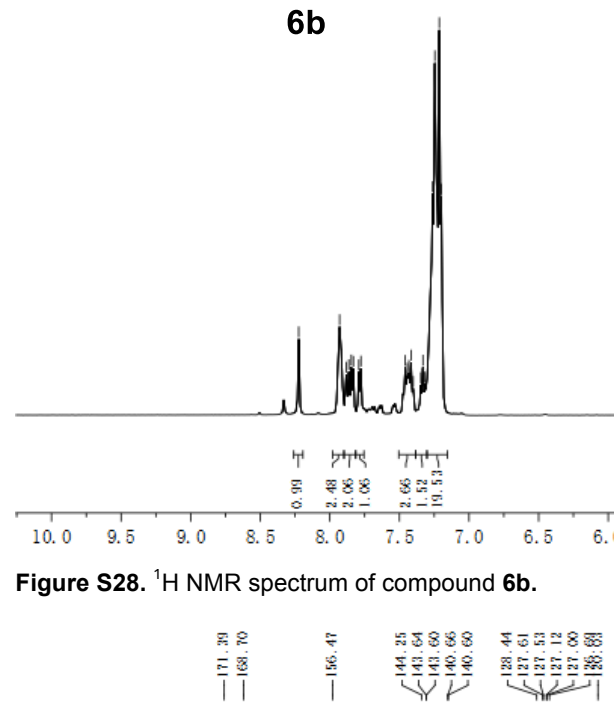

Figure S28. ${ }^{7} \mathrm{H}$ NMR spectrum of compound $\mathbf{6 b}$.

$$
\text { 1) । }
$$
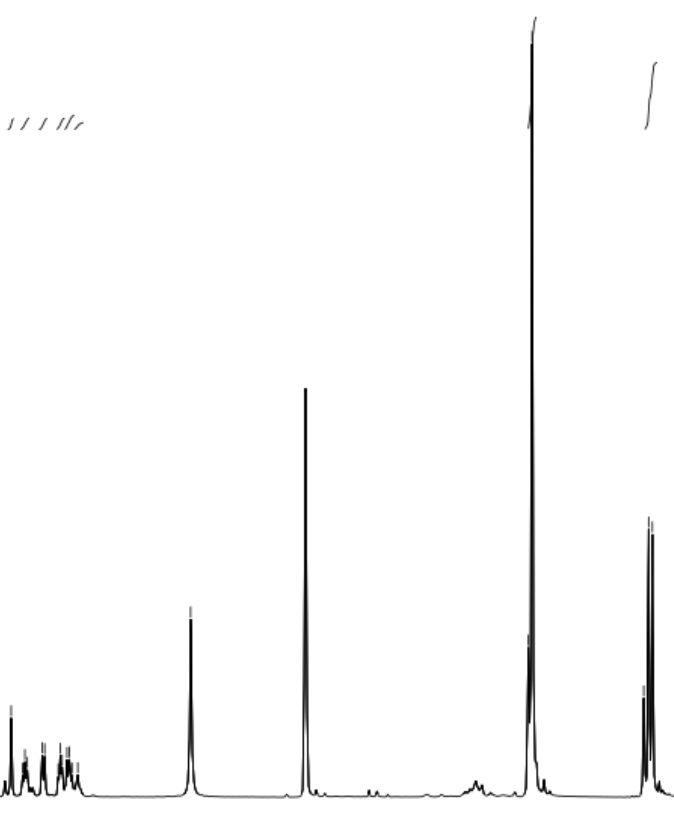

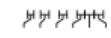

fi 5 (ppmi)
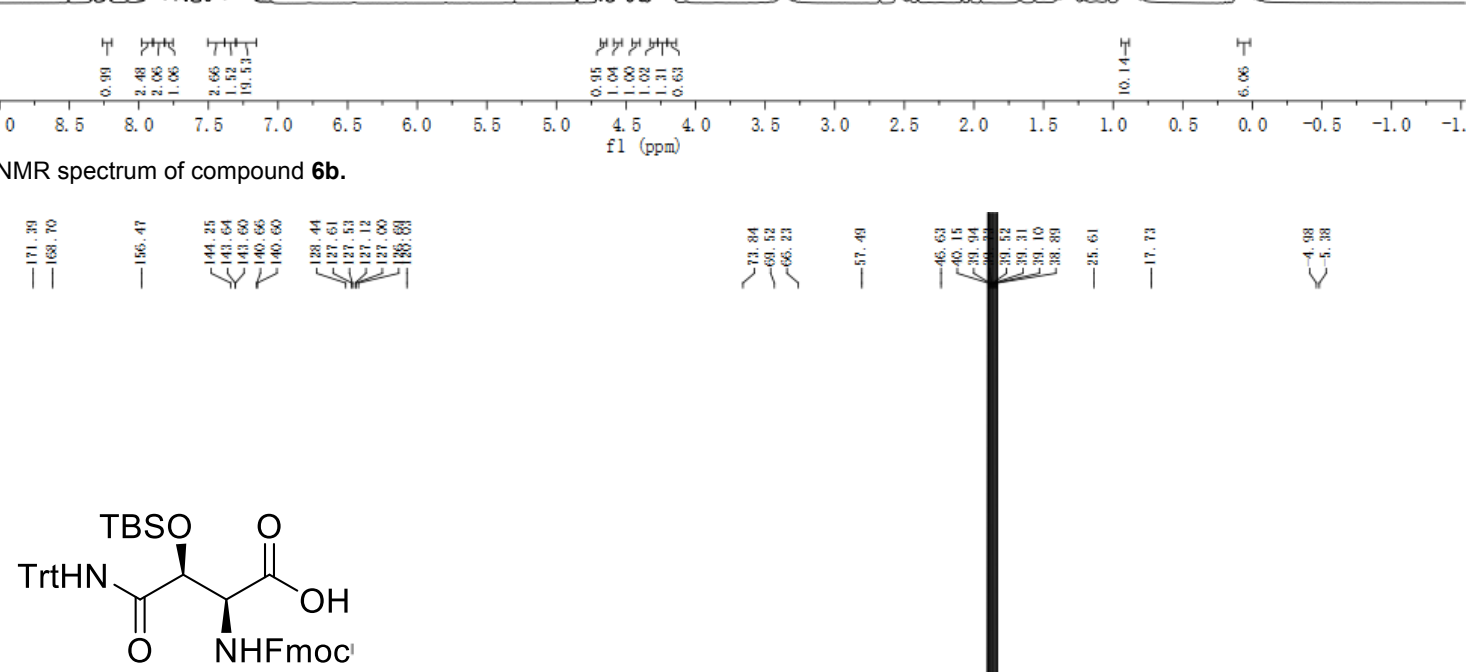

6b
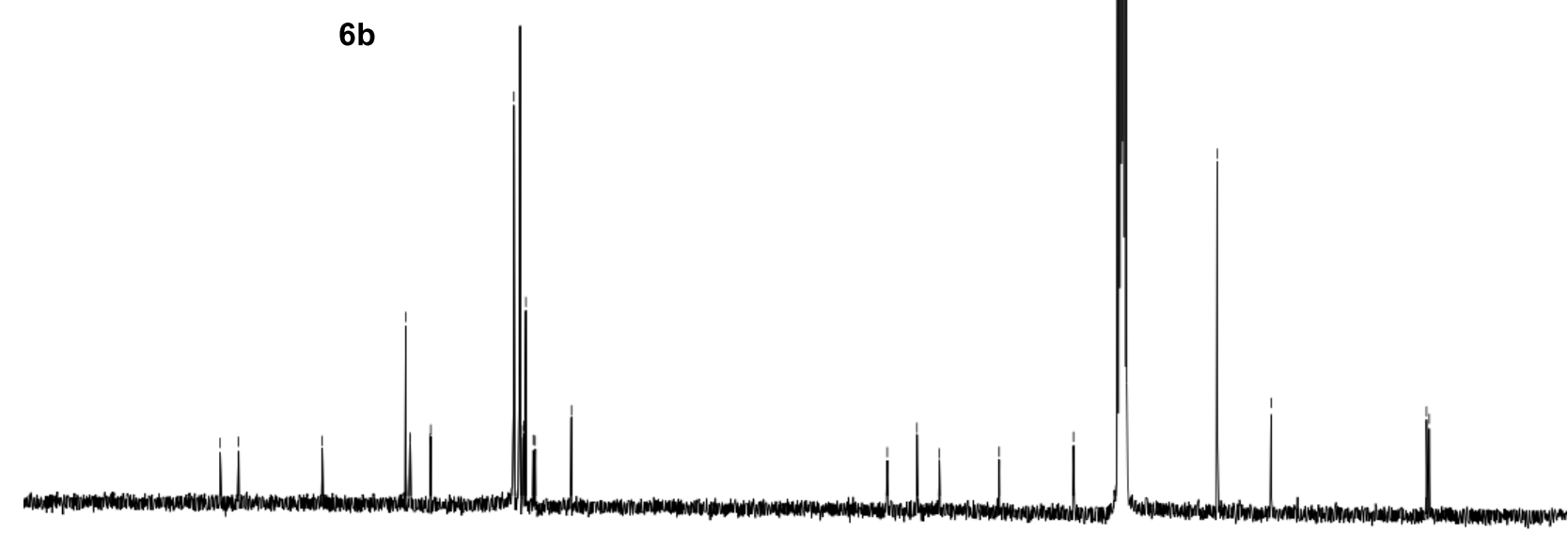

\begin{tabular}{llllllll}
\hline 30 & 190 & 180 & 170 & 160 & 150 & 140 & 130
\end{tabular}

Figure S29. ${ }^{13} \mathrm{C}$ NMR spectrum of compound $\mathbf{6 b}$. 


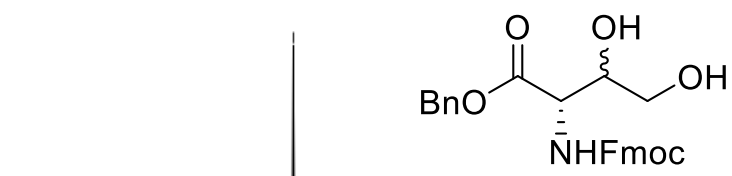

8
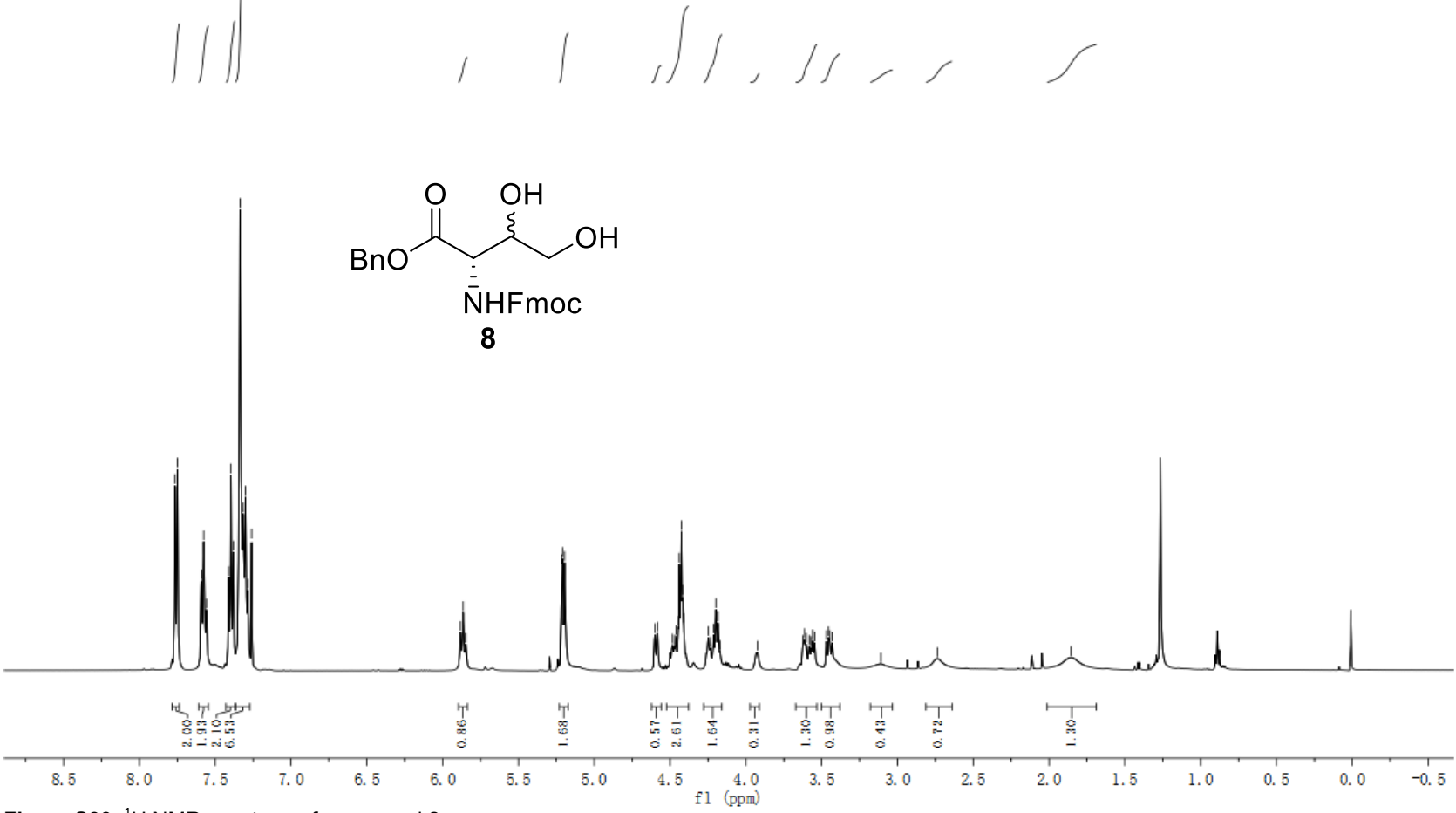

Figure S30. ${ }^{7} \mathrm{H}$ NMR spectrum of compound 8.

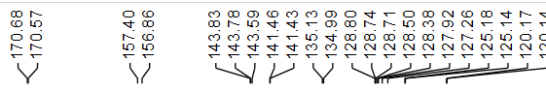

|l| |ل<smiles>O=C(OCc1ccccc1)[C@@H](N=CP)[C@H](O)CO</smiles>

8

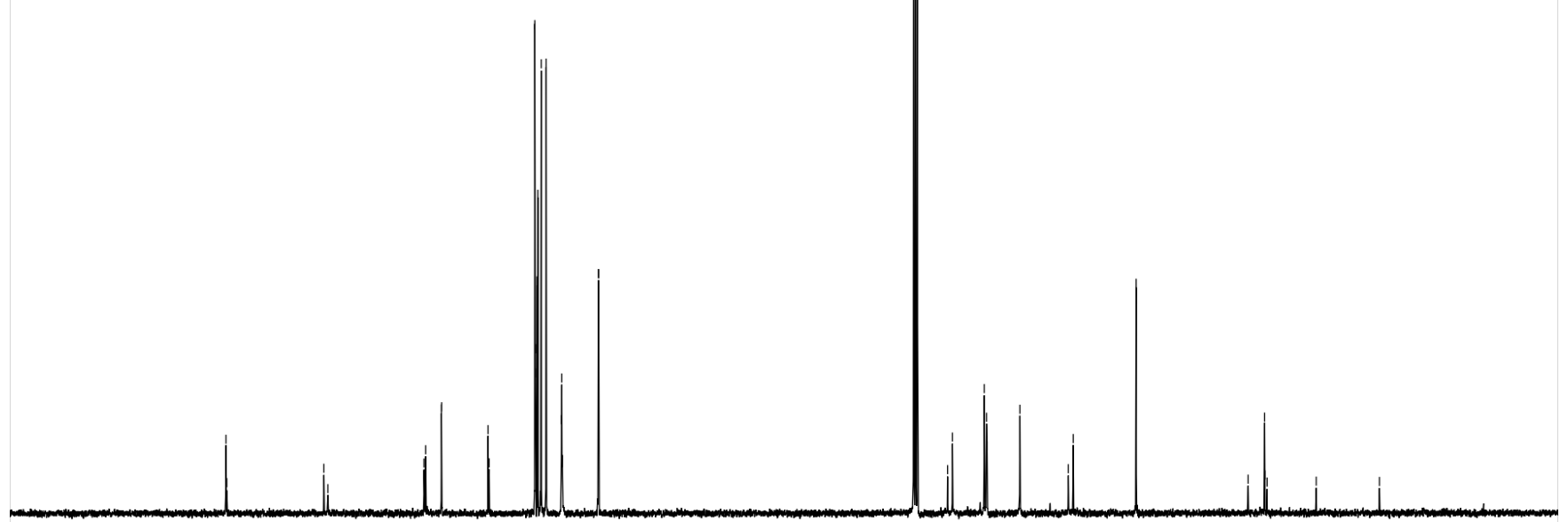

$\begin{array}{lllllll}190 & 180 & 170 & 160 & 150 & 140\end{array}$

Figure S31. ${ }^{13} \mathrm{C}$ NMR spectrum of compound 8 . 


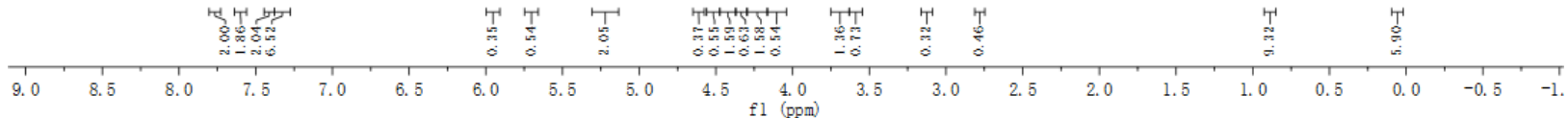

Figure S32. 'H NMR spectrum of compound 9.

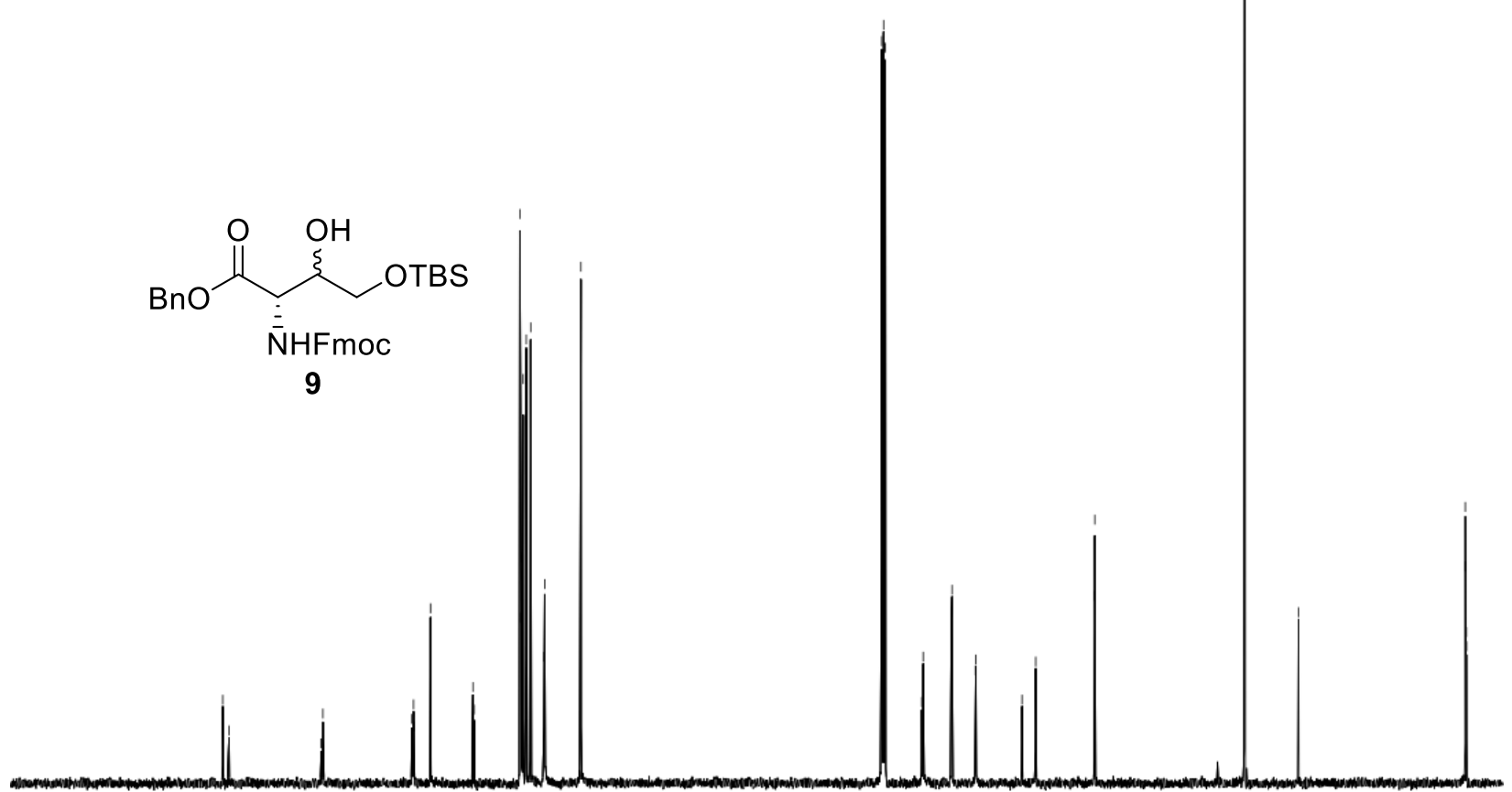

$\begin{array}{llllllll}100 & 190 & 180 & 170 & 160 & 150 & 140 & 130\end{array}$

Figure S33. ${ }^{13} \mathrm{C}$ NMR spectrum of compound $\mathbf{9}$. 
<smiles>COC(CO[SnH3])C(=N)C(=O)OCc1ccccc1</smiles>

syn-10a

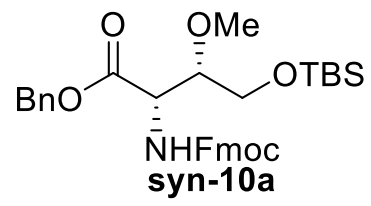

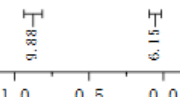

Figure S34. 'H NMR spectrum of compound 10a.

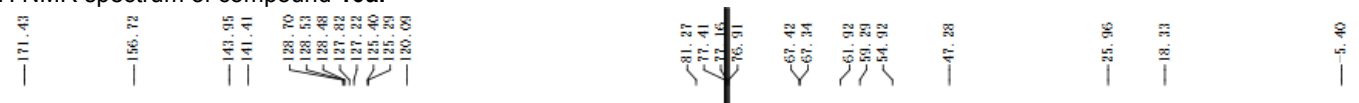

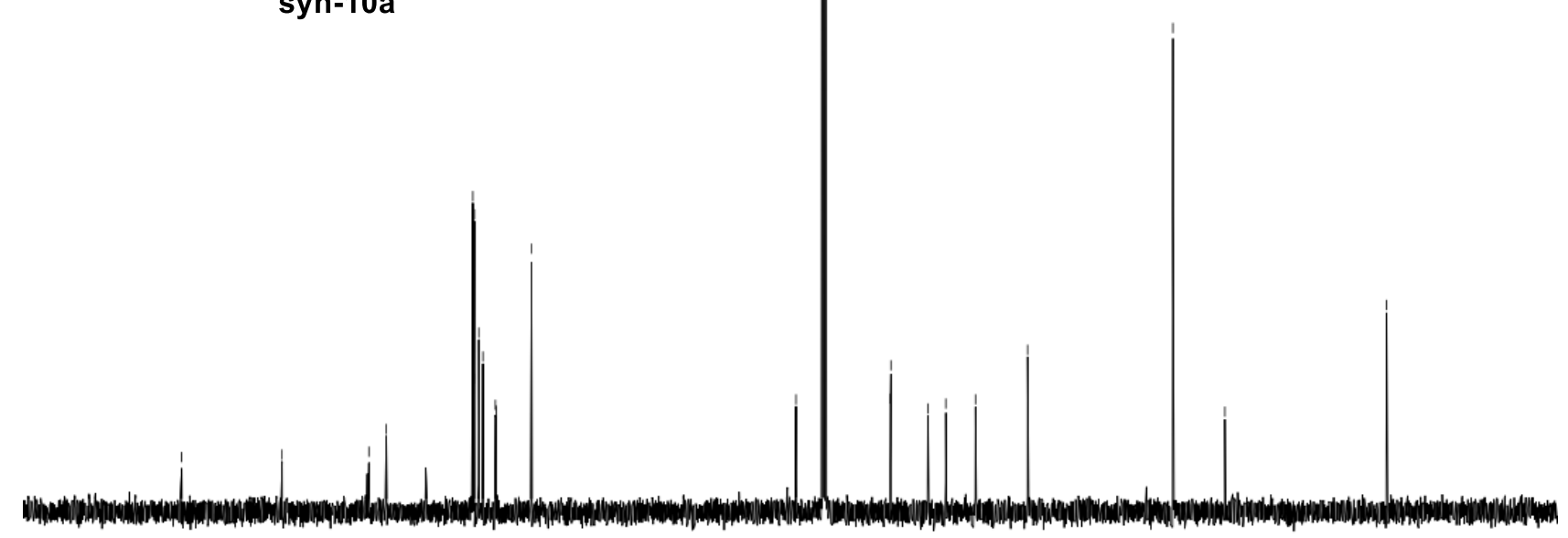

$\begin{array}{llllllll}190 & 180 & 170 & 160 & 150 & 140 & 130 & 1\end{array}$

Figure S35. ${ }^{13} \mathrm{C}$ NMR spectrum of compound 10a. 


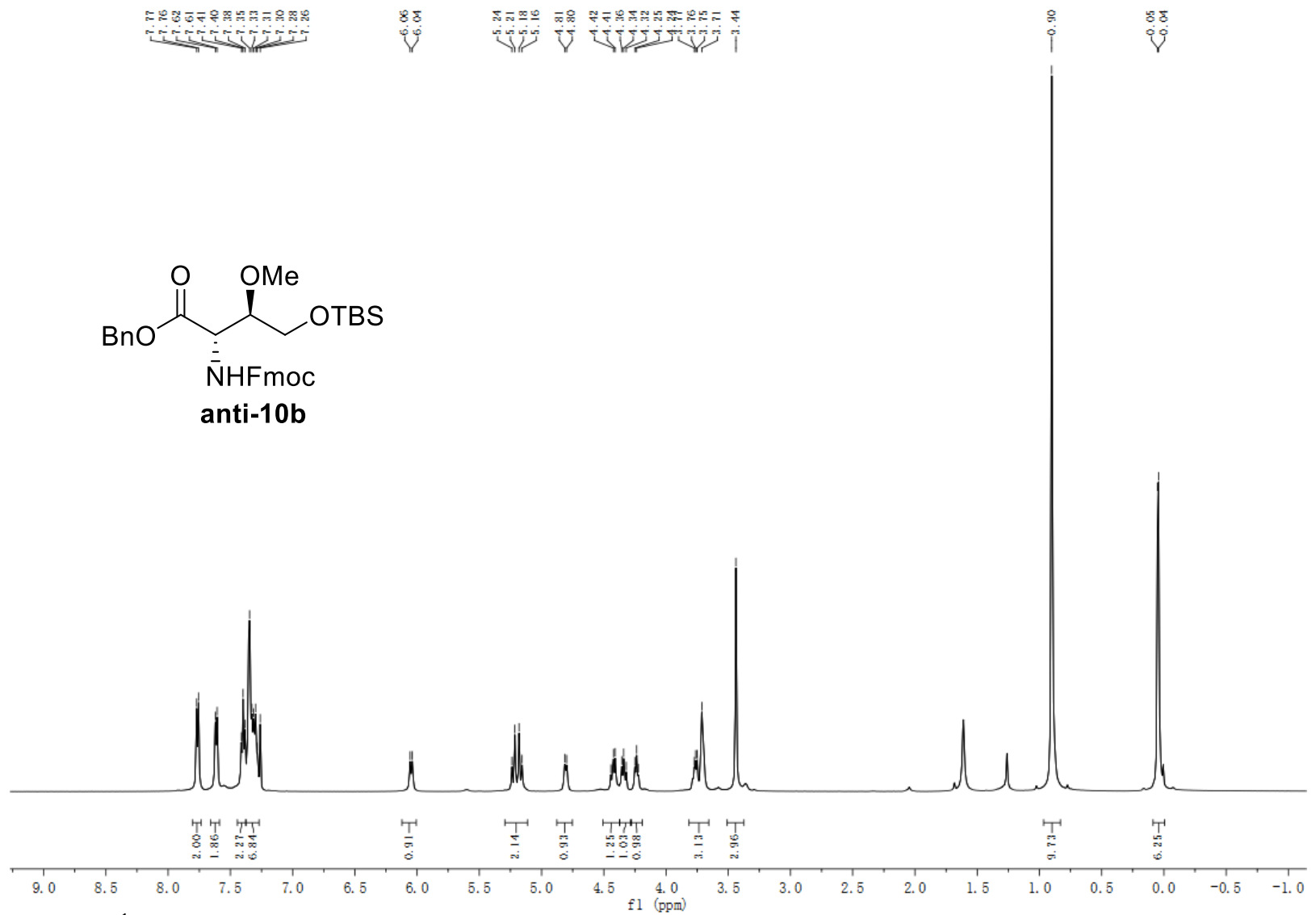

Figure S36. 'H NMR spectrum of compound 10b.

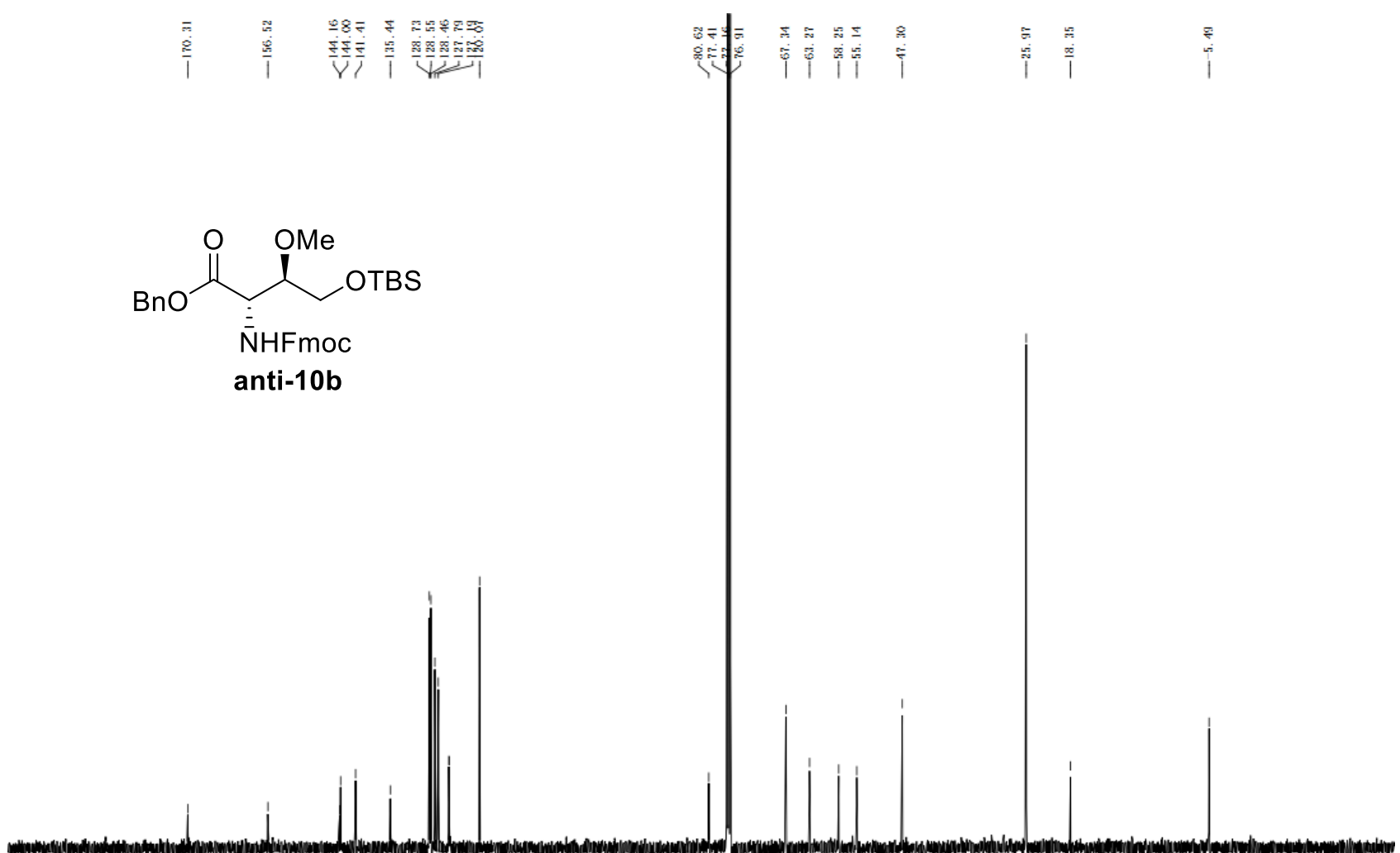

$\begin{array}{lllllllllllllllllllllllllllll}200 & 190 & 180 & 170 & 160 & 150 & 140 & 130 & 120 & 110 & 100 & 90 & 80 & 70 & 60 & 50 & 40 & 30 & 20 & 10 & 0 & -10 & -20 & -30 & 10\end{array}$

Figure S37. ${ }^{13} \mathrm{C}$ NMR spectrum of compound $10 \mathrm{~b}$. 

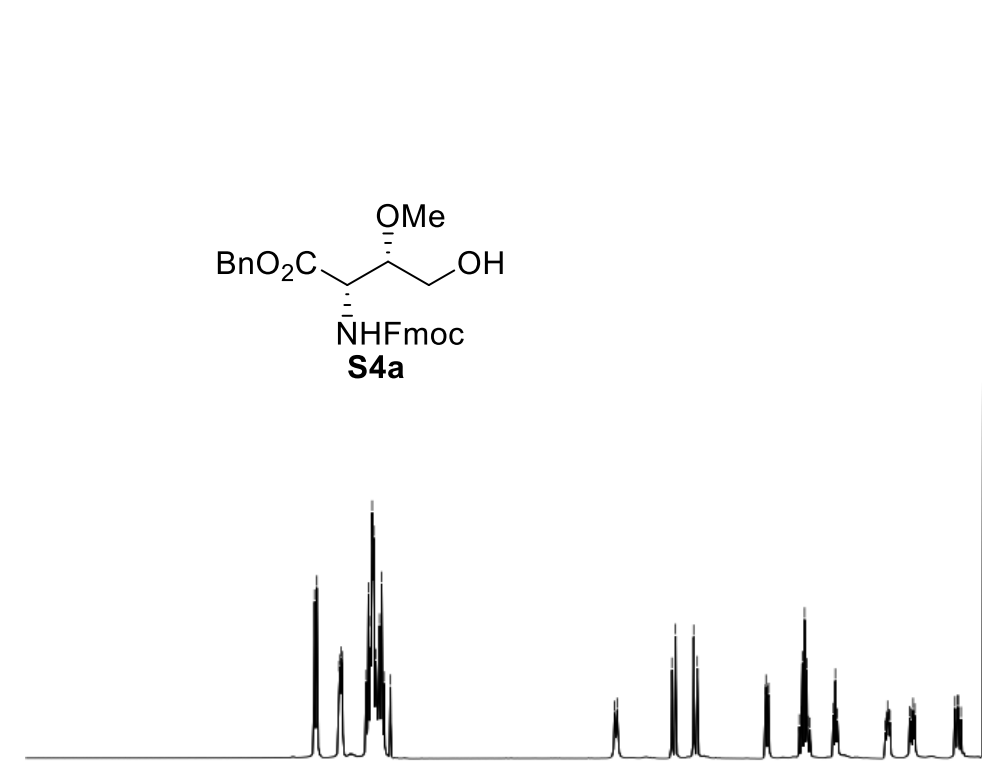

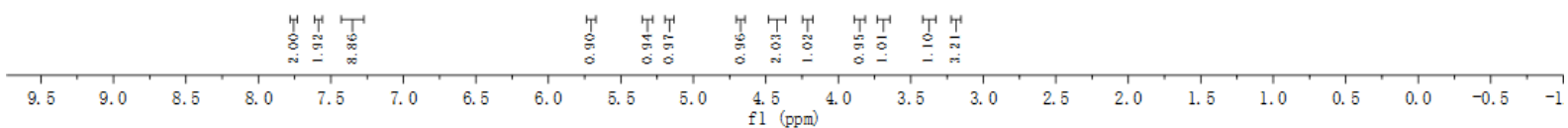

Figure S38. 'H NMR spectrum of compound S4a.

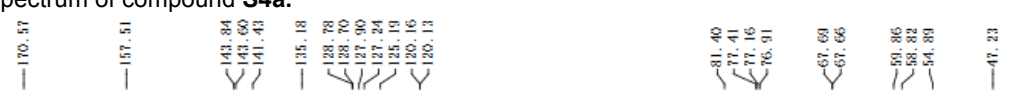

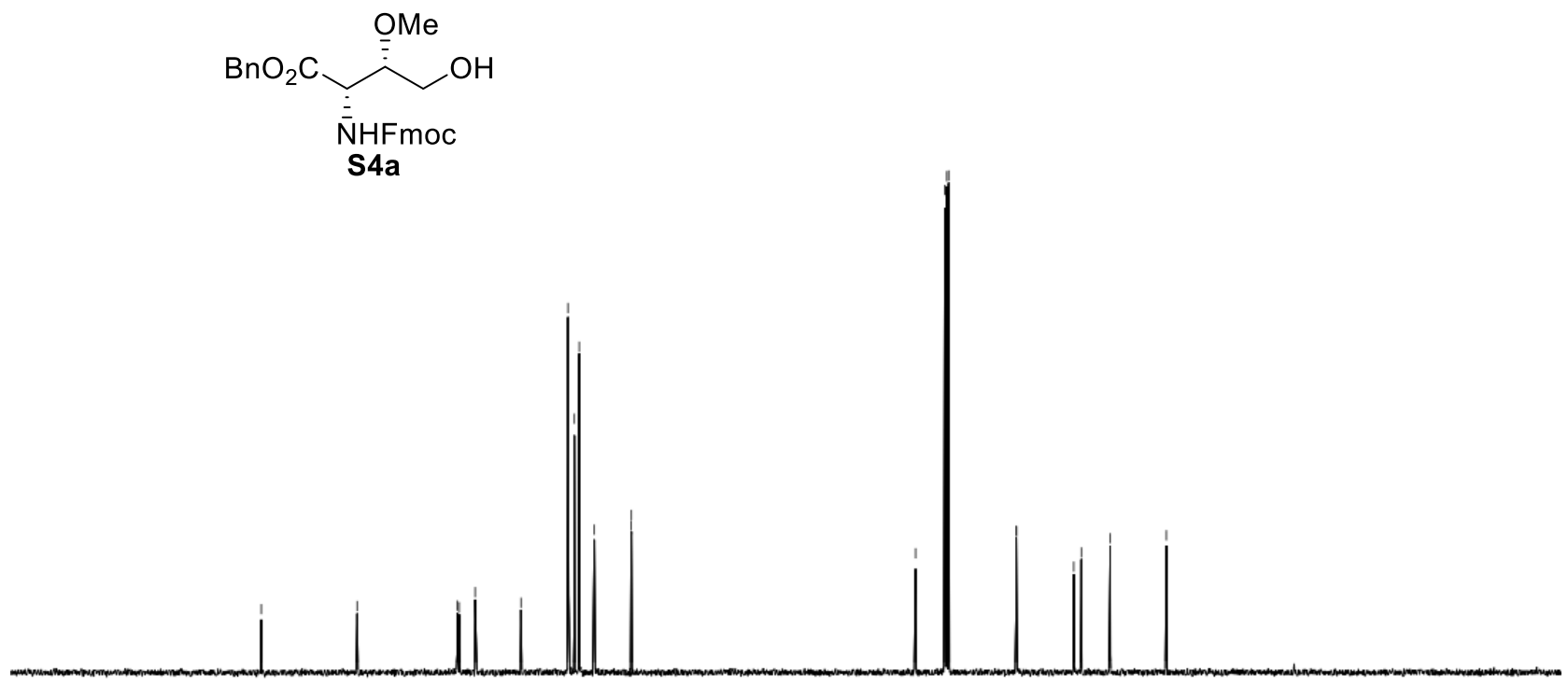

$\begin{array}{lllllll}200 & 190 & 180 & 170 & 160 & 150 & 140\end{array}$

Figure S39. ${ }^{13} \mathrm{C}$ NMR spectrum of compound S4a. 


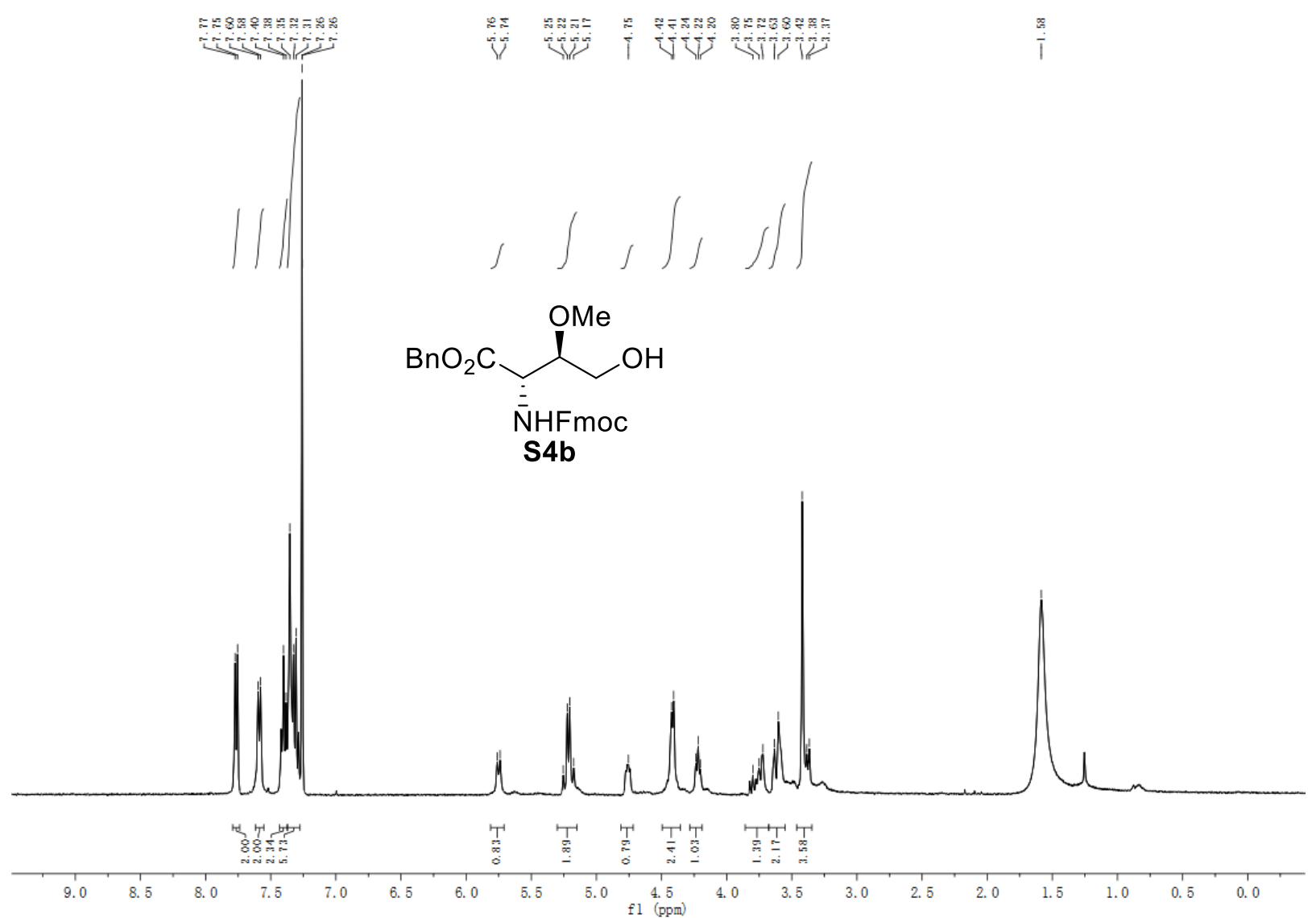

Figure S40. 'H NMR spectrum of compound S4b.

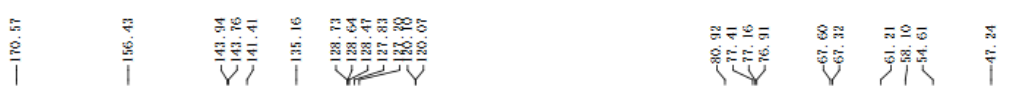

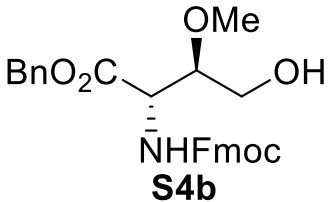

S4b
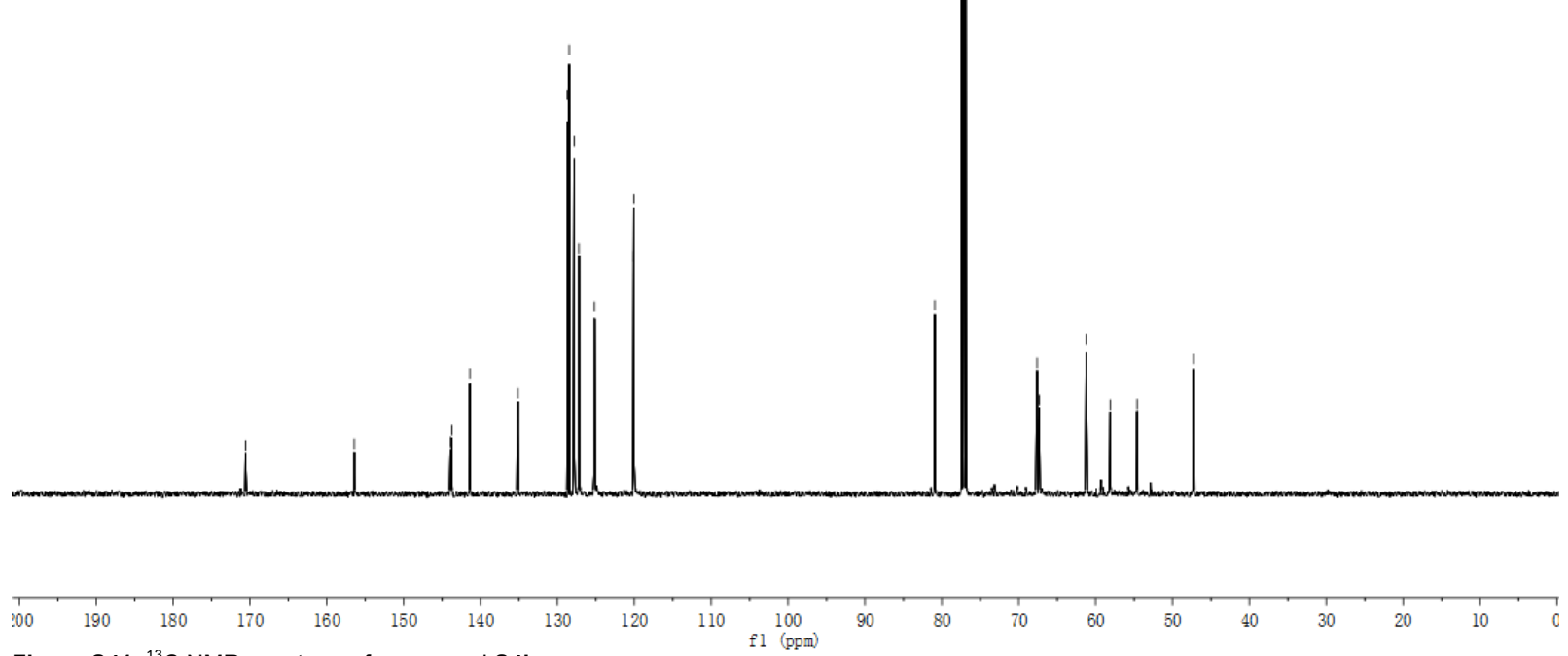

Figure S41. ${ }^{13} \mathrm{C}$ NMR spectrum of compound S4b. 

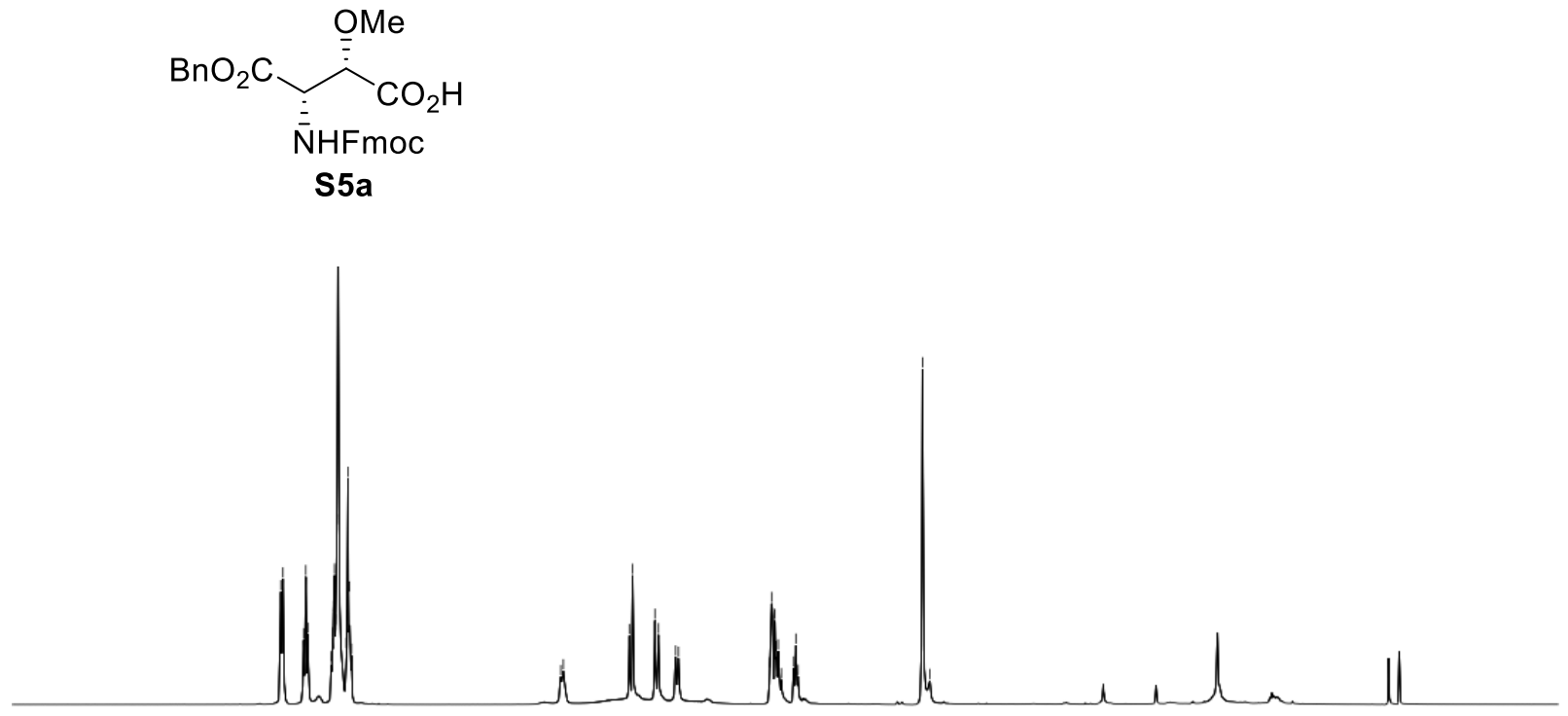

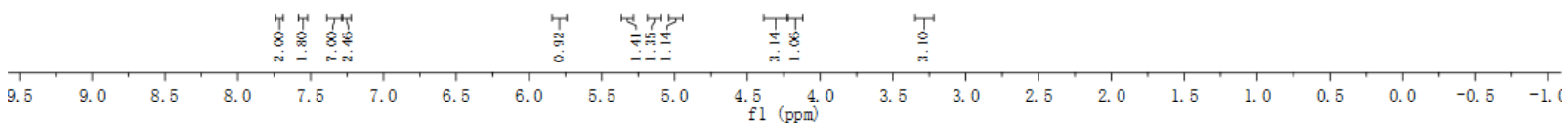

Figure S42. 'H NMR spectrum of compound S5a.

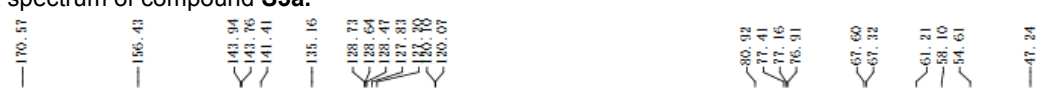

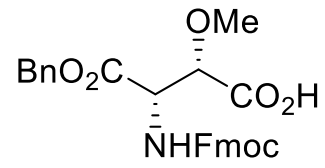

S5a

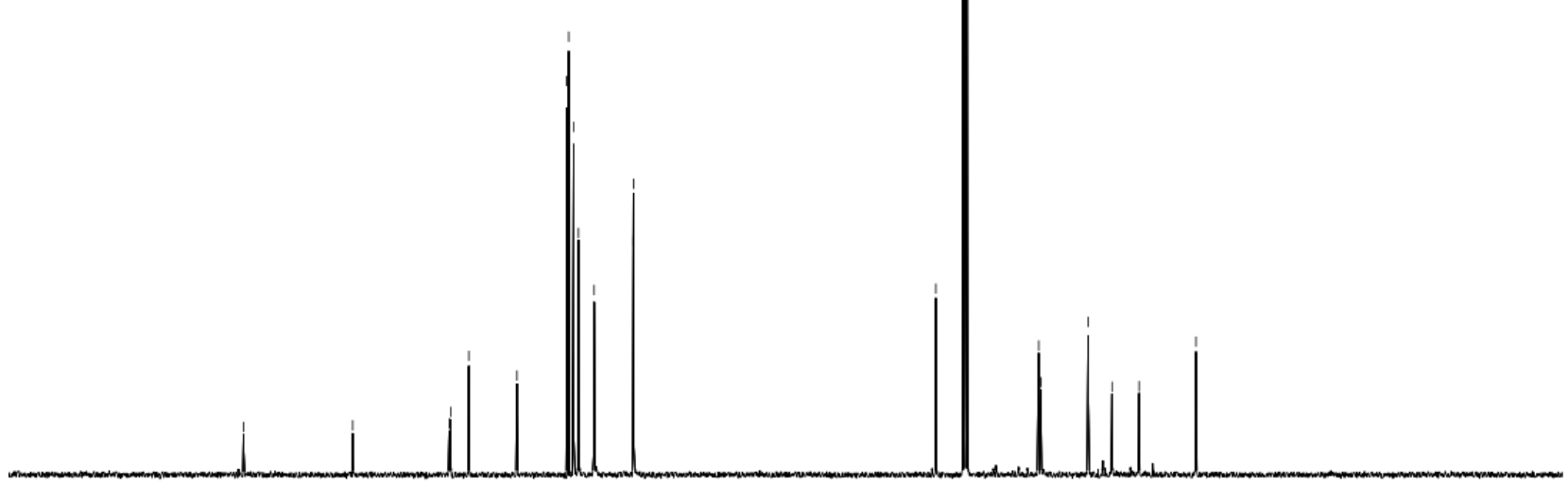

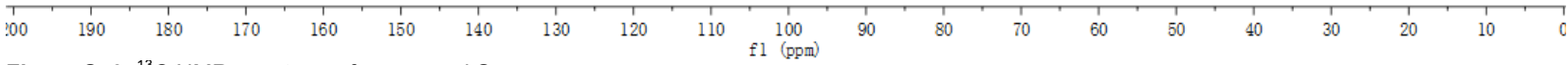

Figure S43. ${ }^{13} \mathrm{C}$ NMR spectrum of compound S5a. 
<smiles>CO[C@H](C(=O)O)[C@H](N=S)C(=O)O</smiles>

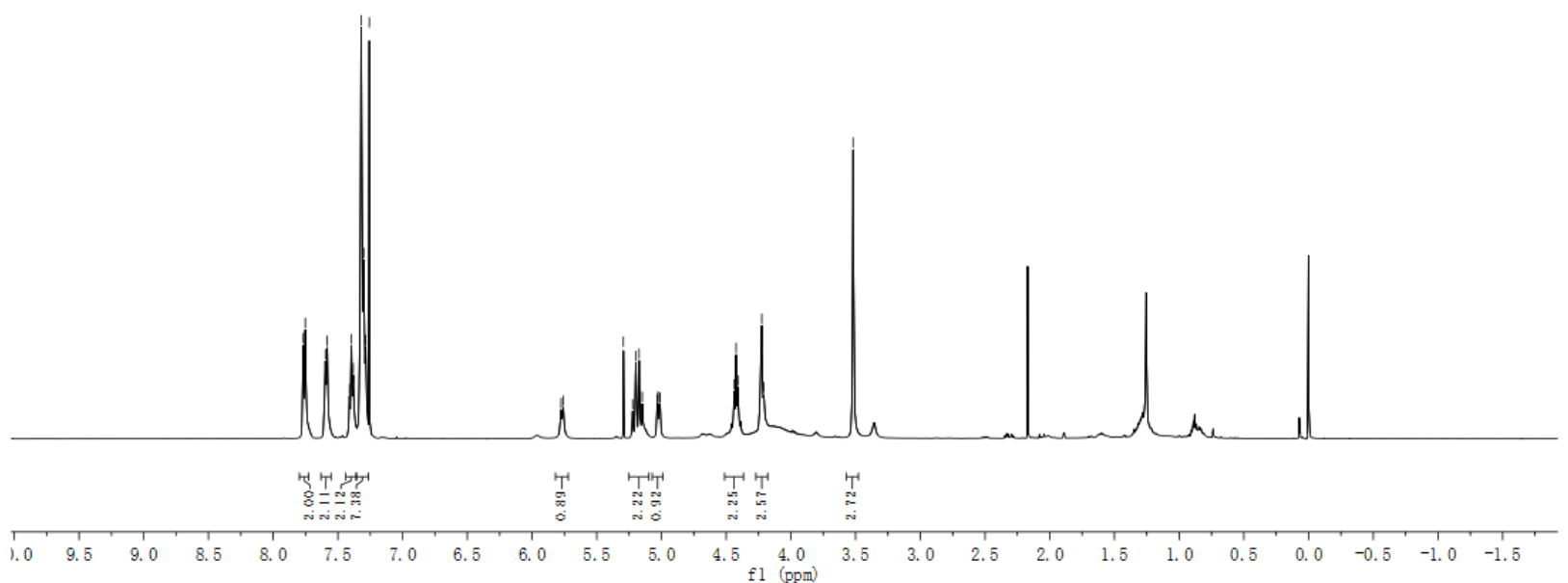

Figure S44. 'H NMR spectrum of compound S5b.

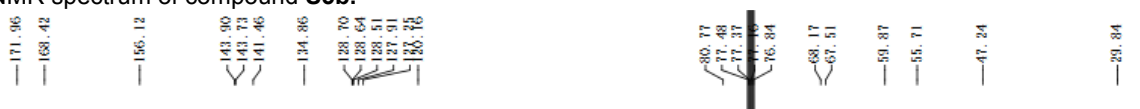

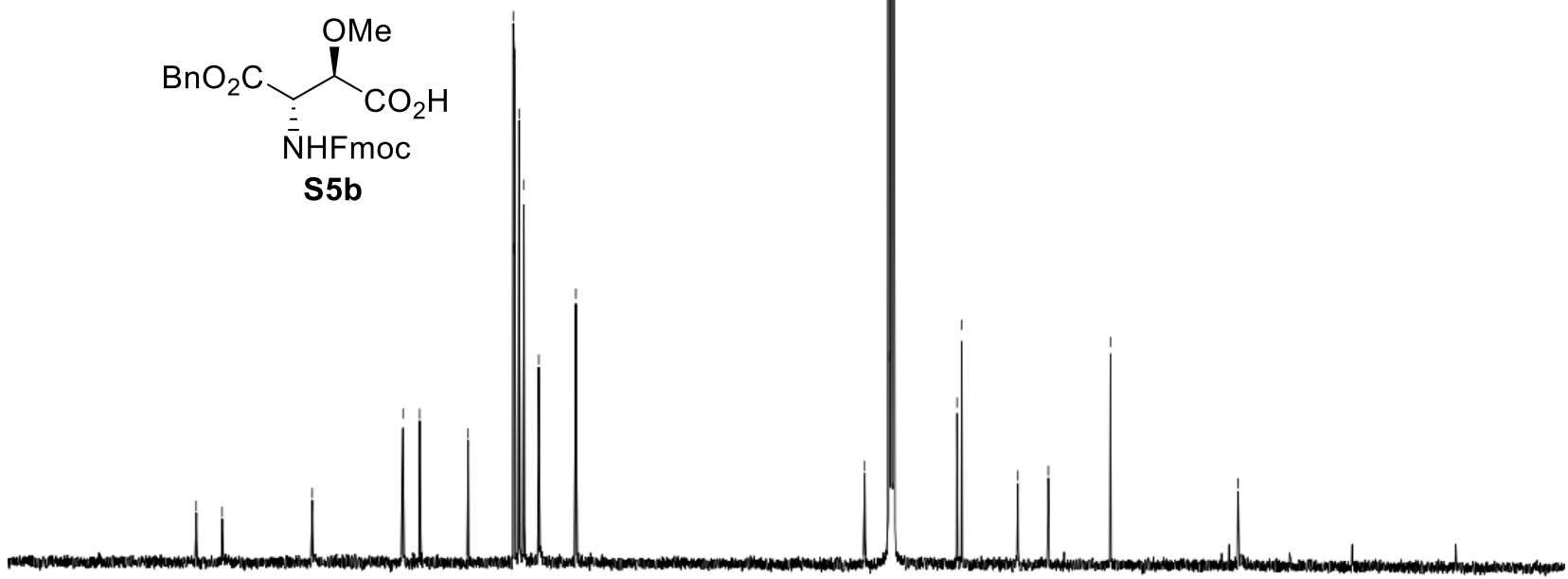

$\begin{array}{lllllll}190 & 180 & 170 & 160 & 150 & 140 & 130\end{array}$

Figure S45. ${ }^{13} \mathrm{C}$ NMR spectrum of compound S5b. 


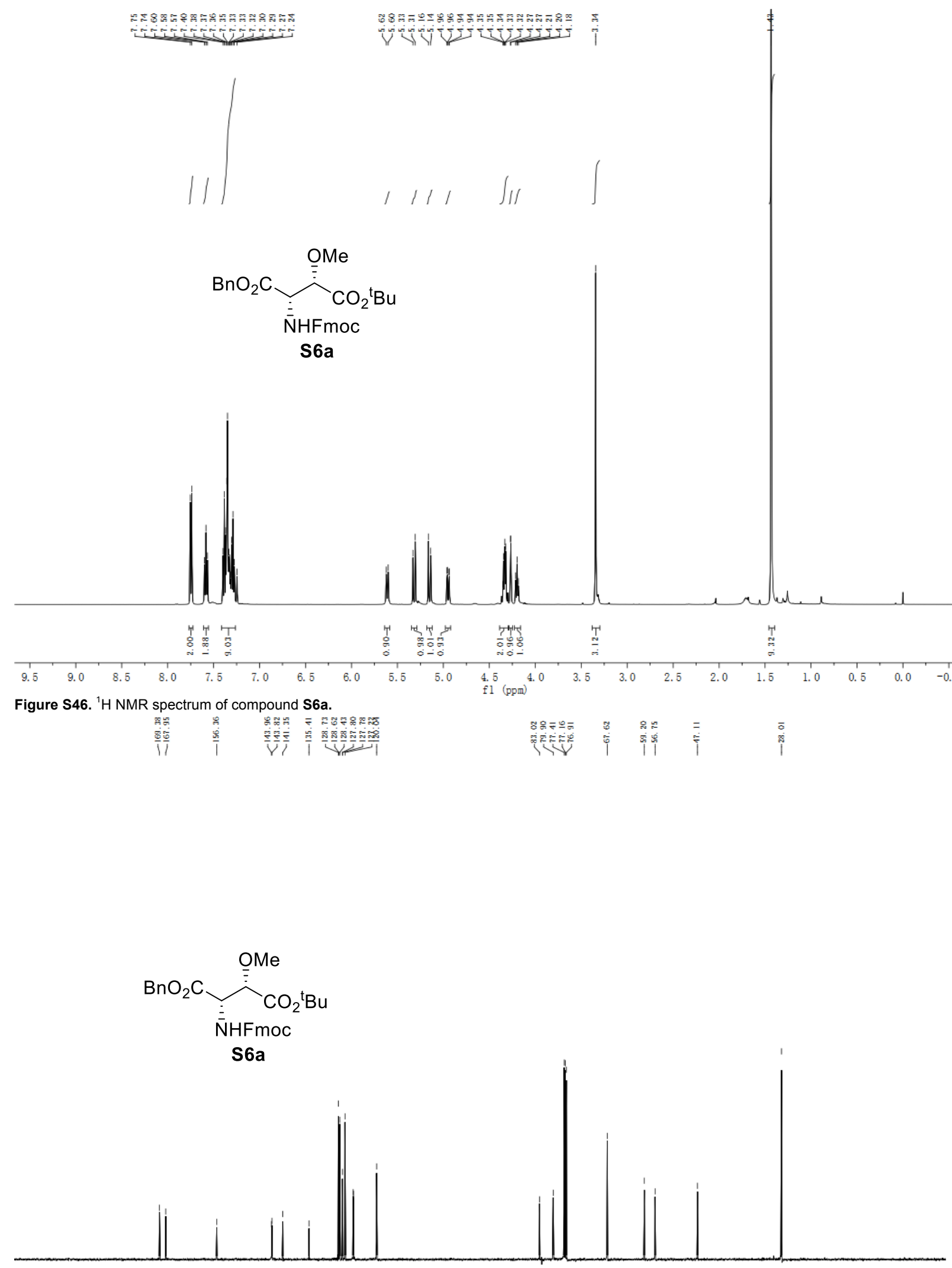

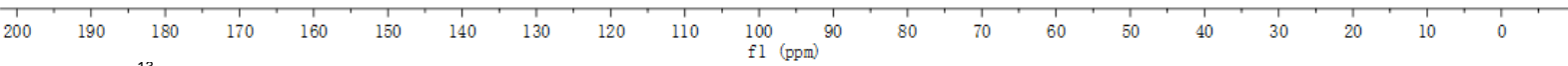

Figure S47. ${ }^{13} \mathrm{C}$ NMR spectrum of compound S6a. 
<smiles>C=C1C=CC1C</smiles><smiles>COC(OC)C(N=COC(=O)OCc1ccccc1)C(=O)OCc1ccccc1</smiles>

S6b

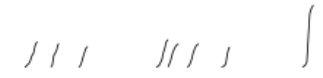




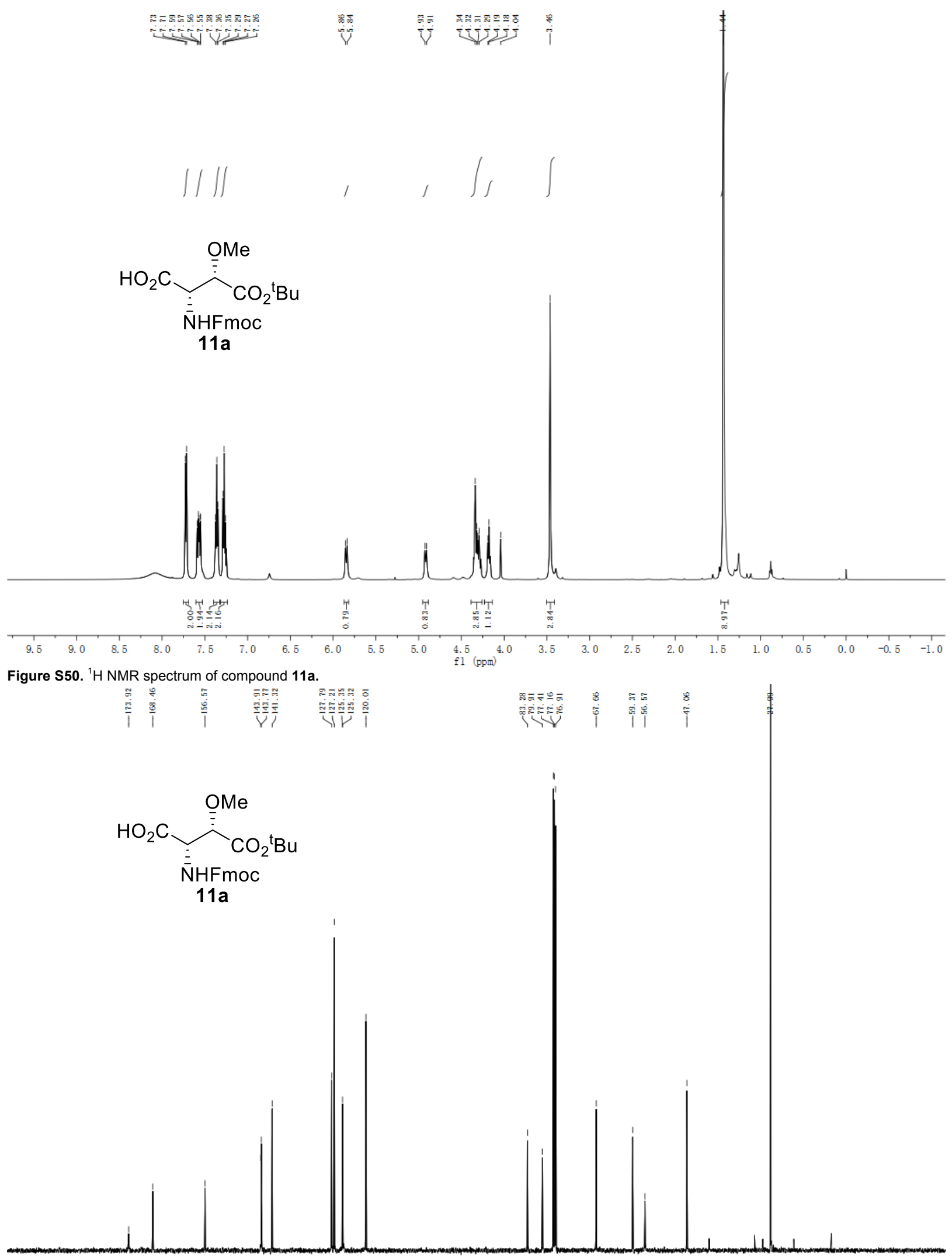

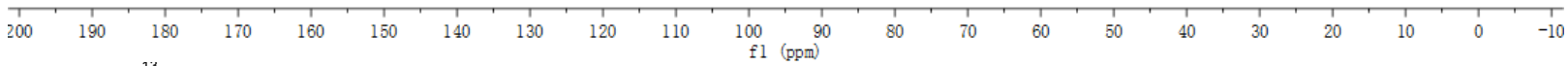

Figure S51. ${ }^{13} \mathrm{C}$ NMR spectrum of compound 11a. 
<smiles>CCOC(=O)C(N=COC)C(C(=O)O)C(=O)OC</smiles>

11b

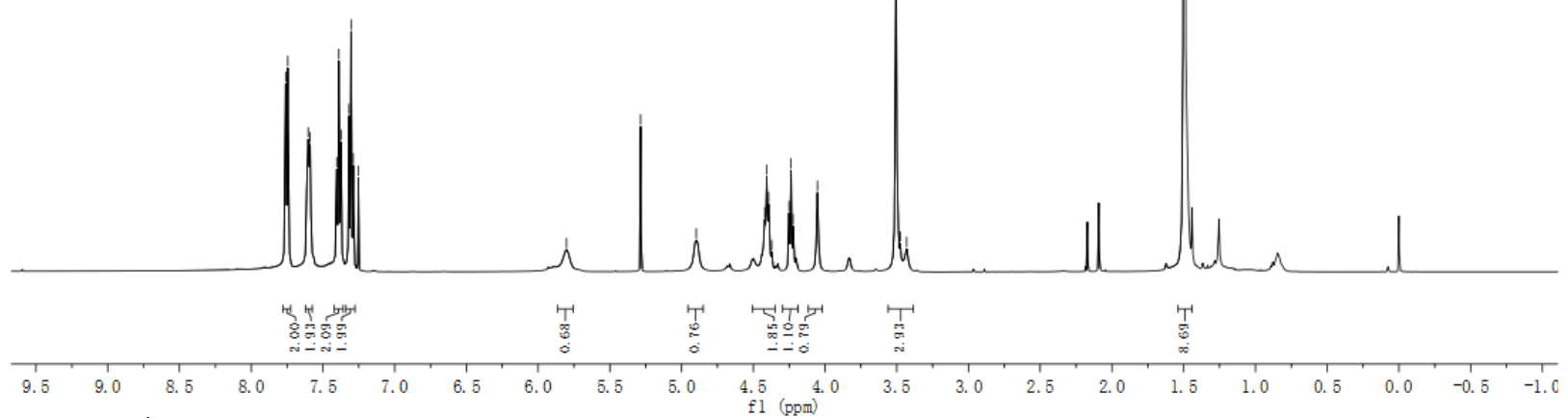

Figure S52. 'H NMR spectrum of compound 11b.
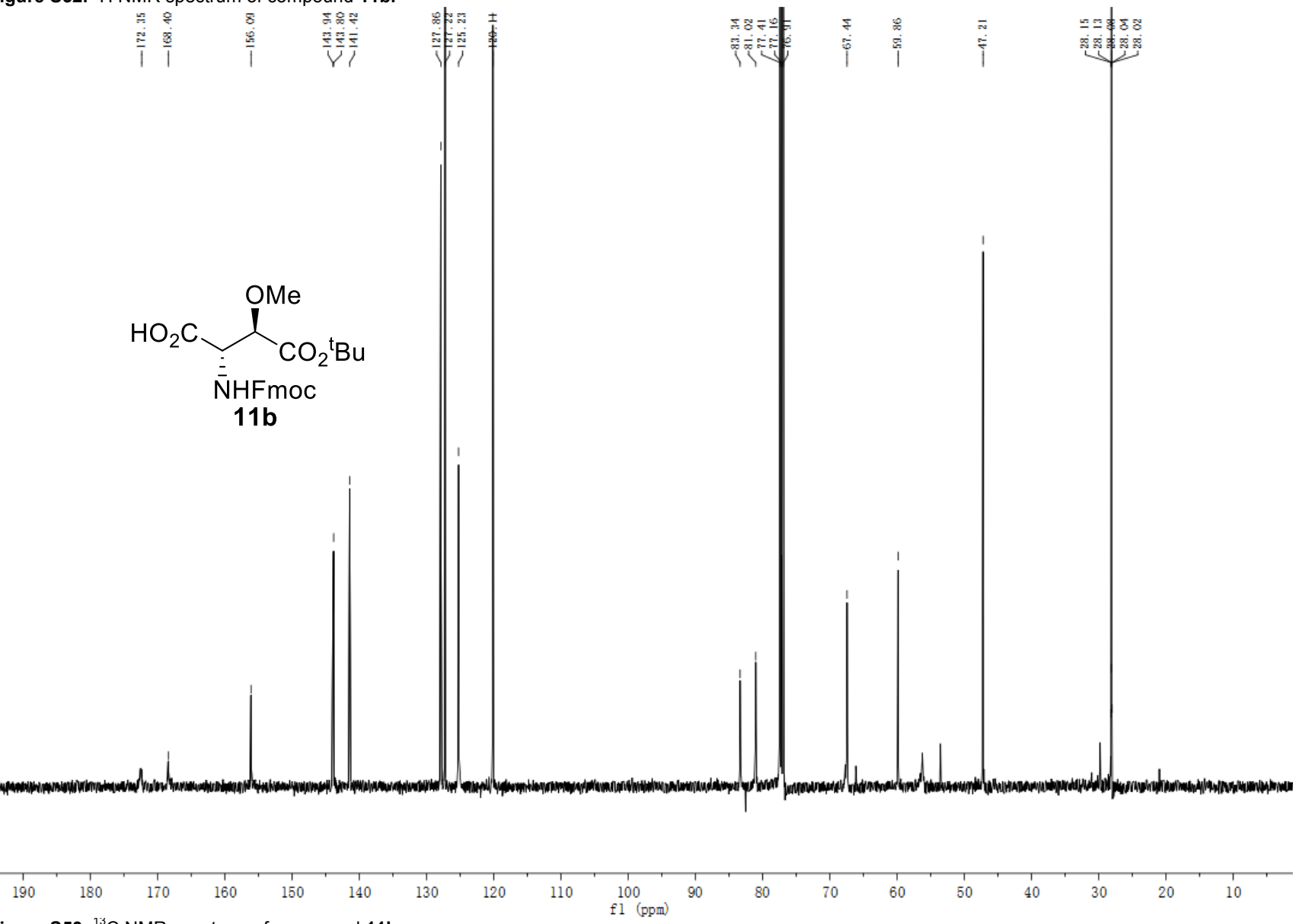

Figure S53. ${ }^{13} \mathrm{C}$ NMR spectrum of compound 11b. 


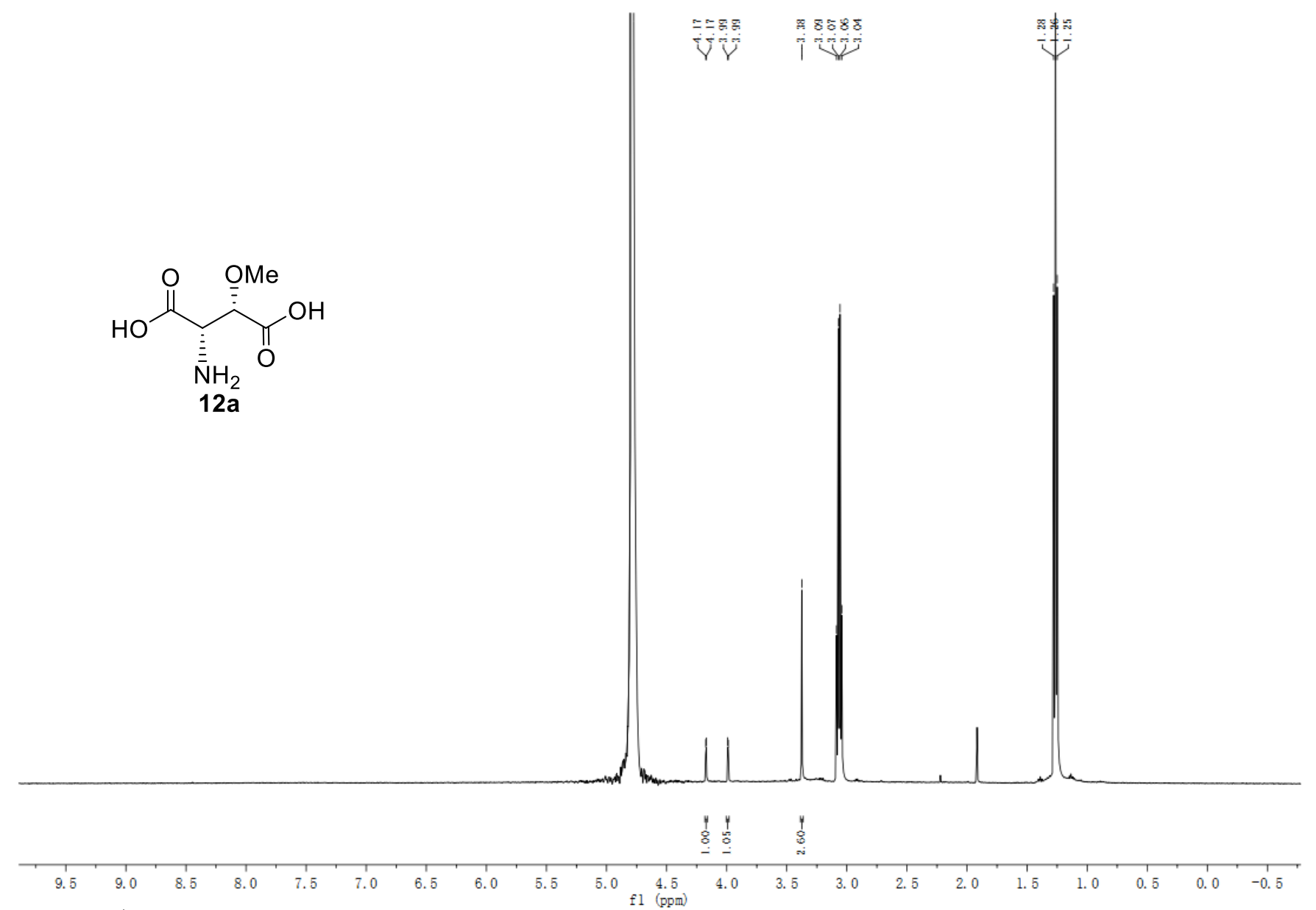

Figure S54. ${ }^{1} \mathrm{H}$ NMR spectrum of compound 12a.

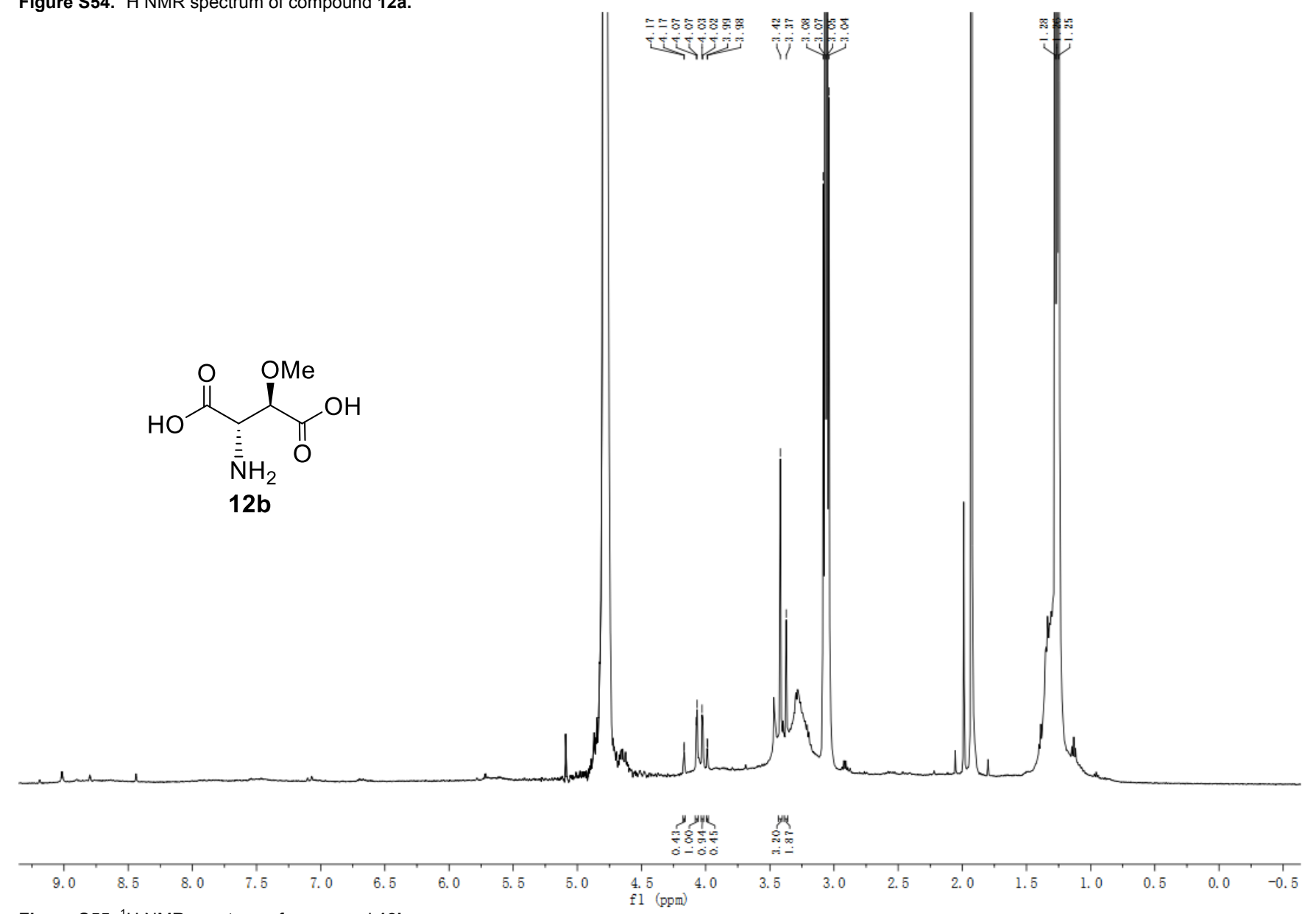

Figure S55. ${ }^{1} \mathrm{H}$ NMR spectrum of compound $\mathbf{1 2 b}$. 


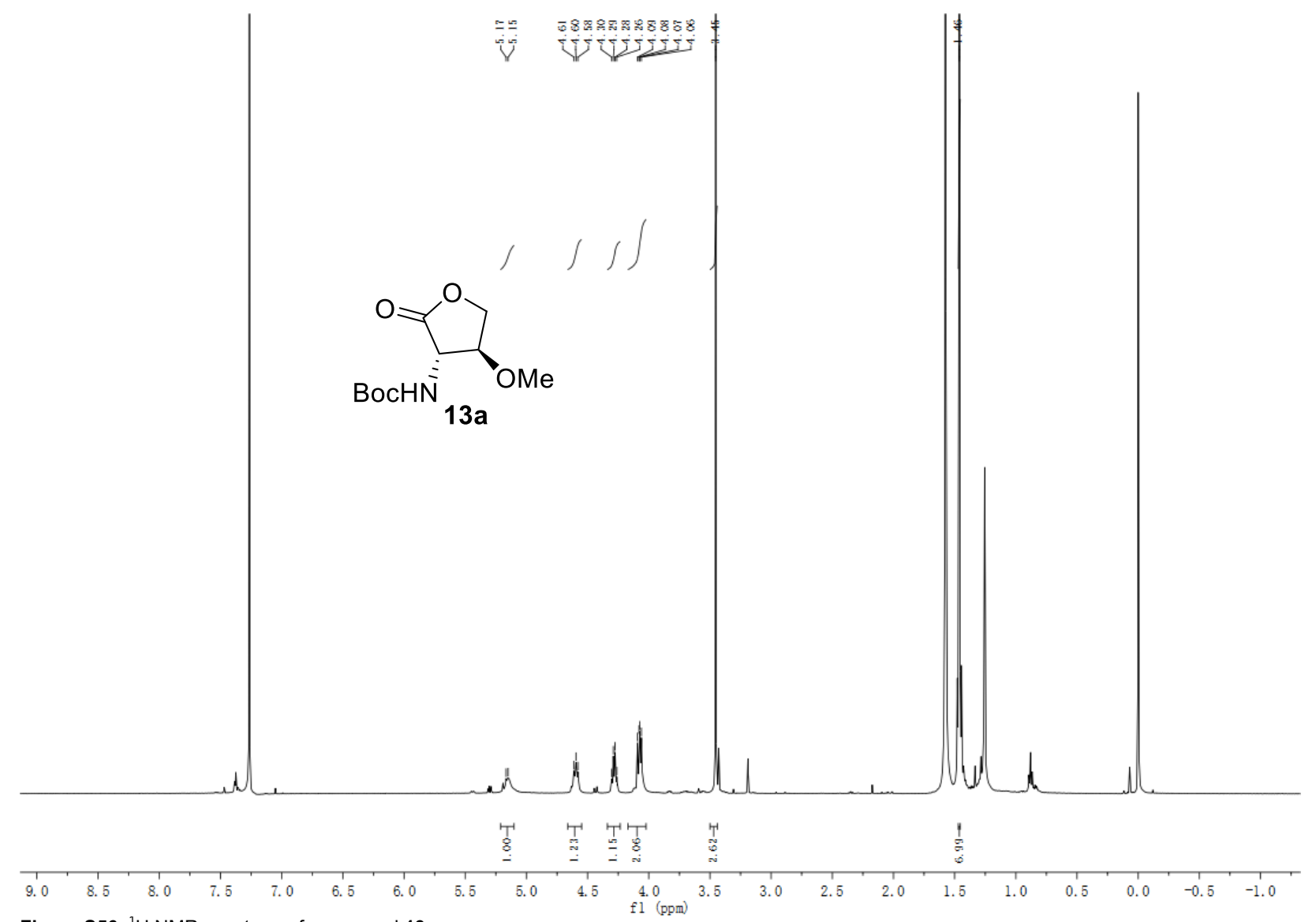

Figure S56. 'H NMR spectrum of compound 13a.
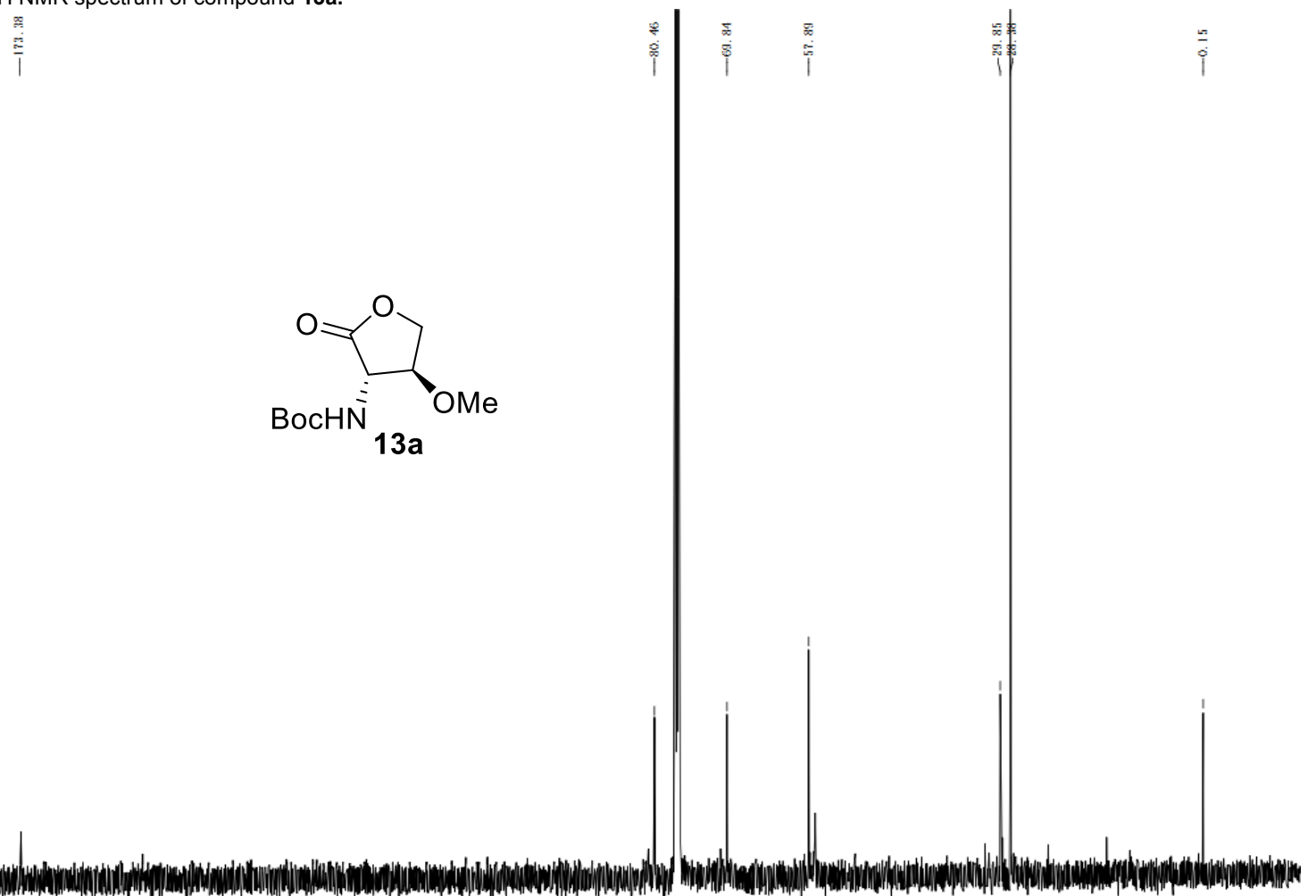

$\begin{array}{llllllll}190 & 180 & 170 & 160 & 150 & 140 & 130 & 120\end{array}$

Figure S57. ${ }^{13} \mathrm{C}$ NMR spectrum of compound 13a. 


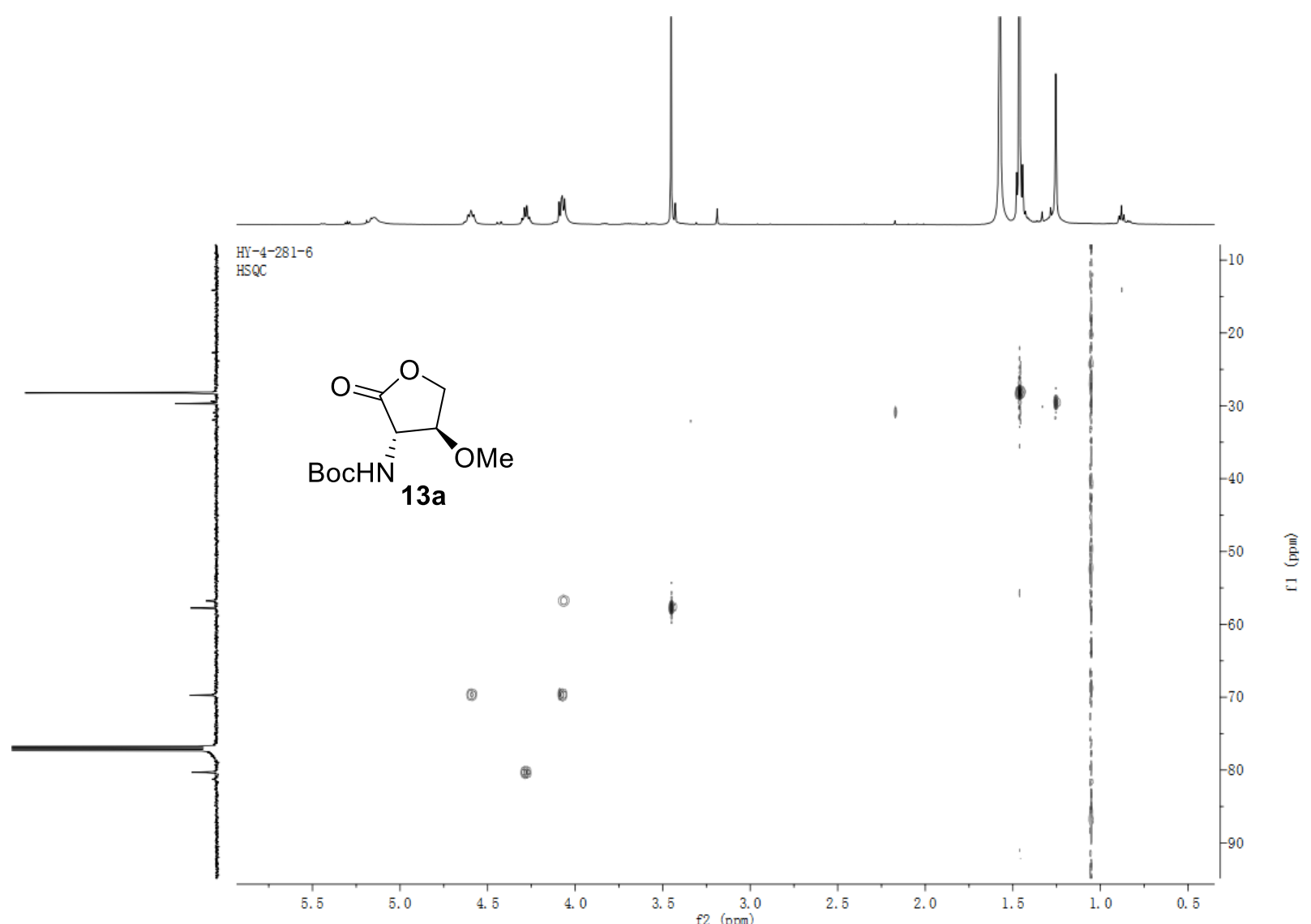

Figure S58. HSQC NMR spectrum of compound 13a.

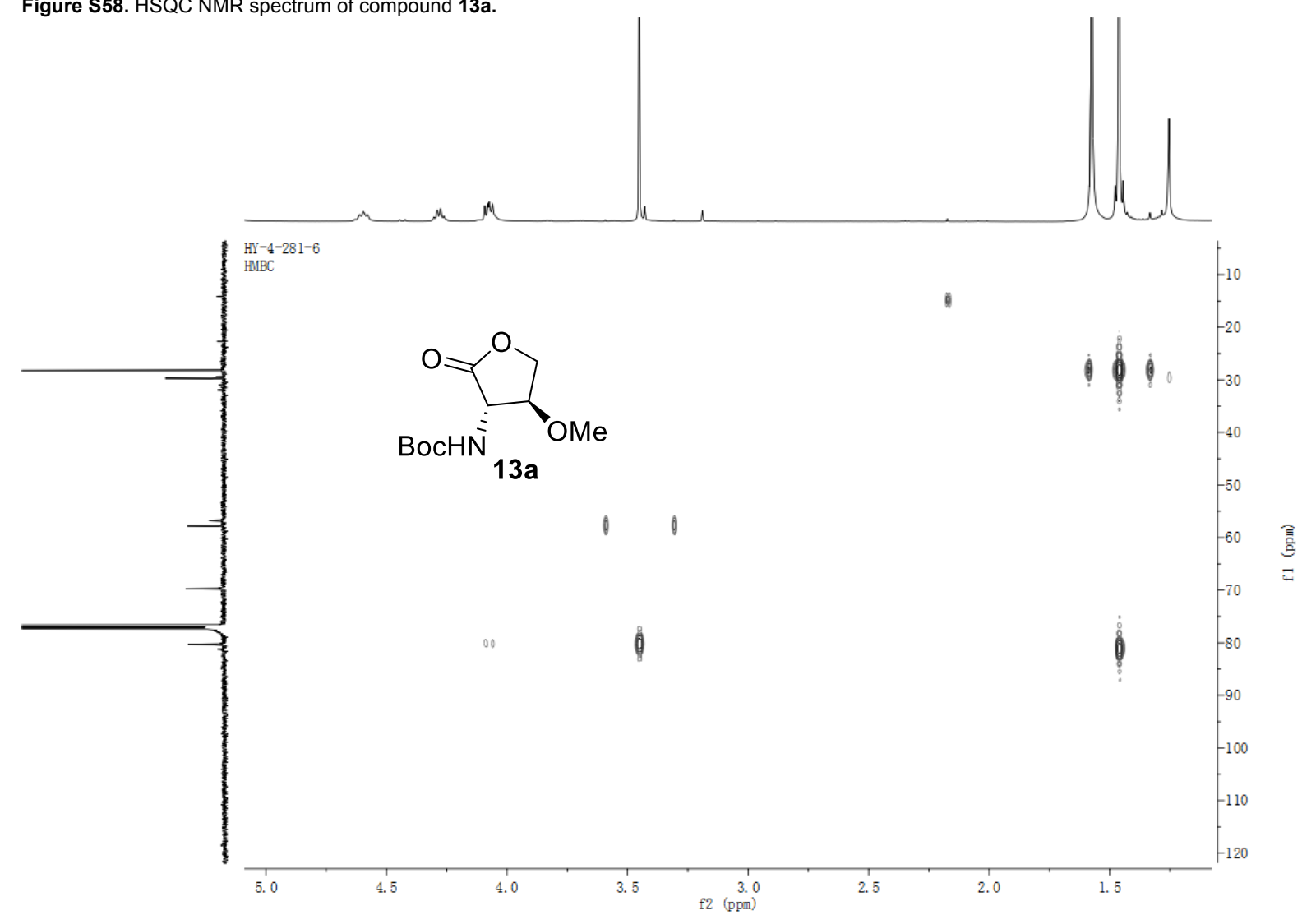

Figure S59. HMBC NMR spectrum of compound 13a. 


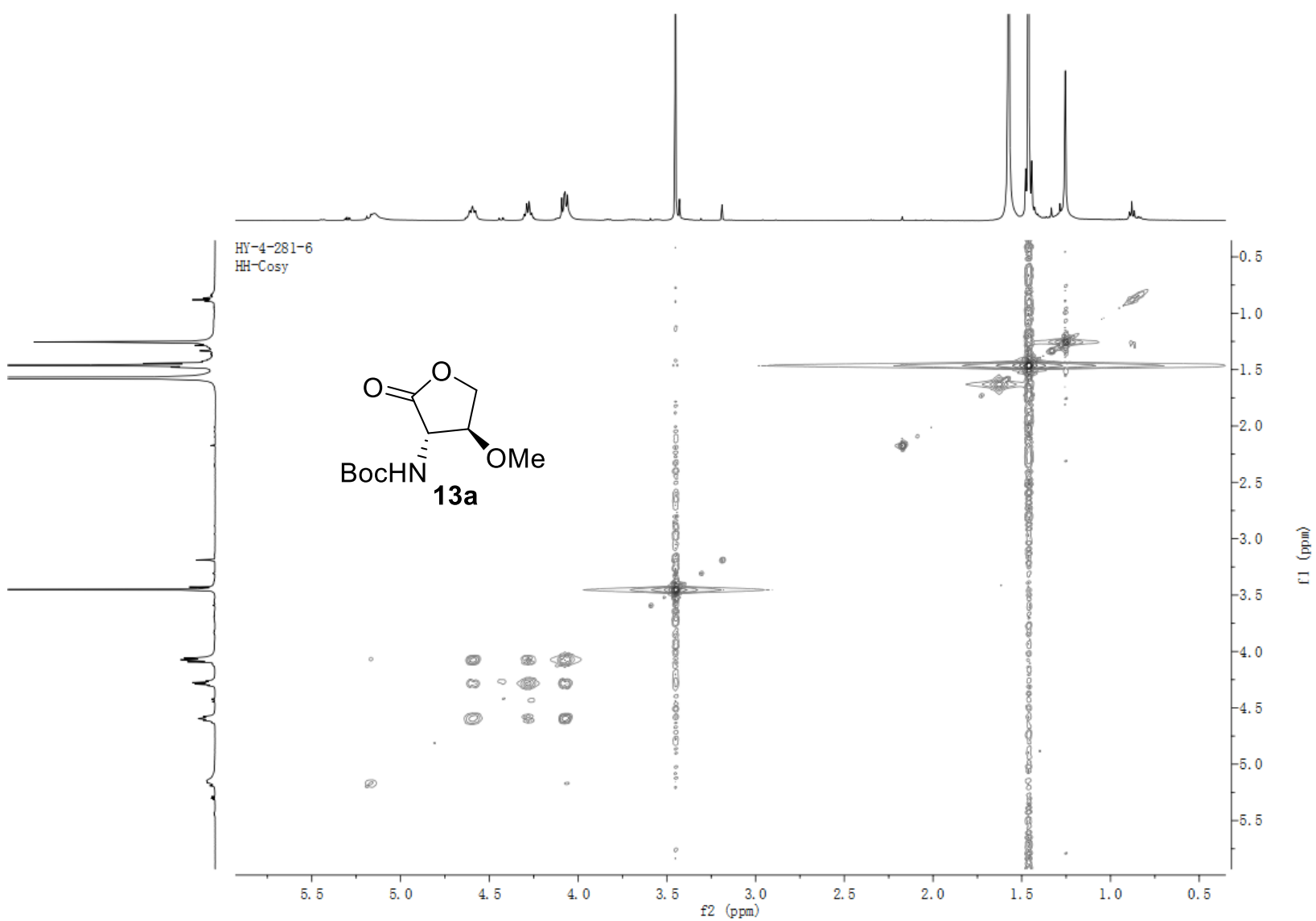

Figure S60. HH-COSY NMR spectrum of compound 13a.

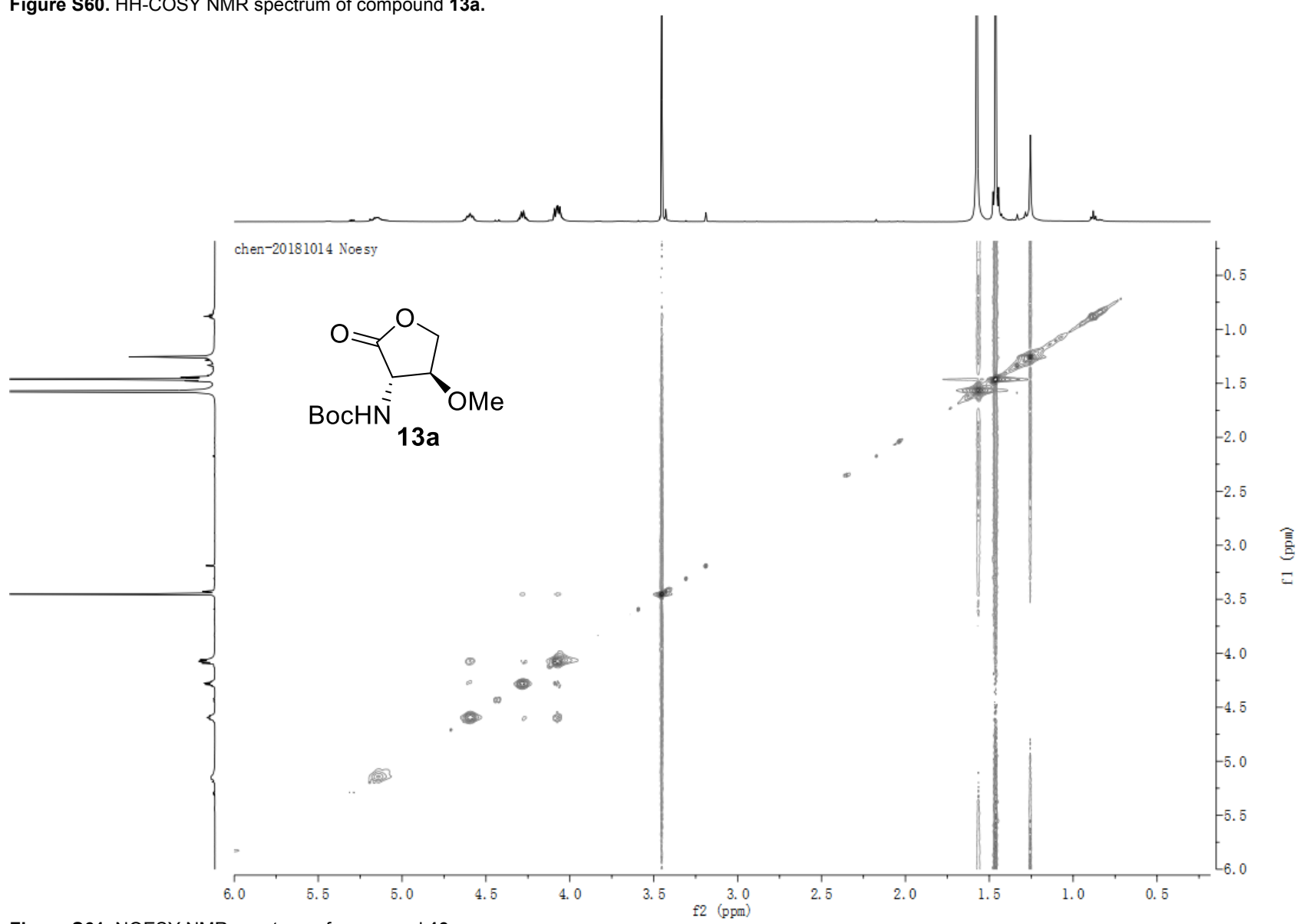

Figure S61. NOESY NMR spectrum of compound 13a. 


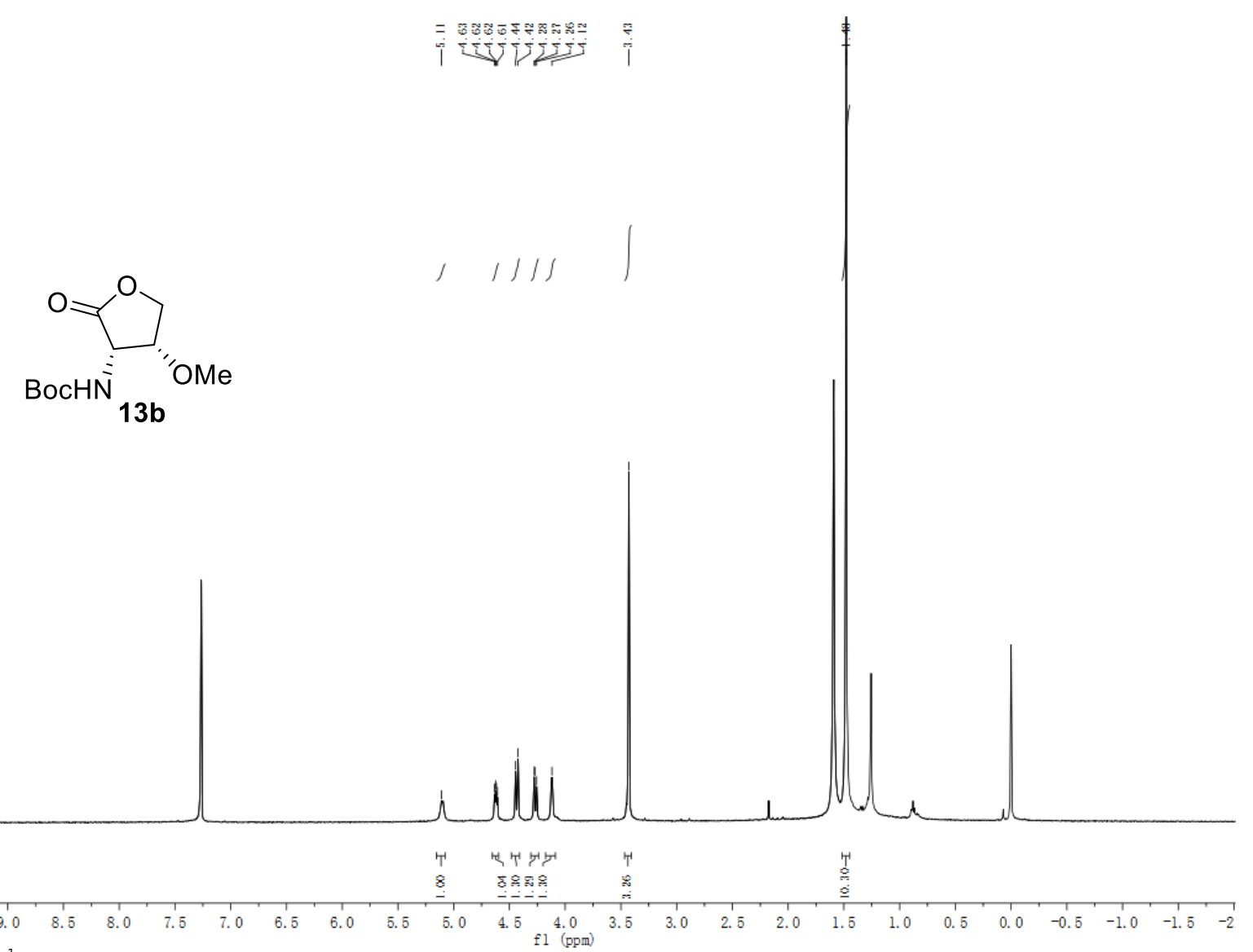

Figure S62. ${ }^{1} \mathrm{H}$ NMR spectrum of compound 13b

i

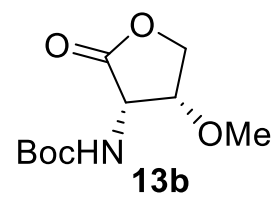

$13 b$

$\begin{array}{rllllll}\text { Figure S63. } & { }^{13} \mathrm{C} & \text { NMR spectrum of compound } & \mathbf{1 3 b}\end{array}$ 


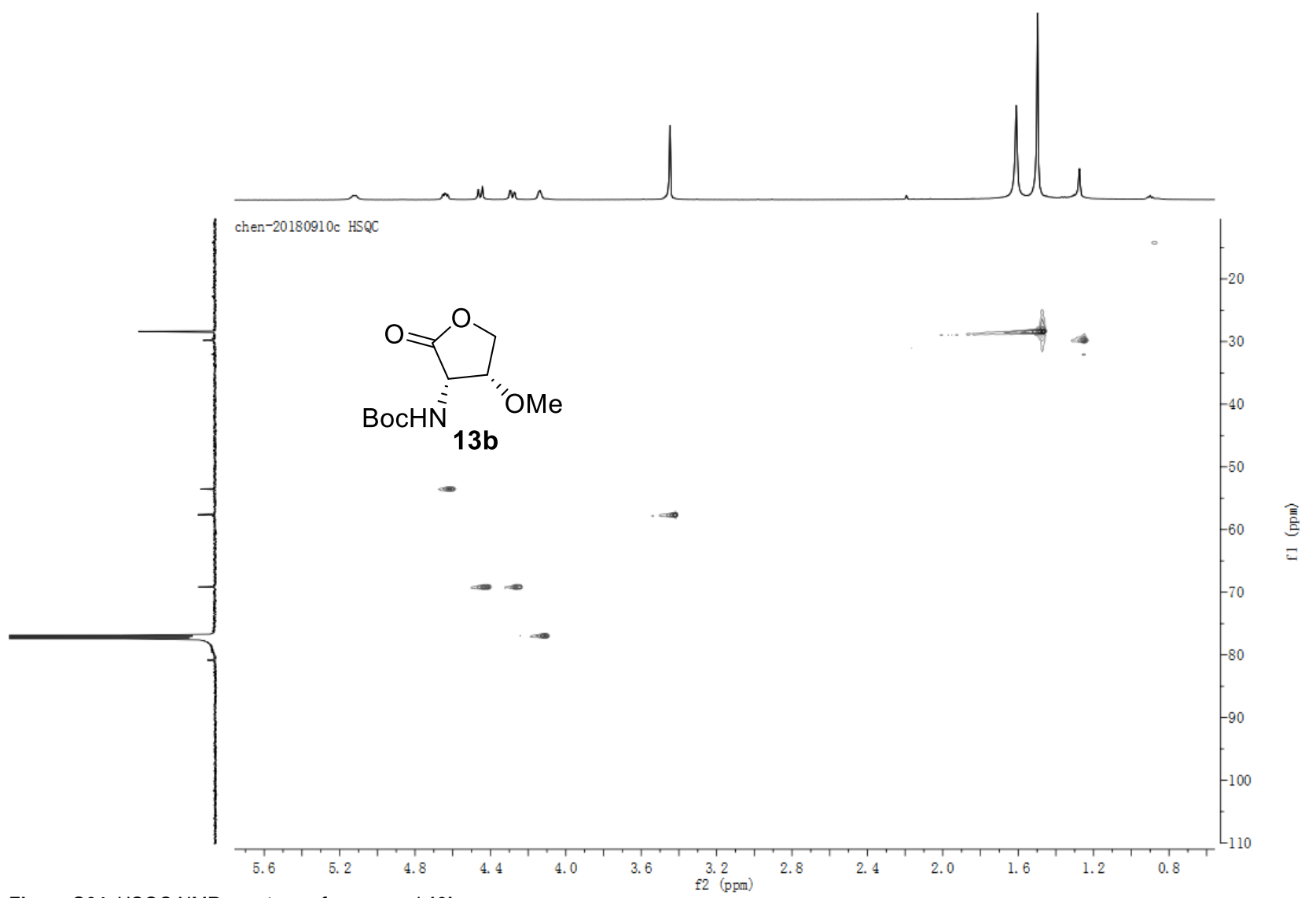

Figure S64. HSQC NMR spectrum of compound 13b.

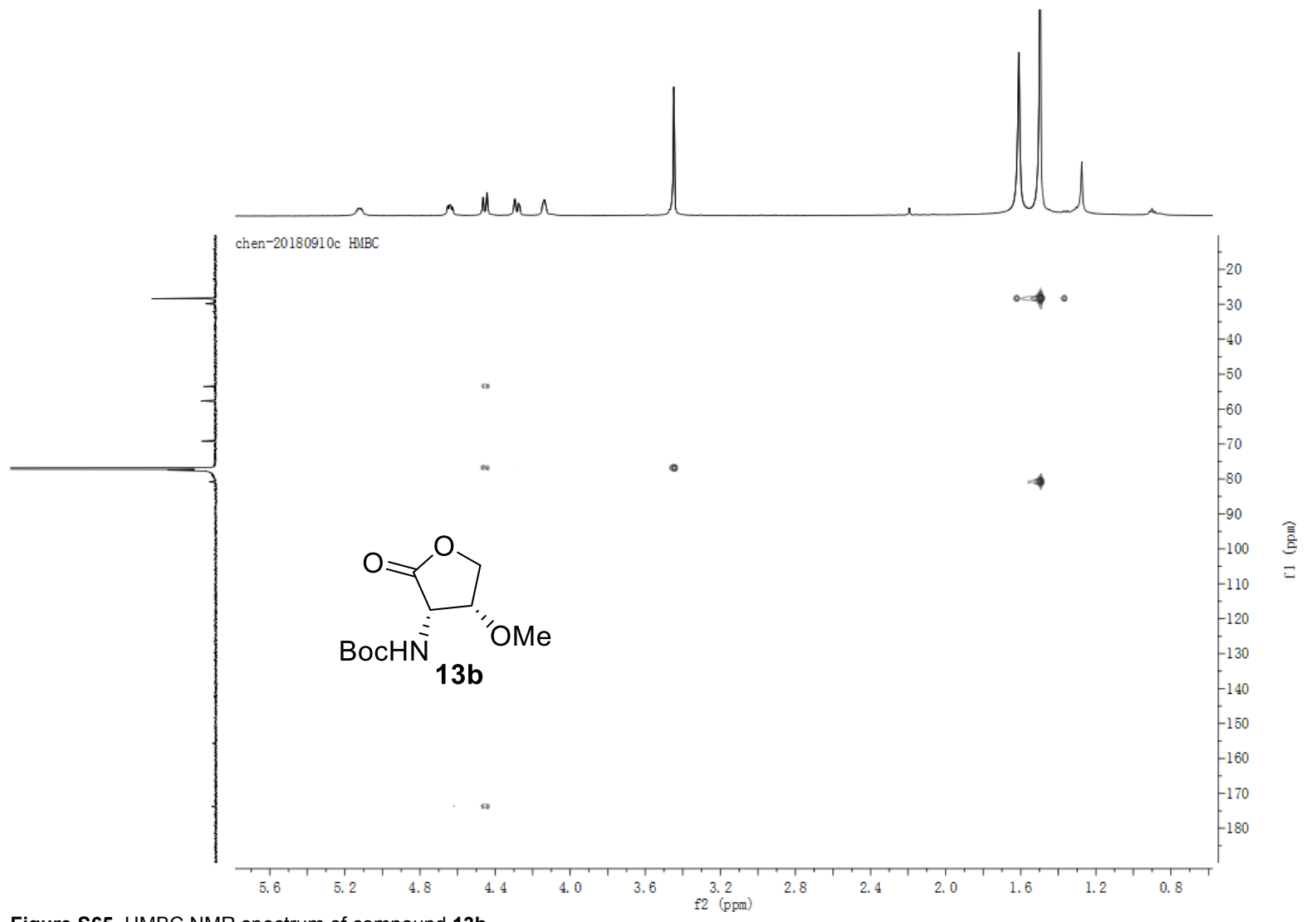

Figure S65. HMBC NMR spectrum of compound 13b. 


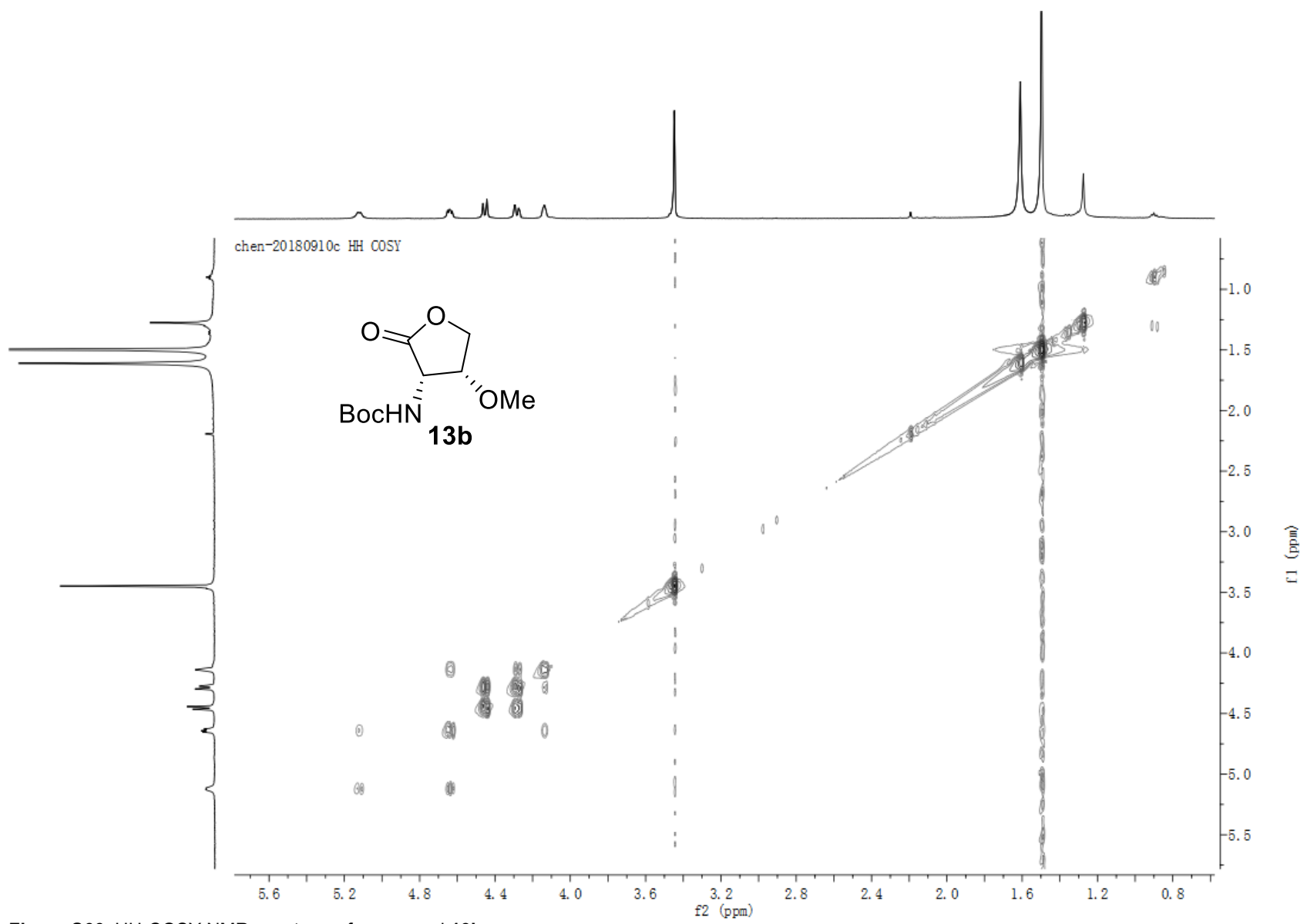

Figure S66. HH-COSY NMR spectrum of compound 13b.

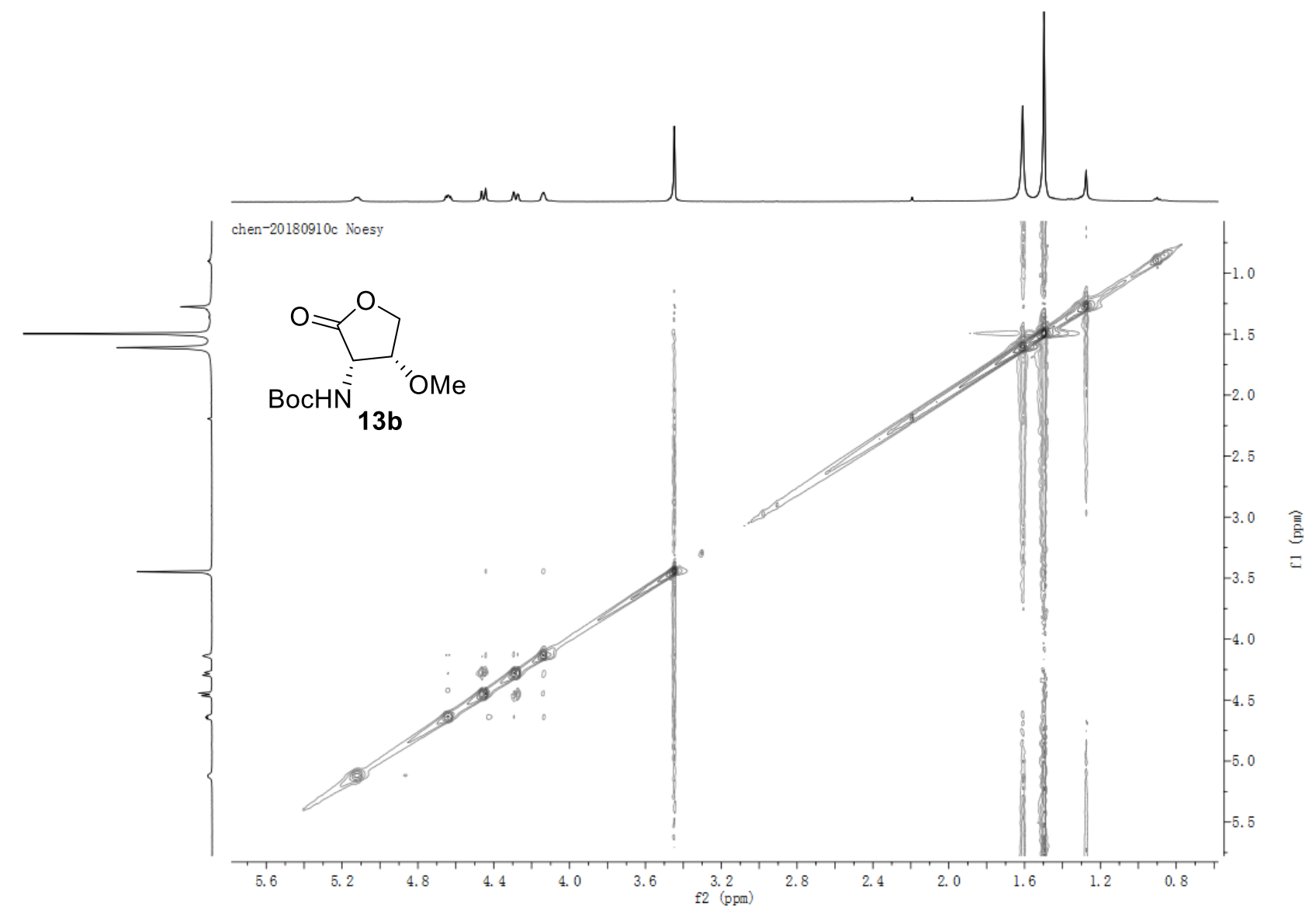

Figure S67. NOESY NMR spectrum of compound 13b. 


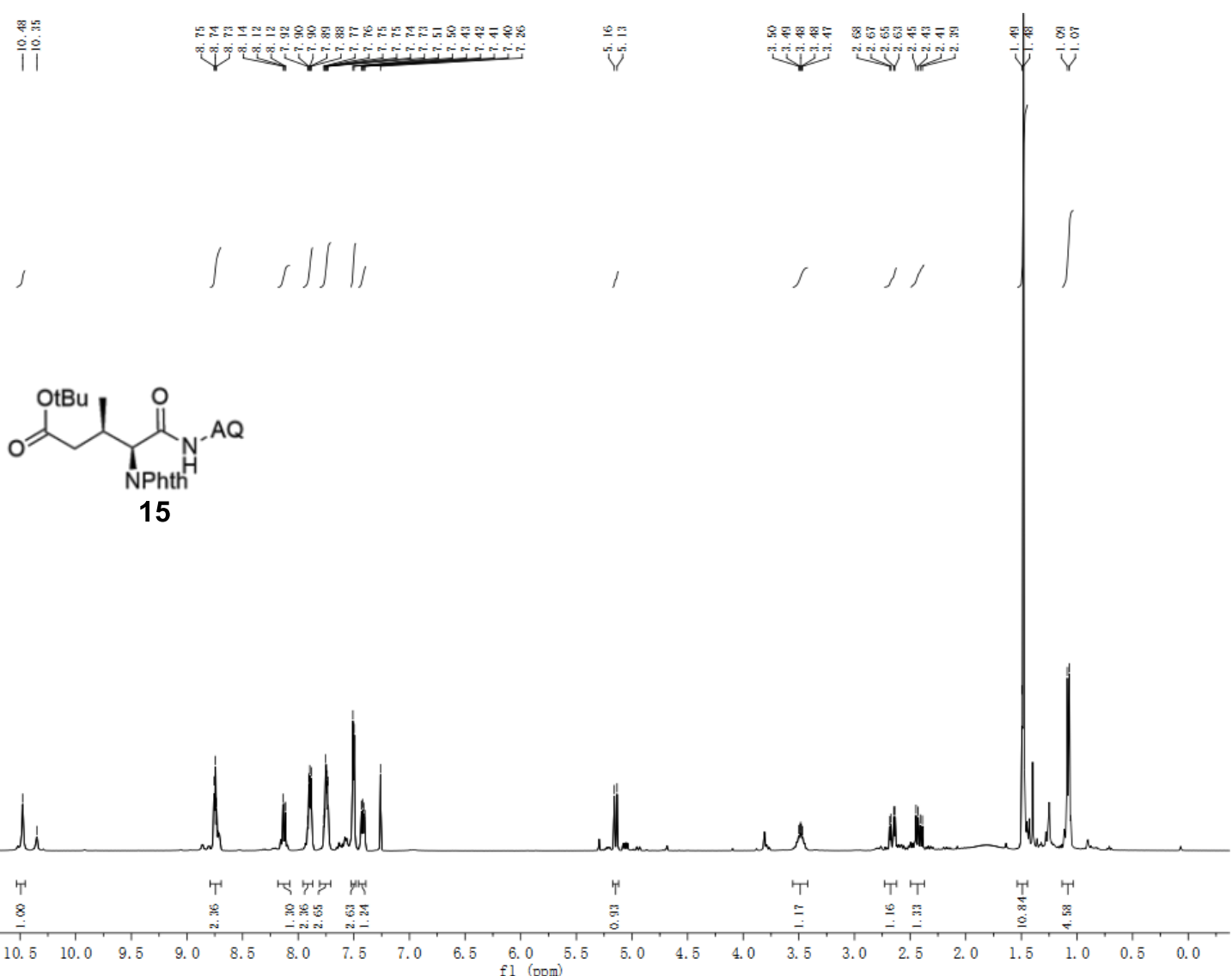

Figure S68. ${ }^{1} \mathrm{H}$ NMR spectrum of compound 15.

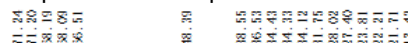

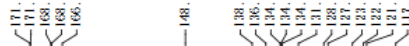

OtBu

15

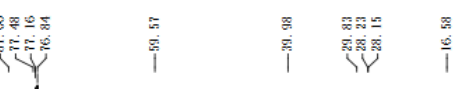

$\begin{array}{llllllllllll}200 & 190 & 180 & 170 & 160 & 150 & 140 & 130 & 120 & 110 & 100 & 90 \\ f 1 & (\mathrm{ppm})\end{array}$

Figure S69. ${ }^{13} \mathrm{C}$ NMR spectrum of compound 15. 

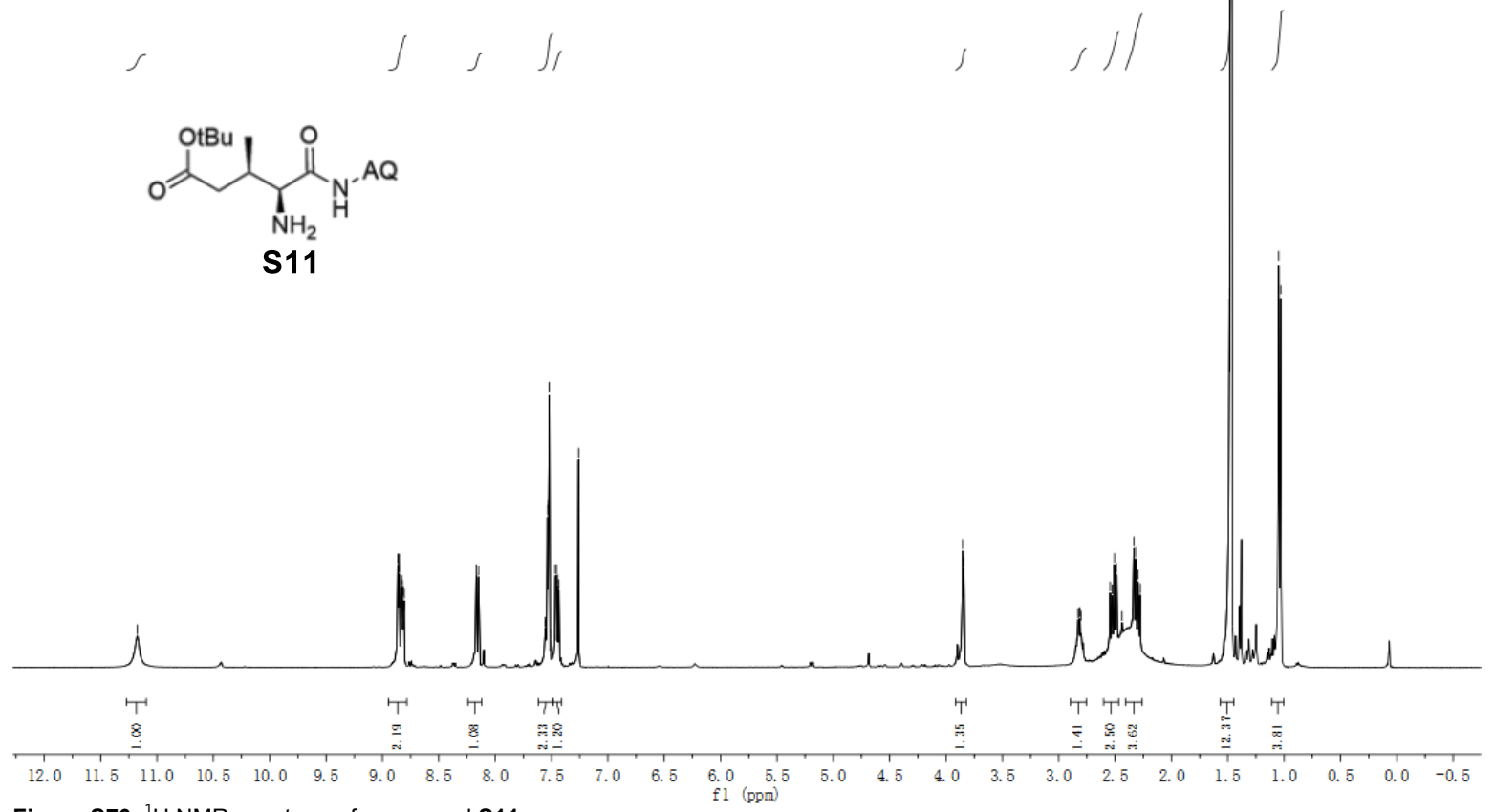

Figure S70. ${ }^{1} \mathrm{H}$ NMR spectrum of compound S11.

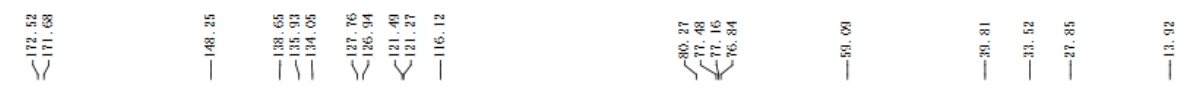<smiles>CC(CC(=O)O)C(N)C(=O)NN=O</smiles>

S11

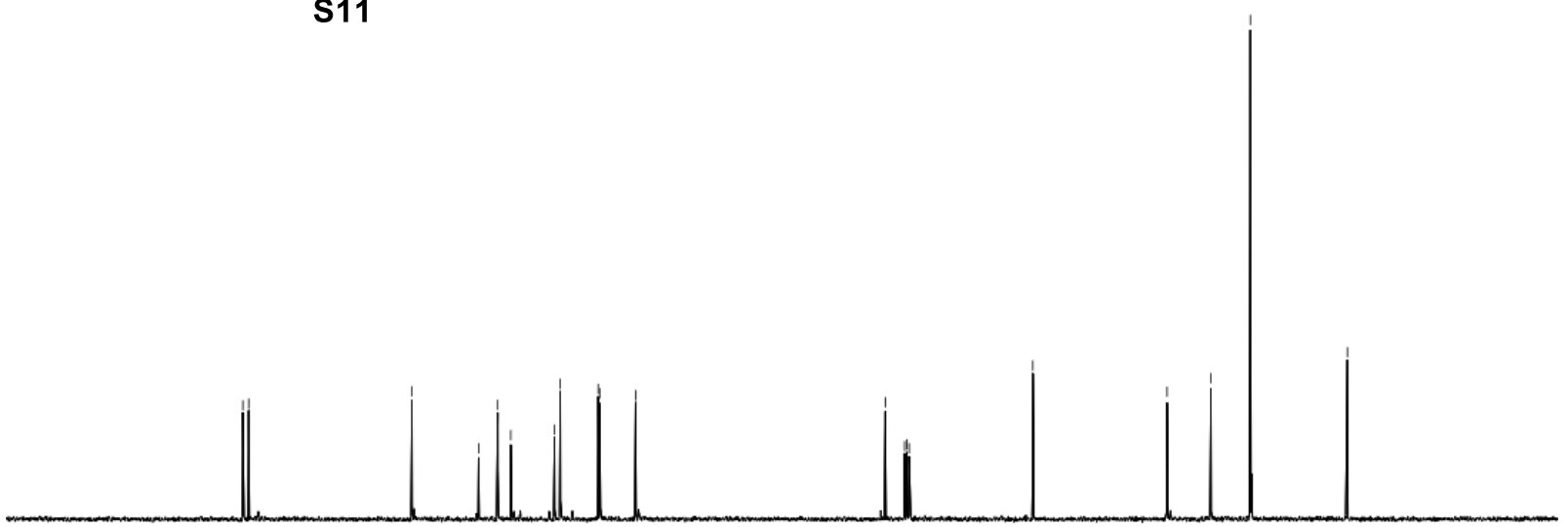

$\begin{array}{lllllllllll}200 & 190 & 180 & 170 & 160 & 150 & 140 & 130 & 120 & 110 & 100 \\ f 1 & (\mathrm{ppm})\end{array}$

Figure S71. ${ }^{13} \mathrm{C}$ NMR spectrum of compound S11. 


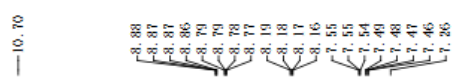

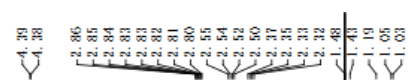

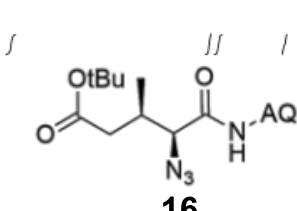

$\iiint$

16

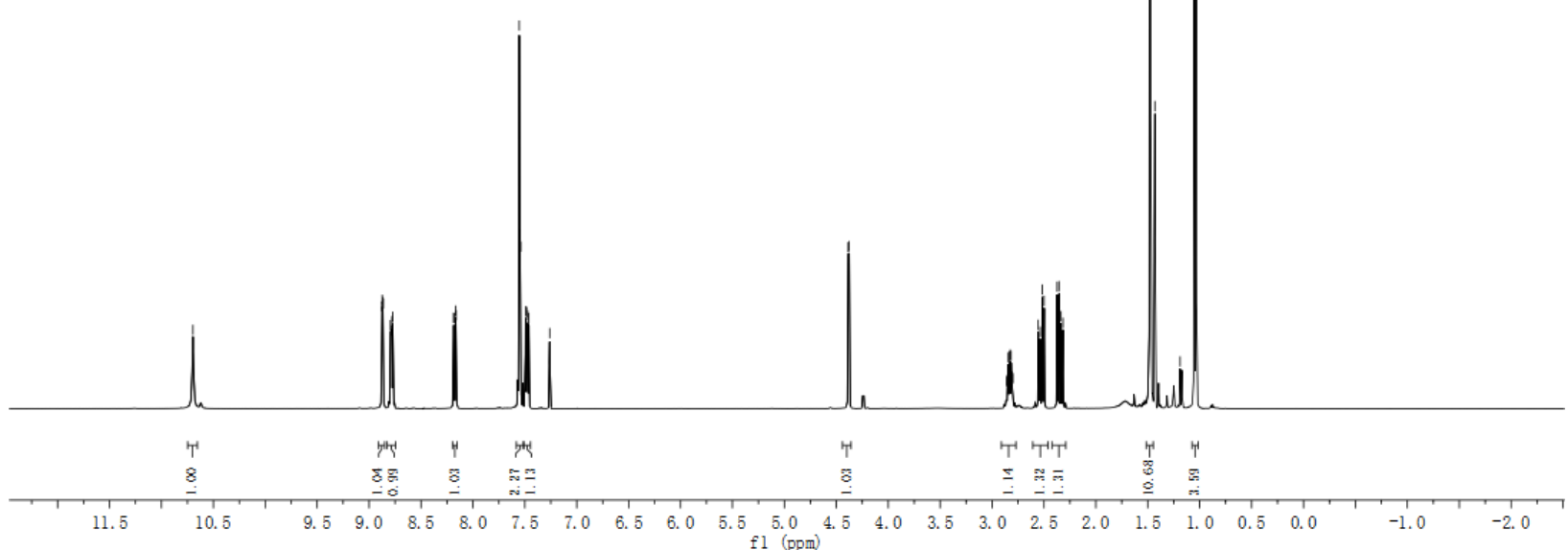

Figure S72. ${ }^{7} \mathrm{H}$ NMR spectrum of compound 16

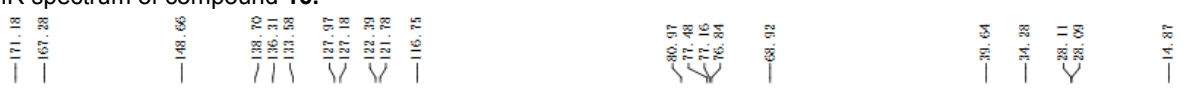

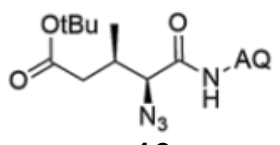

16

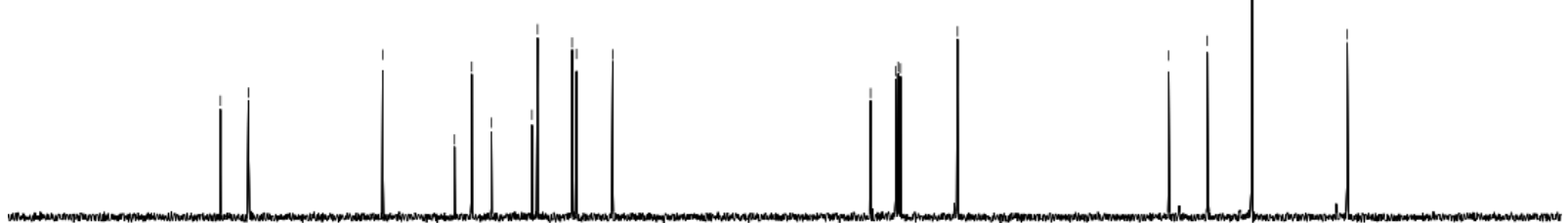

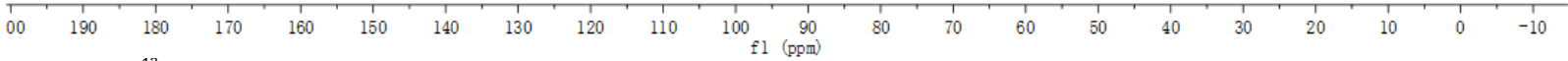

Figure S73. ${ }^{13} \mathrm{C}$ NMR spectrum of compound 16. 


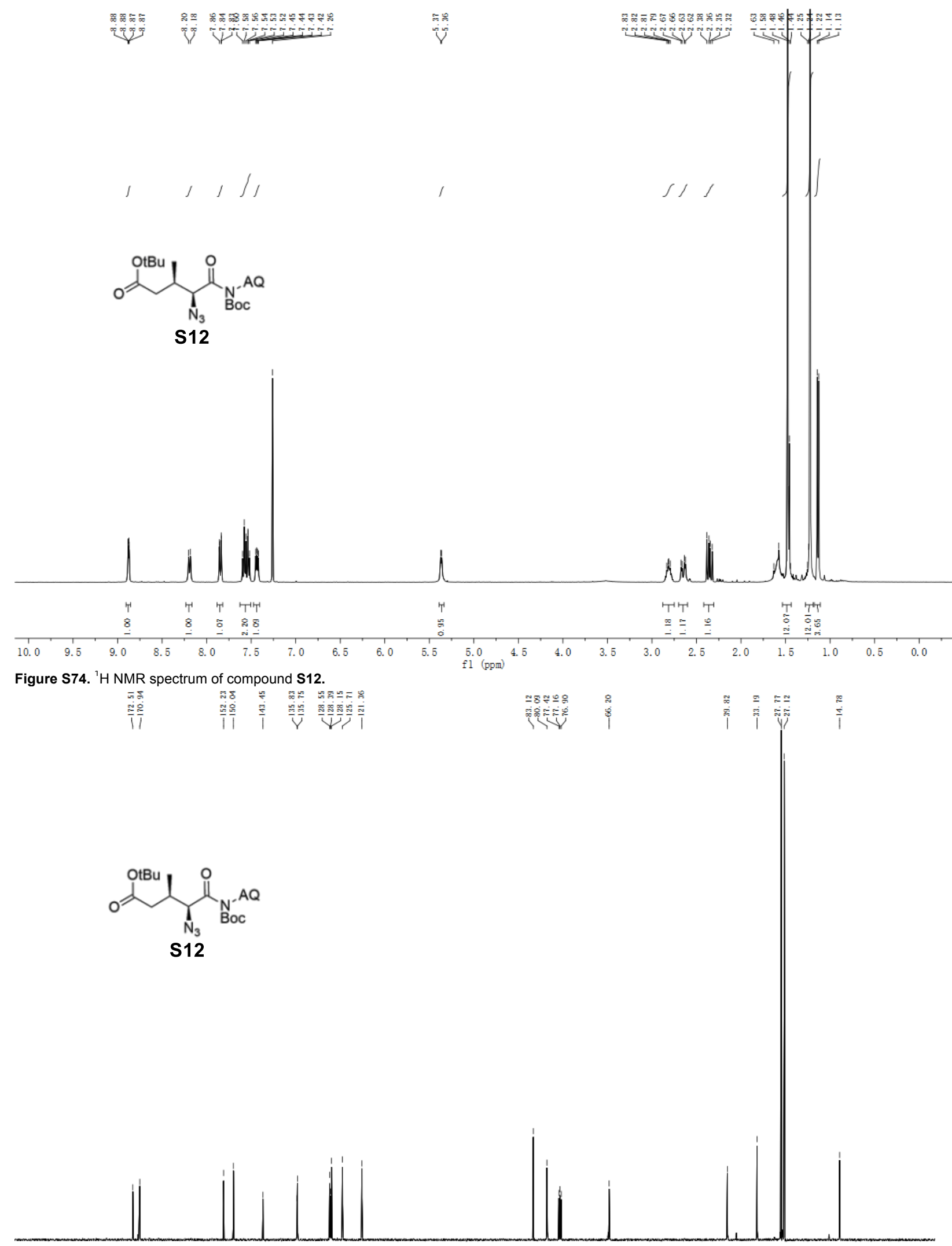

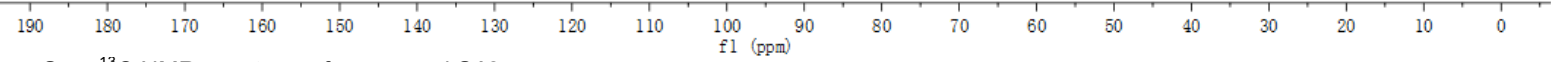

Figure S75. ${ }^{13} \mathrm{C}$ NMR spectrum of compound S12. 


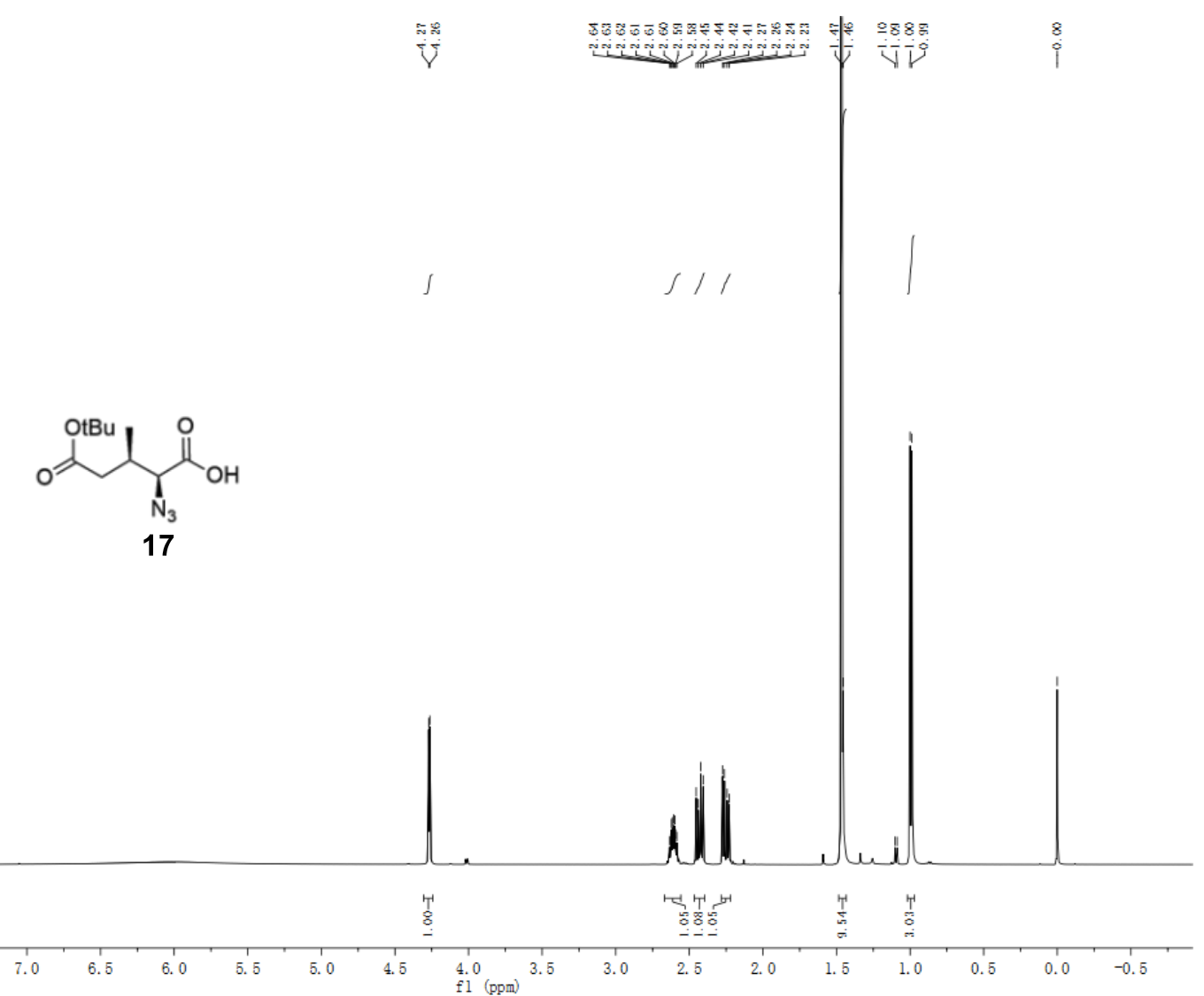

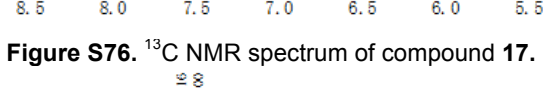

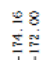

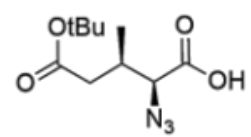

17

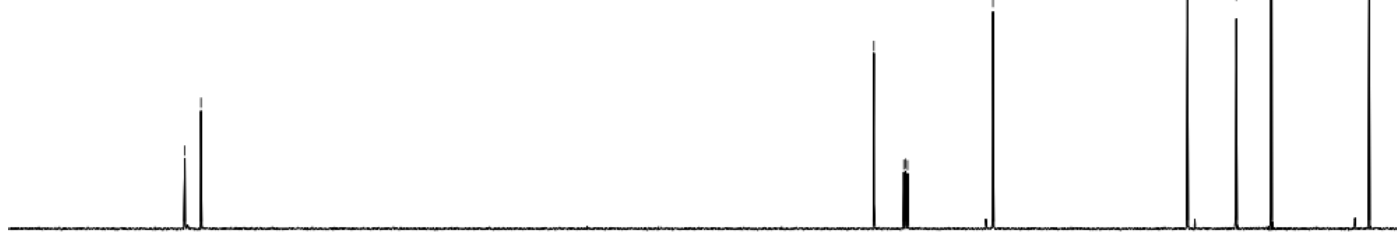

$\begin{array}{lllllll}190 & 180 & 170 & 160 & 150 & 140 & 130\end{array}$

Figure S77. ${ }^{13} \mathrm{C}$ NMR spectrum of compound 17. 


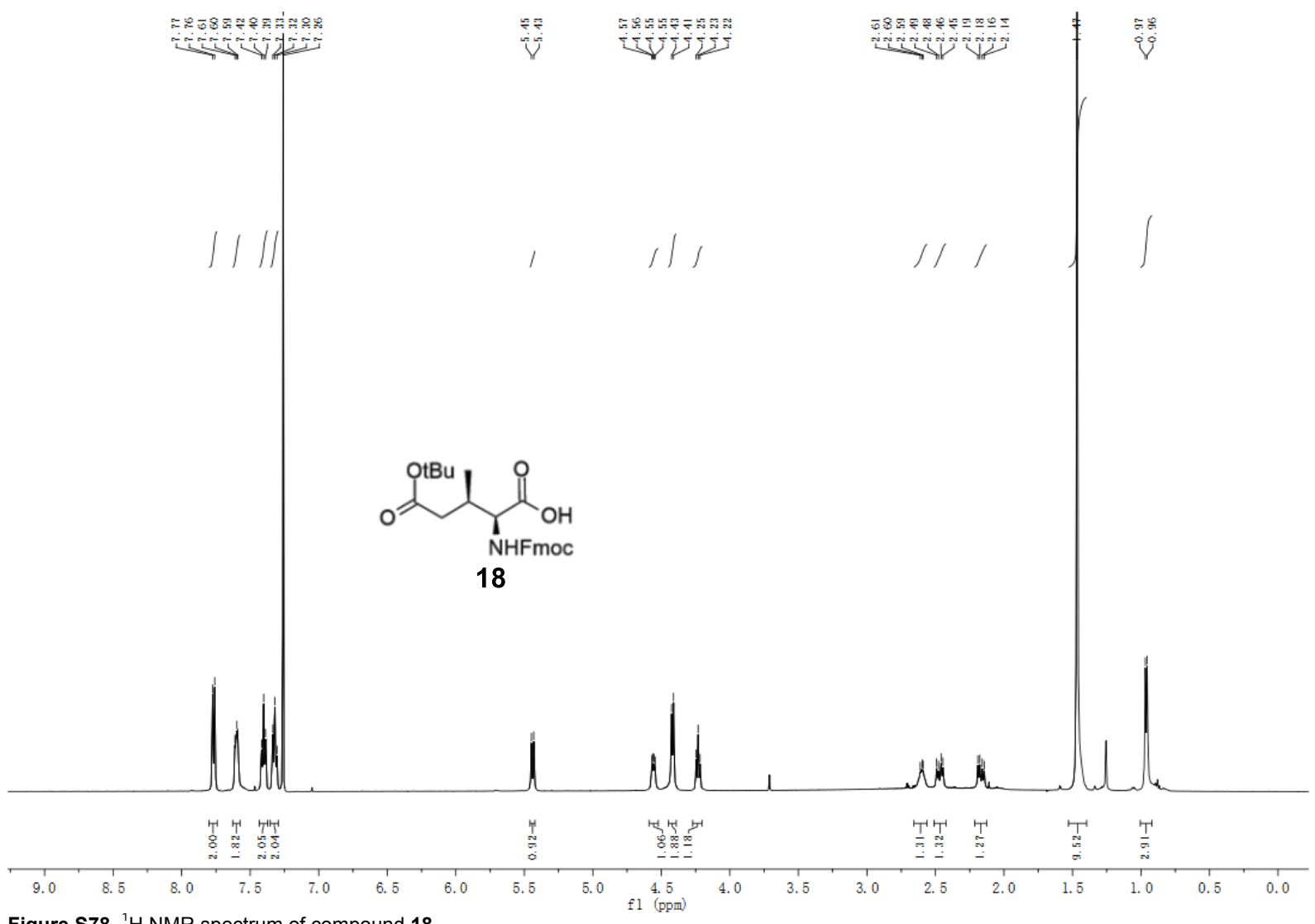

Figure S78. 'H NMR spectrum of compound 18.

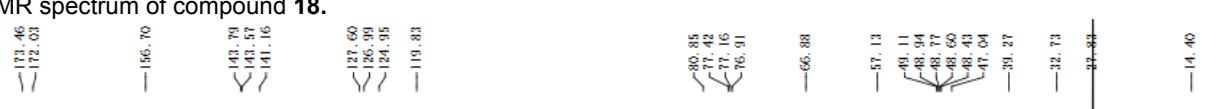
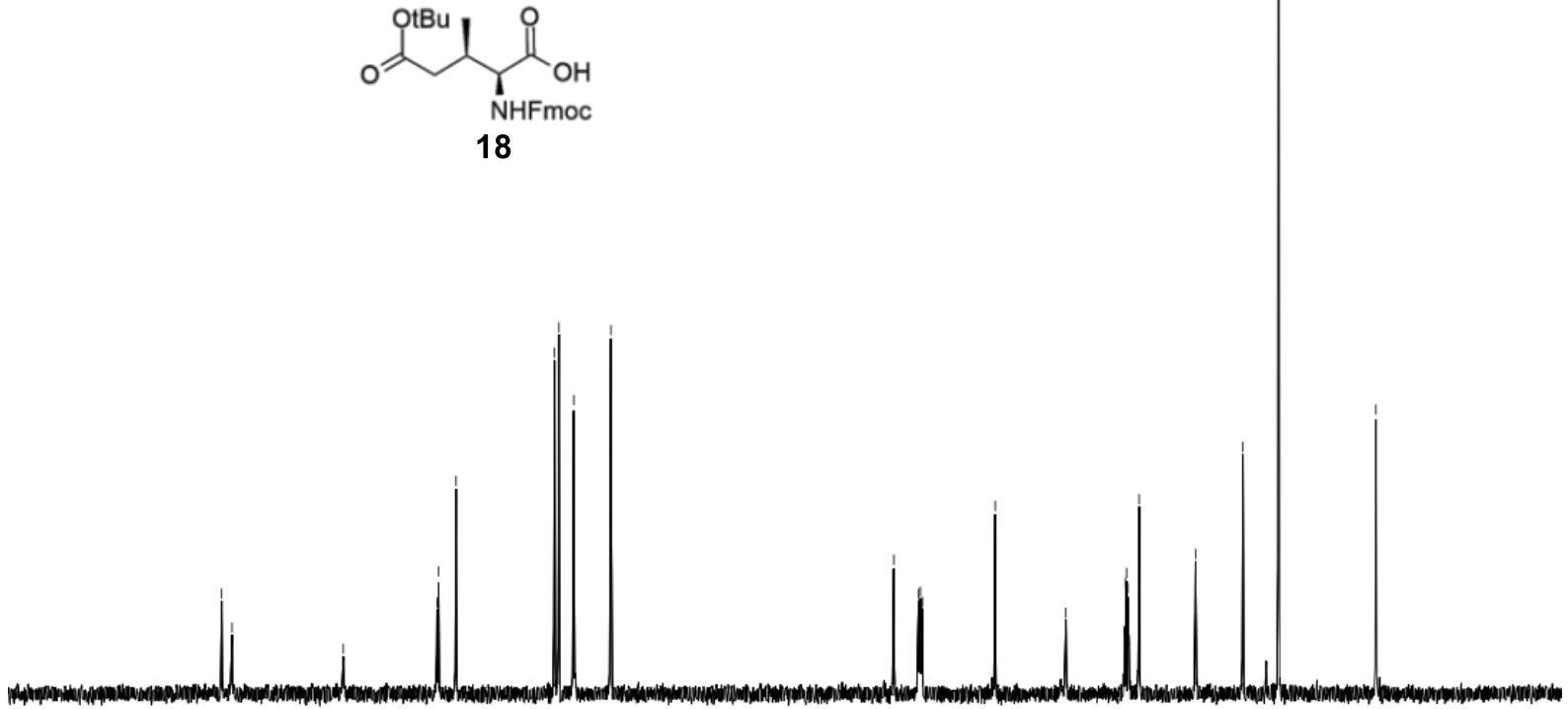

$\begin{array}{llllllll}200 & 190 & 180 & 170 & 160 & 150 & 140 & 130\end{array}$

Figure S79. ${ }^{13} \mathrm{C}$ NMR spectrum of compound 18. 


\section{$7.2^{1} \mathrm{H}$ NMR spectra of synthetic A54145 factors and analogues}

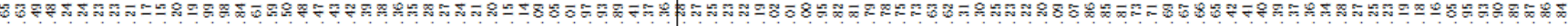

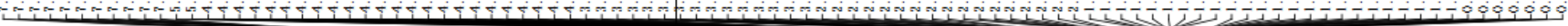
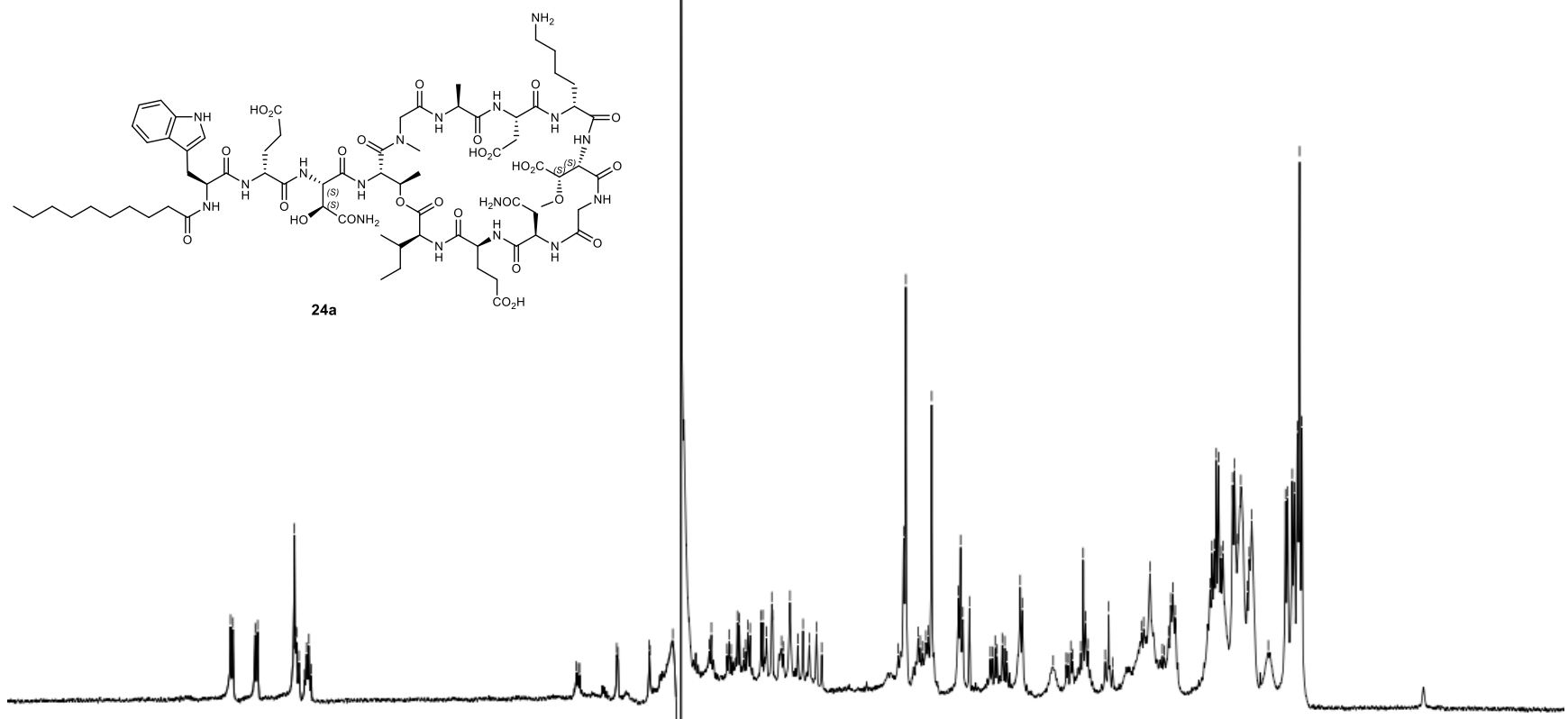

$4 \quad$ Tht

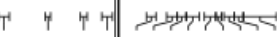

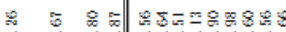

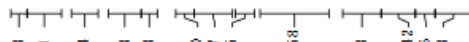

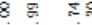

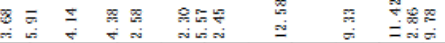

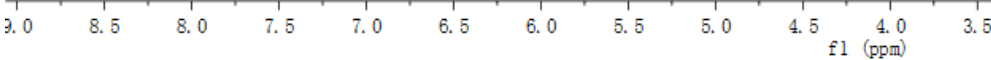

Figure S80. ${ }^{1} \mathrm{H}$ NMR spectrum of compound 24a dissolved in PBS buffer $\mathrm{pH} 7.4$ in $\mathrm{D}_{2} \mathrm{O}$ with a concentration $\sim 1 \mathrm{mg} / \mathrm{mL}$. 


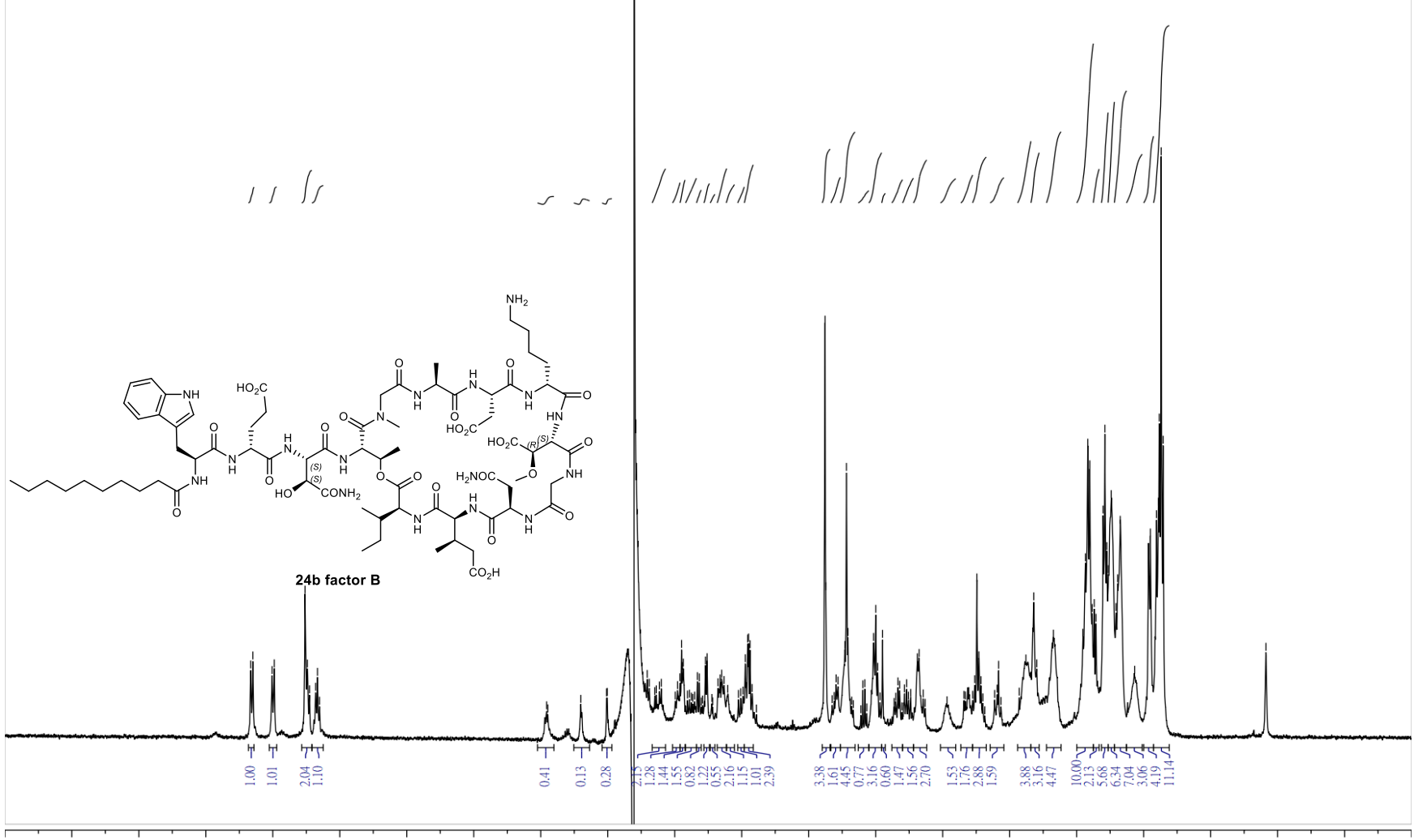

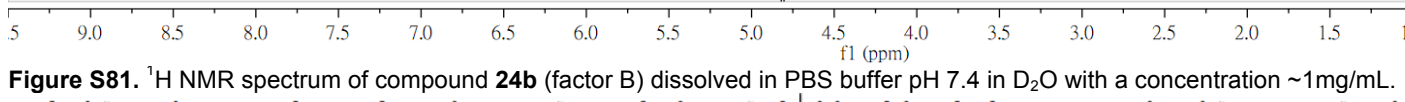

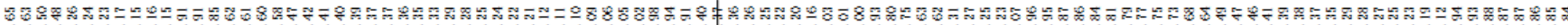

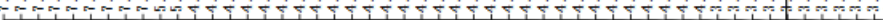

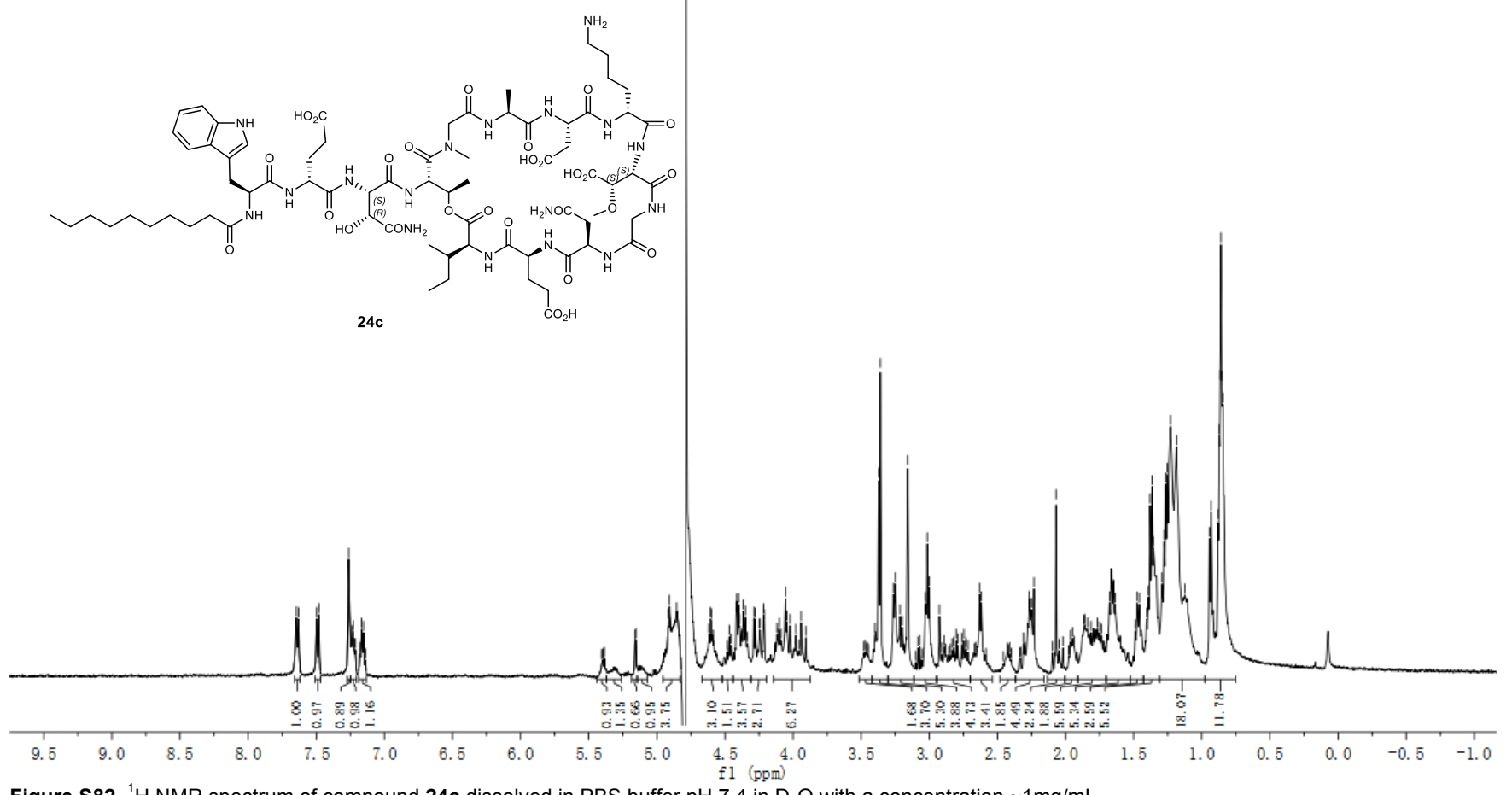

Figure S82. ${ }^{1} \mathrm{H}$ NMR spectrum of compound $24 \mathrm{c}$ dissolved in PBS buffer $\mathrm{pH} 7.4$ in $\mathrm{D}_{2} \mathrm{O}$ with a concentration $\sim 1 \mathrm{mg} / \mathrm{mL}$. 


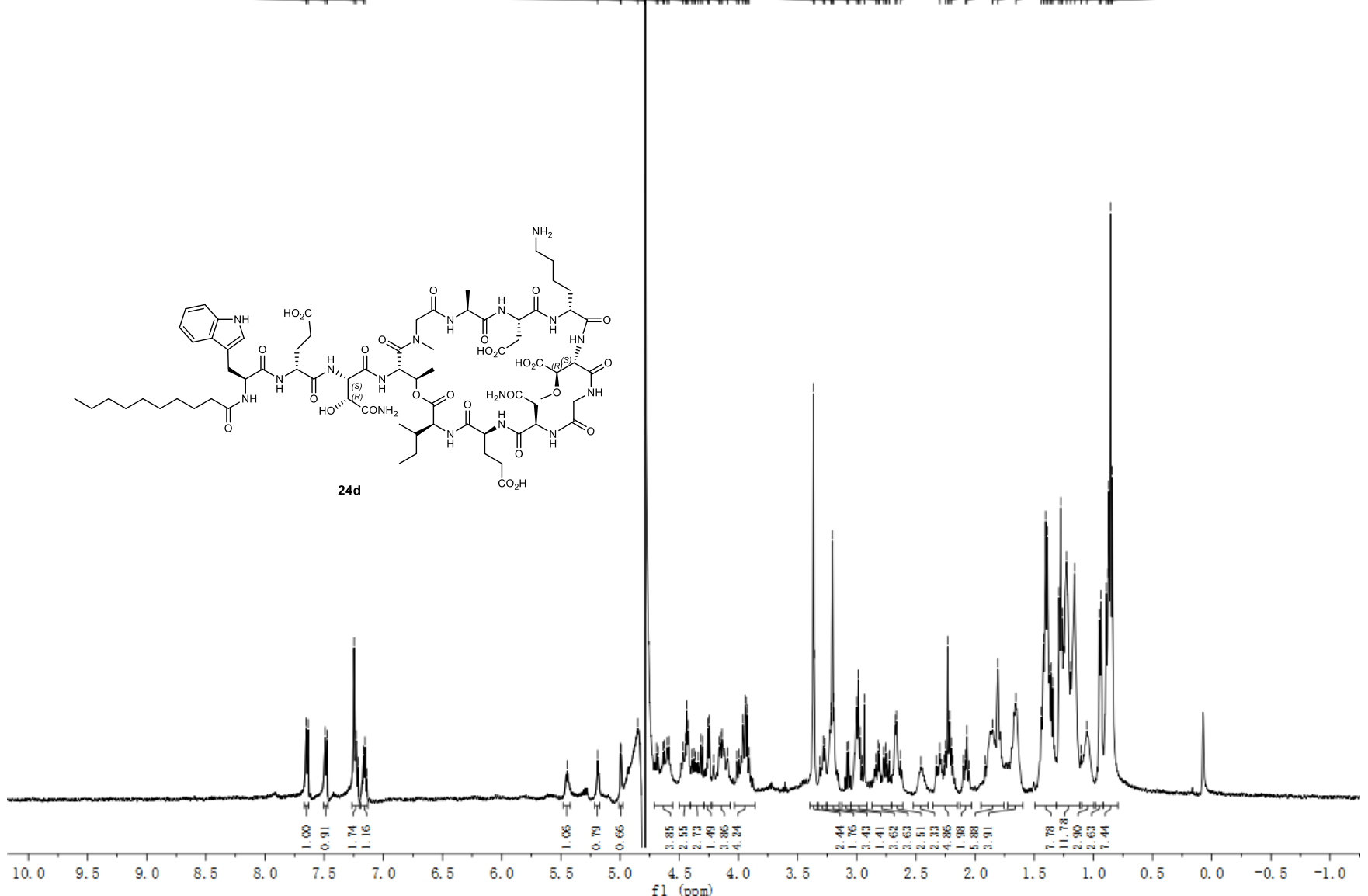

Figure S83. ${ }^{1} \mathrm{H}$ NMR spectrum of compound 24d dissolved in PBS buffer $\mathrm{pH} 7.4$ in $\mathrm{D}_{2} \mathrm{O}$ with a concentration $\sim 1 \mathrm{mg} / \mathrm{mL}$.

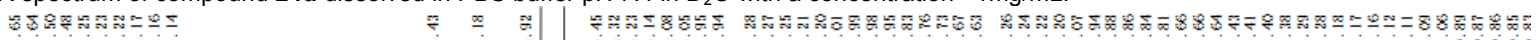

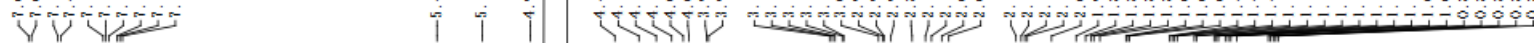

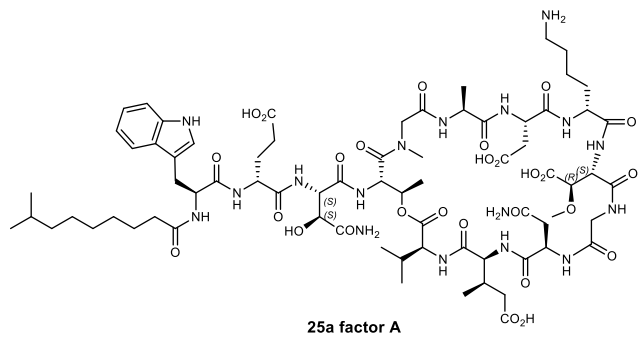

25a factor A 


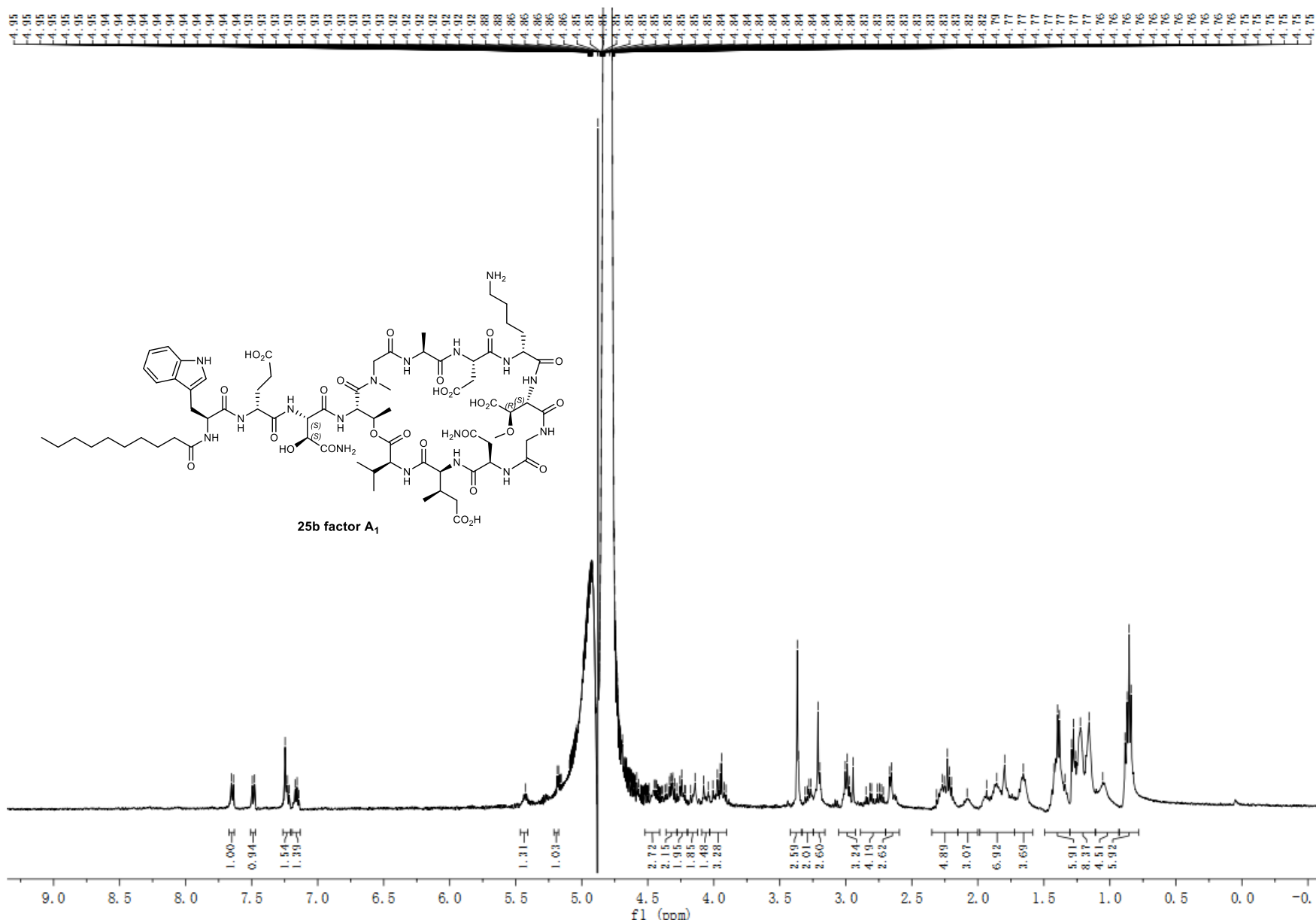

Figure S85. ${ }^{1} \mathrm{H}$ NMR spectrum of compound $25 \mathrm{~b}$ (factor $\mathrm{A}_{1}$ ) dissolved in PBS buffer $\mathrm{pH} 7.4$ in $\mathrm{D}_{2} \mathrm{O}$ with a concentration $\sim 1 \mathrm{mg} / \mathrm{mL}$.

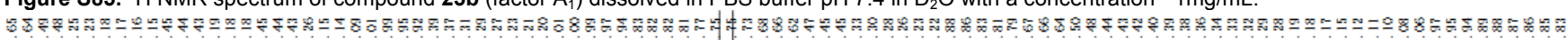

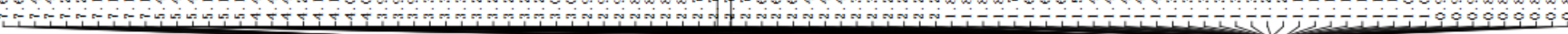

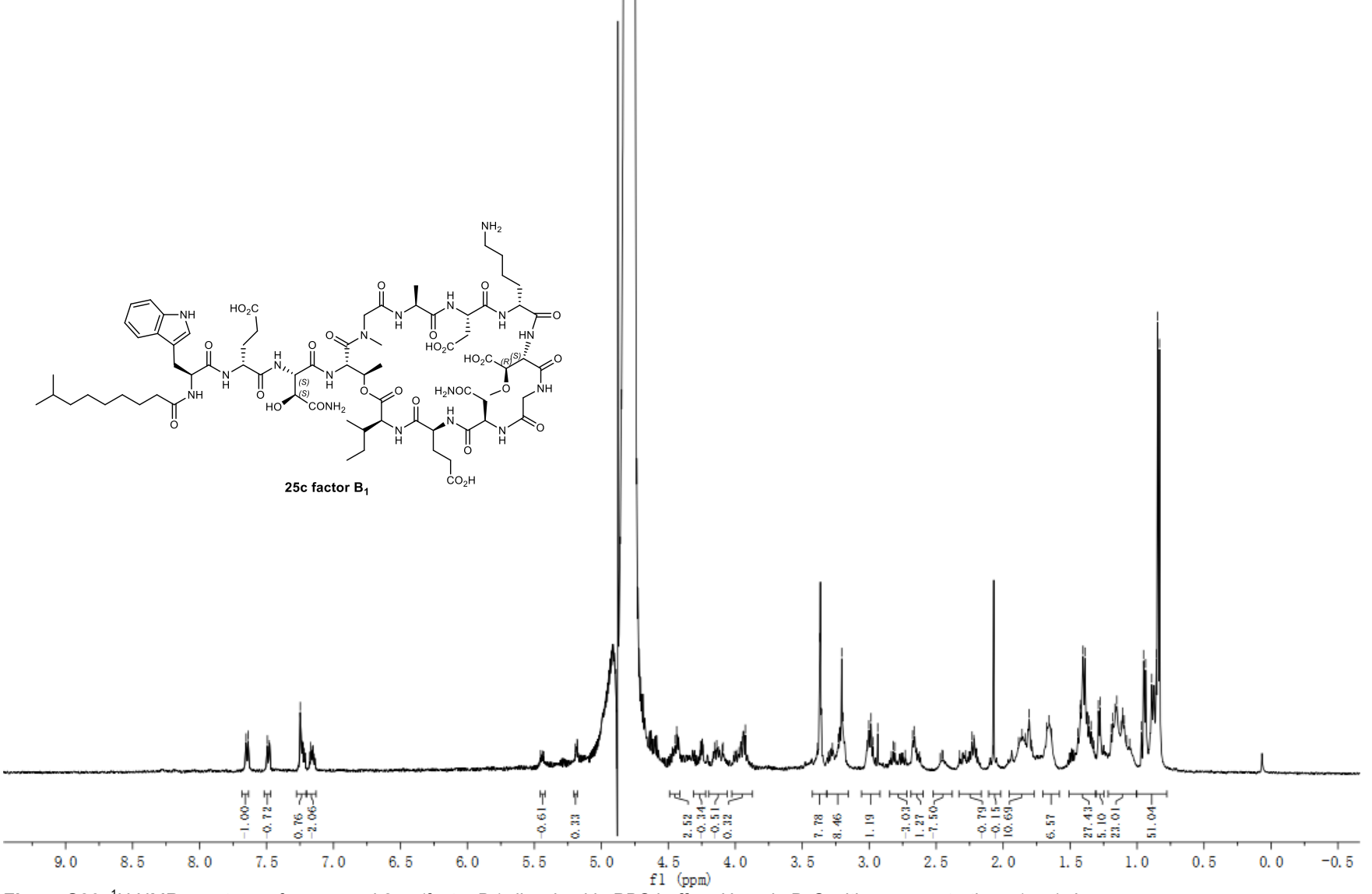

Figure S86. ${ }^{1} \mathrm{H}$ NMR spectrum of compound 25c (factor $\mathrm{B}_{1}$ ) dissolved in $\mathrm{PBS}$ buffer $\mathrm{pH} 7.4$ in $\mathrm{D}_{2} \mathrm{O}$ with a concentration $\sim 1 \mathrm{mg} / \mathrm{mL}$. 


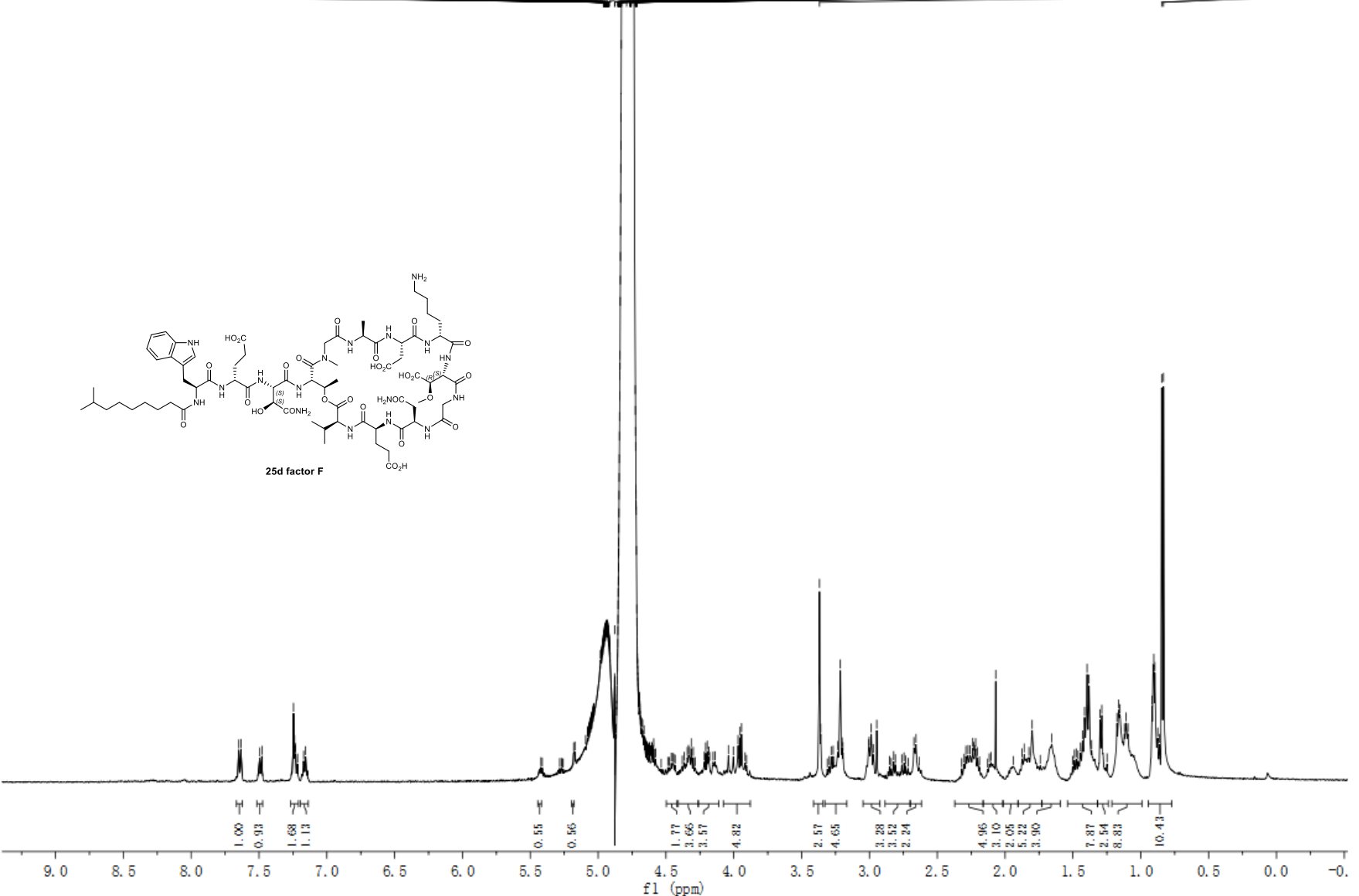

Figure S87. ${ }^{1} \mathrm{H}$ NMR spectrum of compound 25d (factor F) dissolved in PBS buffer $\mathrm{pH} 7.4$ in $\mathrm{D}_{2} \mathrm{O}$ with a concentration $\sim 1 \mathrm{mg} / \mathrm{mL}$. 
Figure 2

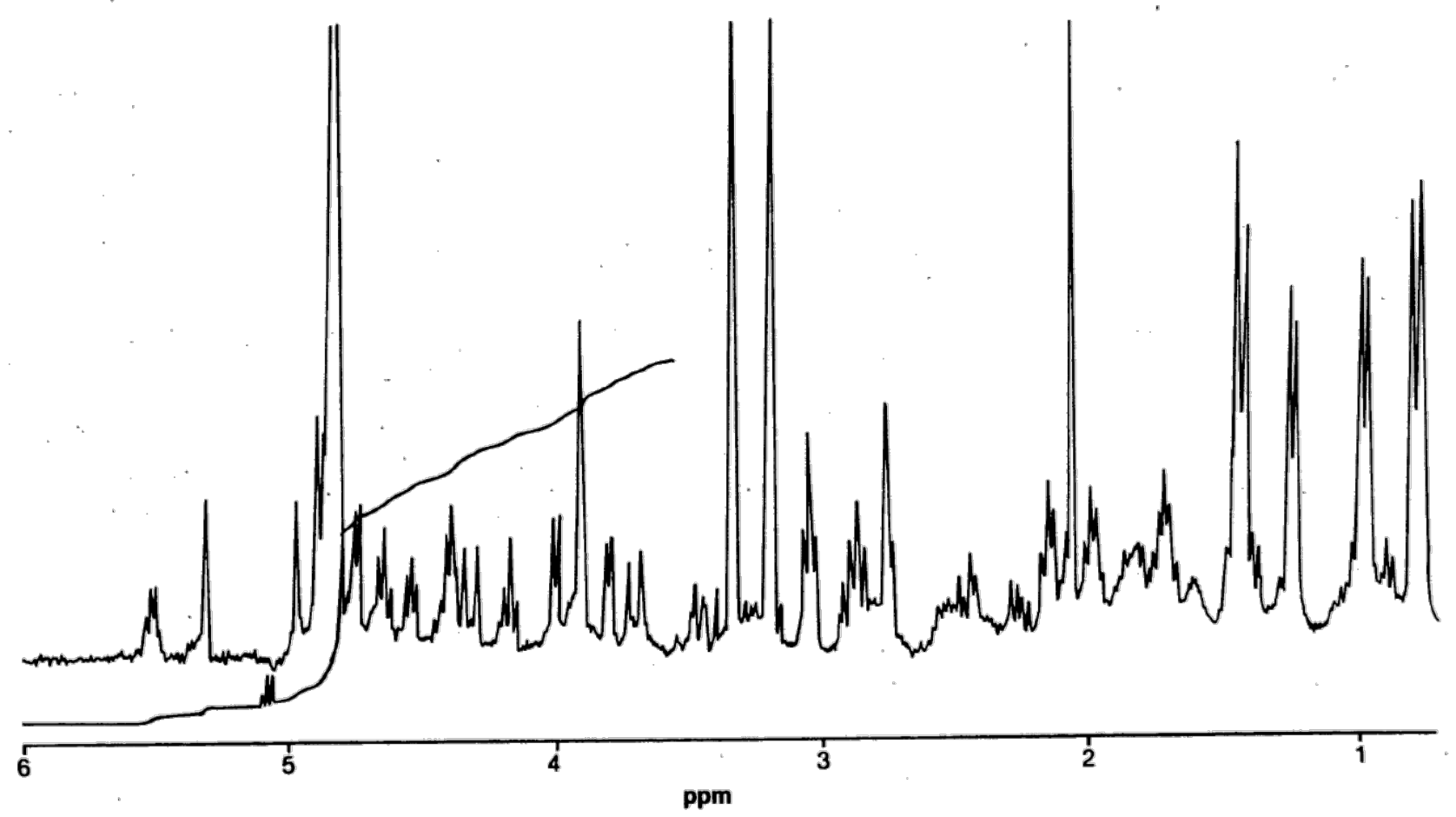

Figure S88. ${ }^{1} \mathrm{H}$ NMR spectrum $(270 \mathrm{MHz})$ of A54145 B nucleus reported in literature. ${ }^{6}$

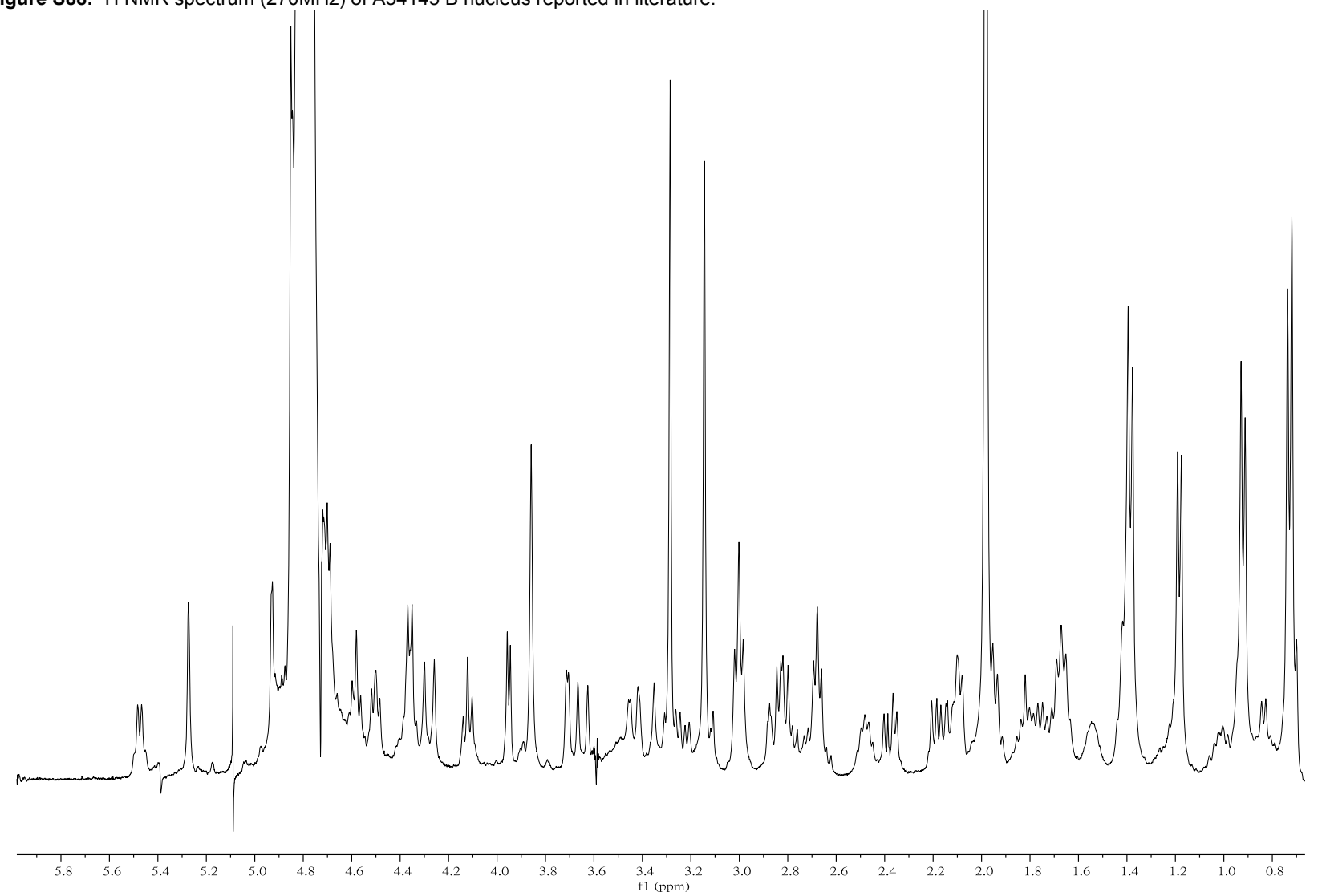

Figure S89. ${ }^{1} \mathrm{H}$ NMR spectrum $(400 \mathrm{MHz})$ of synthetic A54145B nucleus 26 acetate salt in $\mathrm{D}_{2} \mathrm{O}$ at a concentration of $10 \mathrm{mg} / \mathrm{ml}$. Only $1-6 \mathrm{ppm}$ was shown for direct comparison with the literature reported spectrum 


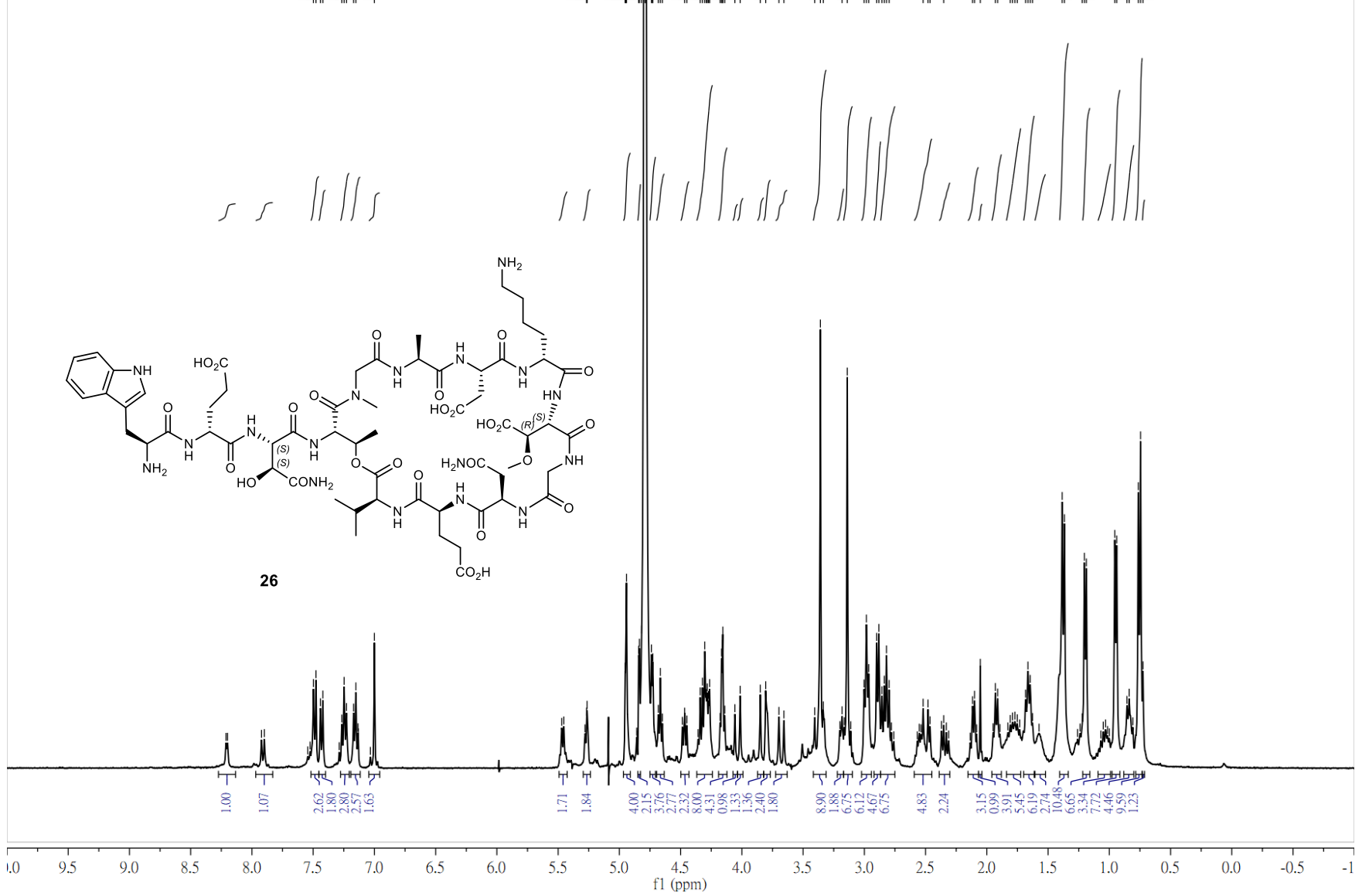

Figure S90. ${ }^{1} \mathrm{H}$ NMR spectrum $(400 \mathrm{MHz})$ of synthetic A54145B nucleus 26 (synthesized using improved synthetic route) acetate salt in $\mathrm{D}_{2} \mathrm{O}$ at a concentration of $10 \mathrm{mg} / \mathrm{ml}$.

\section{References}

1. R. C. Cioc, H. D. Preschel, G. V. D. Heijden, E. Ruijter, R. V. A. Orru, Chem. Eur. J., 2016, 22, 7837-7842.

2. H. Raj, W. Szymański, J. De Villiers, H. J. Rozeboom, V. P. Veetil, C. R. Reis, A. M. W. Thunnissen, Nat. Chem., 2012, 4, 478-484.

3. B. V. S. Reddy, L. R. Reddy, E. J. Corey, Org. Lett., 2006, 8, 3391-3394.

4. J. T. Lundquist IV, J. C. Pelletier, Org. Lett., 2001, 3, 781-783.

5. Institute CaLS. Methods for antimicrobial dilution and disk susceptibility testing of infrequently isolated or fastidious bacteria; approved guideline-2nd ed (M45-A2), Clinical and Laboratory Standards Institute, Wayne, PA, 2010.

6. Fukuda, D. S.; Mynderse, J. S. U.S. Patent 5,039,789, August 13,1991. 